
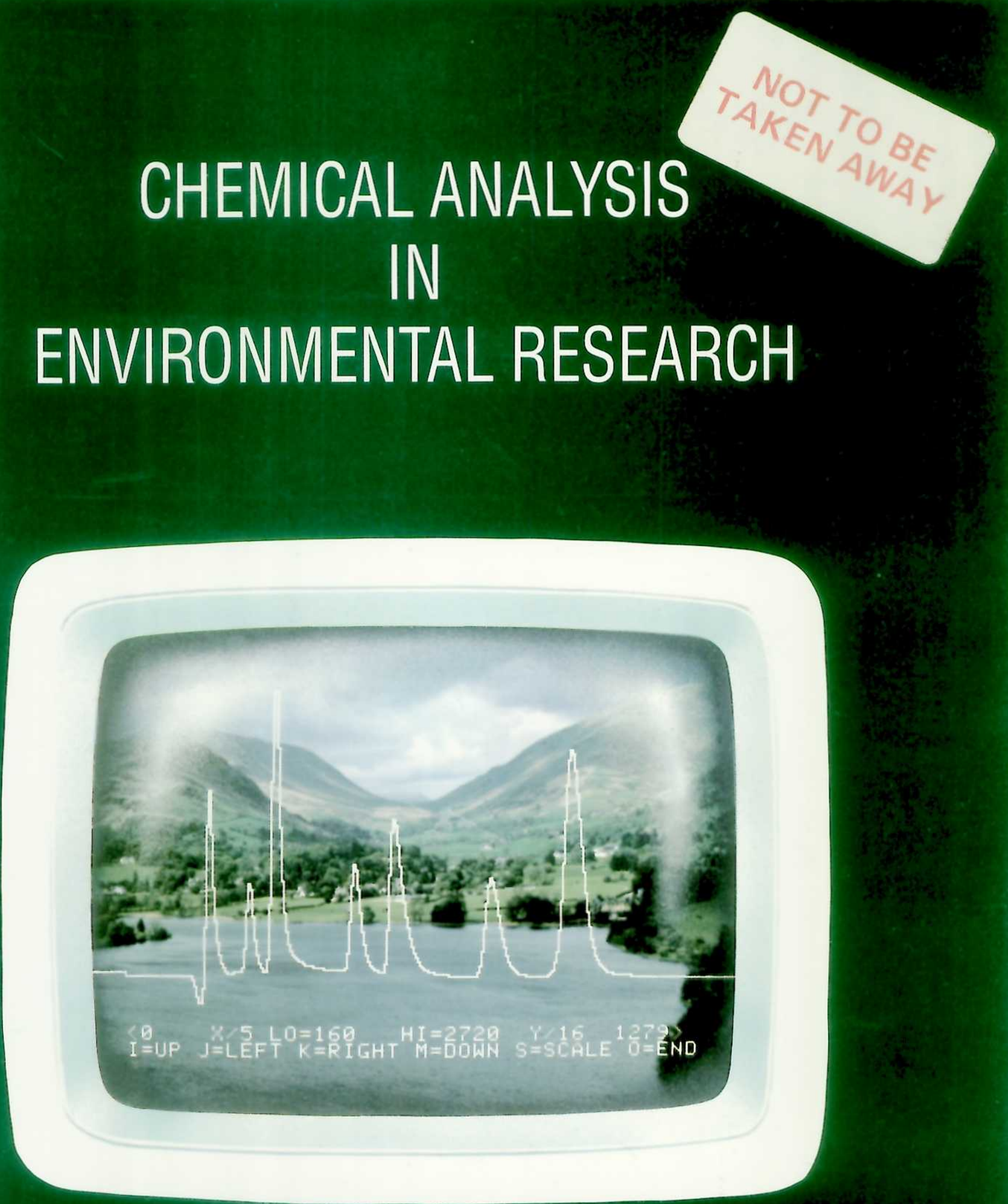

INSTITUTE of TERRESTRIAL ECOLOGY

NATURAL ENVIRONMENT RESEARCH COUNCIL 


\title{
Natural \\ Environment \\ Research \\ Council
}

\section{Chemical analysis in environmental research}

\author{
ITE symposium no.18 \\ Merlewood Research Station \\ 19 20 November 1985
}

Edited by

A PROWLAND

Merlewood Research Station

GRANGE OVER SANDS

Cumbria

INSTITUTE OF TERRESTRIAL ECOLOGY 
Printed in Great Britain by

Reminder Press

C NERC Copyright 1987

Published in 1987 by

Institute of Terrestrial Ecology

Administrative Headquarters

Monks Wood Experimental Station

Abbots Ripton

Huntingdon

PE17 2LS

BRITISH LIBRARY CATALOGUING-IN-PUBLICATION DATA

Chemical analysis in environmental research-(ITE symposium,

ISSN 0263-8614; no. 18

1. Chemistry, analytical 2. Environmental chemistry

I. Rowland, A P(Philip). 1951-. II. Institute of Terrestrial Ecology

III. Series

543 QD 75.3

ISBN 0904282988

\section{ACKNOWLEDGEMENTS}

The Institute of Terrestrial Ecology (ITE) was established in 1973, from the former Nature Conservancy's research stations and staff, joined later by the Institute of Tree Biology and the Culture Centre of Algae and Protozoa. ITE contributes to, and draws upon, the collective knowledge of the 14 sister institutes which make up the Natural Environment Research Council, spanning all the environmental sciences.

The Institute studies the factors determining the structure, composition and processes of land and freshwater systems, and of individual plant and animal species. It is developing a sounder scientific basis for predicting and modelling environmental trends arising from natural or man-made change. The results of this research are available to those responsible for the protection, management and wise use of our natural resources.

One quarter of ITE's work is research commissioned by customers, such as the Department of Environment, the Commission of the European Communities, the Nature Conservancy Council and the Overseas Development Administration. The remainder is fundamental research supported by NERC.

ITE's expertise is widely used by international organizations in overseas projects and programmes of research.

Mr A P Rowland

Institute of Terrestrial Ecology

Merlewood Research Station

GRANGE-OVER-SANDS

Cumbria

LA11 6JU

04484 (Grange-over-Sands) 2264 


\section{Contents}

Preface

Aluminium fractionation in fresh waters

(K R Bull and J R Hall, ITE, Monks Wood Experimental Station, Huntingdon)

The determination of total sulphur in vegetation

(J A Parkinson, ITE, Merlewood Research Station, Grange-over-Sands)

Rain simulation in acid rain research - techniques, advantages and pitfalls

(U Skiba, A Edwards, T Peirson-Smith and M Cresser, Dept of Soil Science, University of Aberdeen, Aberdeen)

Non-suppressed ion chromatography in 'acid rain' analysis

(J N Cape, ITE, Edinburgh Research Station, Edinburgh)

Anion chromatography in agricultural analysis

(I Jane, J Armstrong and K Bremner, MAFF, Agricultural Development and

Advisory Service, Newcastle-upon-Tyne)

Measuring the $\mathrm{pH}$ of fresh waters

(W Davison, Freshwater Biological Association, The Ferry House,

Ambleside)

Measurement of nitric acid and particulate nitrate in air

(A L Goldsmith, Warren Spring Laboratory, Department of Trade and Industry, Stevenage)

The application of inductively coupled plasmas to the analysis of natural waters and acidic deposition

(D L Miles, British Geological Survey, Hydrogeology Research Group,

Wallingford)

Trace element measurements of environmental water samples using inductively coupled plasma optical emission spectrometry

(J M Cook, British Geological Survey, Hydrogeology Research Group,

Wallingford)

Investigation of spectral interferences in the determination of trace elements in water by ICP-OES

(J M Trafford, British Geological Survey, Hydrogeology Research Group,

Wallingford)

Chemical sensors for environmental research

(T E Edmonds, Dept of Chemistry, Loughborough University of Technology, Loughborough)

Measurement of microbial biomass in soil

(E D Vance and P C Brookes, Soils and Plant Nutrition Department,

Rothamsted Experimental Station, Harpenden)

Assessment of stress to microbial biomass

(K Killham, Dept of Soil Science, University of Aberdeen, Aberdeen)

Mineralization of organic phosphorus in relation to soil factors, determined using isotopic ${ }^{32} \mathrm{P}$ labelling

(A F Harrison, ITE, Merlewood Research Station, Grange-over-Sands)

Reference materials for ecological analysis

(A P Rowland, ITE, Merlewood Research Station, Grange-over-Sands)

The determination of total phosphorus in soils by acid digestion

(H M Grimshaw, ITE, Merlewood Research Station, Grange-over-Sands) 
A comparative study of ashing procedures for the analysis of $N, P$ and $K$ in small amounts of plant materials

(P L Gupta, Unit of Comparative Plant Ecology, Dept of Botany, University of Sheffield, Sheffield)

A controlled flow rate leaching method for the determination of exchangeable acidity and aluminium in soils

(K A B Logan and A D Ironside, Hill Farming Research Organisation, Bush Estate, Penicuik)

Appendix 1: List of participants 


\section{Preface}

This symposium was the fourth in a series organized by ITE's Merlewood Research Station on topical subjects in the field of ecology. The symposia were designed to promote the work of the organization and to develop contacts and an interchange of ideas between scientists working in environmental research. We felt it was an appropriate moment to provide a forum on chemical analysis, especially to discuss the latest analytical developments and to review recent applications of more traditional methods. Techniques and instrumental methods for studying the effects of acidic precipitation dominated the meeting, but time was also given to soil and plant methods.

Investigations into the causes and effects of acidic precipitation on the terrestrial environment prompted us to focus on the methods recently developed for analysing samples from these research projects. Measurement of $\mathrm{pH}$ in natural solutions is fundamental to such studies, but subject to large errors when applied to solutions of low ionic concentration. Two complementary papers considered in detail the precautions and equipment required. Sulphur methods, in general, have caused problems in the past, and so it was not surprising to have several papers discussing the analysis of sulphate in waters and plant material. Aluminium species and complexation have recently been linked to acidic deposition and fish mortality in streams and lakes.

Methods for fractionating the toxic labile fractions which were used to study rivers in the north of England were described. Simulation techniques may sometimes be the only way in which an individual component of the ecosystem may be studied in isolation. A review examining the techniques, advantages and pitfalls illustrated how laboratory simulation has developed for pollution research.

Some of the papers relating to acidic deposition also dealt with modern instrumental techniques. $A$ detailed presentation was given in 3 papers on the development of inductively coupled plasma/ optical emission spectrometry for trace element analysis, which also highlighted the problems in pre-concentration techniques. Various applications and techniques in ion chromatography described in 2 papers illustrated the versatility of this rapidly expanding field. Another growth area is the development of chemical sensors, and a review was given of the current status of their applications in environmental research.

Aspects of soil microbial biomass measurement were considered in 2 papers on comparative techniques, one of which assessed the effect of stress on the information obtained. An alternative approach to measuring 'available' phosphorus showed that isotope methods were extremely effective for measuring mineralization rates of phosphorus in soil. Although it is now just over 100 years since Kjeldahl first proposed a sulphuric acid wet oxidation procedure, many developments still appear regularly. Modifications of this procedure enable other elements to be determined from the acidic solution, and 2 papers described such applications. A paper was also given on the use of reference materials in quality control when analysing environmental samples.

The 2-day meeting was attended by 90 delegates who heard 16 papers, and were able to review 14 poster presentations. My thanks go to the speakers who contributed so willingly and to the presenters of the poster papers for their highquality displays which added so much to the meeting. I especially thank Val Kennedy for her valued ideas and efficiency in organizing the symposium, and to other colleagues at Merlewood who helped. Finally, I would like to acknowledge the contribution of the chairman: Stewart Allen (Head of Station, Merlewood), Bill Davison and John Hilton (Freshwater Biological Association, Ferry House), who co-ordinated the discussion and questions.

Philip Rowland 


\section{Aluminium fractionation in fresh waters}

KR BULL and J R HALL

ITE, Monks Wood Experimental Station, Huntingdon

\section{Introduction}

Aluminium is the most abundant metal and the third most abundant element in the earth's crust. Aluminosilicate minerals are common in igneous and metamorphic rocks, and as clay minerals in well-weathered soils.

Although the original source of aluminium to fresh waters is, most likely, the underlying bedrock, weathering processes are slow, so most available aluminium is present in soils. Even here, aluminium is usually complexed in the lower profiles of soil, and is fairly immobile (Jacks et al.1984). The process by which mobilization into fresh waters takes place is complex, and not fully understood, but van Breemen et al. (1984) have explained the process in terms of the internal and external proton sources in soils. In acid soils, soil acidification is relatively slow; in consequence, external proton sources of anthropogenic origin may exceed internally generated protons, leading to a release of inorganic aluminium into soil solution, from where it may be flushed into streams and lakes. Here, at low pH levels, when Ca concentrations are very low, the dissolved aluminium may even replace the usual calcium/bicarbonate buffering system.

The importance of this release of aluminium is not just as an indicator of external proton sources, or the creation of an aluminium buffering system in the acid water draining the soil; the importance lies in the toxicity of inorganic aluminium to freshwater organisms, in particular fish.

Aluminium toxicity has been the subject of many investigations, and the results are as complex as the chemistry of aluminium itself. The toxic effects are dependent upon the species and the life stage of the fish, the concentration of calcium in the water, and the $\mathrm{pH}$. The $\mathrm{pH}$ may not only affect how a fish responds to dissolved aluminium, but can have a pronounced effect upon the chemistry of aluminium itself. Driscoll et al. (1980) have shown that complexation of aluminium can have a marked ameliorating effect on its toxicity. It is important, therefore, to understand something of the chemistry of aluminium, in order to measure the relevant complexes in solution and so predict the consequences of these solutions in streams and lakes.

\section{Aluminium chemistry}

The complexity of aluminium chemistry lies not only in its ability to form a variety of soluble complexes in aqueous solution, but also in its ability to create hydroxide polymers which may grow until, ultimately, microcrystalline minerals result.

At low and high pHs, there is general agreement on the chemical species of aluminium predominating in solution. At $\mathrm{pH}>7.5$, the aluminate anion complex $\mathrm{Al}(\mathrm{OH})_{4}{ }^{-}$is the major ion in solution, whilst at $\mathrm{pH}<4$ the hexa-aquo-Al(III) ion $\mathrm{Al}\left(\mathrm{H}_{2} \mathrm{O}\right)_{6}{ }^{3+}$ dominates (Smith 1972). Between these $2 \mathrm{pHs}$, there is likely to be little agreement on the exact concentrations of chemical species present for any given set of chemical conditions, because there is disagreement on the exact values of the relevant equilibrium constants. Assuming values for equilibrium constants between the different chemical species enables their concentrations to be predicted. Smith (1972) has done the calculation for the Al/hydroxide system over the $\mathrm{pH}$ range 3.5-7.0 (Figure 1). It is clear that at $\mathrm{pH} 5$ several species have similar concentrations. Therefore, any uncertainty in the equilibrium constant values may have a marked effect on the relative concentrations of aluminium species. Calculations are further complicated when fluoride and organic chelates, which are found in fresh waters and effectively compete with hydroxide, are included.

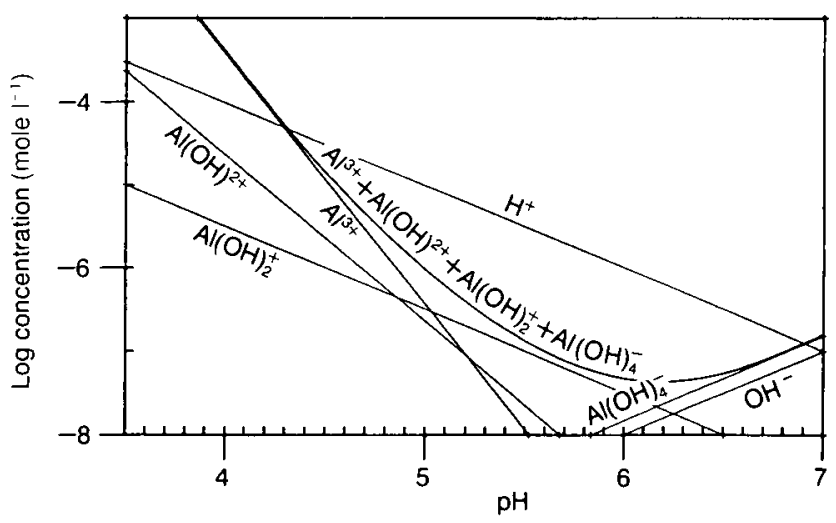

Figure 1. Aluminium concentration against $\mathrm{pH}$ (Smith 1972)

Although we may not be able to define the composition of an aluminium solution in precise terms, this definition may not be necessary. If our aim is to evaluate the biological impact of a given solution, a much more simplified approach may be used.

Driscoll (1980) has defined 3 'types' of aluminium species in solution (Figure 2). These types have 
been shown to have biological significance, as well as being defined fairly clearly in chemical terms. Inorganic monomeric aluminium is the chemically labile form of aluminium which has been correlated with toxic effects on fish (Driscoll 1980). It does, however, include fluoride complexes which are less toxic. Organic monomeric aluminium, the non-labile monomeric aluminium, is far less toxic than the inorganic species. It is complexed, fairly strongly, to organic molecules, often of large molecular weight. Acid soluble aluminium is a mixture of polymeric species and strongly bound organic complexes. It is considered non-toxic. The 3 fractions together represent the total (reactive) aluminium in solution.

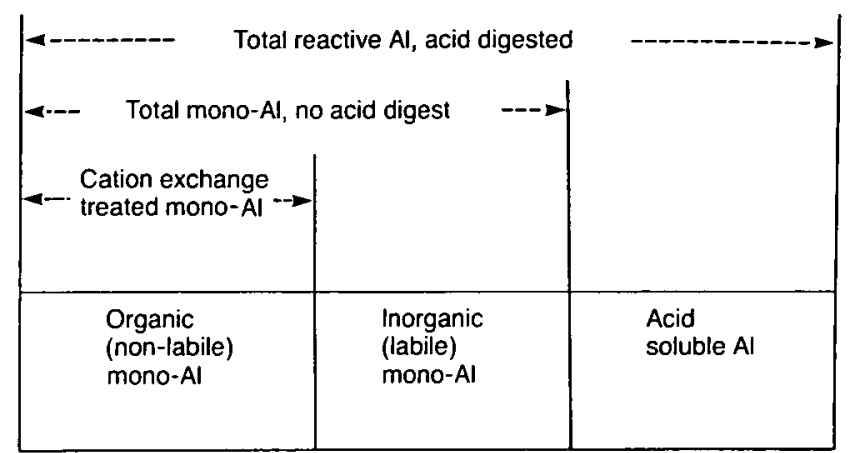

Figure 2. Summary of an aluminium fractionation procedure (Driscoll 1984)

\section{Total reactive aluminium analysis}

There are 2 major requirements for an analytical method suitable for total aluminium, indeed suitable as an analytical method for any aluminium species in fresh water. First, the method must be sensitive: aluminium is generally found in concentrations of $<1 \mathrm{mg} \mathrm{l}^{-1}$ in fresh waters. Second, the method must be free from interferences. Unfortunately, conventional atomic absorption spectrometry (AAS) is not very sensitive, and many colorimetric methods are prone to interference.

Driscoll's early work on aluminium speciation (Driscoll 1980) was done using the ferron-orthophenanthroline colorimetric method (Rainwater \& Thatcher 1960). By acidifying samples to $0.1 \mathrm{~N}$ with $\mathrm{HCl}$, a 'cold acid digest', the total reactive aluminium is changed to monomeric form. This form reacts readily with the ferron reagent. The method is not very sensitive, so large cuvettes are needed. The method also suffers from interferences, particularly from dissolved iron and colour. Corrections are, therefore, needed, adding to errors and increasing analysis time.

Improved sensitivity and reduced interference problems are obtained with a method using catechol violet as the complexing agent (Dougan \& Wilson 1974). Sensitivity is almost an order of magnitude greater, and iron interference is suppressed with hydroxyl-ammonium chloride and
1,10 phenanthroline. Colour correction is usually minimal as the catechol complex absorbs at 585 $\mathrm{nm}$ compared with $270 \mathrm{~nm}$ for ferron. The method is applied to acidified samples as above. Its main practical disadvantage is the increase of optical absorption that occurs with the catechol violet complex with time. An initial rapid absorption is complete within the first few minutes, but a further slow increase continues for many hours. The rate of increase is sufficiently slow and predictable, however, so that consistent results are obtained by waiting for a fixed time interval before absorption is measured. Times ranging from 4 to 40 minutes have been used by different workers.

The ferron and catechol methods have been compared by Seip et al. (1984), using some Norwegian freshwater samples. The agreement is very good, but they recommend the catechol method because of its sensitivity and lack of interferences. These findings are confirmed by work in our own laboratory.

Flameless atomic absorption spectrometry (FAAS) and inductively coupled plasma (ICP) spectrometry both give greatly improved sensitivity over conventional AAS. ICP equipment is, however, expensive and is still not available to many laboratories. FAAS does offer a reasonable alternative to colorimetry; under suitable graphite furnace conditions, the method is almost as sensitive as the catechol method and is relatively free from matrix effects (Campbell et al. 1983; ITE Merlewood, pers. comm.).

It may be expected that not all polymeric aluminium detected by ICP or FAAS would be measured using the 'cold acid digest' of the colorimetric methods. However, Bull and Hall (1986) have found that FAAS and catechol give very similar results for the same samples. Furthermore, Seip et al. (1984) observed only a $6 \%$ increase in aluminium concentration when acidified solutions were boiled with $\mathrm{K}_{2} \mathrm{~S}_{2} \mathrm{O}_{8}$ prior to catechol violet analysis.

Recently, Driscoll (1984) and LaZerte (1984) have used an extraction procedure developed by Barnes (1975), which effectively concentrates the aluminium in solution and may be used to prevent interferences. The aluminium is first coupled with oxine (8-hydroxyquinoline), the $\mathrm{pH}$ of the solution is next adjusted to 8.5, and then the oxine complex is extracted with methyl isobutyl ketone. To ensure polymeric aluminium is extracted, a reaction time of 3-6 hours is used (Turner 1969). Alternatively, water samples are acidified to $\mathrm{pH} 1$ for one hour before analysis (Driscoll 1984). The oxine extract may be stored in a freezer until required for analysis. The extract may be analysed colorimetrically (at $390 \mathrm{~nm}$ ) or, to avoid interferences, FAAS may be used. 


\section{Monomeric aluminium analysis}

We have already described above the 2 types of monomeric aluminium - inorganic and organic, but it is also important to know the concentrations of each, as the toxicity of the organic fraction is much lower (Driscoll 1980). Most laboratories use a 2-step analysis procedure. First, the total monomeric aluminium concentration is measured. Next, either the inorganic or organic fraction is measured and the third fraction found by difference. A different method, used by Campbell et al. (1983), is described later.

Total monomeric aluminium analyses make use of the reactive nature of these species in unacidified solutions. The methods rely upon the speed with which these compounds react with a chelating agent. The ferron analysis (Driscoll 1980) is applied directly to unacidified samples, and the absorption measured soon after adding the agents. If the reaction time is short, polymeric aluminium has no chance to react. Seip et al. (1984) compared the ferron method with a similar approach (unacidified samples and short reaction time), using the catechol violet method. The results were comparable, though again the catechol violet method was recommended because of its sensitivity and lack of interferences. However, using a short reaction time presents some problems because the colour development time usually recommended is 10-30 minutes (Dougan \& Wilson 1974). Seip et al. found that a reaction time of 4 minutes was sufficient for colour development but avoided reactions with aluminium polymers. Bull and Hall (1986) have used a reaction time of 10 minutes, which Seip et al. suggest gives an over-estimation of $2-3 \%$ in the monomeric aluminium due to depolymerization.

The oxine extraction procedure (Barnes 1975) may also be applied to measuring total monomeric aluminium. Now, however, a rapid extraction is substituted for a short colour development time. Driscoll (1984) has used this technique, whilst LaZerte (1984) has modified the method to give an extraction time of about 15 seconds.

Organic monomeric aluminium concentrations may be measured by remeasuring monomeric aluminium in solutions from which the inorganic fraction has been removed. Driscoll (1980) has shown that the inorganic, labile, fraction binds rapidly to a suitable ion exchange resin, leaving the non-labile, organic, fraction in solution. Passing a freshwater sample containing aluminium through a column of ion exchange resin effectively removes the inorganic monomeric species, leaving only organic monomeric aluminium in the eluate. Driscoll used $9.5 \mathrm{ml}$ of Amberlite IR-120 resin in a $1 \mathrm{~cm}^{2}$ cross-section column. A flow rate of at least $35 \mathrm{ml} \mathrm{min}{ }^{-1}$ was needed. The resin, in the hydrogen form, was pre-treated with dilute
$\mathrm{NaCl}$ solution so that eluted samples retained their original $\mathrm{pH}$ value. The same procedure has been used by other laboratories (Seip et al. 1984; Bull \& Hall 1986). The organic monomeric aluminium may be measured using one of the methods described above for total monomeric aluminium, while inorganic monomeric aluminium is calculated by difference. Seip et al. report that direct colorimetric measurements using either ferron or catechol give comparable results. Driscoll originally used the ferron method (Driscoll 1980), but more recently has used the Barnes extraction on eluted samples (Driscoll 1984). Organic monomeric aluminium was measured in a different way by Campbell et al. (1983). They used fractionally loaded Chelex-100 resin in a batch technique (Laxen \& Harrison 1981) to remove inorganic monomeric aluminium from solution. However, under the conditions used, low molecular weight polymers are also retained by the resin. This technique has the advantage that the organic fraction can be measured using a method for total aluminium. Campbell et al. have used FAAS. However, without knowing the concentration of total monomeric aluminium, the inorganic, toxic, fraction cannot be estimated. Campbell et al. did not make such measurements directly but used equilibrium calculations (see below)

Inorganic monomeric aluminium may be separated and measured directly using dialysis (LaZerte 1984). The small, mobile, inorganic ions pass readily through a dialysis membrane, whilst the larger, less mobile, organically bound aluminium is retained. Again, any convenient method for total aluminium may be used on the dialyte.

Individual aluminium species have been calculated by several workers using thermodynamic data. Early work by Hem and Roberson (1967) and Smith (1972) on hydroxide complexes in synthetic solutions has been extended by other workers to include other complexes in natural fresh waters.

Equilibrium calculations show that only $\mathrm{Al}^{3+}$, hydroxide and fluoride complexes are present in most natural waters in significant concentrations (Hem 1968). Sulphate complexes are often included in the calculations but are usually of little importance (Seip et al. 1984). Concentrations of fluoride complexes may be found by calculation using fluoride levels measured with a fluoride selective electrode, and the appropriate equilibrium constants (Seip et al. 1984; LaZerte 1984; Driscoll 1984). Fluoride measurements also provide the means of calculating inorganic monomeric aluminium concentrations, as long as $\mathrm{AlF}^{3-}$ species dominate the total fluoride (LaZerte 1984; Driscoll 1984). Drummond (1984) reports on the work of Turner who has compared literature values of equilibrium constants. Turner notes that 
fluoride constants are better characterized than those for hydroxide. Whilst hydroxide complexes predominate at high $\mathrm{pHs}$, fluoride complexes are more important at low pHs. Although there is no direct evidence, on statistical grounds mixed fluoride/hydroxide complexes should be possible. The limitations of thermodynamic calculations are illustrated by an example by Hunt, also reported by Drummond (1984). Using 2 'alternative' sets of equilibrium constants, Hunt shows that the 2 sets of ion ratios resulting from his calculations give 2 different interpretations to a series of toxicity tests on algae. Further information on aluminium complexes has been obtained by the work of Tipping (Drummond 1984), who has used kinetic studies to look at aluminium species. He has identified a less labile fluoride complex at pH 4-4.3, which he suggests is $\mathrm{AlF}_{2}^{+}$.

Individual organic monomeric aluminium species are even more difficult to characterize because of the vast range of humic substances present in fresh waters (Gjessing 1967). Drummond (1984) reports work by Lee who concludes that most complexation in Lake Gardsjon is caused by low molecular weight fulvic acids. Other work (Water Research Centre, pers. comm.) has shown that aluminium complexation with organics extracted from natural waters is very different from that complexed to commercially available humic and fulvic acids. It is perhaps sufficient to conclude that we know organic monomeric aluminium has a much reduced toxicity and is non-labile, and that the best approach for measuring its concentration at present is to use a purely practical means, such as that suggested by Driscoll.

\section{Sample collection and pre-treatment}

There are risks that concentrations of ions in solution may change between collection of a sample and its analysis, giving a false picture of what was present in the original sample. This is particularly true for aluminium species which are sensitive to $\mathrm{pH}$ changes.

One of the first decisions to be made is whether to filter water samples. Some workers have avoided filtration where possible, because many acid waters are low in suspended solids and direct measurements are made of monomeric species (Driscoll 1984; Bull \& Hall 1986). Avoidance is not always possible with natural samples. Drummond (1984) reports that Wells has used glass fibre filters which he has tested satisfactorily with spiked samples. He also summarizes work by Salbu, who found it necessary to filter samples through a $0.45 \mu \mathrm{m}$ filter in order to obtain reproducible results using neutron activation analysis, which presumably measures both dissolved and solid aluminium together. Campbell et al. (1983) have tested $0.4 \mu \mathrm{m}$ filters in a polycarbonate apparatus and found no contamination or loss of analyte. Nevertheless, if $\mathrm{pH}$ changes are caused by filtration, some shift of species may occur.

Samples for total aluminium analysis samples can be 'fixed' soon after sampling by acidifying them to $0.1 \mathrm{~N}$. These solutions remain stable for many weeks.

Monomeric aluminium is not so easily 'fixed' in aqueous solution. If solutions are being stored for analysis, they should be kept tightly stoppered with minimal air space, at, or near, the temperature when sampled. Solutions should be analysed as soon as possible, though we have found some samples are stable for $2-3$ weeks or longer. The rapid extraction of oxine into MIBK offers a method for on-site extraction of monomeric aluminium (LaZerte 1984; Drummond 1984). The organic solution is stable for several months, if stored at low temperature.

Organic monomeric aluminium may also be separated in the field using Driscoll's ion exchange column. If followed by the oxine/MIBK extraction, concentrations can be fixed for future analysis. Otherwise, care is needed to prevent equilibria shifts whilst samples are transported to the laboratory and stored. We have found unacidified samples transported by car from Cumbria to Huntingdon and then passed through the ion exchange column show only small increases in organic complexation, compared with samples columned on-site. Such increases, which are not found with all samples, may be due to $\mathrm{pH}$ changes or to equilibrium of a non-equilibrated aluminium/ organic mixture collected in the field.

\section{Aluminium concentrations in the Rivers Esk and Duddon}

In our studies of the Esk and Duddon and their tributaries, we have measured total, and inorganic and organic monomeric aluminium concentrations. We have not done any detailed calculations on fluoride species, though the total fluoride concentrations measured are low.

In the River Esk (Table 1), we find that lower pHs and higher aluminium concentrations are found in the upper reaches of the river. Downstream, $\mathrm{pH}$ values are higher and aluminium levels fall. The concentrations of organic monomeric aluminium have generally been low throughout the Esk under all the conditions sampled. Where the total aluminium levels are high, usually the proportion of inorganic monomeric aluminium is also high and the $\mathrm{pH}$ low. At higher $\mathrm{pHs}$, the inorganic monomeric aluminium levels are, not surprisingly, lower. The acid soluble aluminium levels also fall, but not as quickly. Some of the aluminium losses may be explained by dilution of the river water by non-acid tributaries with low aluminium levels. 
Most of the losses, however, must be due to polymerization of inorganic monomeric aluminium to acid soluble polymers, followed by further polymerization to 'insoluble' aluminium. Absorption, too, is likely to occur during the polymerization process.

Table 1. Al $\left(\mu \mathrm{g} \mathrm{I}^{-1}\right)$ in River Esk - moderate flow
(1982) have suggested that such conditions are highly toxic to fish. It may be that similar conditions occur in other parts of the Rivers Esk and Duddon on occasions, with important biological consequences.

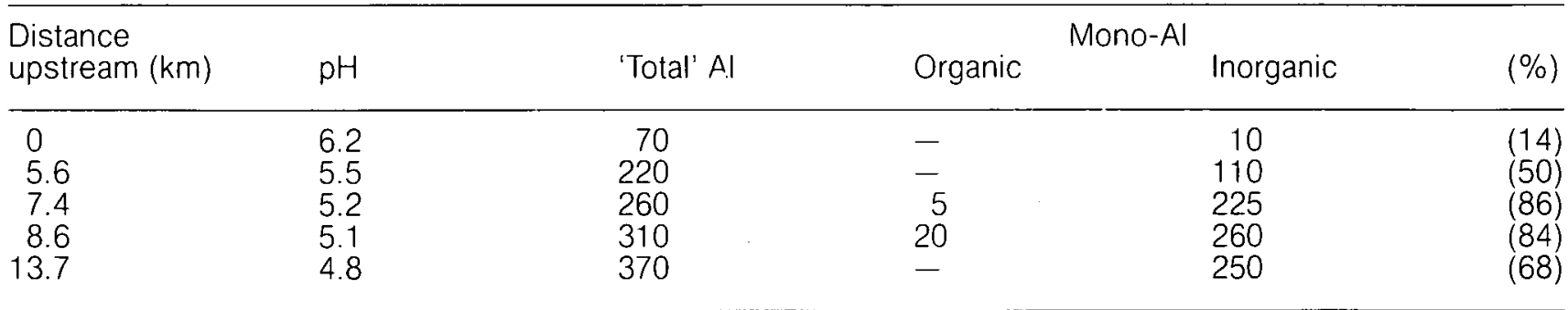

The tributaries of the Esk and Duddon vary considerably in their chemistry, both geographically and with time. Thus, in the Duddon (Table 2), we find that the upper reaches are less acid than the middle reaches of the river. Some tributaries in the upper Duddon are unexpectedly less acid because of the geology of the catchment bedrock (Sutcliffe \& Carrick 1973). In contrast, other tributaries, further down the valley, some of which drain afforested catchments, are much more acid and contain higher aluminium concentrations (Bull \& Hall 1986), as reflected in the chemistry of the main river.

Table 2. Al $\left(\mu \mathrm{g} \mathrm{I}^{-1}\right)$ in River Duddon - moderate flow

\section{Summary}

Aluminium chemistry in fresh waters is complex; the metal may exist in a variety of different species, largely dependent upon the $\mathrm{pH}$ of the solution and dissolved anions present. Because different aluminium species have different toxicities to biota, it is important that some estimation of the species present is made. We have discussed some of the procedures used by various workers to determine aluminium concentrations, together with findings of our own. Some results for the Rivers Esk and Duddon, Cumbria, are used to illustrate the concentrations of aluminium which may be found in running waters.

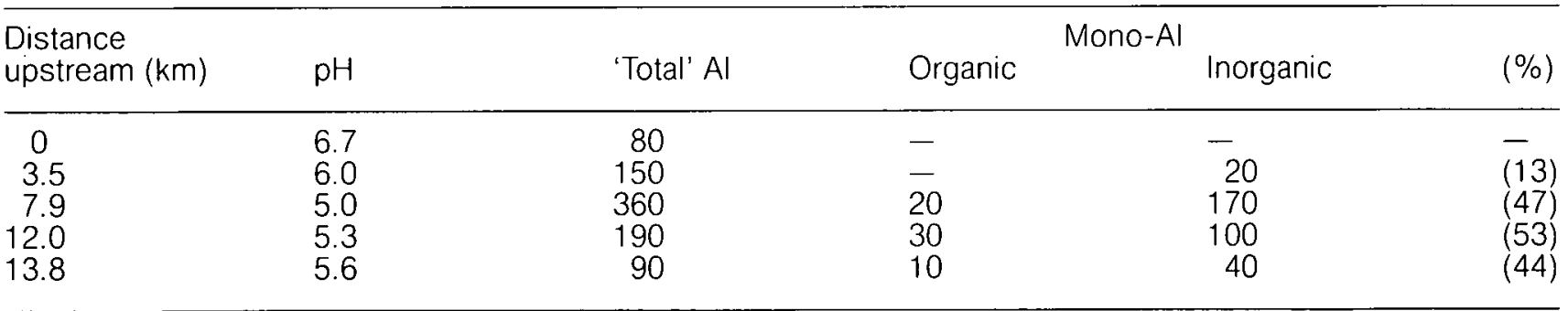

Some tributaries show dramatic changes in their chemistry over quite short distances. Dodknott Gill, in the middle reaches of the Esk, drains from Harter and Birker Fells. Under most conditions, the water running from the fell-side (Figure 3 , site A) is fairly acid, pH 4.5-5.2. Between the fell and the confluence with the Esk (Figure 3, site D), the tributary flows through several hundred metres of improved pasture land. It receives water from land drainage and from springs along this stretch; both sources are more alkaline than the gill itself. As a result, $\mathrm{pH}$, calcium levels and alkalinity increase with distance downstream, whilst aluminium concentrations fall (Figure 3). An important consequence of these changes is likely to be a condition of super-saturation of aluminium along some stretches of the gill. Baker and Schofield

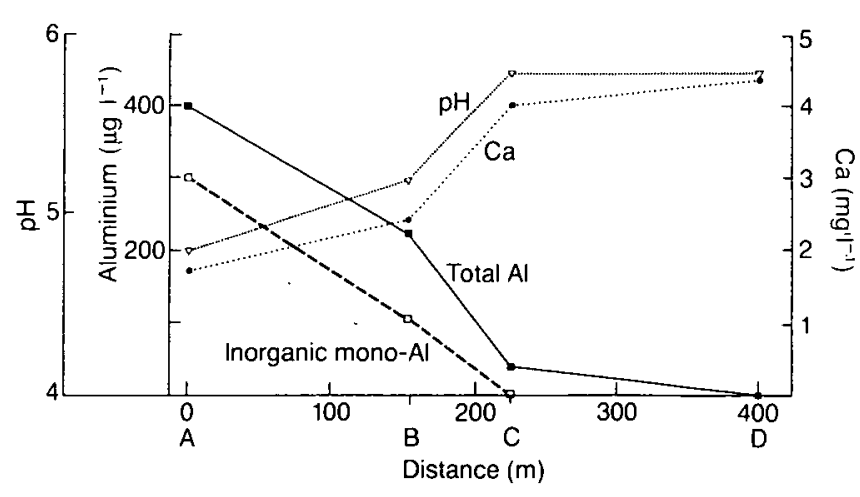

Figure 3. Aluminium, calcium and $\mathrm{pH}$ levels in water collected from 4 points $(A, B, C, D)$ along Dodknott Gill, Cumbria 


\section{References}

Baker, J.P. \& Schofield, C.L. 1982. Aluminium toxicity to fish in acidic waters. Water, Air \& Soil Pollut., 18, 289-309.

Barnes, R.A. 1975. The determination of specific forms of aluminium in natural water. Chem. Geol., 15, 177-191.

Bull, K.R. \& Hall J.R. 1986. Aluminium in the Rivers Esk and Duddon and their tributaries, Cumbria. Environ. Pollut., Ser. A, 12, 165-193.

Campbell, P.G.C., Bisson, M., Bougie, R., Tessier, A. \& Villneuve, J. 1983. Speciation of aluminium in acidic waters. Analyt. Chem., 55, 2246-2252.

Dougan, W.K. \& Wilson, A.L. 1974. The absorptiometric determination of aluminium in water. A comparison of some chromogenic reagents and the development of an improved method. Analyst, Lond., 99, 413-430.

Driscoll, C.T. 1980. Chemical characterization of some acidified lakes and streams in the Adirondack Region of New York State. Ph.D. thesis, Cornell University, Ithaca, NY.

Driscoll, C.T. 1984. A procedure for the fractionation of aqueous aluminium in dilute acidic waters. Int. J. Environ. anal. Chem., 16, 267-283.

Driscoll, C.T., Baker, J.P., Bisogni, J.J. \& Schofield C.L. 1980. Effect of aluminium speciation on fish in dilute acidified waters. Nature, Lond., 284, 161-164.

Drummond, D. 1984. Surface waters acidification programme. Workshop on aluminium speciation and toxicity, London 1984. (Imperial College of Science and Technology report.) University of London.

Gjessing, E.T. 1967. Humic substances in natural water: method for separation and characterization. In: Chemical environment in the aquatic habitat. I.B.P. symposium, October 1966, edited by H. L. Golterman \& R. S. Clymo, 191-201. Amsterdam: N.V. NoordHollandsche Uitgevers Maatschappij.

Hem, J.D. 1968. Graphical methods for studies of aqueous aluminium hydroxide, fluoride and sulphate complexes. (Water Supply paper 1827-B.) Washington, DC: US Geological Survey.
Hem, J.D. \& Roberson, C.E. 1967 Form and stability of aluminium hydroxide complexes in dilute solution. (Water Supply paper 1827-A.) Washington, DC: US Geological Survey.

Jacks, G., Knuttson, G., Maxe, L. \& Fylker, A. 1984. Effect of acid rain on soil and ground water in Sweden. In: Pollutants in porous media, edited by B. Yaron, G. Dagan \& J. Goldshmid, 94-114. (Ecological series no. 47.) Berlin: Springer.

Laxen, D.P.H. \& Harrison, R.M. 1981. A scheme for the physico-chemical speciation of trace metals in freshwater samples. Sci. Total Environ., 19, 59-82.

LaZerte, B.D. 1984. Forms of aqueous aluminium in acidified catchments of central Ontario: a methodological analysis. Can. J. Fish. aquat. Sci., 41, 766-776.

Rainwater, F.H. \& Thatcher, L.L. 1960. Methods for collection and analysis of water samples. (Water supply paper 1454.) Washington, DC: US Geological Survey.

Seip, H.M., Muller, L. \& Naas, A. 1984. Aluminium speciation: comparison of two spectrophotometric methods and observed concentrations in some acidic aquatic systems in southern Norway. Water, Air \& Soil Pollut., 23, 81-95.

Smith, R.W. 1972. Relations among equilibrium and non-equilibrium aqueous species of aluminium hydroxy complexes. Adv. Chem. Ser., 106, 250-279.

Sutcliffe, D.W. \& Carrick, T.R. 1973. Studies on mountain streams in the English Lake District. 1. $\mathrm{pH}$, calcium and the distribution of invertebrates in the River Duddon. Freshwater Biol., 3, 437-462.

Turner, R.C. 1969. Three forms of aluminium in aqueous systems determined by 8-quinolinolate extraction methods. Can. J. Chem., 47, 2521-2527.

Van Breemen, N., Driscoll, C.T. \& Mulder, J. 1984. Acidic deposition and internal proton sources in acidication of soils and waters. Nature, Lond., 307, 599-604. 


\title{
The determination of total sulphur in vegetation
}

\author{
$J$ A PARKINSON \\ ITE, Merlewood Research Station, Grange-over-Sands
}

\section{Introduction}

The standard method traditionally used in ITE's Merlewood Research Station chemical laboratories for estimating total sulphur in vegetation has been a dry ashing/barium sulphate turbidimetric procedure based on Butters and Chenery (1959). Over the years, this method has proved to be reliable and reproducible. However, it is tedious and time-consuming for routine use when large numbers of samples are involved. Throughput can be increased by replacing the dry ashing stage with a nitric/perchloric acid digestion, but this technique has been found to have limitations with some types of sample. A better alternative is $X$-ray fluorescence (XRF), which is both rapid and convenient. The sample matrix is largely cellulose and the spectrometer can, therefore, be calibrated by using, as standards, samples which have been carefully analysed by a suitable chemical method, such as the standard one mentioned above.

During a calibration exercise of this kind, it was found that $X$-ray fluorescent intensity of the sulphur $K \alpha$ line was highly correlated with the total sulphur content of the specimen used. However, for 2 species, dog's mercury (Mercurialis perennis) and bracken (Pteridium aquilinum), the relationship did not hold, and further tests revealed errors in the chemical analysis results for these 2 species. Therefore, various chemical procedures were investigated for the analysis of a wide range of vegetation types, with a view to finding a suitable method for XRF calibration.

\section{Materials and methods}

A selection of air-dry, ground $(0.7 \mathrm{~mm})$ samples of vegetation were obtained covering several different species, including dog's mercury and bracken (Table 1).

Four chemical methods for the determination of total sulphur were compared, involving 4 different oxidation procedures and 2 methods for determination of the sulphate-sulphur formed on oxidation.

i. The standard dry ashing/barium sulphate turbidimetric procedure based on Butters and Chenery (1959). The full procedure is described by Allen et al. (1974).

ii. Wet oxidation/barium sulphate turbidimetric, in which the sample is oxidized with a mixture of nitric and perchloric acids in the presence of vanadium (Mottershead 1971).

iii. Schoniger flask oxidation followed by ion chromatography (Busman et al. 1983). In this study, chemically supressed ion chromatography was carried out on a Dionex (model 2010i) chromatograph using an AS4A column operated under the manufacturer's standard conditions.

iv. Oxygen bomb oxidation, followed by ion chromatography. This procedure was a development from method 3 , in which the oxidation was carried out under pressure (20 atmospheres of oxygen). The bomb used was part of a conventional adiabatic bomb calorimeter (Gallenkamp \& Co, Model CB-100). The samples were pressed into pellets, $13 \mathrm{~mm}$ diameter, and placed in a silica crucible designed

Table 1. Samples used in comparison tests

\begin{tabular}{llll}
\hline Sample & Site & Species & Component \\
\hline 1 & $\begin{array}{l}\text { Merlewood } \\
\text { Oxenthwaite } \\
\text { Merlewood }\end{array}$ & $\begin{array}{l}\text { Dog's mercury } \\
\text { (Mercurialis perennis) }\end{array}$ & $\begin{array}{l}\text { Above-ground } \\
\text { growth }\end{array}$ \\
3 & $\begin{array}{l}\text { Humphrey Head } \\
\text { Oxenthwaite }\end{array}$ & $\begin{array}{l}\text { Meadowsweet } \\
\text { (Filipendula ulmaria) }\end{array}$ & Leaves \\
4 & Angerham & Rosebay willow-herb & \\
5 & Merlewood & (Chamaenerion augustifolium) & Leaves \\
6 & Lindale & $\begin{array}{l}\text { Bracken } \\
\text { (Pteridium aquilinum) }\end{array}$ & Fronds \\
8 & Hampsfell & Heather & Above-ground \\
9 & Lowick & (Calluna vulgaris) & growth \\
10 & Kirkby Moor & &
\end{tabular}


for use with the apparatus. The crucible was positioned in the bomb, pressurized with oxygen and fired according to the manufacturer's instructions, except that $25 \mathrm{ml}$ water was added to the pressure vessel initially. After firing, 15-20 minutes were allowed before releasing the pressure. The walls and cap of the bomb were washed and the washings added to the $25 \mathrm{ml}$ water already present. After dilution of the solution obtained to $50 \mathrm{ml}$, sulphate was determined by ion chromatography.

v. The samples were also analysed by XRF using the calibration mentioned earlier, but excluding the results for the samples which gave trouble in the chemical analysis.

\section{Results and discussion}

The species used in the comparison tests were chosen because low recoveries of total sulphur had been obtained with the dry ashing procedure. With the exception of dog's mercury, all species proved difficult to ash. Nevertheless, the presence of unburnt carbon at the filtration stage did not necessarily result in significantly low recoveries of sulphur. In fact, attempts to ensure complete combustion by extending the time in the furnace often caused more serious losses of sulphur. Possible recovery problems other than incomplete ashing is borne out by the dog's mercury sample, which, although invariably completely ashed, often gave inconsistent values of sulphur content. Reproducible results could only be obtained by controlling closely all stages of the ashing procedure for each individual determination. Such control is tedious but necessary.

The results of the comparison tests are given in Table 2. It was noticeable that the samples which were difficult to ash by dry ashing were also difficult to oxidize by wet digestion. The latter method is known to give low recoveries when used to oxidize methionine alone (Randall \& Spencer 1980; Bethge 1956) and this has been confirmed for the Mottershead procedure ( $\mathrm{H} \mathrm{M}$ Grimshaw, pers. comm.). Two species, meadowsweet (Filipendula ulmaria) and rosebay willowherb (Chamaenerion augustifolium), always gave low and variable results with the wet digestion procedure, despite several attempts and careful attention to the digestion procedure. No attempt was made to determine whether these samples were particularly high in methionine, but the wet digestion procedure is unsuitable in these cases.

The Schoniger oxidation resulted in low recovery of $S$ in most cases. Incomplete combustion was a contributory factor, as there was almost always a residue of unburnt carbon in the platinum basket used to hold the filter paper containing the sample. In addition, the procedure requires some manual skill and practice to obtain good results. The figures given are, therefore, not a true reflection of the potential of the method, and further work would probably have overcome the problems. During the course of the study, however, the Schoniger oxidation was superseded by the oxygen bomb combustion, which was immediately more successful, and work on oxygen flask combustion ceased at that point.

The products of combustion in oxygen tend to remain associated with the water formed during the burning process (Mott \& Parker 1958) and, as a result, a large part of the sulphur is condensed on to the walls and lid of the vessel as sulphuric acid, rather than being absorbed by the added water. It is, therefore, important to wash down the walls and lid of the container to ensure that all the sulphate produced is determined by ion chromatography. This was found to be the main precaution necessary in the bomb oxidation procedure. Otherwise, the combustion of the sample pellet proceeded smoothly and the addition of a firing aid was not necessary, as no car-

Table 2. Comparison of results for total S (\%) in vegetation by various methods

\begin{tabular}{|c|c|c|c|c|c|}
\hline $\begin{array}{l}\text { Sample } \\
\text { number }\end{array}$ & $\begin{array}{l}\text { Dry } \\
\text { ashing }\end{array}$ & $\begin{array}{c}\text { Wet } \\
\text { oxidation }\end{array}$ & $\begin{array}{l}\text { Schoniger } \\
\text { oxidation }\end{array}$ & $\begin{array}{l}\text { Bomb } \\
\text { oxidation }\end{array}$ & XRF \\
\hline $\begin{array}{c}1 \\
2 \\
3 \\
4 \\
5 \\
6 \\
7 \\
8 \\
9 \\
10 \\
11 \\
\text { Mean }\end{array}$ & $\begin{array}{l}0.348 \\
0.419 \\
0.298 \\
0.132 \\
0.136 \\
0.157 \\
0.138 \\
0.158 \\
0.366 \\
0.225 \\
0.130 \\
0.228\end{array}$ & $\begin{array}{l}0.335 \\
0.407 \\
0.310 \\
0.114 \\
0.088 \\
0.107 \\
0.119 \\
0.106 \\
0.343 \\
0.220 \\
0.134 \\
0.207\end{array}$ & $\begin{array}{l}0.312 \\
0.382 \\
0.194 \\
0.122 \\
0.113 \\
0.165 \\
0.164 \\
- \\
0.211 \\
0.190 \\
0.112 \\
0.197\end{array}$ & $\begin{array}{l}0.328 \\
0.397 \\
0.309 \\
0.123 \\
0.122 \\
0.145 \\
0.153 \\
0.145 \\
0.344 \\
0.239 \\
0.129 \\
0.221\end{array}$ & $\begin{array}{l}0.331 \\
0.400 \\
0.313 \\
0.122 \\
0.119 \\
0.143 \\
0.154 \\
0.137 \\
0.347 \\
0.217 \\
0.132 \\
0.220\end{array}$ \\
\hline
\end{tabular}

Results are means of duplicates, except for sample 11 which are day-to-day running means of heather laboratory reference sample (see text and Table 3 ) 
bonaceous residue remained in the crucible.

The sample means for each method indicate that lower results were obtained for wet digestion and Schoniger oxidation flask than for the other procedures, for the respective reasons given earlier. Statistical examination of the data from the other 3 procedures showed no significant differences between them $(P<0.05)$. However, the bomb oxidation figures agree more closely with those of XRF than do the data from dry ashing, which suggests either better precision for the bomb oxidation method, or a slight positive bias in this set of dry ashing results.

A reference material of heather (Calluna vulgaris) (Rowland 1987) was used to assess the long-term reproducibility of the different procedures and also to check whether there were significant differences between them. The data are summarized in Table 3. The dry ashing and wet digestion data were obtained over a period of several years, the Schoniger and bomb oxidation results over a few weeks, and the XRF values over one year. As might be expected, the XRF procedure is the most precise (coefficient of variation (CV) $1.7 \%$ ) followed by the bomb oxidation method (CV 4.1\%). The other methods all had coefficients between $5 \%$ and $10 \%$. Excluding the Schoniger oxidation, the means from the other procedures were not significantly different from each other $(P<0.05)$. The Schoniger mean was significantly different from all the rest, for the reasons given earlier. If a wider range of species were analysed, then it is probable that the wet digestion would also show significant differences, but this procedure appears to be satisfactory for heather. be confirmed using other certified reference vegetation samples.

Table 4. Analysis of NBS-SRM-1575 pine needles

$\% \mathrm{~S}$

Quoted value (Alvarez \& Uriano 1985)

0.117

Value obtained by XRF

0.113

Value obtained by bomb oxidation

0.114

\section{Conclusions}

Both dry ashing/barium sulphate turbidimetry and bomb oxidation/ion chromatography appear to be suitable methods for calibration in X-ray fluorescence, which is rapid and reliable for the determination of total sulphur in vegetation. The bomb oxidation procedure is more precise and more convenient, and is therefore to be evaluated further with a wider range of species. The wet digestion/barium sulphate turbidimetric procedure is not recommended because it is unreliable for some species. Schoniger flask oxidation/ion chromatography requires some manual dexterity, but would probably be satisfactory if the necessary skill was acquired.

\section{Acknowledgements}

The author would like to thank Liverpool Polytechnic students, A G Geraghty and A O'Shea, for help with this project, during their period of industrial training at ITE's Merlewood Research Station.

\section{References}

Allen, S.E., Grimshaw, H.M., Parkinson, J.A. \& Quarmby, C. 1974. Chemical analysis of ecological materials.Oxford: Blackwell Scientific.

Table 3. Results of multiple analyses of heather reference sample for total S

\begin{tabular}{llllll}
\hline & $\begin{array}{c}\text { Dry } \\
\text { ashing }\end{array}$ & $\begin{array}{c}\text { Wet } \\
\text { oxidation }\end{array}$ & $\begin{array}{c}\text { Schoniger } \\
\text { oxidation }\end{array}$ & $\begin{array}{c}\text { Bomb } \\
\text { oxidation }\end{array}$ & XRF \\
\hline $\mathrm{n}$ & 30 & 35 & 7 & 7 & 12 \\
Mean $(\%)$ & 0.130 & 0.134 & 0.112 & 0.129 & 0.132 \\
SD & 0.0096 & 0.0131 & 0.0111 & 0.0053 & 0.0023 \\
(CV) & $(7.4)$ & $(9.8)$ & $(9.9)$ & $(4.1)$ & $(1.7)$ \\
SE & 0.0018 & 0.0022 & 0.0042 & 0.0020 & 0.0007 \\
limit confidence & 0.0037 & 0.0044 & 0.0103 & 0.0049 & 0.0015 \\
\hline
\end{tabular}

The only standard reference material available in the laboratory at the time of writing was National Bureau of Standards (NBS) SRM-1575 pine needles. This sample is not certified for sulphur content but a recommended value of $0.117 \%$ has been published by Alvarez and Uriano (1985). This material was analysed by the 2 most precise procedures as a check on accuracy (Table 4). The figures show that both the bomb oxidation and XRF methods are accurate, but this fact needs to
Alvarez, R. \& Uriano, G.A. 1985. New developments in NBS biological and clinical standard reference materials. In: Biological reference materials, edited by W. R. Wolfe, 19-44. Chichester: Wiley.

Bethge, P.O. 1956. Determination of sulphur by wet combustion with perchloric acid. Analyt. Chem., 28, $119-122$

Busman, L.M., Dick, R.P. \& Tabatabai, M.A. 1983. Determination of total sulphur and chlorine in plant 
materials by ion chromatography. Soil Sci. Soc. Am. J., 47, 1167-1170.

Butters, B. \& Chenery, E. M. 1959. A rapid method for the determination of total sulphur in soils and plants. Analyst, Lond., 84, 239-245.

Mott, R.A. \& Parker, C. 1958. Studies in bomb calor imetry IX: formation of sulphuric acid. Fuel, 37, $371-381$.

Mottershead, B.E. 1971. Determination of sulphur in biological materials using the Technicon AutoAnalyzer.
Lab. Pract., 20, 483-484.

Randall, P.J. \& Spencer, K. 1980. Sulphur content of plant material: a comparison of methods of oxidation prior to determination. Commun. Soil Sci. Plant Anal., 11, 257-266.

Rowland, A.P. 1987. Reference materials for ecological analysis. In: Chemical analysis in environmental research, edited by A. P. Rowland, 88-91. (ITE symposium no. 18.) Abbots Ripton: Institute of Terrestrial Ecology. 


\title{
Rain simulation in acid rain research - techniques, advantages and pitfalls
}

\author{
U SKIBA, A EDWARDS, T PEIRSON-SMITH and M CRESSER \\ Department of Soil Science, University of Aberdeen, Aberdeen
}

\section{Introduction}

Simulation of precipitation was being used extensively in environmental studies long before acid rain research became popular, particularly in soil erosion studies, in investigations of biogeochemical cycling, and for quantifying the weathering-induced deterioration of construction materials such as plastics. The designs typically employed in the laboratory and under field conditions have been reviewed briefly in the literature (eg Chow \& Harbaugh 1965; Chevone et al. 1984). Over the past decade, simulators have often been employed in attempts to elucidate mechanisms for interactions of acidic mist, rain and even snow with various components of the soil/plant/water ecosystem, either in isolation or collectively. Aspects investigated include the leaching of nutrients from seedlings exposed to acid mist (Wood \& Bormann 1975; Scherbatskoy \& Klein 1983), visible foliar injury through acidic rain (Evans \& Curry 1979), deterioration of agricultural crop yields and quality (eg Rebbeck \& Brennan 1984; Rathier \& Frink 1984; Lee et al. 1981), and the effects of acid precipitation upon decomposition of organic matter (Abrahamsen et al. 1980), microbial activity and microbial respiration (eg Strayer \& Alexander 1981). Attempts have been made to simulate acid rain in microcosms (Kelly \& Strickland 1984) and, more recently, both rain and snow in complete enclosed ecosystems (Wright 1985).

The aim of this presentation is to summarize the advantages of simulation techniques in acid deposition research and to give an insight into the types of problems which may be usefully solved. The limitations of such techniques, and some of the pitfalls which may be encountered, perhaps unexpectedly, in short-term and long-term experiments, both in the laboratory and in the field, are also discussed. Finally, the design and construction of some simulators are briefly but critically appraised.

2 The advantages and disadvantages of simulated precipitation

In a review of the effects of acid rain on soil, Tabatabai (1985) was critical of the fact that most allegations on the impact of acid rain upon soils and crops were based upon hypothetical or theoretical considerations, or the results of experiments with synthetic acid rain under conditions that were so extreme that they were unlikely to occur in practice, even in grossly polluted areas.
Two criticisms, in particular, are often appropriate

i. the precipitation may be too acid (eg $\mathrm{cpH} 3$ or even more acidic) for meaningful extrapolations to be valid;

ii. the precipitation may be added routinely at a rate far in excess of reality - in extreme cases, for example, a week's rainfall may be added in minutes from a watering can.

It should be stressed that the criticism is not directed at simulation per se, but rather at inadequately realistic simulation. Provided sufficient attention is paid to detail at the experimental design stage, artificial rain may be a valuable exploratory tool.

\subsection{The provision of suitable controls}

Regardless of which component of an ecosystem is being studied, it is imperative to have suitable control materials/situations for reference purposes so that meaningful interpretation of the data obtained is possible. Provision of adequate controls is perhaps the greatest difficulty to be overcome in much acid rain research based upon field observations. For example, although it may be relatively simple to find 2 field sites with similar vegetation type and age, only one of which is subject to serious pollution, variations may still occur in climate, physical and chemical properties of the soils, physiological growth stage, fungal or other attack, and nutrient status of the plant species present.

On the other hand, if simulation is used, virtually all of the other variables, apart from deposition acidity, may be effectively eliminated, or the importance of any one of them may be studied independently of the others. Variability sometimes may be even further reduced, if deemed desirable, by employing clonal plant materials.

\subsection{Study of leaching of nutrients from vegetation}

The extent to which nutrient cations are leached from vegetation depends upon characteristics of both vegetation and precipitation. Clearly, plant species, physiological growth stage, nutrient status, freedom from disease or other attack, and possibly even a number of associated soil parameters, may be significant (Cresser et al. 1986). As far as precipitation characteristics are concerned, solute chemistry (including acidity) and rainfall intensity and duration are certainly important. Rainfall droplet size range may also be rele- 
vant, and so may be various climatic factors, because they regulate the time foliage contacts the water. Climate between precipitation events may substantially influence dry deposition-derived contributions. This high number of variables complicates meaningful comparisons of data from diverse field sites, and suggests that simulation may be beneficial, provided that precipitation may be added under realistic conditions.

Such an approach has allowed the authors to clarify the importance of the ion exchange mechanism for acid neutralization by 8-year-old Sitka spruce (Picea sitchensis) trees (Skiba et al. 1986), using a simple and inexpensive rain rig described later. Work with fresh branches from near the top of 30-year-old trees showed similar mechanisms, as did work with small twigs kept in water and subjected to acidic mists. Older spruce tends to have an acidifying effect, however (Miller 1984), suggesting that only limited extrapolation is advisable with respect to plant age. Because of the many variables which may affect throughfall chemistry, extrapolation from laboratory to field conditions may be very difficult on a quantitative basis. Simulation in this instance is best seen as a technique for elucidation of mechanisms. Certainly, however, laboratory simulation results obtained by the authors with heather (Calluna vulgaris) and sphagnum have later been ratified in the field in terms of behaviour patterns. Vegetation freeze/thaw cycles may be quite common in the field, but they are rarely even considered when simulated conditions are employed.

Precipitation composition is generally (but not always, see eg Kelly \& Strickland 1984) kept constant when simulators are used, although work by the authors (Edwards et al. 1984) and others has shown that acidity may reach a maximum soon after the onset of a storm as a result of sub-cloud scavenging of acidifying pollutants. Short, light storms may therefore give very acidic water, which is intercepted substantially by the vegetation and may not reach the forest floor. Simulation techniques suggest significant neutralization of such acidity by Sitka spruce (Skiba et al. 1986). Such processes must be borne in mind when the fate of acid inputs is being considered. Changes in acidity with time may be readily simulated. Some typical results showing the corresponding changes in throughfall chemistry with time under young Sitka spruce trees are shown in Figure 1.

2.3 Scope for examination of effects of different acidifying pollutants

Because the solute chemistry of the simulated deposition is controllable and may be constant if required, it is possible to examine the effect of different pollutants, either individually or as mixtures. For example, the authors have compared
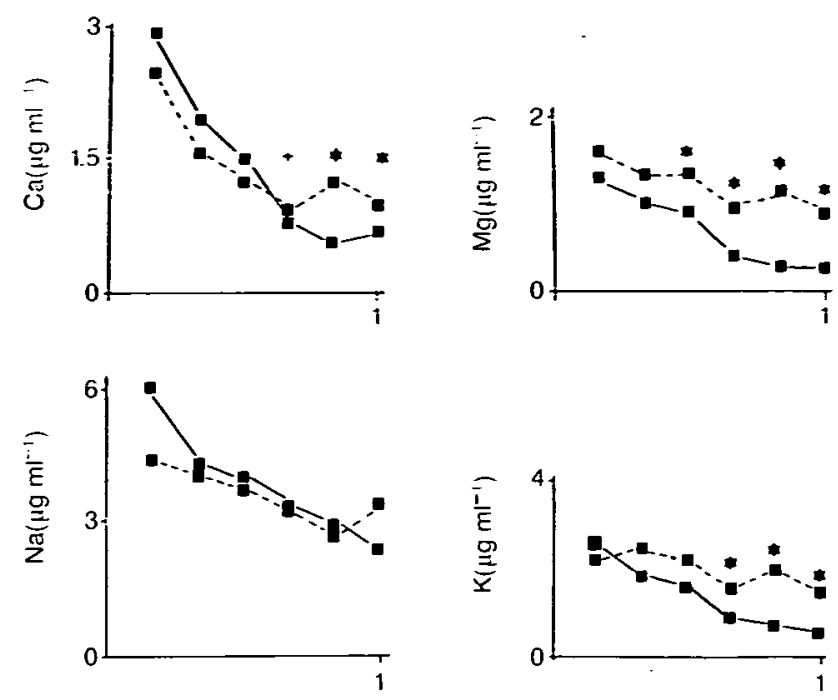

Time (h)

Figure 1. Effect of simulated rain on leaching of $\mathrm{Ca}, \mathrm{Mg}, \mathrm{Na}$ and $\mathrm{K}$ from Sitka spruce branches at $\mathrm{pH} 3$ (-) or at $\mathrm{pH} 3, \mathrm{pH} 4$ and $\mathrm{pH} 5$ for 20 minutes each (a- $\longrightarrow$ ). difference significant at $P<0.01$; + difference significant at $P<0.1$
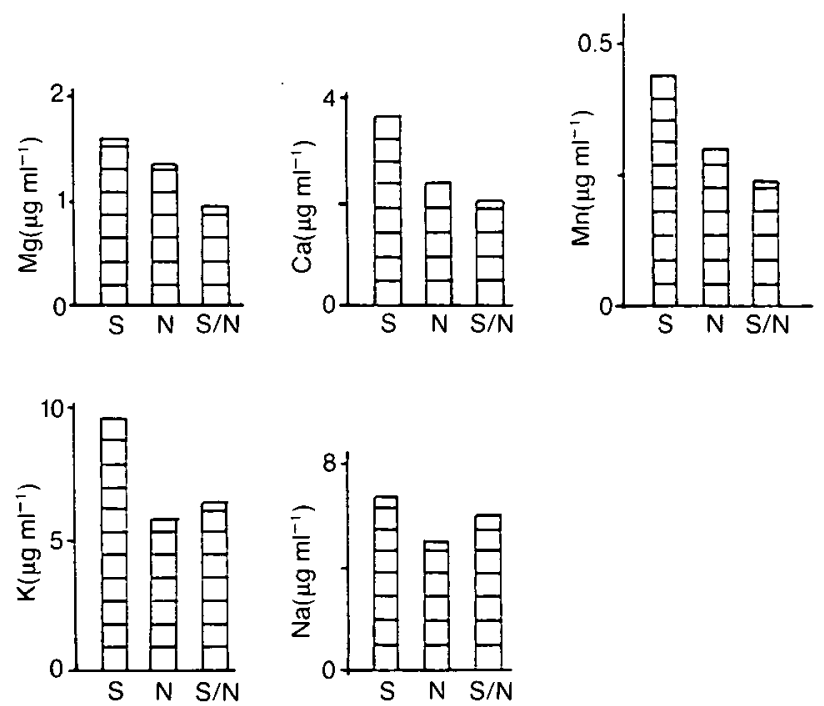

Figure 2. Effect of 'rain' acidified to $\mathrm{pH} 3.5$ with $\mathrm{H}_{2} \mathrm{SO}_{4}(\mathrm{~S}), \mathrm{HNO}_{3}(\mathrm{~N})$ or an equinormal mixture of both $(S / N)$ upon leaching of cations from young Sitka spruce trees

the throughfall chemistry of Sitka spruce trees subjected to simulated rain acidified with $\mathrm{H}_{2} \mathrm{SO}_{4}$, $\mathrm{HNO}_{3}$ or an equinormal mixture of both. Calcium, $\mathrm{K}^{+}$and $\mathrm{Na}^{+}$leaching from trees exposed to $\mathrm{H}_{2} \mathrm{SO}_{4}$-acidified rain was significantly $(\mathrm{P}<0.1)$ higher than from trees exposed to $\mathrm{HNO}_{3}$-acidified rain (Figure 2). The differences in cation leaching by rain acidified with both $\mathrm{HNO}_{3}$ and $\mathrm{H}_{2} \mathrm{SO}_{4}$ or with $\mathrm{HNO}_{3}$ only were insignificant (Skiba et al. 1986). Compared to non-acid rain $(\mathrm{pH} 5.3)$, rain acidified with $\mathrm{H}_{2} \mathrm{SO}_{4}$ to $\mathrm{pH} 3.5$ increased the leaching of cations from Sitka spruce trees to a significantly greater extent than rain acidified with $\mathrm{HNO}_{3}$ or $\mathrm{H}_{2} \mathrm{SO}_{4} / \mathrm{HNO}_{3}$. In a further experiment, 
Sitka spruce twigs were exposed to simulated mist acidified to $\mathrm{pH} 3.5$ with either $\mathrm{H}_{2} \mathrm{SO}_{4}$ or $\mathrm{HNO}_{3}$ on 5 consecutive occasions, followed by washing with distilled water. The sulphuric acidified mist caused significantly more leaching of $\mathrm{Mg}, \mathrm{K}$ and $\mathrm{Na}$ from the twigs (Table 1). Calcium leaching was not significantly different when applying $\mathrm{H}_{2} \mathrm{SO}_{4}$ or $\mathrm{HNO}_{3}$ acidified mist (Skiba et al. 1986).

Table 1. Leaching of cations from Sitka twigs by acid mist

Concentration in eventual leachate

$\left(\right.$ ueq $\left.\mathrm{I}^{-1}\right)$

\begin{tabular}{lrrr}
\hline $\mathrm{Ca}^{21}$ & 55 & & \\
$\mathrm{Mg}^{2+}$ & 10 & $*$ & 66 \\
$\mathrm{~K}^{+}$ & 3.3 & $*$ & 0.8 \\
$\mathrm{Na}^{+}$ & 129 & $*$ & 96.8 \\
\hline
\end{tabular}

Means of triplicates, ${ }^{*} \mathrm{P}<0.05$

2.4 Scope for examination of effects of pollutant concentration

With precipitation simulators, it is much simpler to examine the effects of pollutant acid concentration upon the parameter under study. Inadequate elimination of effects of other variables may make this examination impossible in conventional field experiments. This fact may be particularly important if an attempt is being made to establish whether there is a threshold acidity below which a particular effect is not observed.

2.5 Geographical convenience and ease of maintenance

Whether in the field or in the laboratory, routine use of simulators may be much more convenient than regular visits to a range of geographically remote field sites. Initial construction/installation costs may soon be recouped, and more frequent sampling programmes may be feasible. Maintenance costs are reduced and vandalism risks may be eliminated.

\subsection{Use of simulation in pilot studies}

Simple and rapid experiments with simulated precipitation may provide much useful information for planning field experiments, and thus avoid the establishment of long-term field studies in which results will be of limited value through inadequate sampling strategy or replication of sites, or a poor choice of sites.

2.7 Use of artificial rain for confirming or refuting predicted mechanisms

Where statistical analysis of field data reveals correlations between chemical parameters and/or relationships between chemical and physical parameters, simulation techniques may often be employed to show whether the relationship between any pair of variables is causal or coincidental, both depending upon a third parameter.

\subsection{Value of simulation in predictive research}

Simulation allows experiments to be performed
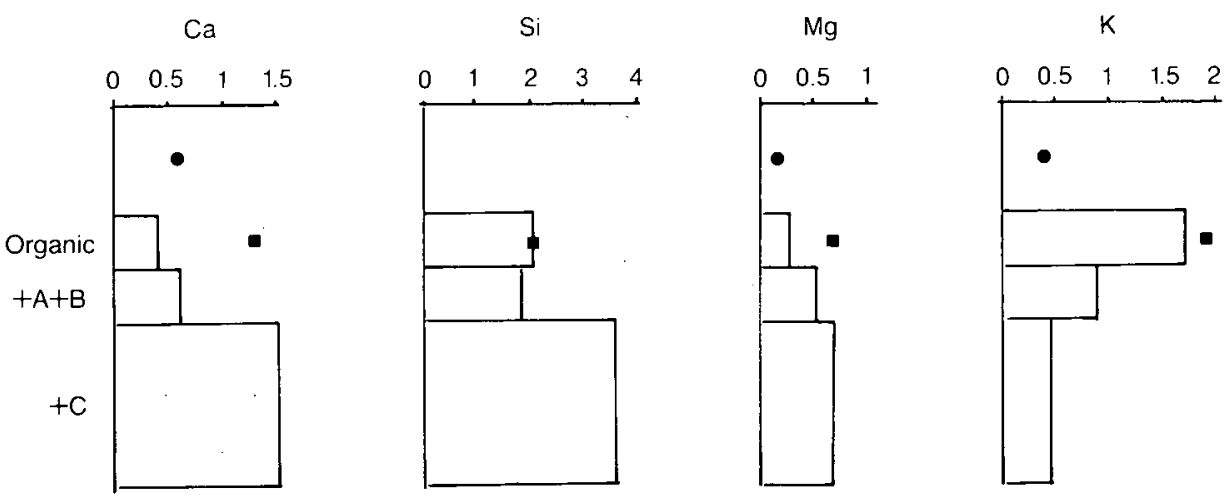

$\mathrm{Na}$

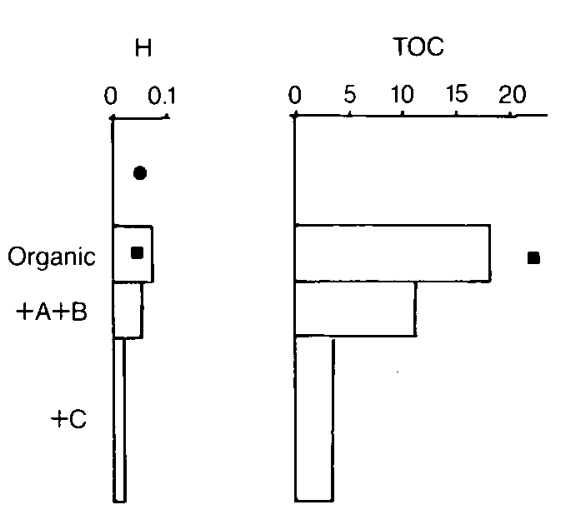

Al

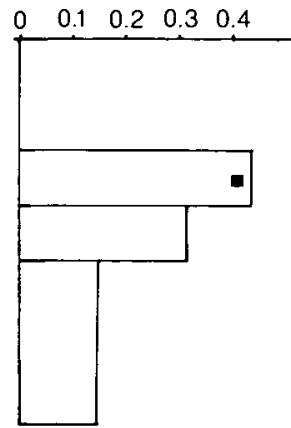

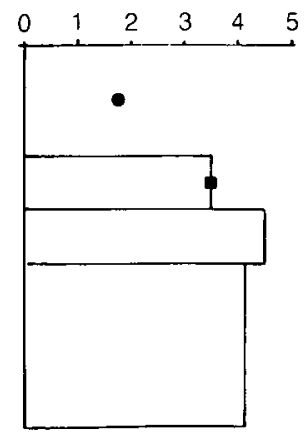

$\mathrm{Fe}$

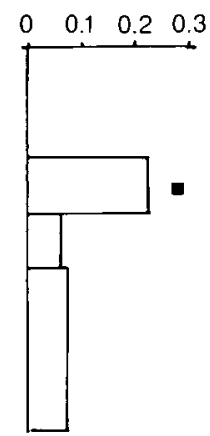

Figure 3. Change in leachate chemistry $\left(\mu \mathrm{g} \mathrm{m}^{-1}\right)$ from intact cores with soil depth (organic only, organic $A+B$, organic $+A+B+C$ horizons). Also shown are the mean annual rain concentrations ( $\bullet$ ) and the mean annual leachate concentrations from lysimeters in the field at Peatfold ( $\mathbf{\square})$ 
which may demonstrate the effects of deterioration or improvement in acidic pollutant levels. Particularly important is their potential for assessing recovery potential.

\subsection{Effects of acid deposition on drainage water chem-} istry

Chemical information obtained from soil and river water samples collected in the field can be supplemented by laboratory leaching of either intact or repacked soil columns. Both laboratory systems have certain advantages and disadvantages. A major limitation is generally the elimination of the lateral downslope flow component often observed in upland soil profiles. This limitation can be overcome only to a limited extent by using soil cores containing various combinations of soil horizons.

The use of repacked soil columns rather than intact cores poses more of a problem. Repacked columns of fresh, sieved, field-moist soil are easily prepared and have the added advantage of allowing increased replication, and therefore more treatments, which may be difficult using larger, intact cores. The major disadvantages in using repacked cores are related to the reproducibility of packing densities between columns, and the total destruction of the original soil structure, which may be very important in studies of leachate chemistry. A comparison of chloride breakthrough curves has been made for undisturbed cores and repacked columns for a silt loam (Elrick \& French 1966) and a swelling clay (Kissel et al. 1973). Chloride appeared earlier from the intact cores in both cases, an observation attributed to the presence of continuous channels and cracks in the undisturbed cores and their absence in the repacked columns. Intact soil cores are, therefore, often more suitable for acid rain studies, whereas repacked cores may be valuable for establishing patterns of behaviour and elucidation of mechanisms.

The results presented in Figure 3 compare the leachate chemistry from leachings of intact cores from Peatfold, Glenbuchat, in the Grampian Region, containing either organic, organic plus $B$ or the whole profile. A total of $70 \mathrm{~mm}$ of 'rain' was applied over $20 \mathrm{~h}$, with leachate samples collected every $15 \mathrm{ml}$. A large increase in the total solute determinants load (excluding TOC) per $\mathrm{ml}$ occurs as the rainwater $\left(2.8 \mu \mathrm{g}\right.$ of solute $\left.\mathrm{ml}^{-1}\right)$ infiltrates the soil and percolates down the profile $\left(8.4,8.65\right.$ and $10.4 \mu \mathrm{g}$ of solute $\mathrm{ml}^{-1}$ respectively for the organic, organic plus $B$ and whole profile). The relative contribution of individual elements to the total output, however, alters with depth of percolation. The authors have found relative element concentrations to be very useful in interpretation of changes in river water chemistry through storm events in terms of changing hydrological path- ways through the soil as the storm proceeds. They have also found (Cresser et al. 1986) studies of sulphate absorption done with repacked cores to be valuable in demonstrating the importance of soil parent material with respect to the potential fate of sulphate deposited on 2 contrasting upland catchments. Some typical results from the latter study are shown in Figure 4.

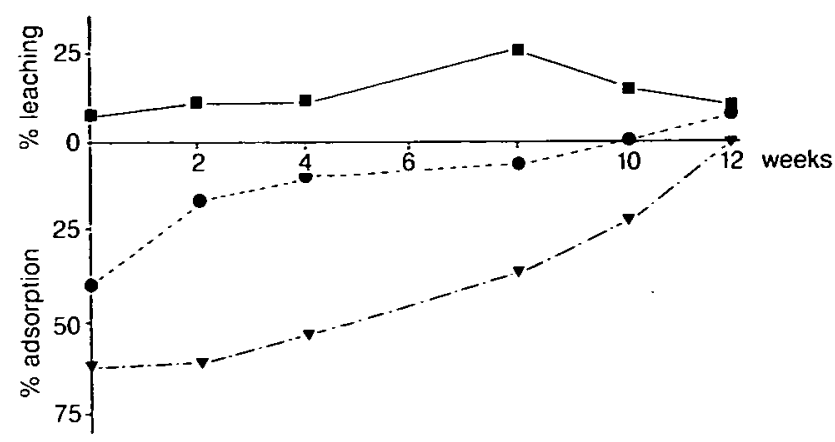

Figure 4. The patterns of $\mathrm{SO}_{4}{ }^{2-}$ adsorption or leaching down reconstituted podzol profiles from Peatfold as a result of simulated rain at $\mathrm{pH} 3.5$ : $0-50 \mathrm{~mm}(\mathbf{\square}), 0-150 \mathrm{~mm}(\bullet)$ and $0-250 \mathrm{~mm}$ ( $)$

2.10 Effects of acid deposition on soil chemical and microbiological properties

Simulation experiments with soils and acid rain may be conducted to assess short-term or longer-term changes in soil chemical or microbiological properties and, if intact cores are used, changes in soil structure, as well as changes in drainage water chemistry. It then becomes particularly important to add water at an appropriate rate and as a spray. Addition of water at an excessive rate may sometimes dramatically alter the path water follows through a lysimeter, to the extent that much of the soil may be scarcely contacted by the water, and drainage may be too rapid to allow weathering to proceed to a realistic extent. The environment thus produced in the soil in a medium- to long-term experiment may bear little relation to that which would occur naturally. Furthermore, as for drainage water chemistry, the interpretation of the results for related field sites is again complicated by the lack of modifications resulting from lateral flow, which may be substantial on medium to lower hill slopes.

Relatively few lysimeter studies have been performed with vegetation in situ, but again this may be an important factor which should not be ignored. Our results have shown, for example, that dissolved organic matter from foliage or litter tends to stimulate microbial activity by providing a highly suitable substrate. There is also now much evidence for increased nutrient cation leaching from foliage in relation to rainfall acidity. The cations returned to the soil surface may be absorbed, thus helping to ameliorate the cation leaching losses to some extent by the redistri- 
bution of proton inputs to rooting depth in the soil. Vegetation, particularly heather and sphagnum on low nutrient status acid moorland soils, may absorb nitrate from acid deposition to a very substantial extent (Edwards et al. 1985). Furthermore, plant roots may play an important role in stabilizing soil structure. Long-term (4 months) experiments with sieved peat soils without vegetation (Peirson-Smith \& Cresser, unpubl.) suffered from substantial shrinkage to relatively impermeable, structureless, blocks. The effect was most pronounced initially for more acidic $(\mathrm{pH} 3.5)$ 'rain' on very acidic soils. Structure collapse problems have also been encountered with repacked columns after 12 weeks.

The general conclusions which may be drawn from the above observations are that relatively large, intact cores, or at least repacked systems with well re-established plant communities, are most appropriate for long-term studies, and that repacked systems generally should be confined to shorter-term, mechanistic, investigations.

The authors have studied the importance of changes in rainwater chemistry with time through storms. No different response of microbial respiration to fluctuating acidity of the precipitation was observed when soil from Peatfold, Glenbuchat, was subjected to 'rain' acidified with sulphuric acid to $\mathrm{pH} 2.75,4.25,4.5,5.0$ and 5.5 , added in the above or a reversed order. $\mathrm{A}$ constant $\mathrm{pH}(\mathrm{pH}$ 3.4) rain with the same total $\mathrm{H}^{+}$loading was also applied. Four hours after applying the 'rain', the rates of microbial respiration were measured, but they were not significantly different in the soils that received different treatments (Table 2).

Table 2. Effect of acid rain treatments on soil respiration rates

Treatment

Rate of respiration

Treatment $\quad\left(\mu \mathrm{g} \mathrm{CO}_{2} \mathrm{~g}^{-1}\right.$ soil h$\left.^{-1}\right)$

Constant $\mathrm{H}^{+}$loading

$60.3 \pm 3.3$

$(\mathrm{pH} 3.4)$

$\mathrm{pH} 5.50-2.75$

$\mathrm{pH} 2.75-5.50$

$62.7 \pm 2.1$

$61.6 \pm 1.6$

Means of triplicates $\pm S D, P<0.1$

\section{The chemistry of artificial rain}

In a number of studies, the 'rain' used has been dilute sulphuric acid (eg Baath et al. 1980; Scherbatskoy \& Klein 1983; Fritz-Sheridan 1985; Hovland et al. 1980; Morrison 1983). Rain, however, also contains substantial amounts of sodium, magnesium, calcium, potassium, ammonium, chloride, nitrate and organic matter, as well as minor trace constituents, apart from sulphate. The precise composition may vary considerably with both time and space (Martin \& Barber 1978). The chemical composition of 'rain' used in our studies has been based upon the mean rainfall composition of weekly samples collected at Peatfold (Grampian Region) during 1979-80 (Table 3). The major mechanism of cation leaching from foliage and soil is by cation exchange. The relative proportion of individual base cations leached depends on their concentrations in the incoming rain or throughfall. Tukey (1970) reported that $\mathrm{K}^{+}$ and $\mathrm{Na}^{+}$ions increased the quantities of nutrients leached from foliage, whereas $\mathrm{Ca}^{2+}$ ions tended to inhibit leaching losses. Studies with simulated precipitation by the authors showed that $\mathrm{Ca}^{2+}$ may, in fact, be retained from rain or throughfall by surface soils of low base status (Table 4). The Glendye soil has a lower base status and therefore retains $\mathrm{Ca}^{2+}$ more effectively than Peatfold soil.

Table 3. Mean composition of Peatfold rain ( $\mathrm{pH} 4.6$ )

\begin{tabular}{llll}
\hline \multicolumn{2}{c}{$\begin{array}{c}\text { Cations } \\
(\mu \text { eq ml }\end{array}$} & \multicolumn{2}{c}{$\begin{array}{c}\text { Anions } \\
(\mu \text { eq ml }\end{array}$} \\
\hline $\left.\mathrm{Na}^{+}\right)$ & 0.079 & $\mathrm{Cl}^{-}$ & 0.060 \\
$\mathrm{~K}^{+}$ & 0.012 & $\mathrm{SO}_{4}{ }^{2-}$ & 0.105 \\
$\mathrm{Ca}^{2+}$ & 0.031 & $\mathrm{NO}_{3}{ }^{2-}$ & 0.033 \\
$\mathrm{Mg}^{2+}$ & 0.014 & $\mathrm{PO}_{4}{ }^{3-}$ & 0.003 \\
$\mathrm{NH}_{4}{ }^{+}$ & 0.025 & & \\
\hline
\end{tabular}

Table 4. Calcium ${ }^{\star}\left(\mu \mathrm{g} \mathrm{ml}^{-1}\right)$ in leachates from soils exposed to 'rain' at $\mathrm{pH} 3.5$ or $\mathrm{pH} 5.3$

\begin{tabular}{lll} 
Soil & $\mathrm{pH} 3.5$ rain & $\mathrm{pH} 5.3$ rain \\
\hline Peatfold & +0.196 & -0.201 \\
Glendye & -0.086 & -0.267
\end{tabular}

* Concentrations are means of triplicates over 12 weeks, expressed relative to the concentration in the rain

Throughfall studies with young Sitka spruce trees exposed to simulated artificial rain acidified to $\mathrm{pH}$ 3.5 with $\mathrm{HNO}_{3}$ showed a net uptake of $\mathrm{N}$ by the trees after several weeks of treatment (Skiba et al. 1986). The above results all point clearly to the importance of using 'proper rain' and not just dilute sulphuric acid in simulation studies.

\section{The acidity of simulated acid rain}

4.1 The acidity of natural rain

The average acidity of rainfall in western Europe measured from 1972-81 lay between 4.3 and 4.5 (Environmental Resources Ltd 1983). Unpolluted rain may have a $\mathrm{pH}$ range of 4.5-7.4. At Banchory, in the Grampian Region, $50 \%$ of yearly rainfall samples collected daily had a $\mathrm{pH}$ of less than 4.4 (Nicholson et al. 1980). At Peatfold in Grampian, the mean rain $\mathrm{pH}$ for weekly samples was 4.6 , and the range from 3.8 to 6.0 . In very polluted areas, for example near the Sudbury smelter (Ontario, Canada), the $\mathrm{pH}$ of water collected 
during most rain events was below $\mathrm{pH} 4.0$ (Freedman \& Hutchinson 1980).

4.2 The acidity of precipitation in simulation studies In acid rain simulation studies, precipitation generally has been acidified to $\mathrm{pH} 3,3.5$ or 4 (eg Shriner \& Cowling 1974; Lee \& Weber 1979; Abrahamsen et al. 1980). One has to remember that such studies only simulate conditions occurring in highly polluted areas, or during isolated showers in less polluted areas. Such studies may sometimes be useful tools in predicting long-term effects of acid precipitation. Intensifying the acid inputs can be done either by increasing the acidity of the precipitation (eg Firestone et al. 1984) or by increasing the volume of rain added (eg Strayer and Alexander 1981). Both approaches have their limitations. Interactions of acidity with the soil physical and microbial components, for example, are time-dependent and therefore a too high $\mathrm{H}^{+}$ ion loading could give seriously misleading results (Bache 1980). Furthermore, response may not vary linearly with $\mathrm{H}^{+}$ion concentration. On the other hand, too large amounts of precipitation added to soil cores may cause waterlogging. In throughfall studies, excessively large volumes of simulated precipitation would not significantly increase nutrient leaching from foliage.

\section{$4.3 \mathrm{H}_{2} \mathrm{SO}_{4}$ and $\mathrm{HNO}_{3}$ in acid rain}

Sulphuric and nitric acids generally make the major contributions to the rain's activity. The annual average contribution of $\mathrm{H}_{2} \mathrm{SO}_{4}$ and $\mathrm{HNO}_{3}$ to rain acidity in northern Britain was $70 \%$ and $30 \%$ respectively (Fowler et al. 1982). It is important to include $\mathrm{HNO}_{3}$ in simulation studies, especially when looking at effects of rain acidity on plant growth and microbial activity. From acid rain, $20 \mathrm{~kg}$ nitrogen $\mathrm{ha}^{-1} \mathrm{yr}^{-1}$ enters the ecosystem in central Europe and increased forest growth occurs at many sites (Ulrich 1980).

\section{Simulator designs}

In our initial work, artificial rainwater was applied using a simple nebulizer system (Edwards 1984) to produce an even and reproducible 'rainfall' distribution. Continual dripping of water or even the use of a saturated constant head of liquid may well have been easier to set up. The latter technique does not nearly reproduce natural field conditions and, if cores with little or no organic layers are to be used, problems from soil structural deterioration may develop very rapidly. A saturated constant liquid head also bears little resemblance to the field situation (flow being controlled by the soil's infiltration capacity and hydraulic conductivity) and may also suffer from problems caused by preferential flow down the core sides. Wilson et al. (1961) and Nielsen and Biggar (1962) showed that salts can be leached more efficiently by rainwater than by continuous ponding of water on the soil surface. They concluded that with rain- fall much more of the water was transmitted through the soil than through cracks, so permitting more efficient salt removal. Using the nebulizer system, edge effects are thought to be negligible during leaching of intact soil cores (Brunstad \& Njös 1980).

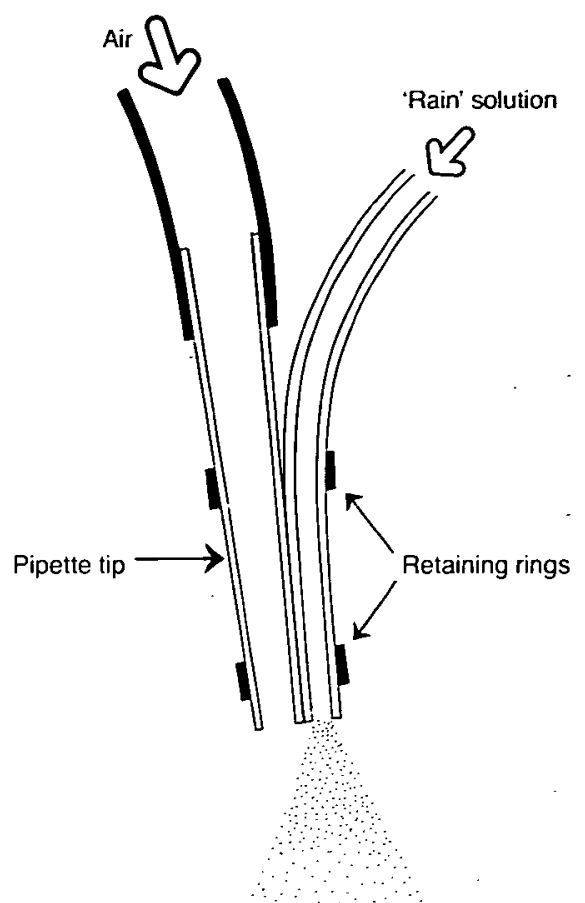

Figure 5a. The simple pneumatic nebulizer design used in the authors' rain simulator

The authors make extensive use of simple, laboratory-made pneumatic nebulizers to produce rain. Initially, glass melting point tubes were fixed in grooves in a rigid perspex support at an angle of $45^{\circ}$ and solution gravity fed to one tube and air at $c 10$ psi to the other, to produce a cross-flow nebulizer. Solution flow rate may be controlled by the solution head and the use of a suitable length of capillary tubing. The tube positions and air pressure are adjusted to give a suitable spray. More recently, pairs of plastic pipette tips have been used, held together with plastic rings (Figure 5a). A Dexion rig containing up to 14 such nebulizers was used in the foliar leaching experiments described earlier. Whenever information is required on changes with distance, eg.along a branch, parallel gutter channels have been made by looping polythene sheet over parallel support bars (Figure $5 b$ ).

With a little care, systems such as that described above may give a reasonably uniform distribution of fine rain. Alternatively, 'rain' may be made to drip from arrays of suitable capillaries (eg Chevone et al. 1984; Chow \& Harbaugh 1965). In the former study, uniformity of wetting was ensured by placing plants on a rotating table under a series 
of 'rain' arms coming radially from a central hub. In the latter work, a very large number of tubes at 1 " spacing was used. Perforated discs may also be used, but tend to give excessively large droplets over a short period. The most elaborate systems to date are undoubtedly the enclosed mini-catchment systems at Risdalsheia in southern Norway (Wright 1985). Here, sprinklers are used for 'rain'. Snow, too, has been simulated using snow generators of the type used in winter sports activities, but only with modest success. Air temperatures too close to $0^{\circ} \mathrm{C}$ lead to slush production and tree damage. In this and other field-based simulation studies, incident rain is often collected and deionized, and used to produce the simulated rain. To economize on apparatus, it is possible to use mobile rain rigs which may be moved over different plots to apply the appropriate treatment.

\section{Conclusions}

Rain simulation is a valuable tool in acid rain research, provided the limitations of simulation techniques are not overlooked. It is particularly useful for the elucidation of mechanisms, although quantitative transfer of results from the simulation system to a field situation is often difficult. Generally, the 'rain' produced by the simulator should be chemically and physically as close as possible to that encountered in the field, and even then the results should be complemented by field studies. When simulation is useful, valuable results may often be obtained with simple and inexpensive apparatus. Use of artificial rain may provide otherwise unobtainable controls to facilitate data interpretation.

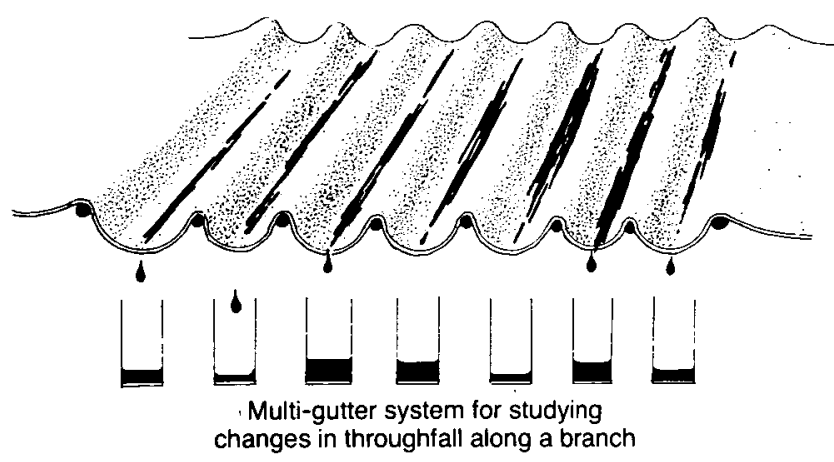

Figure 5b. Guttering system used to fractionate throughfall along a branch

\section{Summary}

The advantages of employing simulated precipitation in laboratory- and field-based acid rain research are summarized with respect to techniques for the study of effects upon plants, soils and drainage water chemistry. The practical limitations of such an empirical approach are also critically discussed. The different types of simulator design which have been used, from the simplest to the most complex, are described briefly, and the advantages and disadvantages of the various systems summarized. Applications of simulation techniques from the authors' laboratories and elsewhere are considered for a range of specific acid deposition-related problems. The results obtained in each case are outlined, and the possibility of extrapolation from laboratory results to explanations of behaviour in the field situation is critically appraised. The problems associated with making predictions of long-term trends in the field from shorter-term field and/or laboratory experiments are considered briefly.

\section{Acknowledgements}

The authors are indebted to NERC and the UK Department of the Environment for financial support for this work.

\section{References}

Abrahamsen, G., Hovland, J. \& Hagvar, S. 1980. Effects of artificial acid rain and liming on soil organisms and the decomposition of organic matter. In: Effects of acid precipitation on terrestrial ecosystems, edited by T.C. Hutchinson \& M. Havas, 341-362. New York: Plenum.

Baath, E., Berg, B., Lohm, U., Lundgren, B., Lundkvist, H., Rosswall, T., Söderström, B. \& Wiren, A. 1980. Soil organisms and litter decomposition in a Scots pine forest - effects of experimental acidification. In: Effects of acid precipitation on terrestrial ecosystems, edited by T.C. Hutchinson \& M. Havas, 375-380. New York: Plenum.

Bache, B.W. 1980. The acidification of soils. In: Effects of acid precipitation on terrestrial ecosystems, edited by T.C. Hutchinson \& M. Havas, 183-202. New York: Plenum.

Brunstad, K. \& Njös, A. 1980. Simulation of flow patterns and ion-exchange in soil percolation experiments. Part 1. Tracer experiments and flow model. Water, Air \& Soil Pollut., 13, 459-472.

Chevone, B.I., Yang, Y.S., Winner, W.E., Storks-Cotter, I. \& Long, S.J. 1984. A rainfall simulator for laboratory use in acidic precipitation studies. J. Air Pollut. Control Ass., 31, 355-359.

Chow, V.T. \& Harbaugh, T.E. 1965. Raindrop production for laboratory watershed experimentation. J. geophys. Res., 70, 6111-6119.

Cresser, M.S., Edwards, A.C., Ingram, S., Skiba, U. \& Peirson-Smith, T. 1986. Acid deposition interactions and their possible effects on geochemical weathering rates in British uplands. J. geol. Soc. Lond., 143, 649-658.

Edwards, A.C. 1984. Some factors influencing elemental mobilities in an upland catchment in the Grampian region. Ph.D. thesis, University of Aberdeen.

Edwards, A.C., Creasey, J. \& Cresser, M.S. 1984. The conditions and frequency of sampling for elucidation of transport mechanisms and element budgets in upland drainage basins. Proc. int. Symp. Hydrochemical 
balances of freshwater systems, Uppsala, Sweden, 187-202.(IAHS publication no. 150.)

Edwards, A.C., Creasey, J. \& Cresser, M.S. 1985. Factors influencing nitrogen inputs and outputs in two Scottish upland catchments. Soil Use Manage., 1, 83-87.

Elrick, D.E. \& French, L.K. 1966. Miscible displacement patterns on disturbed and undisturbed soil cores. Proc. Soil Sci. Soc. Am., 30, 153-156.

Environmental Resources Ltd. 1983. Acid rain. A review of the phenomenon in the EEC and Europe. London: Graham \& Trotman for the Commission of the European Communities.

Evans, L.S. \& Curry, T.M. 1979. Differential responses of plant foliage to simulated acid rain. Am. J. Bot., 66, 953-962.

Firestone, M.K., McColl, J.G., Killham, K.S. \& Brooks, P.D. 1984. Microbial responses to acid deposition and effects on plant productivity. In: Direct and indirect effects of acidic deposition on vegetation, edited by R.A. Linthurst, 51-63. Boston: Butterworths.

Fowler, D., Cape, J.N., Leith, I.D., Paterson, I.S., Kinnaird, J.W. \& Nicholson, I.A. 1982. Rainfall acidity in northern Britain. Nature, Lond., 297, 383-386.

Freedman, B. \& Hutchinson, T.C. 1980. Smelter pollution near Sudbury, Ontario, Canada, and effects on forest litter decomposition. In: Effects of acid precipitation on terrestrial ecosystems, edited by T.C. Hutchinson \& M. Havas, 395-434. New York: Plenum.

Fritz-Sheridan, R.P. 1985. Impact of simulated acid rains on nitrogenase activity in Peltigera aphthosa and P. polydactyla. Lichenologist, 17, 27-31.

Hovland, J., Abrahamsen, G. \& Ogner, G. 1980. Effects of artificial acid rain on decomposition of spruce needles and on mobilization and leaching of elements. Pl. Soil, 56, 365-378.

Kelly, J.M. \& Strickland, R.C. $1984 . \mathrm{CO}_{2}$ eflux from deciduous forest litter and soil in response to simulated acid rain treatment. Water, Air \& Soil Pollut., 23, $431-440$

Kissel, D.E., Ritche, J.T. \& Burnett, E. 1973. Chloride movement in undisturbed swelling clay soil. Proc. Soil Sci. Soc. Am., 37, 21-24.

Lee, J.T. \& Weber, D.E. 1979. The effects of simulated acid rain on seedling emergence and growth of eleven woody species. Forest Sci., 25, 393-398.

Lee, J.J., Neely, G.E., Perrigan, S.C. \& Grothaus, L.S. 1981. Effects of simulated acid rain on yield, growth and foliar injury of several crops. Environ. exp. Bot., 21, 171-185.

Martin, A. \& Barber, F.R. 1978. Some observations of acidity and sulphur in rainwater from rural sites in central England and Wales. Atmos. Environ., 12, $1481-1487$.
Miller, H.G. 1984. Deposition-plant-soil interactions. Phil. Trans. R. Soc. B, 305, 339-352.

Morrison, I.K. 1983. Composition of percolate from reconstructed profiles. In: Effects of accumulation of air pollutants in forest ecosystems, edited by B. Ulrich \& J. Pankrath, 195-206. Dordrecht: Reidel.

Nicholson, I.A., Cape, J.N., Fowler, D., Kinnaird, J.W. \& Paterson, I.S. 1980. pH and sulphate content of precipitation over northern Britain. In: Ecological impact of acid precipitation, edited by D. Drablos \& A. Tollan, 142-143. Oslo-As: SNSF.

Nielsen, D.R. \& Biggar, J.W. 1962. Miscible displacement. III. Theoretical considerations. Proc. Soil Sci. Soc. Am., 26, 216-221.

Rathier, T.M. \& Frink, C.R. 1984. Simulated acid rain: effects on leaf quality and yield of broadleaf tobacco. Water, Air \& Soil Pollut., 22, 389-394.

Rebbeck, J. \& Brennan, E. 1984. The effect of simulated acid rain and ozone on the yield and quality of glasshouse grown alfalfa. Environ. Pollut., A, 36, 7-16.

Scherbatskoy, T. \& Klein, R.M. 1983. Response of spruce and birch foliage to leaching by acidic mists. $J$. environ. Qual., 12, 189-195.

Shriner, D.S. \& Cowling, E.B. 1974. Effects of rainfall acidification on plant pathogens. In: Effects of acid precipitation on terrestrial ecosystems, edited by T.C. Hutchinson \& M. Havas, 435-442. New York: Plenum.

Skiba, U., Peirson-Smith, T.J. \& Cresser, M.S. 1986. Effects of simulated precipitation acidified with sulphuric and/or nitric acid on the throughfall chemistry of Sitka spruce Picea sitchensis and Calluna vulgaris. Environ. Pollut., B, 11, 255-270.

Strayer, R.F. \& Alexander, M. 1981. Effects of simulated acid rain on glucose mineralisation and some physicochemical properties of forest soil. J. environ. Qual., 10, 460-465.

Tabatabai, M.A. 1985. Effect of acid rain on soils. CRC Crit. Rev. environ. Contr. (Chem. Rubb. Co.), 15, 65-110.

Tukey, H.B., Jr. 1970. The leaching of substances from plants. PI. Physiol., Lancaster, 21, 305-324.

Ulrich, B. 1980. Production and consumption of hydrogen ions in the ecosphere. In: Effects of acid precipitation on terrestrial ecosystems, edited by T.C. Hutchinson \& M. Havas, 225-282. New York: Plenum.

Wilson, L.G., Luthin, J.N. \& Biggar, J.W. 1961. Drainage salinity investigation of the Tule lake lease lands. Bull. Calif. agric. Exp. Stn, no. 779.

Wood, T. \& Bormann, F.H. 1975. Increase in foliar leaching caused by acidification of an artificial mist. Ambio, 4, 169-175.

Wright, R.F. 1985. RAIN project. Annu. Rep. Nor. Inst. Water Res. (NIVA), 1984. 


\title{
Non-suppressed ion chromatography in 'acid rain' analysis
}

\author{
J N CAPE \\ ITE, Edinburgh Research Station, Edinburgh
}

\section{Introduction}

The ITE Edinburgh and Banchory Research Stations have been collecting and analysing rain samples since late 1977. Recently, interest has turned to more intensive sampling of rainfall events in addition to bulk monthly samples, and to the study of cloudwater chemistry. Until 1984, chemical analyses were performed at ITE Edinburgh using a variety of methods, including continuous flow colorimetry, ion-selective electrodes and atomic absorption/emission. A non-suppressed ion chromatograph was commissioned during 1984 and has been performing all the chemical analyses, with the exception of $\mathrm{pH}$, for about a year. It has allowed a greater number of samples to be analysed within the constraints of staff time.

\section{Theory}

The use of a single chromatographic column to separate anions and their subsequent direct detection by conductivity were described by Gjerde et al. (1979) and developed by the same group to include cation analysis (Gjerde et al. 1980; Fritz et al. 1980). Their approach differed from the earlier ion chromatographic techniques of Small et al. (1975), developed commercially by Dionex, in that the background conductivity of the eluant was subtracted electronically, rather than chemically, thereby eliminating the need for a chemical 'suppressor' column to reduce eluant conductivity after the chromatographic column. However, the separation method is similar, using a low-capacity ion exchange column with an aqueous eluant at a controlled $\mathrm{pH}$. Initially, anion separations were performed using phthalic acid (normally ortho-, but the 2 other isomers have been used (Glatz \& Girard 1982)) at a pH less than 6.0 , the highest $\mathrm{pH}$ which may be used with a silica-based column. More recent column technology using resin-based columns has allowed the use of $\mathrm{pH}$ range $1-12$, and a wider range of buffer eluants such as $p$-hydroxy benzoic acid at $\mathrm{pH}$ 8.5. Monovalent cations are generally separated using dilute nitric acid $\left(2 \times 10^{-3} \mathrm{M}\right)$, and separation of divalent cations is achieved by using a complexing agent such as ethylenediamine. Detection of the ions after separation can be achieved by measuring conductivity changes. For an eluant such as phthalic acid with low background conductivity, the presence of an inorganic anion, eg chloride, in the detector cell increases the conductivity, and a positive peak is produced. In cation analysis, where the nitric acid

eluant has a larger conductivity, the presence of an ion such as sodium produces a decrease in the conductivity and a negative peak. In either case, both peak heights and areas are linearly related to the amount of each ion injected on to the column. Alternative detection methods have been employed, and for anions these may be significantly more sensitive than straightforward conductivity detection. Small and Miller (1982) in the USA, and Cochrane and Hillman (1982) in the UK reported the use of indirect ultra-violet detection with phthalate as eluant. The UV absorption of the phthalate eluant is decreased as non-absorbing anions pass through the detector. This method has the added advantage of allowing the estimation of an unknown ion's valency from the variation of retention time with eluant concentration. The response (expressed as the area of the negative peak) also depends only on the concentration of the ion present in a sample, when measured in equivalents per litre, so that the response is independent of the ion and allows quantitative estimation of an unknown (Small \& Miller 1982).

A similar technique, but using changes in refractive index, has been applied by Haddad and Heckenberg (1982) to the analysis of both anions and cations.

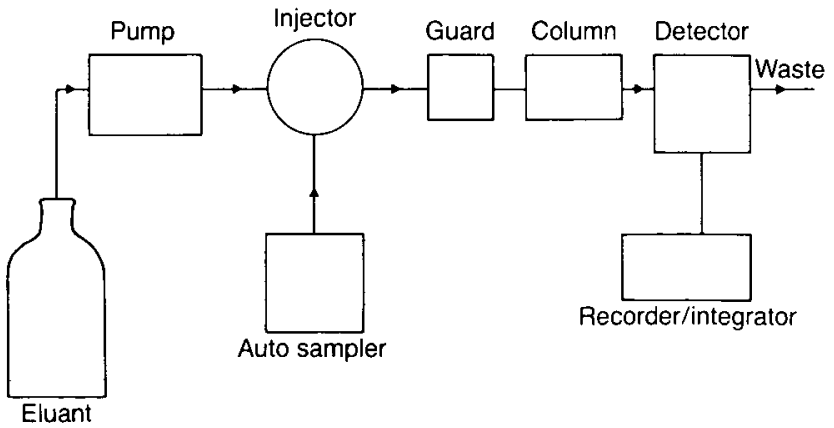

Figure 1. Schematic ion chromatography system based on standard HPLC equipment

\section{Practice}

The great practical advantage of non-suppressed ion chromatography over suppressed (ie using a chemical suppressor column) is that a system can be built from readily available standard components for high-performance liquid chromatography (HPLC). A schematic diagram of such a system is shown in Figure 1, and the equipment used at ITE Edinburgh is listed in Table 1. Other detectors (eg UV detector) could be used 
in place of the conductivity detector. For a laboratory with existing HPLC equipment, only a suitable column needs to be purchased to achieve a capability for ion chromatography.

Table 1. Ion chromatography equipment used at ITE Edinburgh

Pump: Kontron 414 single-piston pump with pulse dampener

Autosampler: Kontron MSI660 with pneumatic injector (Rheodyne) capacity $60 \times 2$ $\mathrm{ml}$ vials

Column holder and detector: Wescan ion chromatography module (conductivity)

Recorder/integrator: Shimadzu C-R1A single channel printer/plotter

The operation of the system requires the same care as any HPLC equipment. All samples are filtered through a disposable $0.2 \mu \mathrm{m}$ filter, and eluants are also filtered through an $0.2 \mu \mathrm{m}$ 'candle' filter before use. Initially, problems were found with the quality of the laboratory supply of deionized water which, although 'pure' in that its conductivity was around $0.1 \mu \mathrm{S}$, had sufficient colloidal material present to accumulate on the guard column and create a high back-pressure. Analytical columns are not cheap ( $200-£ 600$ ), but the use of a guard column and care in sample preparation permits several thousand injections without serious loss of column efficiency. The size of the injection loop can be varied to suit the samples: for normal rain samples, we use a $200 \mu$ l loop, but for cloudwater samples, which generally have much larger concentrations, a $20 \mu$ loop has been used successfully.

The limits of detection are around $2 \times 10^{-6} \mathrm{M}$ for direct injection. Other workers (eg Roberts et al. 1981) have pre-concentrated samples on a short column in place of the sample loop. Up to $10 \mathrm{ml}$ of sample may be passed through the concentrating column; the ions are retained at the head of the concentrating column and are then flushed on to the analytical column by pumping eluant backwards through the concentrating column. In this way, concentrations down to $10^{-8} \mathrm{M}$ may be detected, but at these levels the likelihood of contamination is very great, and precautions such as using pre-soaked polycarbonate labware and a dust-free environment must be observed to obtain reproducible results.

\section{Analysis of anions}

The 3 major anions in rainwater (chloride, nitrate and sulphate) are readily separated and detected, and, by choice of a suitable eluant, other inorganic ions such as fluoride and phosphate may be separated and measured. The order of elution is

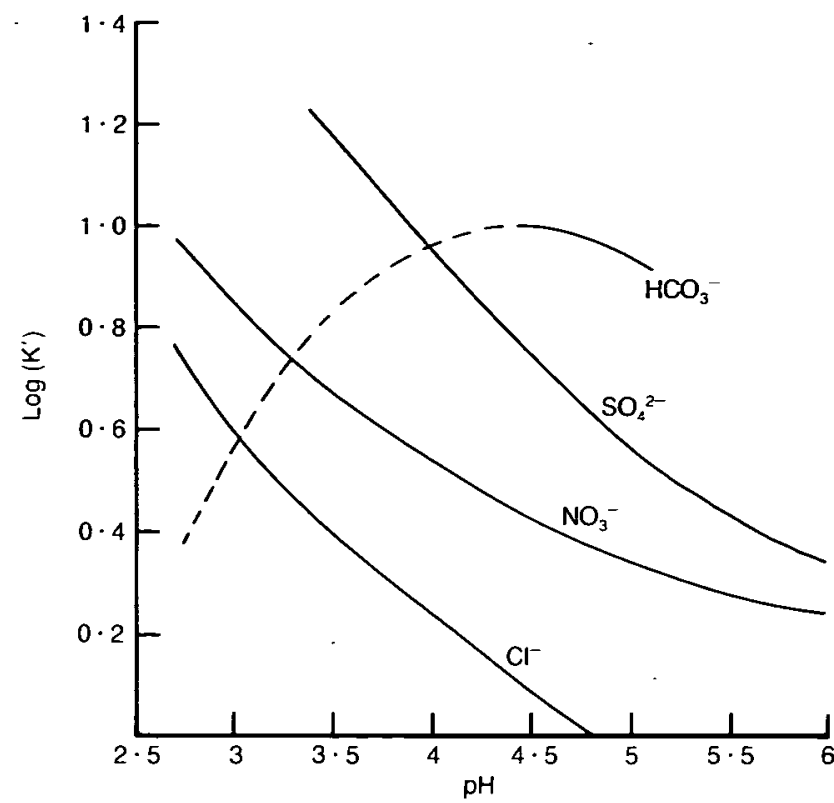

Figure 2. Retention of major inorganic ions in rainwater as a function of $\mathrm{pH}$, using $4 \times 10^{-3} \mathrm{M}$ phthalate eluant (after The Wescan Ion Analyser. 4, 3 (1982), Wescan Inc., Santa Clara, California)

determined by the concentration of the eluant and its $\mathrm{pH}$. For a phthalate eluant, the optimum $\mathrm{pH}$ is between 4 and 5 to achieve elution of the sulphate ion in reasonable time. The sensitivity of the method increases as eluant concentration is decreased, but a compromise must be sought between elution time (which increases with decreasing concentrations) and sensitivity. For a $4 \times 10^{-3} \mathrm{M}$ solution of potassium hydrogen phthalate, Figure 2 shows the effect of changing $\mathrm{pH}$ on retention of the common anions. For rainwater analysis, a $\mathrm{pH}$ must be chosen sufficiently high to elute sulphate quickly without 'losing' the chloride peak in the initial 'solvent' peak. After some trial and error, we have adopted as standard an eluant for anion anlaysis of $0.332 \mathrm{~g}$ o-phthalic acid, $24.0 \mathrm{ml} 0.1 \mathrm{M} \mathrm{NaOH}$ and $10 \mathrm{ml}$ methanol per litre of deionized water. This is equivalent to a phthalate concentration of $2 \times$ $10^{-3} \mathrm{M}$ at $\mathrm{pH} 4.74$. Addition of a small quantity $(1 \%)$ of methanol alters the retention characteristics to some extent, but has been found useful for avoiding bubble formation in the detector, which can occur even with vacuumdegassed eluant. Methanol (5\%) is also added to the wash-water of the autosampler to prevent droplet formation in the PTFE (polytetrafluoroethylene) sample tubing. This eluant allows the separation of the 3 major ions in less than 15 minutes at a flow rate of $3 \mathrm{ml} \mathrm{min}^{-1}$ using a $25 \mathrm{~cm} \times 4 \mathrm{~mm}$ column. A typical analysis is shown in Figure 3 for a rainwater sample. Calibration is achieved by inserting a single standard solution (usually $200 \times 10^{-6} \mathrm{M} \mathrm{Cl}^{-}, 50 \times$ $10^{-6} \mathrm{M}, \mathrm{NO}_{3}^{-}, 50 \times 10^{-6} \mathrm{M} \mathrm{SO}_{4}{ }^{2-}$ ) after every 5 samples. Response factors are calculated automatically by the integrator and used for 


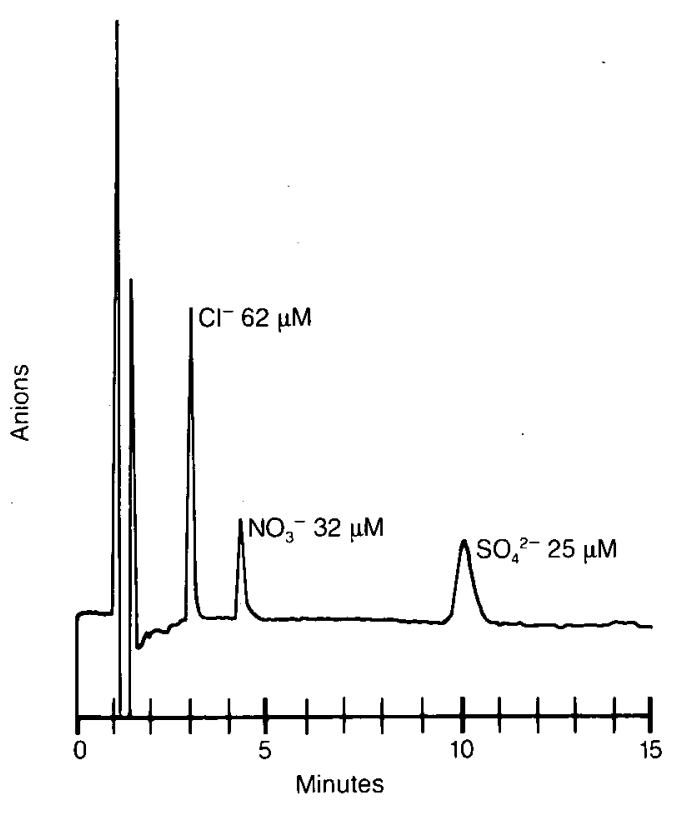

Figure 3. Anion analyser of rainwater sample from Great Dun Fell, Cumbria (17 April 1985). Flow rate: $3 \mathrm{ml} \mathrm{min} \mathrm{m}^{-1}, 100 \mu /$ injection; eluant: $2 \times 10^{-3} \mathrm{M}$ phthalate at $\mathrm{pH} 4.74$ in $1 \%$ methanol; column: Vydac $302 / \mathrm{C} 25 \mathrm{~cm} \times 4 \mathrm{~mm}$

subsequent samples. Analysis of a range of standard solutions has demonstrated a rectilinear response through the origin (Figure 4 ), which

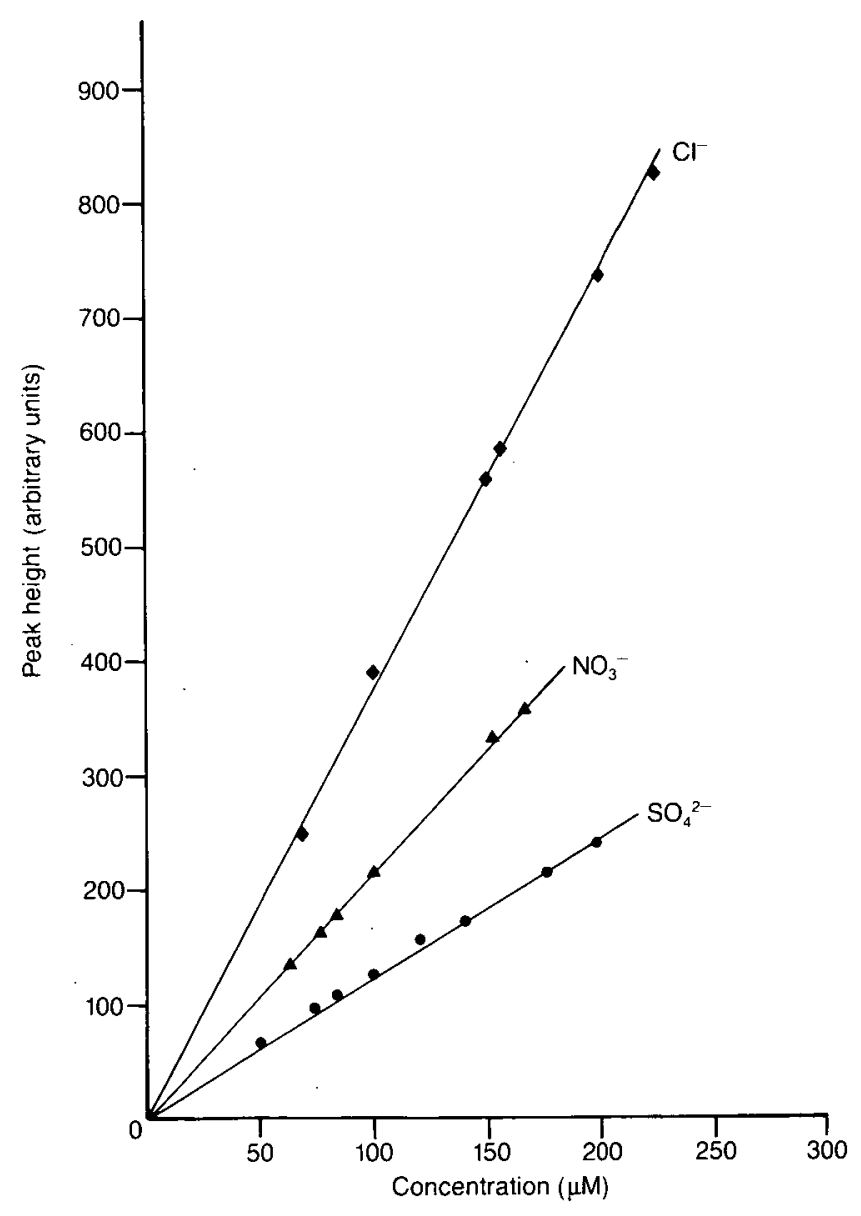

Figure 4. Calibration of anion analyser using a range of standard solutions. Conditions as for Figure 3 permits the routine use of a single-point standard. Most samples are analysed in duplicate, with agreement usually to within $2 \%$. The limits of detection vary, and are best for chloride $(<1 \times$ $\left.10^{-6} \mathrm{M}\right)$ and worst for sulphate $\left(1-2 \times 10^{-6} \mathrm{M}\right)$, but are adequate for rainwater samples, where systematic errors introduced in the process of sampling may be up to $30 \%$ (Fowler \& Cape 1984).

\section{Analysis of cations}

With the exception of hydrogen ions, the most important cations in rainwater analysis are sodium, potassium, ammonium, calcium and magnesium. Although potassium concentrations are usually rather small, they are a good indicator of contamination of a sample from bird droppings, etc. Large concentrations of ammonium and high $\mathrm{pH}$ are not sufficient in themselves to designate a sample as 'contaminated', as they could arise from dissolution of atmospheric ammonia (Cape et al. 1984). As yet, no simple and reliable method is available for simultaneous analysis of monovalent and divalent cations by nonsuppressed ion chromatography, so samples must be analysed using 2 different eluants.

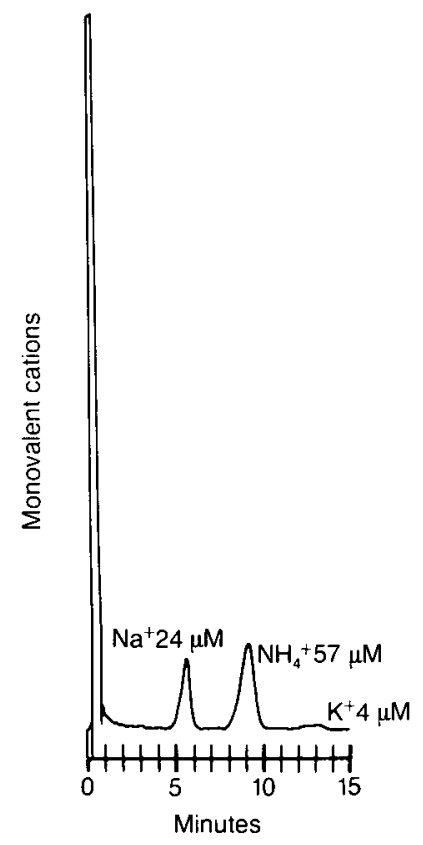

Figure 5. Monovalent cation analysis of rainwater sample from Castlelaw, Midlothian (24-27 March

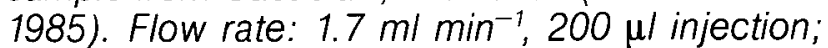
eluant: nitric acid at $\mathrm{pH} 2.50$ in $1 \%$ methanol; column: Wescan cation $25 \mathrm{~cm} \times 4 \mathrm{~mm}$

Monovalent cations are separated (with a suitable low-capacity cation exchange column) using an eluant containing high-purity nitric acid at $\mathrm{pH} 2.50$ in $1 \%$ methanol at a flow rate of $1.7 \mathrm{ml} \mathrm{min}{ }^{-1}$. An analysis takes less than 15 minutes, but the length of the column $(25 \mathrm{~cm})$ and consequent pressure drop precludes larger flow rates. Again, a balance must be found between speed of analysis (larger 
eluant concentrations) and sensitivity (smaller eluant concentrations). A typical analysis is shown in Figure 5 for a rain sample. The calibrations are again linear, permitting the routine use of a single standard (usually $200 \times 10^{-6} \mathrm{M}$ $\left.\mathrm{Na}^{+}, 100 \times 10^{-6} \mathrm{M} \mathrm{NH}_{4}^{+}, 50 \times 10^{-6} \mathrm{M} \mathrm{K}^{+}\right)$. However, peak areas must be used, as divalent cations accumulate on the column and retention times decrease systematically as ion exchange sites are filled, giving rise to higher peaks and shorter retention times. The original column performance can be restored using a 'sample' of $1 \%$ nitric acid injected routinely every 6 samples prior to the calibration standard. Sensitivity is better than $1 \times 10^{-6} \mathrm{M}$ for sodium and $1-2 \times 10^{-6} \mathrm{M}$ for potassium, with reproducibility similar to the anion analysis.

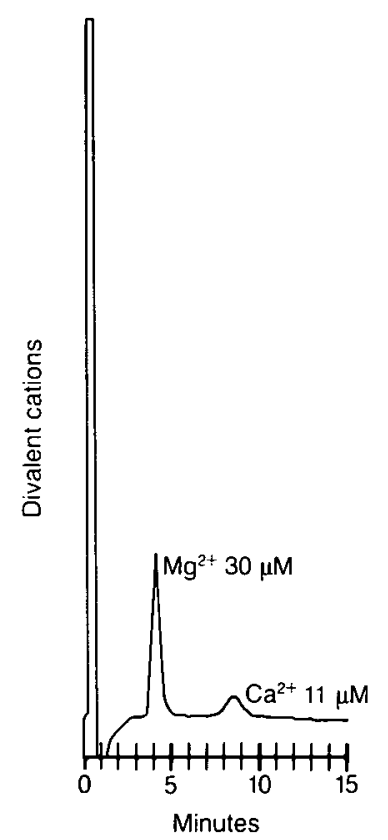

Figure 6. Divalent cation analysis of rainwater sample from Achnagoichan, Speyside (January 1983). Flow rate: $1.5 \mathrm{ml} \mathrm{min}^{-1}, 200 \mu /$ injection; eluant: $0.84 \times 10^{-3} \mathrm{M}$ ethylenediamine at $\mathrm{pH} 6.0$ adjusted with conc. nitric acid in $1 \%$ methanol; column: Wescan cation $25 \mathrm{~cm} \times 4 \mathrm{~mm}$

Divalent cations are separated on the same column but using an eluant comprising $56 \mu \mathrm{l}$ ethylenediamine per litre of $1 \%$ methanol, adjusted to $\mathrm{pH} 6.0$ with concentrated nitric acid $\left(0.84 \times 10^{-3} \mathrm{M}\right.$ in ethylenediamine). A typical analysis (Figure 6 ) takes 10 minutes at a flow rate of $1.5 \mathrm{ml} \mathrm{min}{ }^{-1}$. Calibrations using peak heights or areas are linear, and standard solutions (usually $50 \times 10^{-6} \mathrm{M} \mathrm{Ca}^{2+}, 50 \times 10^{-6} \mathrm{M} \mathrm{Mg}^{2+}$ ) are used to recalibrate automatically every 6 samples. Detection limits are not quite as good as for the other analyses, being around $2 \times 10^{-6} \mathrm{M}$ under optimum conditions.

\section{Discussion}

The main advantage of any form of ion chromatography over other methods (eg colorimetry, ion-selective electrodes) is that all anions or cations present in a sample are analysed simultaneously. This means that interferences from components which are not expected can be identified, where separate analysis for individual ions would perhaps not show the presence of a 'contaminating' ion. This advantage is best illustrated by means of an example: a monthly bulk rainwater sample (from Waterhead, SW Scotland, July 1984) had been contaminated by (presumably) bird droppings, given the large $\mathrm{NH}_{4}^{+}$and $\mathrm{K}^{+}$concentrations and high $\mathrm{pH}$. Re-analysis of this sample for anions after one year gave the trace shown in Figure 7, in which the additional peak (cf Figure 3) was identified as nitrite ion. In the previous

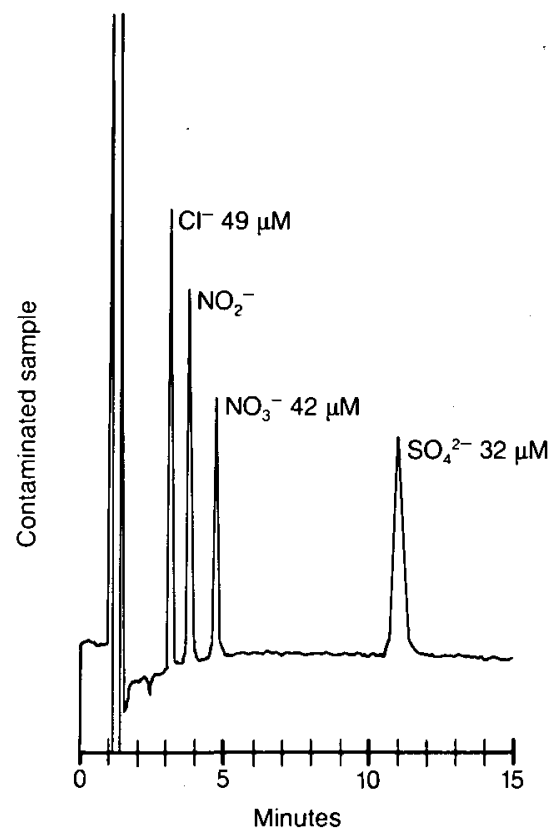

Figure 7. Anion analysis of contaminated rainwater sample after one year's storage, showing the presence of nitrite in solution. Conditions as for Figure 3

colorimetric technique, it would have appeared as nitrate, as the method did not distinguish between nitrite and nitrate. In practice, this is not usually a problem in rainwater analysis as nitrite ions are rarely, if ever, present. It appears, in this case, that the nitrite ions were produced by oxidation of ammonium ions in the sample over the year, even though the sample was kept at $4^{\circ} \mathrm{C}$ in an unlit coldroom. However, the sample was grossly contaminated, and there has been no evidence of similar oxidation in uncontaminated samples with a lower $\mathrm{pH}$.

A secondary, but very important, advantage of ion chromatography is its ease of automation, and non-suppressed ion chromatography has the added advantage that there is no need to regenerate a suppressor column (although in 
practice this problem is not insuperable). The system used at ITE Edinburgh routinely runs 24 hours per day for 5 days a week. Samples are analysed in batches for anions, monovalent cations and divalent cations over a period of about one month using a single analyser. In this way, about 100 samples per month can be analysed in duplicate for 9 ions (including $\mathrm{H}^{+}$from $\mathrm{pH}$ ) by one technician. This figure allows for re-analysis using appropriate standards and/or sample injection loops where one ion $\left(\mathrm{eg} \mathrm{Cl}^{-}\right.$) may be present in very large concentrations.

Planned improvements to the present system include active control of the column and detector temperatures, which is expected to reduce baseline noise and drift and to improve sensitivity and reproducibility. There has been an occasional problem when the system has been left running unattended overnight in an unheated laboratory.

\section{Summary}

The technique of ion chromatography may be employed using conventional HPLC hardware and low-capacity ion exchange columns. For conductivity detection, eluants must have conductivities very different (greater or smaller) than the ions to be measured. Modern detectors have the capacity to suppress the background conductivity electronically, in a manner similar to the chemical background suppression used in 'suppressed' ion chromatography (eg Dionex).

The routine use of non-suppressed ion chromatography for the analysis of rainwater and cloudwater, both for anions and cations, is described. Care must be taken in sample preparation to remove particles in order to prolong column life, but this is not usually a problem for this type of sample. The major anions of interest $\left(\mathrm{Cl}^{-}, \mathrm{NO}_{3}^{-}, \mathrm{SO}_{4}{ }^{2-}\right)$ are separated using a $2 \times$ $10^{-3} \mathrm{M}$ solution of phthalic acid in $1 \%$ methanol, adjusted to $\mathrm{pH} 4.74$ with $\mathrm{NaOH}$. The monovalent cations $\left(\mathrm{Na}^{+}, \mathrm{NH}_{4}^{+}, \mathrm{K}^{+}\right)$are separated using $\mathrm{pH}$ 2.5 nitric acid, while divalent cations $\left(\mathrm{Mg}^{2+}, \mathrm{Ca}^{2+}\right)$ are separated using $0.84 \times 10^{-3} \mathrm{M}$ ethylenediamine solution adjusted to $\mathrm{pH} 6.0$ with $\mathrm{HNO}_{3}$. Each analysis takes about 15 minutes.

Peak heights (recorded on a dedicated integrator) are linearly related to concentration over at least 3 orders of magnitude. Using a $200 \mu l$ injection loop, sensitivity is better than $2 \times 10^{-6} \mathrm{M}$ and reproducibility is usually within $1 \%$ for multiple analyses.
An autosampler, autoinjector and integrator allow for continuous operation, with up to 40 duplicate analyses per day. There is no suppressor column to be regenerated, but for rain samples column 'clean-up' is required daily for about 30 minutes.

\section{References}

Cape, J.N., Fowler, D.; Kinnaird, J.W., Paterson, I.S., Leith, I.D. \& Nicholson, I.A. 1984. Chemical composition of rainfall and wet deposition over northern Britain. Atmos. Environ., 18, 1921-1932.

Cochrane, R.A. \& Hillman, D.E. 1982. Analysis of anions by ion chromatography using ultraviolet detection. J. Chromat., 241, 392-394.

Fowler, D. \& Cape, J.N. 1984. The contamination of rain samples by dry deposition on rain collectors. Atmos. Environ., 18, 183-189.

Fritz, J.S., Gjerde, D.T. \& Becker, R.M. 1980. Cation chromatography with a conductivity detector. Analyt. Chem., 52, 1519-1522.

Gjerde, D.T., Fritz, J.S. \& Schmuckler, G. 1979. Anion chromatography with low-conductivity eluants. J. Chromat., 186, 509.

Gjerde, D.T., Schmuckler, G. \& Fritz, J.S. 1980. Anion chromatography with low-conductivity eluants II. J. Chromat., 187, 35.

Glatz, J.A. \& Girard, J.E. 1982. Factors affecting the resolution and detectability of inorganic anions by nonsuppressed ion chromatography. J. chromatogr. Sci., 20, 266-273.

Haddad, P.R. \& Heckenberg, A.L. 1982. Highperformance liquid chromatography of inorganic and organic ions using low-capacity ion-exchange columns with indirect refractive index detection. J. Chromat., 252, 177-184.

Roberts, K.M., Gjerde, D.T. \& Fritz, J.S. 1981. Singlecolumn ion chromatography for the determination of chloride and sulfate in steam condensate and boiler feed water. Analyt. Chem., 53, 1691-1695.

Small, H. \& Miller, T.E. 1982. Indirect photometric chromatography. Analyt. Chem., 54, 462-469.

Small, H., Stevens, T.S. \& Baumann, W.D. 1975. Novel ion exchange chromatographic method using conductimetric detection. Analyt. Chem., 47, 1801-1809. 


\title{
Anion chromatography in agricultural analysis
}

\author{
I JANE, J ARMSTRONG and $K$ BREMNER \\ MAFF, Agricultural Development and Advisory Service, Newcastle upon Tyne
}

\section{Introduction}

The majority of routine methods for the analysis of anions in digest or extracts of agricultural materials rely on specific chemical reactions with quantification by colorimetry or titration (MAFF 1981). For a number of anions, in particular nitrate, bromide and sulphate, these methods have serious limitations for agricultural analysis. The extensive use of the commercial ion chromatography system (Small et al. 1975) has demonstrated the advantages that a chromatographic approach can provide. In addition, recent publications, most notably those by Small and Miller (1982) and Wheals (1983), have shown that excellent separation and quantification of anions can be obtained using conventional high-performance liquid chromatography (HPLC) equipment.

We have developed methods for the analysis of a number of anions based on a system fundamentally the same as that described by Wheals (1983). Separations are performed on a conventional HPLC reversed-phase column, modified by the introduction of an ion-pairing agent into the eluant. An eluant containing citric acid is used, with detection being by direct or indirect ultra-violet (UV) absorbance or electrochemical oxidation (ECD). An ion chromatograph using chemical suppression (Dionex) has recently been introduced, in which separations are carried out on a conventional ion exchange resin column using a sodium carbonate/bicarbonate eluant with conductivity detection. The intention of this paper is to describe briefly the methods developed for the analysis of some anions of agricultural interest, and to compare the use of the 2 alternative approaches. Wherever possible, the sample extraction and digestion methods used are standard procedures. This fact imposes some restrictions on the chromatographic system, but helps to ensure that the results obtained are comparable with standard methods.

\section{Results}

\subsection{Nitrate}

The determination of nitrate in soils and plant materials is of agricultural importance for both crop and animal nutrition. In addition, considerable interest has been shown recently in nitrate pollution in watercourses, caused by agricultural runoff. Nitrate is extracted from plant materials by shaking the dried ground sample with water; soil samples are extracted with saturated calcium sulphate solution.
Either chromatographic system can be used for the direct quantification of nitrate in waters or sample extracts; however, the strong UV absorbance of the nitrate ion at $220 \mathrm{~nm}$ means that UV detection is the most sensitive and specific. Practical detection limits on the HPLC system correspond to $1 \mathrm{ppm}$ in soil and $10 \mathrm{ppm}$ in plant material. The suppressed conductivity method is approximately 5 times less sensitive for this ion, and the analysis time for soil samples is considerably extended by the long retention of the sulphate in the extractant. Similar problems on the HPLC are avoided by replacing the citric acid counter ion with the perchloric ion. This prevents the indirect detection of sulphate and reduces the analysis time per sample from 12 to 4 minutes.

\subsection{Bromide}

Methyl bromide is used extensively for the sterilization of glasshouse soils. Residual bromide produced by the breakdown of this compound can impair the growth of certain types of crops. In addition, there is concern in Europe over possible human health risks associated with elevated bromide levels in salad crops. It is important, therefore, to be able to monitor bromide levels in both soils and plant materials. Soil samples are extracted with saturated calcium sulphate solution and plants are dry ashed after treatment with ethanolic sodium hydroxide, the residue being taken up in dilute sulphuric acid (Roughan et al. 1983).

The bromide ion shows UV absorbance at $205 \mathrm{~nm}$ and is electrochemically oxidizable at $1.6 \mathrm{~V}$ applied potential. It is therefore particularly amenable to analysis on the HPLC anion system. However, the citric acid eluant is unsuitable because it gives a high UV and electrochemical background under the conditions optimum for bromide detection. An eluant containing perchloric acid allows both low wavelength UV and high-potential electrochemical to be used. Detection limits for UV are approximately $1 \mathrm{ppm}$ for soil samples and $10 \mathrm{ppm}$ for plant materials. Some problems are encountered with interference from nitrate in soil extracts, which restricts the effective sensitivity for soils to 10 $\mathrm{ppm}$, but the additional selectivity of the ECD for bromide eliminates this problem because nitrate does not give any response. The sensitivity of the Dionex system is approximately 5 -fold less than for the HPLC with UV detection, and similar problems with interference from high levels of nitrate in soil extracts are also observed. 


\subsection{Sulphate}

The renewal of interest in the possibility of crop growth being restricted by sulphur deficiency has led to an increased demand for sulphur analysis both in plant material and as extractable sulphate in soils. Threshold levels for crop sulphur deficiency are thought to be in the range $2-7 \mathrm{ppm}$ extractable sulphur in the soil. It is therefore important to be able to reliably quantify sulphate down to at least this level. Soil samples are extracted with $0.016 \mathrm{M}$ potassium dihydrogen phosphate. Plant samples are dry ashed with magnesium nitrate and the residue taken up in $10 \%$ hydrochloric acid.

On the HPLC system, sulphate, which is neither UV nor electrochemically active, has to be detected indirectly as a negative UV peak (Small \& Miller 1982). Sensitivity is, therefore, seriously limited. With sufficient sample pre-treatment and concentration, it is possible to quantify sulphate at levels of agricultural interest in both soils and plants; the procedure, however, is very laborious and does not form the basis of a practical method. Suppressed conductivity detection gives approximately a 50-fold increase in sensitivity and allows easy quantification of sulphate in our samples. Soil extracts are injected directly, whilst plant digests require dilution 100 -fold before injection to eliminate the effect of the high acid strength on the chromatography. Initial results indicate that this method will be reliable for total sulphur estimation. Problems have, however, been encountered with column contamination, possibly from the high concentration of magnesium ions in the digest, and we have not yet acquired sufficient data to justify its routine use.

\section{Discussion}

Both of the described approaches to anion chromatography are effective in the quantification of anions in agricultural samples. Reproducibility tests for replicate injections of the same extracts show that coefficients of variation range from $1.1 \%$ to $2.5 \%$, and a wide linear range is obtained for both systems for the anions described. Significant savings in staff time are made over traditional agricultural analysis methods. The results obtained from the chromatographic methods have been verified for a range of sample types by standard addition, comparison with standard methods, and analysis of standard materials, where these are available. Where problems did occur with comparison with established methods, further work invariably showed that the chromatographic system was providing the more accurate result.

Effective and rapid separation of the common anions is obtained on both systems. Column contamination is a serious problem on the commercial ion exchange resin column in that, despite precautions to exclude the majority of possible contaminants, a limited lifetime is obtained for the guard columns incorporated into the system. Because these represent a significant expense, this is a major limitation in the use of the method. A wide range of sample types were analysed in the development period, and we are not yet certain of the origin of the contamination. However, it appears likely that the major problem arises from organic co-extractives of the soil and plant extracts. We are currently investigating methods of extending the lifetime of the columns for routine agricultural analyses. The HPLC system is subject to fewer problems in this respect. Columns are initially relatively inexpensive and are not subject to contamination, despite the injection of a very wide range of sample types.

All the detection methods described were easy to use and reliable in routine operation. For nitrate and bromide, the HPLC system provides the most effective method of analysis because of the additional sensitivity and selectivity of UV and electrochemical detection. For sulphate, the additional sensitivity obtained from the use of suppressed conductivity detection provides significant practical advantages.

\section{Summary}

Anion chromatographic methods have been developed for a number of agricultural analyses: sulphate in soil extracts; nitrate in plant and soil extracts; and bromide in plant and soil extracts and digests. Chromatographic separations were carried out both on a conventional reversedphase HPLC column converted to an ion exchange system by incorporating an ion-pairing agent into the eluant, and on a commercial ion exchange resin column. Both systems provided excellent resolution of all the commonly encountered anions; the HPLC system proved to be less subject to contamination with sample coextractives. The eluted ions on the HPLC system were monitored using direct or indirect UV absorbance and oxidative electrochemical detection. This system provided the optimum sensitivity and selectivity for nitrate and bromide. For other ions, in particular sulphate, the ion exchange column with the chemically suppressed conductivity detector gave a much improved performance as compared to indirect UV detection.

\section{References}

Ministry of Agriculture, Fisheries and Food. 1981. The analysis of agricultural materials. (Reference book no. 427.) London: MAFF.

Roughan, J.A., Roughan, P.A. \& Wilkins, J.P.G. 1983. Modified gas-liquid chromatographic method for 
determining bromide/total bromide in foodstuffs and soils. Analyst, Lond., 108, 742-747.

Small, H. \& Miller, T.E. 1982. Indirect photometric chromatography. Analyt. Chem., 54, 462-469.

Small, H., Stevens, T.S. \& Bauman, W.C. 1975. Novel ion exchange chromatographic method using conductometric detection. Analyt. Chem., 47, 1801-1809.

Wheals, B.B. 1983. Multiple column and detector approach to anion screening by isocratic high performance liquid chromatography. J. Chromat., 262, 61-76. 


\title{
Measuring the $\mathrm{pH}$ of fresh waters
}

\author{
W DAVISON \\ Freshwater Biological Association, The Ferry House, Ambleside
}

\section{Introduction}

$\mathrm{pH}$ is probably the most frequently determined analytical quantity. It is easy to measure with simple, inexpensive equipment. Meters, electrodes, and buffers for use as calibration solutions are all readily available, and electrodes usually respond quickly to provide a stable answer within minutes.

Rarely are problems encountered when measurements are made on high ionic strength solutions, but at low ionic strengths it is often difficult to obtain reliable measurements. Only recently, particularly with the impetus of research into acid rain, has the problem become documented and generally accepted. Different results may be obtained, depending on whether the solution is stirred or quiescent, and this stirring shift may be typically $0.1-0.2 \mathrm{pH}$ (Davison $\&$ Gardner 1986). Measurements on quiescent solution have been advocated (Galloway et al. 1979), but even with this procedure there can be considerable disagreement between laboratories, and results may be no better than $\pm 0.2 \mathrm{pH}$ (Davison \& Gardner 1986).

Several recent studies have investigated the nature of the problem (Brezinski 1983; Covington et al. 1985; Davison \& Woof 1985). Although errors due to the glass electrode, particularly the possibility of interference by organics, have been reported (Herczeg \& Hesslein 1984), there is little doubt that the problem is chiefly associated with the liquid junction of the reference electrode.

\section{Liquid junctions and the definition of $\mathrm{pH}$}

To appreciate problems associated with the liquid junction, it is necessary to understand the $\mathrm{pH}$ scale. $\mathrm{pH}$ is defined operationally in terms of the operation or method used to measure it. Cell $A$ represents a reference electrode and glass electrode inserted into the solution, $X$, of unknown $\mathrm{pH}$. In cell $\mathrm{B}$, the unknown solution is replaced by a standard buffer solution, $\mathrm{S}$.

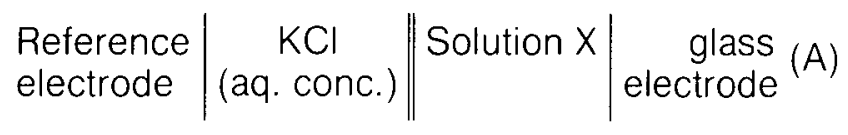

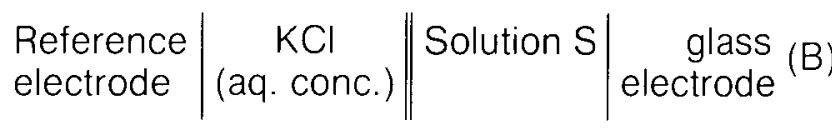

To determine $\mathrm{pH}$, the potentials of cells $\mathrm{A}$ and $\mathrm{B}$, $E(X)$ and $E(S)$, are measured and compared. The unknown $\mathrm{pH}$ of solution $\mathrm{X}$, denoted by $\mathrm{pH}(X)$, is related to the $\mathrm{pH}$ of a standard reference solution, $\mathrm{S}$, denoted by $\mathrm{pH}(\mathrm{S})$, by the definition:

$$
p H(X)=p H(S)+\frac{E(S)-E(X)}{(R T / F) \ln 10}
$$

where $R$ is the gas constant, $T$ the thermodynamic temperature and $\mathrm{F}$ the Faraday constant.

The definition of $\mathrm{pH}$ is completed by assigning a value of $\mathrm{pH}$ at each temperature to one or more chosen solutions, designated as standard reference solutions (Covington et al. 1983a), and used as calibration buffers.

Liquid junctions, which are an integral part of cells $A$ and $B$, have to be considered in most practical measurements of $\mathrm{pH}$. The concentrated $\mathrm{KCl}$ solution which forms part of the reference electrode is in contact with either the unknown solution, $\mathrm{X}$, or the buffer solution, S. Junctions between 2 different solutions give rise to a potential. In any measurement, this is included as part of the potential of the cell. $\mathrm{pH}$ is defined by taking the difference between the potentials of 2 cells, so, if the liquid junction potential is the same in cells $A$ and $B$, it will not contribute to the measured $\mathrm{pH}$. If the individual junction potentials differ, there will be a residual liquid junction potential which will constitute an error in the measured $\mathrm{pH}$ of the unknown solution.

In practice, liquid junction potentials depend on the construction and geometry of the junction. $\mathrm{pH}$ scales, such as the NBS scale, have been defined in such a way that, if the geometry is ideal, so that there is no restraining element and ions can diffuse freely into one another, the residual liquid junction potential should be negligibly small for all solutions with an ionic strength less than $0.1 \mathrm{M}$ (Bates 1981). However, most practical junctions are formed at a restraining frit which is found to give rise to different junction potentials, depending on the solution in which the electrode is immersed. Precise reasons for the non-ideal behaviour of restrained junctions are unknown, but some possible causes have been suggested (Brezinski 1983). Potentials may arise due to perturbation of the diffusion profiles which extend from the junction into solution, or to large surface charges within the pores of a partially clogged junction. Inadequate flushing of the junction between measurements may also cause errors. Whatever the cause of the finite residual liquid junction potential, it depends on the construction of the junction and introduces errors in the 
determination of $\mathrm{pH}$

\section{Overcoming liquid junction problems}

3.1 Alternative measurements

One proposed solution to the measurement of $\mathrm{pH}$ is to calculate its value from alternative analytical procedures. Total acidity can be determined by titration (Marinenko \& Koch 1984). It is a measure of all the hydrogen ions which may be titrated, including those associated with weak acids. Therefore, in natural waters of unknown composition, it cannot be equated to $\mathrm{pH}$ which approximates to the activity of free hydrogen ions.

If the $\mathrm{pH}$ of a water is exclusively determined by carbonate equilibria, it can be calculated from the concentrations of particular carbonate components. Herczeg et al. (1985) have proposed determining total dissolved inorganic carbon and the partial pressure of $\mathrm{CO}_{2}$ by gas chromatography and then calculating $\mathrm{pH}$. This procedure suffers because it only works for waters which contain appreciable bicarbonate ions and so have a $\mathrm{pH}$ greater than 5.5.

Neither of the above procedures give an estimate of hydrogen ion activity suitable for use in speciation calculations and kinetic or equilibrium studies. Although these alternative measurements do not determine $\mathrm{pH}$, they may be useful as indicators of environmental change in their own right.

\subsection{Calibration with low ionic strength solutions}

Calibration using dilute acids or buffers has been considered (Galloway et al. 1979; Covington et al. 1983b). In using such a procedure, there is a presumption that the liquid junction potential in the dilute calibrating solution is the same as in the natural water. The implicit assumption does not appear to hold because electrode pairs can perform well in dilute acid and still produce errors in natural waters (Davison \& Gardner 1986), and $\mathrm{pH}$ errors are not generally constant for different low ionic strength solutions (Davison \& Woof 1985). There is little intrinsic justification for using dilute standards because the problem is not due to the buffers, which, as already stated, will contribute negligible residual liquid junction potential if the junction is ideally formed.

\subsection{Raising the ionic strength}

One obvious procedure would be to add neutral salt, such as $\mathrm{KCl}$, to raise the ionic strength of fresh water to a level where the liquid junction problems are inappreciable. However, there could be little guarantee that the $\mathrm{pH}$ would remain unaffected. Even in a simple homogeneous solution, changes in activity coefficients would change stability constants and solution equilibria, and there is always the possibility of adding contaminants with the $\mathrm{KCl}$.
3.4 Free-flowing junctions

$\mathrm{pH}$ errors can be reduced by ensuring a good flow of bridge solution (10-100 $\mu / \mathrm{h}^{-1}$ ) through the frit. With free-flowing frits, the $\mathrm{pH}$ shifts observed in stirred solutions are usually small and can be less than $0.01 \mathrm{pH}$. There is also good evidence (Brezinski 1983; Davison \& Woof 1985) that the value obtained is close to the true $\mathrm{pH}$.

Such junctions suffer from being poorly defined, because they are still dependent upon a frit whose manufacture can be highly variable. Moreover, the high leakage rate of bridge solution can contaminate the unknown solution, if the measurement takes more than a few minutes.

\subsection{Free-diffusion junctions}

Frits are employed in constrained junctions to provide electrical contact between the bridge solution and solution being measured, while preventing the solutions from mixing. Removing the frit alleviates errors due to residual liquid junction potentials but introduces practical problems. Consequently, free-diffusion junctions have rarely been used for routine measurements.

Ideally, a free-diffusion junction should have cylindrical geometry and so should be formed in a tube (Bates 1964). Brezinski (1983) formed such a junction by withdrawing the sample solution into a tube initially filled with bridge solution. Covington et al. (1983b, 1985) also withdrew the sample solution into a tube, but they formed the junction at a ' $T$ ' intersection. Their junction, which could be readily renewed for fresh measurements, was tested by using it in the determination of the second dissociation constant of phosphoric acid in dilute solutions. This test verified that the $\mathrm{pH}$ could be measured accurately, to $\pm 0.02 \mathrm{pH}$, in a $10^{-3} \mathrm{M}$ solution. These free-diffusion junctions have proved useful as reference systems for assessing the performance of other junctions (Davison \& Woof 1985), but they are impractical for routine use.

One manufacturer, Hach, lowa, USA, has produced a commercial reference electrode using a free-diffusion junction based on the design of Illingworth (1981). It consists of a $1 / 2 \mathrm{~mm}$ bore plastic tube into which is inserted a silver wire. The end of the wire nearest the opening is chloridized. A syringe piston supplies a $2.4 \mathrm{M}$ solution of $\mathrm{KCl}$ saturated with $\mathrm{AgCl}$ and containing $40 \%$ glycerol as an antifreeze. The liquid junction is formed at the end of the plastic tube which is positioned upward in the solution being measured. New junctions can be formed by dispensing more filling solution from the syringe. Such an electrode has an ill-defined and noncylindrical junction geometry, and, as the bridge solution is expelled to form each new junction, contamination of the sample being measured is inevitable. 
Table 1 compares the performance of the Hach electrode with a Beckman calomel, quartz-fibre reference electrode. The latter uses a free-flowing junction and has been found to work well (Davison \& Woof 1985). Both reference electrodes gave good results, showing very little potential shift on stirring even in very dilute solutions. Results for the Hach electrode were slightly more scattered, probably reflecting irreproducibility due to renewing the junction for each measurement. There was a systematic difference of $0.01-0.06 \mathrm{pH}$ between " the electrode assemblies, the results being closer to the values calculated from concentrations when the Beckman reference electrode was used. As the Beckman electrode was easier to use, there appears to be little gain in using the Hach system. fundamental issues as the use of inappropriate liquid junctions. There are 2 main approaches to overcome this latter problem and so provide accurate $\mathrm{pH}$ measurements for fresh waters: use of free-diffusion junctions, or of free-flowing restrained junctions.

Generally, it is difficult to assign a true value to an analytical determinand in an unknown solution such as a natural water. $\mathrm{pH}$ is no exception. Because it is operationally defined, there is a temptation to say that a measurement made using the prescribed cell (Covington et al. 1983a) must give the correct answer. However, clearly the measurement depends on how the liquid junction is formed, the criteria for which have not been explicitly defined. Free-diffusion junctions are

Table 1. Performance of Beckman 39416 quartz fibre sat. $\mathrm{KCl}$-filled, and Hach injection, reference electrodes at $20 \pm 0.1^{\circ} \mathrm{C}$. The same Corning $00311101 \mathrm{~J}$ triple-purpose glass electrode was used with both reference electrodes for all measurements. Daily duplicate measurements were made on 5 different solutions using each electrode pair. The solution was stirred for 2 minutes, a reading taken and then the stirrer switched off for 2 minutes when another reading was taken. The procedure was repeated on 10 different days. A new liquid junction was formed for each measurement made with the Hach electrode. Electrode pairs were calibrated freshly each day using the same $\mathrm{pH} 4.001$ and $\mathrm{pH} 6.881$ buffer solutions which were prepared from standard reagents and used throughout the tests. The 'unknown' buffer was prepared freshly each day from commercial buffer tablets nominally $\mathrm{pH} 4.00$. Dilute acids were prepared freshly each day. Natural water samples were subsampled each day from bulk stock solutions collected from streams. Analysis of variances provided means and total standard deviations

\begin{tabular}{llcc}
\hline $\begin{array}{l}\text { Reference } \\
\text { electrode }\end{array}$ & \multicolumn{1}{c}{ Solution } & Mean pH & $\begin{array}{c}\text { Standard } \\
\text { deviation }\end{array}$ \\
\hline $\begin{array}{llll}\text { Beckman } \\
\text { Hach }\end{array}$ & $\begin{array}{l}\mathrm{pH} 4.00 \text { buffer } \\
\mathrm{pH} 4.00 \text { buffer }\end{array}$ & $3.973(3.970)^{1}$ & $0.003(0.001)^{1}$ \\
Beckman & $5 \times 10^{-5} \mathrm{M} \mathrm{H}_{2} \mathrm{SO}_{4}{ }^{2}$ & $3.951(3.951)$ & $0.014(0.009)$ \\
Hach & $5 \times 10^{-5} \mathrm{M} \mathrm{H}_{2} \mathrm{SO}_{4}$ & $4.003(4.009)$ & $0.004(0.002)$ \\
Beckman & $1.5 \times 10^{-5} \mathrm{M} \mathrm{H}_{2} \mathrm{SO}_{4}{ }^{3}$ & $3.964(3.980)$ & $0.018(0.011)$ \\
Hach & $1.5 \times 10^{-5} \mathrm{M} \mathrm{H}_{2} \mathrm{SO}_{4}{ }^{3}$ & $4.525(4.535)$ & $0.008(0.005)$ \\
Beckman & Natural water A & $4.496(4.500)$ & $0.017(0.013)$ \\
Hach & Natural water A & $5.754(5.747)$ & $0.104(0.122)$ \\
Beckman & Natural water $\mathrm{B}$ & $5.700(5.690)$ & $0.147(0.151)$ \\
Hach & Natural water B & $4.453(4.453)$ & $0.006(0.004)$ \\
\hline
\end{tabular}

${ }^{1}$ Numbers in parentheses are for quiescent solutions, other numbers are for stirred solutions

${ }^{2}$ Calculated $\mathrm{pH}$ from concentration using activity correction is 4.006

${ }^{3}$ Calculated $\mathrm{pH}$ from concentration using activity correction is 4.524

\section{Conclusions and recommendations}

The preceding discussion is by no means exhaustive. It has concentrated on problems in the measurement of the $\mathrm{pH}$ of low-ionic strength solutions, which are associated with the liquid junction. Other causes for concern, such as possible errors due to the glass electrode and sampling and handling procedures, have not been discussed. Although they should not be neglected, they do not raise the same implicitly incorporated into $\mathrm{pH}$ scales. The NBS scale uses such a junction for determining the $\mathrm{pH}$ of different standard buffers and the selfconsistency of the NBS scale has been verified by showing that the residual liquid junction potential between different buffers is minimal. Thus, a freediffusion junction with cylindrical symmetry is an obvious choice as a standard junction for precise measurements. Unfortunately, the mechanics of producing such a junction are complicated and 
procedures reported to date have not been suitable for routine measurements. There is a need to develop a standard $\mathrm{pH}$ measuring system, based on a free-diffusion junction, which is easy to use and readily available. Such a system could, by agreed definition, be used to assign the value of the 'true' $\mathrm{pH}$ of any dilute solution including natural waters. It could be used to calibrate more conventional and more convenient electrodes which use constrained junctions. The widespread use of such a system as a standard reference procedure would ensure the comparability, between laboratories and with respect to time, of future $\mathrm{pH}$ measurements.

The preceding paragraph addresses the future. What of the present? We have to make the best possible measurements with the electrodes which are currently available. Where possible, use of a free-flowing junction will help, but equally important is the strict adherence to a well-defined analytical procedure. The measurement of $\mathrm{pH}$ is apparently so simple that it has encouraged poor analytical technique. All measurements must be made under identical conditions, paying attention to such apparently trivial details as a fixed geometry for electrodes, stirrer and beaker, a defined washing procedure between all solutions, and a minimum time before the meter reading is accepted. Few laboratories apply any quality control in their $\mathrm{pH}$ determinations. The appendix gives some recommended procedures for measuring the $\mathrm{pH}$ of fresh water. Simple methods of quality control are suggested, including tests which verify that the liquid junction of the reference electrode is suitable for waters of low ionic strength.

\section{Summary}

Errors associated with measuring the $\mathrm{pH}$ of low ionic strength solutions are usually due to nonideal behaviour of the liquid junction formed between the reference electrode and the solution. Selection of appropriately designed junctions can result in the accurate determination of the $\mathrm{pH}$ of fresh waters, using existing procedures and standard buffer solutions. Conventional frit junctions which allow a high flow rate of filling solution from the reference compartment, although not ideal, can provide high-quality data, especially if quality control is strictly applied. This pragmatic approach is used to formulate practical guidelines for measuring $\mathrm{pH}$ using commercially available equipment. Free-diffusion junctions with no restraining element such as a frit provide a means of measuring $\mathrm{pH}$ which, by definition, will be correct. At present, they are impractical for routine use, but they could form the basis of a new, standard reference procedure for measuring $\mathrm{pH}$.

\section{Acknowledgements}

I thank Colin Woof for performing the measurements and Lars Lovgren and Terry Harbinson for commenting on the manuscript. The NERC and the Surface Water Acidification Programme provided financial support.

\section{References}

Bates, R.G. 1964. Determination of $\mathrm{pH}$ : theory and practice. New York: John Wiley.

Bates, R.G. 1981. The modern meaning of $\mathrm{pH}$. CRC Crit. Rev. anal. Chem. (Chem. Rubb. Co.), 10, 247-278.

Brezinski, D.P. 1983. Kinetic, static and stirring errors of liquid junction reference electrodes. Analyst, Lond., 108, 425-442.

Covington, A.K., Bates, R.G. \& Durst, R.A. 1983a. Definition of $\mathrm{pH}$ scales, standard reference values, measurement of $\mathrm{pH}$ and related terminology. Pure appl. Chem., 55, 1467-1476.

Covington, A.K., Whalley, P.D. \& Davison, W. 1983b Procedures for the measurement of $\mathrm{pH}$ in low ionic strength solutions including freshwater. Analyst, Lond., 108, 1528-1532.

Covington, A.K., Whalley, P.D. \& Davison, W. 1985. Improvements in the precision of $\mathrm{pH}$ measurements. A laboratory reference electrode with renewable freediffusion liquid junction. Analytica chim. Acta, 169, 221-229.

Davison, W. \& Gardner, M.J. 1986. Interlaboratory comparisons of the determination of $\mathrm{pH}$ in poorly buffered freshwater. Analytica chim. Acta, 182, 17-31.

Davison, W. \& Woof, C. 1985. Performance tests for the measurement of $\mathrm{pH}$ with glass electrodes in low ionic strength solutions including natural waters. Analyt. Chem., 57, 2567-2570.

Galloway, J.R., Cosby, B.J. \& Likens, G.E. 1979. Acid precipitation: measurement of $\mathrm{pH}$ and acidity. Limnol. Oceanogr., 24, 1161-1165.

Herczeg, A.L. \& Hesslein, R.H. 1984. Determination of hydrogen ion concentration in softwater lakes using carbon dioxide equilibria. Geochim. Cosmochim.Acta, 48, 837-845.

Herczeg, A.L., Broecker, W.S., Anderson, R.F., Schiff, S.L. \& Schindler, D.W. 1985. A new method for monitoring temporal trends in the acidity of fresh waters. Nature, Lond., 315, 133-135.

Illingworth, J.A. 1981. A common source of error in $\mathrm{pH}$ measurements. Biochem. J., 195, 259-262.

Marinenko, G. \& Koch, W.F. 1984. A critical review of measurement practices for the determination of $\mathrm{pH}$ and acidity of atmospheric precipitation. Environ. int., 10, 315-319.

Westcott, C.C. 1978. pH measurement. New York: Academic Press. 


\section{Appendix \\ Recommended procedures for measuring the $\mathrm{pH}$ of fresh waters - a practical guide \\ Introduction}

If these recommendations are followed, the measured $\mathrm{pH}$ should be a good estimate of the true value. No procedure can guarantee the correct answer, and other equipment and procedures may produce equally good results. Selection of an appropriate reference electrode and adoption of a well-defined anaiytical procedure with built-in quality control are the 2 most important considerations. Combination electrodes are usually more prone to error and often deteriorate more quickly than separate glass and reference electrodes. No account is taken here of sample collection and storage which may contribute significant errors.

\section{Equipment}

Reference Electrode. Use a Beckman 39416 calomel with quartz fibre junction, and filled with $3.5 \mathrm{M} \mathrm{KCl}$.

Glass Electrode. Most manufacturers' research grade electrodes are adequate. A Corning 00311 101 and a Radiometer G202C have been found to work well.

Meter. Most modern meters with a facility to read in $\mathrm{mV}$ to $<1 \mathrm{mV}$ should be satisfactory. Beware of dampness affecting battery-operated instruments.

\section{Calibration and storage}

Use buffers, based on phthalate $(\mathrm{pH} 4)$ and phosphates $(\mathrm{pH}$ 6.8-7.6), purchased from a reputable manufacturer. If they require preparation from a powder or tablet, take great care and avoid contamination. Buffers and unknowns should be at the same temperature $\left( \pm 2^{\circ} \mathrm{C}\right)$ and the $\mathrm{pH}$ of the buffer, appropriate to that temperature, should be used. Calibrate each day and recheck at the end of each series of measurements; with good electrodes, there should be no change, to within $0.02 \mathrm{pH}$. Store the reference electrode in $3.5 \mathrm{M}$ $\mathrm{KCl}$, and the glass electrode in $\mathrm{pH} 4$ buffer.

Quality control

Adopt a well-defined routine for performing the measurements and do not deviate from it.

\section{Electrode performance tests}

These should be applied to newly purchased electrodes, to electrodes which have not been used for more than a week, and to regularly used electrodes at monthly intervals.

1. Electrode sensitivity. Using the standard calibration buffers and the $\mathrm{pH}$ meter in $\mathrm{mV}$ mode, verify that the electrodes give Nernstian response: at $20^{\circ} \mathrm{C}, 58 \pm 1 \mathrm{mV}$ per $\mathrm{pH}$ unit and at $25^{\circ} \mathrm{C}, 59 \pm 1 \mathrm{mV}$ per pH unit.

2. Accuracy in dilute solutions. Prepare accurately by weight, from a commercial volumetric stock, a solution of $10^{-4} \mathrm{M}$ hydrochloric acid, or $5 \times$ $10^{-5} \mathrm{M}$ sulphuric acid. The $\mathrm{pH}$ should be 4.00 \pm 0.02 , irrespective of whether the solution is stirred or quiescent. If the $\mathrm{pH}$ of the acid is outside these limits, dilute accurately, by 5 fold, a solution of $\mathrm{pH} 4.00$ buffer. At $20^{\circ} \mathrm{C}$, the $\mathrm{pH}$ should be $4.11 \pm 0.01$, at $25^{\circ} \mathrm{C} 4.12 \pm 0.01$ (Covington et al. 1983b). If these values are obtained on stirred and unstirred solutions, the preparation of the acid is probably in error.

3. Stirring shift. The shift in $\mathrm{pH}$ upon stirring a formerly quiescent solution of the acid should be $<0.02 \mathrm{pH}$.

4. Response time. The reading obtained using dilute acid should be stable, to within $0.01 \mathrm{pH}$ units within $2 \mathrm{~min}$ of immersion of the electrodes, irrespective of the solution used prior to washing.

If the electrodes fail these tests, establish, by substitution of alternative electrodes, whether the glass or reference components are responsible. Failure of tests (2) and (3) are usually associated with the reference electrode. (1) and (4) could also be due to the glass electrode. Either try to rejuvenate the defective electrode and retest it, or discard it.

The Beckman reference electrode should have a flow rate $>0.05 \mathrm{ml}$ per hour (Davison \& Woof 1985). To verify this, weigh the tissue-dried electrode, immerse to $1 \mathrm{~cm}$ in distilled water for 1 hour, dry with a tissue and reweigh. The weight should decrease by $>50 \mathrm{mg}$. If the junction is clogged, discard the electrode.

\section{Daily checks}

To ensure fast response and homogeneous solutions, measurements should usually be performed whilst stirring. Occasionally switch off the stirrer and verify that the $\mathrm{pH}$ of a low ionic strength sample does not change by more than 0.02 . Wash between measurements with distilled water which, when it has been air-equilibrated, should have a $\mathrm{pH}$ of $5.64 \pm 0.1$. Plot the daily $\mathrm{pH}$ of the distilled (not deionized) water, from a given laboratory source on a quality control chart. It will probably be fairly constant. If it suddenly changes, retest the electrodes.

\section{General}

Try to understand how electrodes work (see Westcott 1978) and follow manufacturers' recommendations. The Corning guide to electrode troubleshooting is excellent. Because of the high flow rate of $\mathrm{KCl}$, the Beckman 
reference electrode is unsuitable for continuous measurements or determinations of small volumes of solution. Ideally, it should be used for rapid $\mathrm{pH}$ measurements, $<4 \mathrm{~min}$ on $>50 \mathrm{ml}$ of solution. 


\title{
Measurement of nitric acid and particulate nitrate in air
}

\author{
A L GOLDSMITH \\ Warren Spring Laboratory, Department of Trade and Industry, Stevenage
}

\section{Introduction}

As evidence has increased that inorganic nitrogen species play an important role in atmospheric chemistry and the acid deposition phenomenon, interest has developed in the sampling and measurement of these species, which are generally present only at very low concentrations.

A variety of methods has been used to measure nitric acid/particulate nitrate. Dual filter techniques, which rely on the collection of particles on an inert pre-filter and $\mathrm{HNO}_{3}$ on a second, reactive filter, are simple to use but subject to interferences. High particulate values can result from retention of $\mathrm{HNO}_{3}$ gas by reaction with particles collected on the first filter, whilst high nitric acid values can occur due to volatilization of particles (Appel \& Tokiwa 1981; Appel et al. 1980; Forest et al. 1982).

Diffusion denuder techniques, based on the more rapid diffusion of gases than particles to the walls of a tube through which the sample stream is passed, avoid these problems. The tube walls are coated with a base and act as a perfect sorbent for $\mathrm{HNO}_{3}$. Particles are carried through and are collected by downstream filter packs.

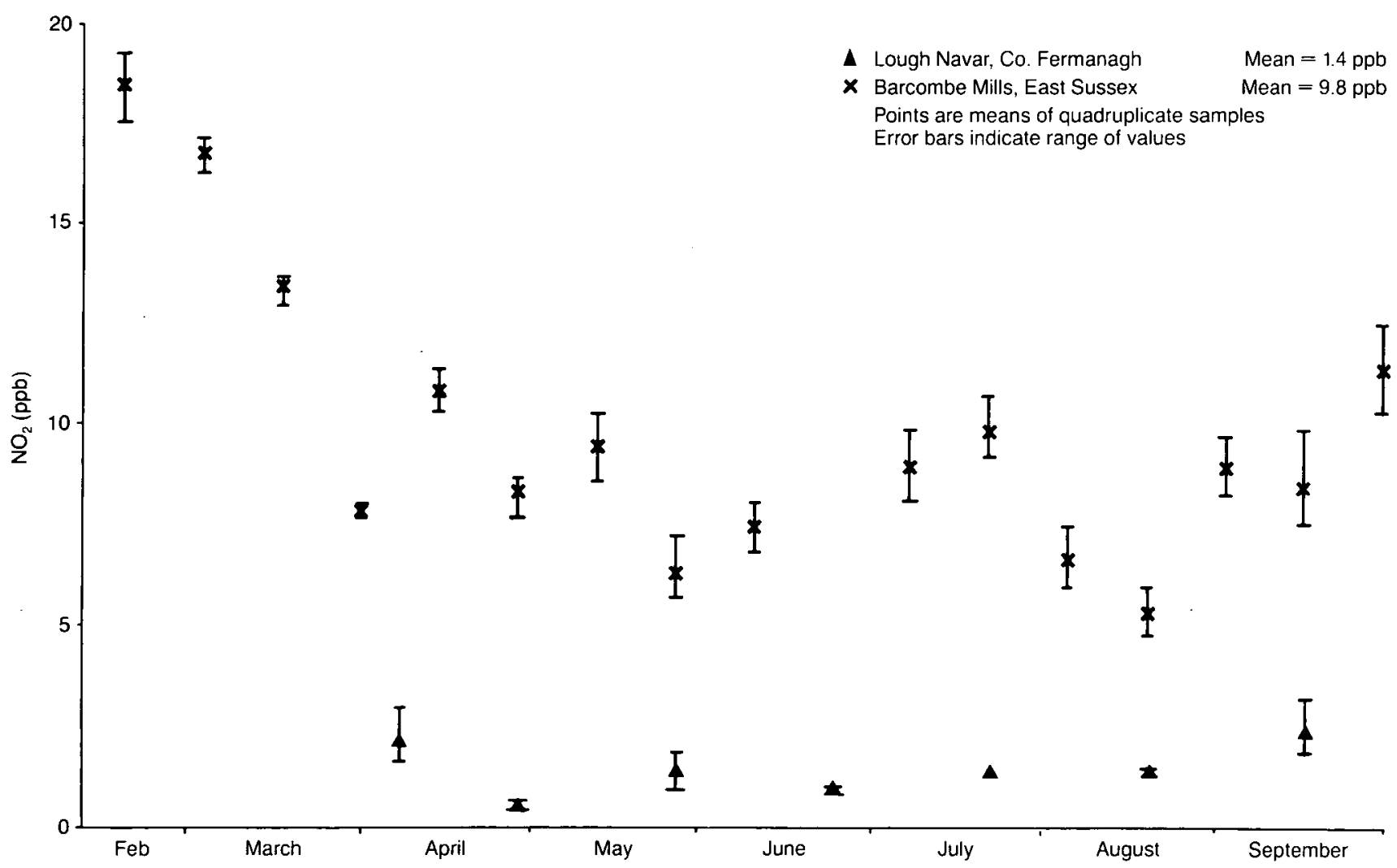

At Warren Spring Laboratory, filter and denuder techniques are currently being evaluated with a view to measuring $\mathrm{HNO}_{3}$ and particulate nitrate at rural sites. At these sites, Palmes' diffusion tubes (Palmes et al. 1975) are being exposed to measure average $\mathrm{NO}_{2}$ levels. These tubes collect $\mathrm{NO}_{2}$ by passive diffusion to a triethanolamine coated gauze at the end of a sealed tube, which is then extracted and determined colorimetrically (Atkins et al. 1978).

\section{Filter tests}

Tests were carried out to compare the efficiency of different filters for collecting $\mathrm{HNO}_{3}$. Nylon (Appel et al. 1980; Shaw et al. 1982) and cellulose impregnated with $\mathrm{Na}_{2} \mathrm{CO}_{3}$ (Ferm 1982) or $\mathrm{NaCl}$ (Forest et al. 1980, 1982) were used behind PTFE filters. The results of these tests were variable but showed no significant systematic differences between filter types, except for showing that nylon filters had to be extracted with ion chromatographic buffer solution, because aqueous extraction, used for the other filters, was inefficient. Cellulose filters impregnated with $\mathrm{Na}_{2} \mathrm{CO}_{3}$, however, gave the most reproducible results. Results of experiments where ambient air was sampled, at the edge of an
L Lough Navar, Co. Fermanagh $\quad$ Mean $=1.4 \mathrm{ppb}$
X Barcombe Mills, East Sussex $\quad$ Mean $=9.8 \mathrm{ppb}$
Points are means of quadruplicate samples
Error bars indicate range of values

Figure 1. $\mathrm{NO}_{2}$ concentrations during 1985 
urban area, gave values of $<2 \mathrm{ppb}$ particulate nitrate and $<3 \mathrm{ppb}$ total nitrate. These results are similar to those found for a comparable site in Michigan (Mulawa \& Cadle 1985).

\section{Denuder experiments}

$\mathrm{MgO}$ (Shaw et al. 1982) and $\mathrm{NaF}$ (Slanina et al. 1981) posed difficulties for ion chromatographic analysis and so were rejected as possible coatings. Limited results using $\mathrm{Na}_{2} \mathrm{CO}_{3}$ coatings, which were prepared after the method of Ferm (1982) using $\mathrm{NaOH}$ in methanol, and leached with deionized water, showed great variability. In many cases, however, the division between particulate and gaseous nitrate was similar for each denuder assembly, which suggests that this variation may have been due to difficulties with flow regulation. For example, in one experiment where ambient air was sampled, total nitrate varied between 0.58 $\mathrm{ppb}$ and $2.7 \mathrm{ppb}$ but the fraction of the total which appeared as particulate nitrate varied only from $69 \%$ to $75 \%$. The corresponding fraction for filter packs operated in parallel was $56 \%$, indicating possible losses due to volatilization of about one quarter of the total particulate nitrate.

\section{Results from $\mathrm{NO}_{2}$ tubes}

Results from 2 sites are shown in Figure 1. Tubes were exposed for fortnightly periods and no results exceeded $20 \mathrm{ppb}$. At Lough Navar, Northern Ireland, where concentrations were below 3 ppb, 4 weeks' exposure was necessary to collect measurable amounts. At these low levels, high blank values were a problem and conditions for preparing and analysing tubes are being modified to reduce these. It appears that there may be a seasonal variation, but a longer study is required to confirm this.

\section{Acknowledgements}

The work described in this report was funded by the Department of the Environment and carried out with the kind assistance of the Northern Ireland Forestry Service and the Mid Sussex Water Company, which is gratefully acknowledged.

\section{References}

Appel, B.R. \& Tokiwa, Y. 1981. Atmospheric particulate nitrate sampling errors due to reactions with particulate and gaseous strong acids. Atmos. Environ., 15, $1087-1089$

Appel, B.R., Wall, S.M., Tokiwa, Y. \& Haik, M. 1980. Simultaneous nitric acid, particulate nitrate and acidity measurements in ambient air. Atmos. Environ., 14, 549-554.

Atkins, D.H.F., Healey, C. \& Tarrant, J.B. 1978. The use of simple diffusion tubes for the measurement of nitrogen dioxide levels in homes using gas and electricity for cooking. (AERE-R9184.) London: HMSO.

Ferm, M. 1982. Method for determination of atmospheric nitric acid. Paper presented at EMEP Expert Meeting on Chemical Matters, Geneva. (EMEP/ CCC report 1/82.)

Forest, J., Tanner, R.L., Spandau, D. \& Newman, L. 1982. Determination of atmospheric nitrate and nitric acid employing a diffusion denuder with a filter pack. Atmos. Environ., 16, 1473-1485.

Forest, J., Tanner, R.L., Spandau, D., D'Ottavio, T. \& Newman, L. 1980. Determination of total inorganic nitrate utilizing collection of nitric acid on $\mathrm{NaCl}$ impregnated filters. Atmos. Environ., 14, 137-144.

Mulawa, P.A. \& Cadle, S.H. 1985. A comparison of nitric acid and particulate nitrate measurements by the penetration and denuder difference methods. Atmos. Environ., 19, 1317-1324.

Palmes, E.D., Gunnison, A.F., DiMattio, J. \& Tomczyk, C. 1975. Personal sampler for nitrogen dioxide. Am. Ind. Hyg. Ass. J., 37, 570-577.

Shaw, R.W., Stevens, R.K., Bowermaster, J., Tesch, J.W. \& Tew, E. 1982. Measurement of atmospheric nitrate and nitric acid: the denuder experiment. Atmos. Environ., 16, 845-853.

Slanina, J., Lamoen-Doornenbal, L.V., Lingerak, W.A., Meilof, W., Klockow, D. \& Niebner, R. 1981. Application of a thermo-denuder analyser to the determination of $\mathrm{H}_{2} \mathrm{SO}_{4}, \mathrm{HNO}_{3}$ and $\mathrm{NH}_{3}$ in air. Int. J. environ. anal. Chem., 9, 59-70. 


\title{
The application of inductively coupled plasmas to the analysis of natural waters and acidic deposition
}

\author{
D L MILES \\ British Geological Survey, Hydrogeology Research Group, Wallingford
}

\section{Introduction}

High-power, electrodeless, plasma discharges were first sustained in air at atmospheric pressure by Babat (1947), working at the Svetlana plant in Leningrad during World War II. His research ceased when the entire power system of that blockaded city failed and several of his colleagues perished in the hostilities. Almost 20 years later, Reed (1961) described the formation and stabilization of an inductively coupled argon plasma which he used as a very high temperature torch in research on the growth of single crystals of refractory oxides.

The analytical potential of Reed's inductively coupled plasma (ICP) as a spectroscopic source was recognized independently in the UK by Greenfield et al. (1964) and in the USA by Wendt and Fassel (1965). Since the mid-1960s, and particularly during the last 10 years, when various types of commercial spectrometer using ICP sources have been available, there has been an enormous increase in the use of ICP spectrometric techniques in many fields of analysis. This paper seeks to review briefly those techniques relevant specifically to the analysis of natural waters.

\section{The ICP source}

A conventional ICP torch typically consists of 3 accurately aligned, concentric silica tubes (Figure 1 ). The longest, outermost tube is surrounded at its tip by a 2- or 3-turn, water-cooled induction coil, connected to a radio-frequency generator operating usually at 27.12 or $40-50 \mathrm{MHz}$. Argon flows at carefully controlled rates through the 2 annular spaces formed between the tubes. The normally non-conducting argon is partially ionized initially by a spark from a Tesla coil and a toroidal plasma is sustained by inductive coupling between the coil and the ionized gas. Temperatures of $6000-9000^{\circ} \mathrm{K}$ result from Ohmic heating, and one of the functions of the high argon flow rate $\left(10-201 \mathrm{~min}^{-1}\right)$ between the outer and middle tubes is to cool and protect the torch tip from the intense heat. Sample aerosol is injected into the axial channel of the plasma via a stream of argon flowing up the central quartz tube.

3 Inductively coupled plasma-optical emission spectrometry (ICP-OES)

3.1 Instrumentation

By far the largest number of ICP spectrometric systems in use at the present time involve the

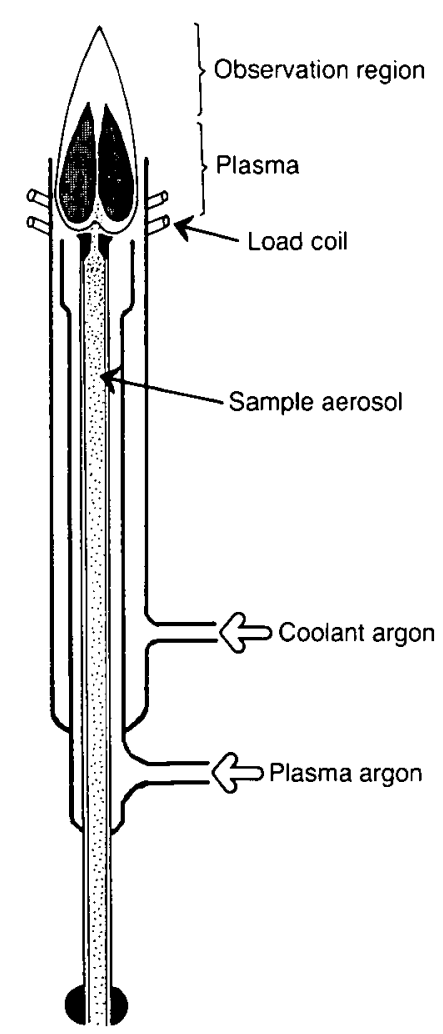

Figure 1. ICP torch

detection of the photon emission from the ICP by means of some form of spectrometer having conventional optics consisting of lenses, primary entrance slit, diffraction grating, and one or more exit slits and detectors. Two types of spectrometer are commonly employed: polychromators having the Paschen-Runge mounting with a fixed concave grating and typically 20-60 fixed exit slits on the Rowland circle, each with its own detector (Figure 2); and monochromators with a movable flat grating in a Czerny-Turner mounting (Figure 3). Polychromators permit the simultaneous determination of many elements at pre-determined wavelengths, whereas in monochromators the grating is turned, usually under computer control, so that spectral lines chosen at the start of each analytical programme are monitored sequentially. One manufacturer has recently produced a novel sequential system based on a Paschen-Runge mounting, in which small displacements of the primary slit are used to image the chosen spectral line on one of 200 exit slits equally spaced around the Rowland circle, where it is monitored with a movable detector. Simultaneous and sequential systems each have their strengths and weaknesses. An ideal system 


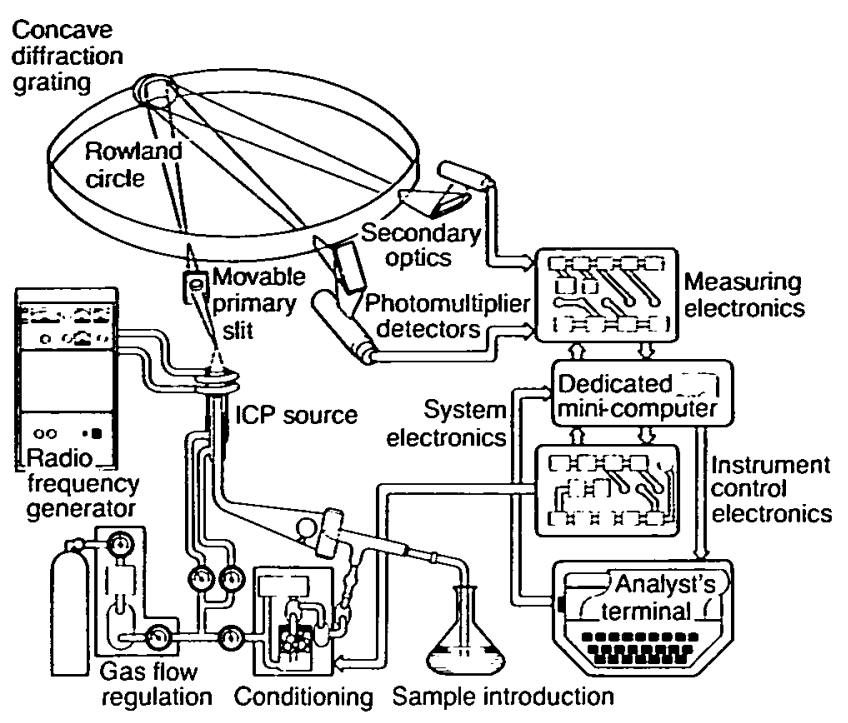

Figure 2. Schematic diagram of an ICP polychromator

would combine the high data rate and good stability of a polychromator with the flexibility of a monochromator. This combination can be achieved by viewing the plasma with both types of spectrometer at the same time, as is done in some systems.

\subsection{Sample introduction}

The most commonly used method of sample introduction in ICP-OES is as an aerosol generated by pneumatic nebulization of a liquid into a spray chamber, and thence to the torch. Natural waters are thus in an ideal form for direct analysis, requiring the minimum of pre-treatment. Concentric glass Meinhard nebulizers (Figure 4) have proved very popular and will run consistently for long periods, provided that no suspended matter is present in the test solutions (Baginski \& Meinhard 1984); membrane filtration of water samples is recommended if blockage is to be avoided.

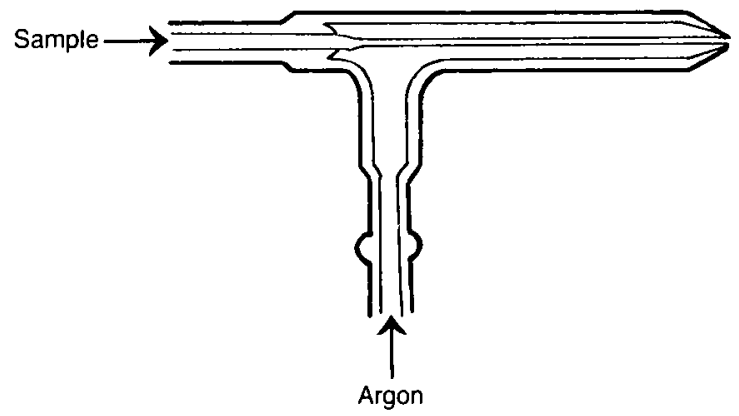

Figure 4. Concentric glass Meinhard nebulizer

Sample uptake rate is usually $1-2 \mathrm{ml} \mathrm{min}^{-1}$ which, combined with the simultaneous, multielement capability of ICP-OES, enables large amounts of analytical data to be acquired from relatively small volumes of solution. In studies of acidic deposition, this feature is particularly helpful when sample volume is very limited, for

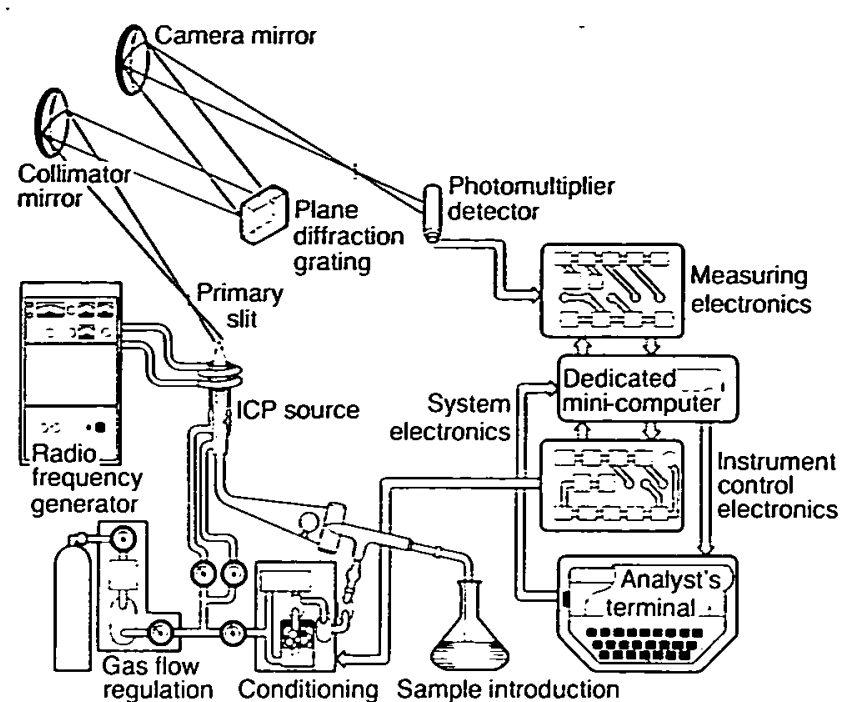

Figure 3. Schematic diagram of a scanning ICP monochromator

example during investigations of solute mobilization and transport in soil and unsaturated zone pore waters extracted by centrifugation (Kinniburgh \& Miles 1983).

Despite the relatively low sample consumption rate, the transport efficiency of the combination of aerosol-producing nebulizers such as the Meinhard and a conventional spray chamber is very poor, with only about $2 \%$ of the aspirated sample reaching the plasma and the remainder draining to waste. A novel approach to improving the overall efficiency of the sample nebulization and transport system, by ensuring that a much higher proportion of the liquid aspirated is ultimately injected into the ICP, has been described by Hulmston (1983) in the form of a recirculating nebulizer (Figure 5). A normal Meinhard nebulizer is mounted vertically in a specially designed spray chamber such that aerosol droplets impacting on the chamber walls drain down to the inlet of the nebulizer and the solution is recirculated. Approximately $2 \mathrm{ml}$ of sample are required for 20 minutes of continuous operation, and sensitivity, precision and stability are reported to be comparable to those obtained with a conventional nebulizer system (Hulmston \& McKillop 1985). However, wash-out times could be expected to be long with such a system, if sample carry-over is to be avoided. Alternative pneumatic nebulizers include the cross-flow (Kniseley et al. 1974) and Babington types, of which the latter is particularly suitable for nebulizing solutions containing high concentrations $(>5 \%)$ of dissolved salts or those containing suspended particles (Ebdon \& Cave 1982). The conespray nebulizer, recently developed by Sharp and co-workers (British Technology Group 1984), was designed to combine the merits of both the cross-flow and Babington V-groove nebulizers. 
Ultrasonic nebulization followed by desolvation has been used to improve detection limits significantly by increasing the amount of solute entering the ICP in unit time (Taylor \& Floyd 1981). Although, in principle, it is an inherently attractive technique, it has not been widely used in routine analysis, possibly because of the operational reliability of such nebulizers in terms of stability and memory effects. A commercial ultrasonic nebulizer and desolvation system has recently been produced by the Baird Corporation, and it will be interesting to see if it gains acceptance.

Direct nebulization of aqueous samples does not provide sufficient sensitivity to enable several important trace elements to be determined by ICP-OES at the concentrations at which they typically occur in natural waters. For those elements such as germanium, tin, lead, arsenic, antimony, bismuth, selenium and tellurium, which form gaseous hydrides at ambient temperatures, vapour phase sample introduction may be used to obtain considerably enhanced sensitivity and lower limits of detection. Thompson and coworkers (1978a, b, 1979, 1981) described a continuous-flow hydride generation system which they used for the simultaneous determination of $\mathrm{As}, \mathrm{Sb}, \mathrm{Bi}, \mathrm{Se}$ and Te in waters; pre-concentration by collection on freshly precipitated lanthanum nitrate lowered detection limits further to about 50 $\left.\mathrm{ng}\right|^{-1}$.

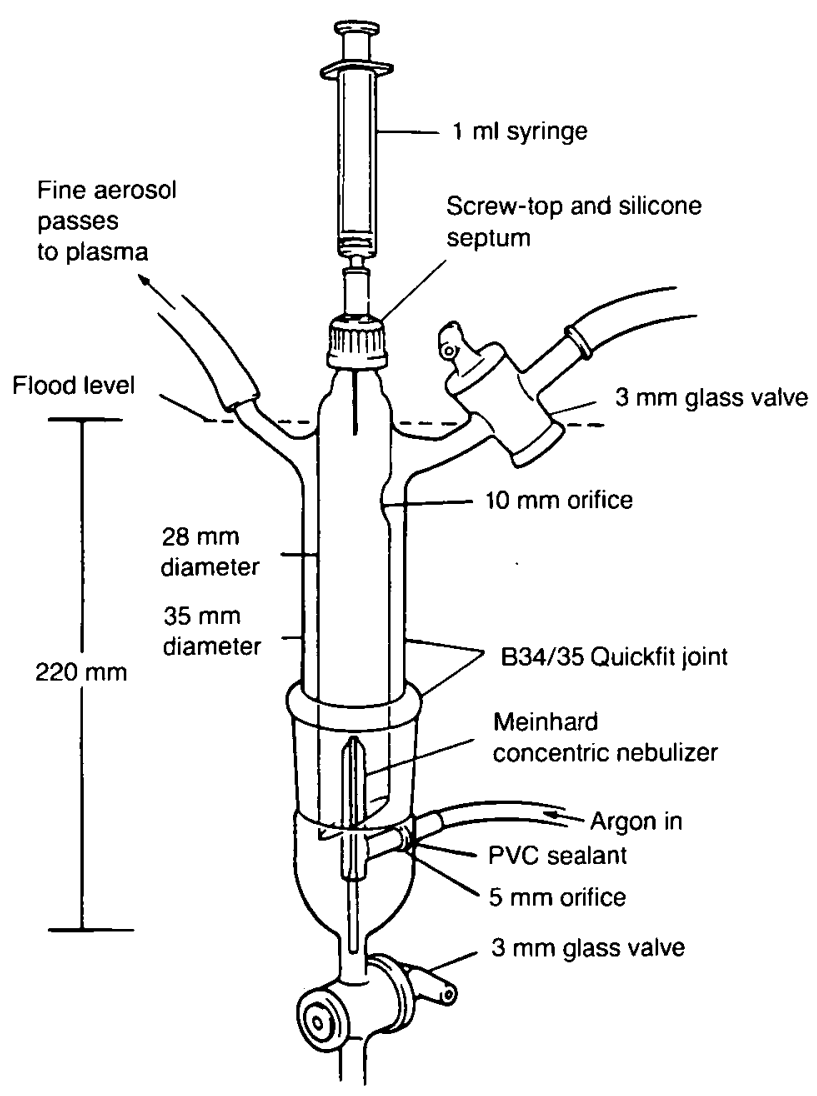

Figure 5. Recirculating nebulizer. (Redrawn from Hulmston 1983. Copyright: Royal Society of Chemistry)
3.3 Wavelength selection

The wide calibration ranges spanning 4-6 orders of magnitude, which are characteristic of ICPOES, mean that most elements can be determined in natural water samples by choosing a single, appropriate wavelength. Occasionally, to maintain good precision, and to avoid saturation of the detector or the need to dilute samples, it may be helpful to use an alternative spectral line of considerably different intensity for those few elements which may be encountered at extreme concentrations, eg calcium in rainwater or geothermal brines.

Four main factors govern wavelength selection in ICP-OES: analyte concentration, overall sample composition, potential spectral interferences, and the spectral range of the instrument. In the case of natural waters, the major analytes are $\mathrm{Na}, \mathrm{K}, \mathrm{Ca}$, $\mathrm{Mg}, \mathrm{Si}$ and total $\mathrm{S}$, and their concentrations typically range from 0.1 to $10^{4} \mathrm{mg} \mathrm{I}^{-1}$. With the possible exception of the determination of potassium in very dilute waters, appropriate spectral lines can be selected which will allow all these constituents to be determined directly in most samples, without the need for dilution or pre-concentration. In the case of $\mathrm{Ca}$ and $\mathrm{Mg}$, it is necessary to avoid their most sensitive lines in order to achieve calibration ranges which can be extended to high enough concentrations. For minor and trace elements, present at concentrations ranging from $<1$ to $10^{3} \mu \mathrm{g} \mathrm{I}^{-1}$, the most sensitive emission lines are usually chosen, subject always to any constraints imposed by spectral interferences from major components of the sample. Several elements, including $\mathrm{Sr}, \mathrm{Ba}$, $\mathrm{Li}, \mathrm{B}, \mathrm{Fe}$ and $\mathrm{Mn}$, can be determined directly in natural waters at typical environmental concentrations. However, the limits of detection attainable in ICP-OES are insufficient to allow many important transition and rare earth elements to be determined without pre-concentration. Nevertheless, direct measurement may still be used to screen large numbers of samples rapidly for anomalously high concentrations of a wide range of geochemically significant or potentially toxic elements. Numerous pre-concentration procedures have been reported in the literature (Sturgeon et al. 1980, 1982; Thompson et al. 1982; Long \& Snook 1983; Vos et al. 1984), and an example of this application of ICP-OES to the analysis of natural waters is discussed elsewhere in this volume by Cook (1987).

Several compilations of ICP spectral lines have been published recently (Parsons et al. 1980; Michaud \& Mermet 1982; Anderson et al. 1982; Boumans 1984; Brenner \& Eldad 1984; Anderson \& Parsons 1984; Winge et al. 1985; Forster et al. 1982; Wohlers 1985). These compilations may be used in the initial selection of analytical wavelengths, but it is vital that the suitability of 
individual lines be fully evaluated in relation to the spectroscopic characteristics of the instrumental system employed and the composition of the waters under investigation. Modern computercontrolled data acquisition and display facilities make this a relatively rapid and straightforward operation.

The most intense and sometimes the only analytically useful ICP emission lines of several elements lie in the ultra-violet region of the spectrum below $200 \mathrm{~nm}$ and may be utilized with the vacuum spectrometer systems which are now widely available. Sulphur emission at $180.7 \mathrm{~nm}$ has been used as the basis of a rapid means of determining sulphate simultaneously with major and trace metals in oxygenated waters (Miles \& Cook 1982). Total phosphorus may be determined down to $c 0.1 \mathrm{mg} \mathrm{|}^{-1}$ using the $178.29 \mathrm{~nm}$ line (Cook \& Miles 1985). Of particular relevance to the application of ICP-OES to studies of acidic deposition is the recent investigation of the vacuum ultra-violet region by Uehiro et al. (1984), which revealed that the aluminium $167.1 \mathrm{~nm}$ line provides much greater sensitivity than the 308.2 $\mathrm{nm}$ line commonly used (Figure 6). A $3 \sigma$ detection limit of $0.5 \mu \mathrm{g} \mathrm{I}^{-1}$ was reported, enabling $A$ l to be directly determined in lake waters; slight interference from a nearby iron line was recorded.

A typical wavelength programme that is routinely used for the determination of major, minor and

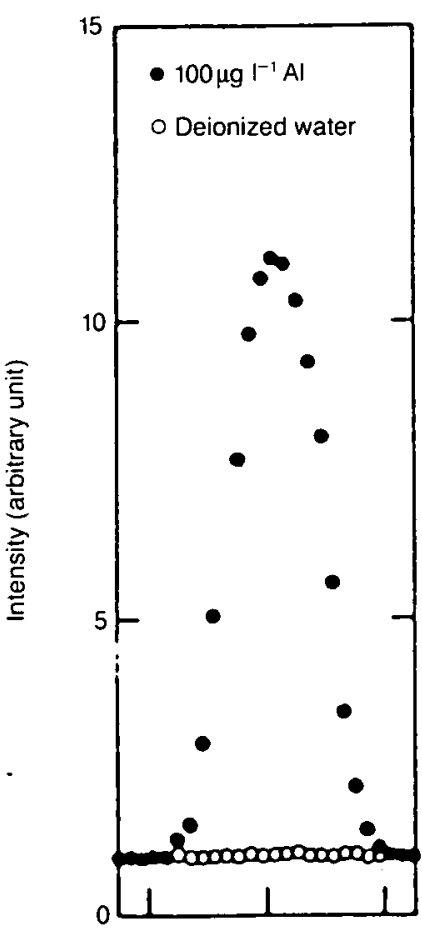

$167.1 \mathrm{~nm}$

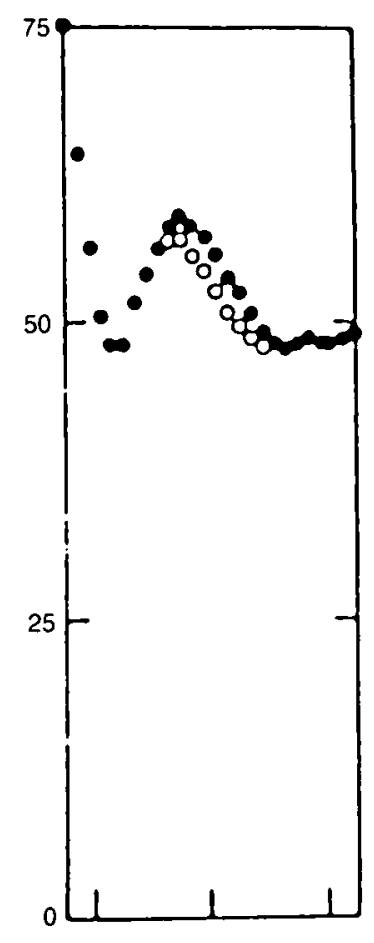

$308.2 \mathrm{~nm}$
Figure 6. Spectra in the vicinity of the $167.1 \mathrm{~nm}$ and $308.2 \mathrm{~nm}$ lines of aluminium showing the enhanced sensitivity obtained with the vacuum ultra-violet line. (Redrawn from Uehiro et al. 1984. Copyright: American Chemical Society)

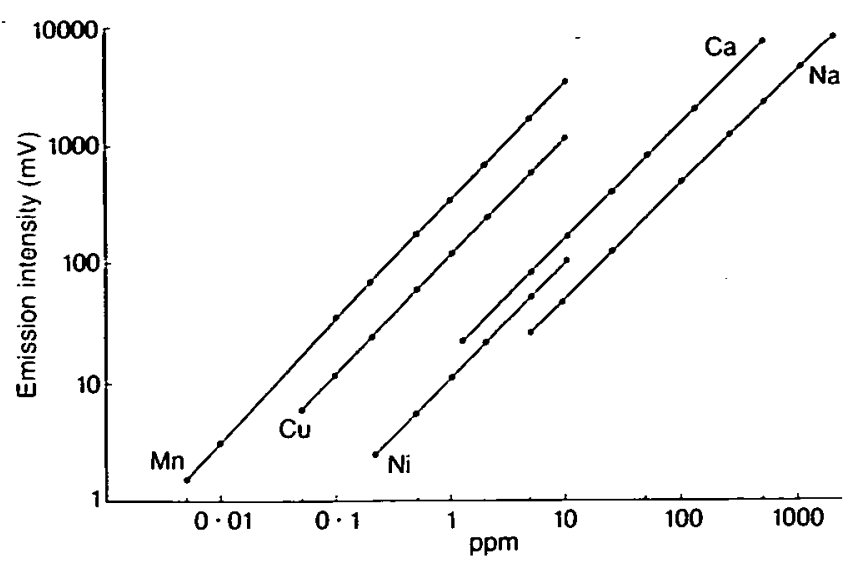

Figure 7. Typical ICP-OES calibration graphs for $\mathrm{Na}, \mathrm{Ca}, \mathrm{Cu}, \mathrm{Mn}$ and $\mathrm{Ni}$

Table 1. Typical ICP-OES wavelength programme for the determination of major, minor and trace elements in natural waters

\begin{tabular}{ccc}
\hline Element & $\begin{array}{c}\text { Wavelength } \\
(\mathrm{nm})\end{array}$ & $\begin{array}{c}\text { 30 Detection limits } \\
\left(\mathrm{mg} \mathrm{l}^{-1}\right)\end{array}$ \\
\hline $\mathrm{Na}$ & 589.0 & 0.02 \\
$\mathrm{~K}$ & 766.5 & 0.15 \\
$\mathrm{Ca}$ & 315.9 & 0.006 \\
$\mathrm{Mg}$ & 279.1 & 0.03 \\
$\mathrm{Si}$ & 288.2 & 0.015 \\
$\mathrm{~S}$ & 180.7 & 0.1 \\
$\mathrm{~B}$ & 249.7 & 0.007 \\
$\mathrm{Li}$ & 670.8 & 0.002 \\
$\mathrm{Sr}$ & 407.8 & 0.0005 \\
$\mathrm{Ba}$ & 455.4 & 0.0005 \\
$\mathrm{Fe}$ & 259.9 & 0.002 \\
$\mathrm{Mn}$ & 257.6 & 0.0006 \\
$\mathrm{Cu}$ & 324.8 & 0.002 \\
$\mathrm{Zn}$ & 213.9 & 0.002 \\
$\mathrm{Cr}$ & 267.7 & 0.006 \\
$\mathrm{Ni}$ & 231.6 & 0.02 \\
$\mathrm{Al}$ & 308.2 & 0.02 \\
$\mathrm{Cd}$ & 226.5 & 0.005 \\
$\mathrm{Sc}$ & 361.4 & 0.0005 \\
$\mathrm{Y}$ & 371.0 & 0.0005 \\
$\mathrm{Be}$ & 313.0 & 0.0005 \\
\hline
\end{tabular}

trace elements in rain, surface and groundwaters is given in Table 1. Examples of calibration graphs are shown in Figure 7.

\subsection{Spectral interferences}

Two types of spectral interference are recognized in ICP-OES: spectral line coincidence or overlap, and enhanced spectral background caused by recombination continuum radiation or stray light from intense emission lines, typically those of alkaline earth elements. In addition, instrumentspecific stray light interferences may arise because of, for example, incomplete optical isolation of adjacent detectors in a multi-channel spectrometer. These interferences must be avoided or quantified and compensated for, if accurate data are to be obtained during the analysis of natural waters. 


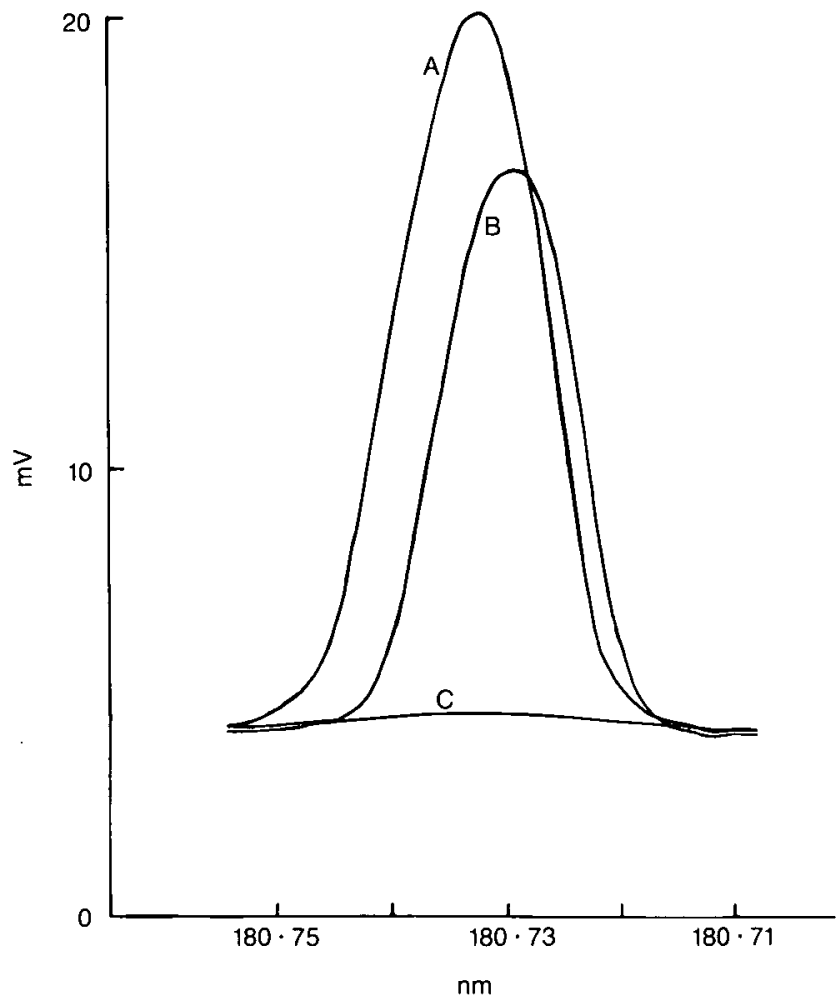

Figure 8. Spectra in the vicinity of $180.73 \mathrm{~nm}$ during the aspiration of (A) $8 \mathrm{mg}^{-1}$ sulphur, (B)

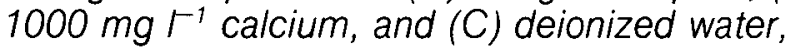
showing almost complete line overlap interference

An example of interference caused by almost complete spectral line overlap is shown in Figure 8. A weak calcium line virtually coincides with the most sensitive sulphur line at $180.73 \mathrm{~nm}$. However, the difference in intensity of the 2 lines is such that a $1000 \mathrm{mg} \mathrm{I}^{-1} \mathrm{Ca}$ solution produces a signal corresponding to an apparent sulphur concentration of only c. $8 \mathrm{mg} \mathrm{|}^{-1}$. Because of the very different relative intensities of the 2 lines, and the fact that these 2 elements occur at similar order of magnitude concentrations in water, correction for this slight interference effect is easily achieved by establishing the relationship between calcium concentration and apparent sulphur signal, and inserting this information in the controlling software. The effect of calcium is thereby automatically subtracted during the analysis of samples.

Interference caused by the partial overlap of the wing of one spectral line on another is illustrated in Figure 9. The wing of the $202.58 \mathrm{~nm} \mathrm{Mg}$ line overlaps the nearby $202.55 \mathrm{~nm} \mathrm{Zn}$ line to an extent that, although automatic correction is possible at low $\mathrm{Mg}$ concentrations, above c 500 $\mathrm{mg} \mathrm{I}^{-1} \mathrm{Mg}$ it would be wise to choose an alternative $\mathrm{Zn}$ line, such as the slightly less intense $213.86 \mathrm{~nm}$ line.

Small but significant shifts in spectral background intensity are observed when high concentrations of certain elements are nebulized into the ICP. Radiation is emitted between $190 \mathrm{~nm}$ and $220 \mathrm{~nm}$ when large amounts of aluminium are present, because of the recombination in the plasma of aluminium ions with free electrons having a continuous energy distribution. This interference can be a serious problem in the analysis of many geological samples, where aluminium is a major constituent, but is insignificant as far as most natural waters are concerned because $\mathrm{Al}$ is present only at trace concentrations. Much more important are the enhanced background signals which are observed at certain wavelengths in the presence of calcium and magnesium at concentrations typical of some moderately saline waters. An example of the interference caused by calcium at the $371.03 \mathrm{~nm}$ yttrium line is given by Cook (1987).

The magnitude of this type of spectral interference is both analyte and interferent specific (Table 2), and probably also varies between instruments because of differences in optical configuration. While the so-called 'onpeak' mode of correction outlined for the $\mathrm{Ca} / \mathrm{S}$ interference may be used to minimize the errors caused by background shifts, an alternative 'offpeak' correction procedure may also be used, particularly where the background in the vicinity of the analyte line is relatively flat and unstructured. In addition to making the usual intensity measurement at the correct wavelength (ie onpeak), intensity measurements are made at predetermined positions on either side of the line by displacing the entrance slit or grating under computer control. A mean background level is then interpolated for each sample and subtracted from the total intensity.
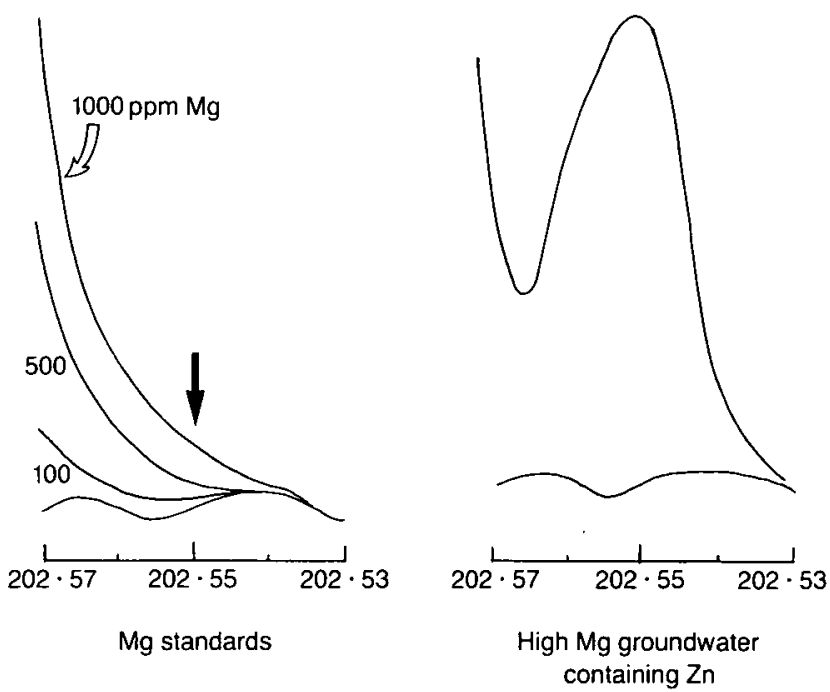

Figure 9. Spectra in the vicinity of the 202.55 $\mathrm{nm}$ line of zinc showing interference from the wing of the $202.58 \mathrm{~nm}$ line of magnesium at high concentrations 
Table 2. Apparent analyte concentrations, in $\mu \mathrm{gl}^{-1}$, arising from background shifts in ICP-OES when calcium and magnesium solutions are nebulized

\begin{tabular}{lcccccccc}
\hline & \multicolumn{8}{c}{ Analyte element and wavelength (nm) } \\
Interferent & Cr 267.7 & Fe 259.9 & La 398.8 & Mn 257.6 & Si 288.16 & Ti 337.3 & Y 371.0 \\
\hline $1000 \mathrm{mg} \mathrm{l}^{-1} \mathrm{Ca}$ & - & - & 200 & - & $\bullet$ & 130 & 4 \\
$1000 \mathrm{mg} \mathrm{l}^{-1} \mathrm{Mg}$ & 48 & 25 & - & 5 & 350 & - & - \\
\hline
\end{tabular}

- Line overlap interference from a weak Ca line at approximately $288.17 \mathrm{~mm}$

Compared with some types of sample, eg geological and biological materials, natural waters tend to present fewer spectral interference problems. Elements such as aluminium with its recombination continuum and iron with its very line-rich spectrum are typically present as trace constituents rather than major components, and so exert little influence. Precipitation samples and upland surface waters of the type frequently examined in studies of acidic deposition are usually so dilute that interferences from major cations on minor and trace element measurements are minimal. However, all spectral interferences become proportionately more important as the true analyte signal decreases and the detection limit is approached, and thus must be carefully evaluated when reliable trace element data are being sought. Trafford (1987) has described how additional problems of reagent purity have to be taken into account when examining spectral interferences.

\subsection{Advantages and limitations}

Within the specific context of the analysis of natural waters, as opposed to, say, geological materials or metals, some of the main advantages and limitations of ICP-OES may be summarized as follows.

\subsubsection{Advantages}

i. Samples are in an ideal form for presentation.

ii. Calibration ranges covering $4-5$ orders of magnitude allow samples of widely varying composition, eg rainwater and moderately saline groundwater, to be analysed without further treatment using a single spectral line and calibration function.

iii. Good sensitivity for some minor and trace elements, eg $\mathrm{Sr}, \mathrm{Fe}$ and $\mathrm{Mn}$, permits their direct determination at environmental concentrations, simultaneously with the major constituents. Samples may be screened for several other trace metals, eg Co, Cu and $\mathrm{Zn}$, at potentially toxic or legislatively undesirable levels.

iv. Elements such as $\mathrm{Fe}$ and $\mathrm{Al}$, which can give rise to spectroscopic problems if present at high concentrations, as for example in metallurgical analysis, occur mainly at trace levels in natural waters. v. The high temperature of the ICP minimizes chemical interferences.

vi. The multi-element capability of the technique, whether simultaneous or rapid sequential, considerably reduces sample handling. and the attendant risk of contamination.

vii.Elements such as $B$ and $B a$, which for various reasons are difficult or tedious to determine by other techniques, can be determined rapidly by ICP-OES with adequate sensitivity.

\subsubsection{Limitations}

i. Suspended material may block certain nebulizers.

ii. High concentrations of certain major constituents, particularly calcium and magnesium, give rise to spectral interferences in the determination of trace elements.

iii. The sensitivity of ICP-OES is inadequate to permit the direct determination of many trace elements at the very low concentrations at which they typically occur in natural waters.

iv. Emission intensities relate to total elemental concentration; information on the chemical speciation of the analyte cannot be obtained without additional treatment, eg by HPLC. Data on isotopic composition are not recoverable.

\section{Inductively coupled plasma-fourier transform} spectrometry (ICP-FTS)

Fourier transform spectrometry (FTS) is a very widely used technique in infra-red spectroscopy, where it has virtually replaced conventional dispersive-based measurement, but its application to the visible and UV regions has been much more limited, partly because of the more demanding mechanical and optical tolerance dictated by the shorter wavelengths. However, in recent years, various workers have been actively exploring the coupling of Fourier "transform spectrometers to ICP sources, both for plasma diagnostic studies and as the basis of potentially powerful analytical systems (Faires 1986).

In FTS, a Michelson interferometer replaces the conventional grating spectrometer. Collimated light from the ICP is divided by a beam splitter and reflected from one fixed and one moving mirror 
before being recombined and reflected to the detector (Figure 10). Differences in path length caused by the moving mirror result in an interference pattern which is related to wavelength and the position of the mirror. The original spectrum is recovered from the interferogram by Fourier transformation of the digitized wave form.

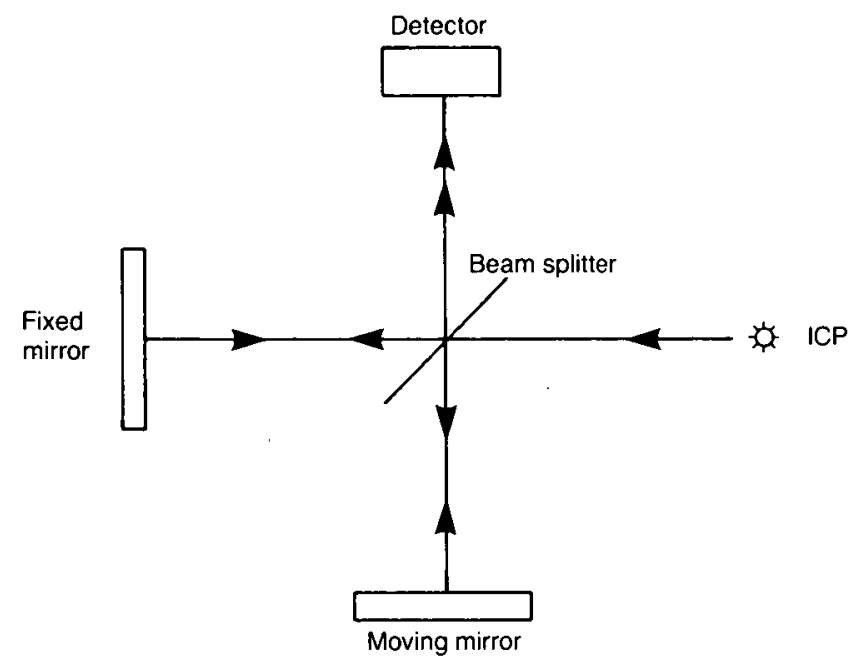

Figure 10. Schematic diagram of an ICP Fourier transform spectrometer

The inherent attractions of FTS are considerable. Spectral information is gathered simultaneously over the entire region of interest, rather than at specific wavelengths corresponding to preselected lines. High resolution is attainable and excellent wavelength accuracy is provided by the laser-referenced interferometer. Execution of the Fourier transformation requires significant computing capacity, but the power and speed of modern, small computers allows this to be accomplished relatively rapidly.

In contrast to IR-FTS, where noise is detectorlimited, noise in ICP-FTS is source-limited. Consequently, because of the multiplex nature of the technique, noise from the more intense spectral lines is distributed into the spectral baseline. In addition to this so-called multiplex disadvantage, intense emission at certain wavelengths also poses problems through the dynamic range limitations of the detector. Comparisons conducted so far (Stubley \& Horlick 1985a) indicate that ICP-FTS detection limits are 1-2 orders of magnitude poorer than those attainable by ICP-OES using a modern polychromator. Stubley and Horlick (1985b) have recently demonstrated that the interposition of a medium resolution monochromator between the ICP and the interferometer, to provide an adjustable optical filter with a bandpass of $c 4 \mathrm{~nm}$, can very largely overcome both dynamic range and signal-to-noise limitations. Improvements in detection limits of about one order of magnitude were reported. As a novel departure from the use of the fast Fourier transform algorithm to recover the original spectrum, $\mathrm{Ng}$ and Horlick (1985a) have also used cross-correlation techniques to process the interferogram directly. Square-wave, digital, cross-correlation masks of any number of spectral lines of interest can be stored compactly in the computer, and the advent of powerful electronic multiplier chips opens up the possibility of real-time correlation-based data processing and rapid, automatic qualitative analysis by ICPFTS (Ng \& Horlick 1985b).

At present, no complete ICP-FTS system is commercially available and studies of the technique are confined to a small number of research laboratories. However, it is understood that at least one major ICP equipment manufacturer will shortly be marketing an ICPFTS system.

\section{Inductively coupled plasma-mass spectrometry (ICP-MS)}

The principle of using an atmospheric pressure plasma as an ion source for atomic mass spectrometry was first demonstrated in the early 1970s by Gray (1974, 1975a, b), initially using a DC capillary arc plasma. Because of the severe inter-element and matrix effects experienced with this type of plasma, an ICP source was later substituted (Houk et al. 1980; Date \& Gray 1981).

A schematic diagram of a typical ICP-MS system is shown in Figure 11. A conventional ICP source is positioned horizontally so that the plasma tail flame plays on a water-cooled, metal cone having a small $(0.5-1.1 \mathrm{~mm}$ diameter) hole at its tip through which a portion of the ionized gas passes into the vacuum system of a quadrupole mass spectrometer. Considerable research effort continues to be concentrated on elucidating the processes controlling ion transport and recombination which occur in and around this interface between the very hot, atmospheric pressure plasma and the ambient temperature, high-vacuum environment of the mass spectrometer. A major step forward in the development of ICP-MS was the achievement of continuum flow sampling of ions from the bulk plasma, rather than from the cool boundary layer (Gray \& Date 1983), and this form of ion extraction is embodied in the 2 commercial ICP-MS systems which have recently become available.

Liquid sample introduction in ICP-MS is fundamentally identical to that in optical ICP spectrometry, and is thus considerably more direct and rapid than that involved in thermal ionization mass spectrometry. Even for complex natural samples, the mass spectra obtained are relatively simple compared with corresponding optical emission spectra, and inherent in the 


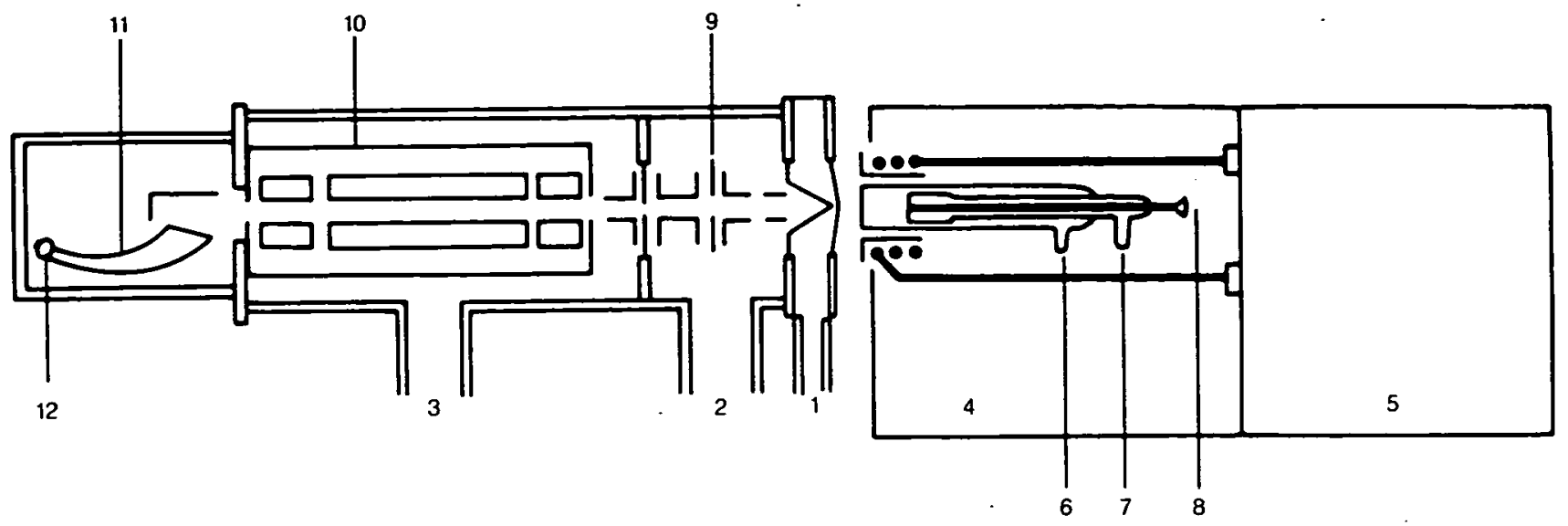

Arrangement of plasma and mass analyser. 1, 2, 3, Successive vacuum stages; 4 , torch housing; 5 , radiofrequency matching unit; 6,7 , coolant and plasma gas inlet; 8 , sample (injector) gas flow; 9 , ion lens; 10 , quadrupole analyser; 11 , ion detector; and 12, signal output

Figure 11. Schematic diagram of an ICP-MS system. (Redrawn from Gray \& Date 1983. Copyright: Royal Society of Chemistry)

technique is the provision of information on the isotopic as well as total elemental composition of samples. This latter feature opens up the possibilities of the wider use of stable isotopic tracers in studies of hydrologic systems and of the use of stable isotope dilution techniques in accurate and precise, low-level, analytical methods.

Spectral interferences in ICP-MS arise from a variety of sources, including plasma gases, solvent, isobaric singly charged analyte ions, doubly charged ions, oxide and other molecular ions. Thus, background spectra show strong peaks at 40 and $41 \mathrm{~m} / \mathrm{z}$ corresponding to ${ }^{40} \mathrm{Ar}^{+}$ and ${ }^{40} \mathrm{ArH}^{+}$respectively, which preclude the detection of ${ }^{40} \mathrm{Ca}^{+}$and ${ }^{41} \mathrm{~K}^{+}$. Similarly, peaks corresponding to ions of $\mathrm{H}, \mathrm{C}, \mathrm{N}$ and $\mathrm{O}$, singly or in combination, occur at various $\mathrm{m} / \mathrm{z}$ values below 81. The significance of these interferences depends upon the relative intensity of the corresponding analyte peak. For example, ${ }^{40} \mathrm{Ar}^{14} \mathrm{~N}^{+}$and ${ }^{40} \mathrm{Ar}^{16} \mathrm{O}^{+}$peaks degrade the detection limits for ${ }^{54} \mathrm{Fe}^{+}$and ${ }^{56} \mathrm{Fe}^{+}$, but do not totally preclude the determination of these isotopes. Interference from ions of even a minor isotope of a major constituent can swamp the signal derived from a trace element in the same sample, eg ${ }^{48} \mathrm{Ca}^{+} /{ }^{48} \mathrm{Ti}^{+}$. In such cases, it is often possible to choose an alternative, interference-free isotope by which to determine the trace element, but some sensitivity may be sacrificed because of its lower abundance.

Careful choice of sample pre-treatment can substantially reduce some molecular ion interferences. McLaren et al. (1985) have shown that acidification with $\mathrm{HNO}_{3}$ rather than $\mathrm{HCl}$ is to be preferred in order to avoid interference from chlorine-containing molecular species, such as that of ${ }^{35} \mathrm{Cl}^{16} \mathrm{O}^{+}$on ${ }^{51} \mathrm{~V}^{+}$and ${ }^{40} \mathrm{Ar}^{35} \mathrm{Cl}^{+}$on ${ }^{75} \mathrm{As}^{+}$. Interferences from metal-oxide species $\left(\mathrm{MO}^{+}\right)$ have been widely reported, but their origin, magnitude and control are disputed. However, available evidence points to their being produced in the region of the ion extraction zone. In addition, Olivares and Houk (1985) have recently demonstrated that $\mathrm{MO}^{+} / \mathrm{M}^{+}$ratios can be related to plasma operating conditions, such as nebulizer gas flow rate and forward power.

Current ICP-MS detection limits under realistic multi-element operating conditions are typically of the order of $0.1 \mu \mathrm{g} \mathrm{I^{-1 }}$ for a wide range of elements. They are characteristically more uniform than those attainable by ICP-OES, to which they are generally superior by $1-2$ orders of magnitude.

\section{Conclusion}

In the 20 years since its initial recognition as a potential spectroscopic source, the ICP has proved to be a stable and powerful vaporization, atomization, excitation and ionization cell. It has been successfully combined with several different modes of spectrometric detection, including direct and Fourier transform optical emission spectrometry, atomic fluorescence spectrometry and mass spectrometry. Used in appropriate combination, these techniques provide the bases of analytical methods by which natural waters may be characterized almost completely for their total elemental and isotopic composition. However, much remains to be achieved in extending the sensitivity of the overall analytical procedures to enable many trace elements to be detected reliably at the sub-ppb concentrations at which they typically occur in the environment.

\section{Summary}

Traditionally, molecular and atomic absorption spectrometry has been widely used in the analysis of natural waters, with the latter being especially popular for the determination of alkali, alkaline earth and some transition metals. In recent years, the development of the inductively 
coupled plasma (ICP) as a spectroscopic source has provided the basis of sensitive atomic emission spectrometric techniques utilizing both optical and mass spectrometric detection. The advantages and disadvantages of plasma emission spectrometry for the analysis of natural waters and acidic deposition are reviewed, including instrumentation, sensitivity, sample treatment and interference effects. Utilization of emission in the UV region for the determination of non-metals such as sulphur and phosphorus are discussed.

\section{References}

Anderson, T.A. \& Parsons, M.L. 1984. ICP emission spectra: III. The spectra of the group IIIA elements and spectral interferences due to group IIA and IIIA elements. Appl. Spectrosc., 38, 625-634.

Anderson, T.A.; Forster, A.R. \& Parsons, M.L. 1982. ICP emission spectra: II. Alkaline earth elements. Appl. Spectrosc., 36, 504-509.

Babat, G.I. 1947. Electrodeless discharges and some allied problems. J. Instn elect. Engrs, 94, 27-37.

Baginski, B.R. \& Meinhard, J.E. 1984. Some effects of high-solids matrices on the sample delivery system and the Meinhard concentric nebulizer during ICP emission analyses. Appl. Spectrosc., 38, 568-572.

Boumans, P.W.J.M. 1984. Line coincidence tables for inductively coupled plasma atomic emission spectrometry. 2nd ed. Oxford: Pergamon.

Brenner, I.B. \& Eldad, H. 1984. A spectral line atlas for multitrace and minor element analysis of geological and ore mineral samples by ICP-AES. ICP Inf. Newsl., 10, 451-508.

British Technology Group. 1984. Method of and apparatus for the nebulization of liquids and liquid suspensions. UK Patent Appl. no. 8432338.

Cook, J.M. 1987. Trace element measurements of environmental samples using inductively coupled plasma optical emission spectrometry. In: Chemical analysis in environmental research, edited by A.P. Rowland, 50-55. (ITE symposium no. 18.) Abbots Ripton: Institute of Terrestrial Ecology.

Cook, J.M. \& Miles, D.L. 1985. Utilisation of emission in the ultra-violet region for the determination of phosphate in geochemical samples by inductively coupled plasma optical emission spectrometry. Analyst, Lond., 110, 547-549.

Date, A.R. \& Gray, A.L. 1981. Plasma source mass spectrometry using an inductively coupled plasma and a high resolution quadrupole mass filter. Analyst, Lond., 106, 1255-1267.

Ebdon, L. \& Cave, M.R. 1982. A. study of pneumatic nebulization systems for inductively coupled plasma emission spectrometry. Analyst, Lond., 107, 172-178.

Faires, L.M. 1986. Fourier transforms for analytical atomic spectroscopy. Analyt. Chem., 58 , 1023A-1034A.

Forster, A.R., Anderson, T.A. \& Parson, M.L. 1982. ICP spectra: I. Background emission. Appl. Spectrosc., 36, 499-503.

Gray, A.L. 1974. A plasma source for mass analysis. Proc. Soc. anal. Chem., 11, 182-183.

Gray, A.L. 1975a. Mass-spectrometric analysis of solutions using an atmospheric pressure ion source. Analyst, Lond., 100, 289-299.

Gray, A.L. 1975b. Plasma sampling mass spectrometry for trace analysis of solutions. Analyt. Chem., 47, 600-601.

Gray, A.L. \& Date, A.R. 1983. Inductively coupled plasma source mass spectrometry using continuum flow ion extraction. Analyst, Lond., 108, 1033-1050

Greenfield, S., Jones, I.L. \& Berry, C.T. 1964. Highpressure plasmas as spectroscopic emission sources. Analyst, Lond., 89, 713-720.

Houk, R.S., Fassel, V.A., Flesch, G.D., Svec, H.J., Gray, A.L. \& Taylor, C.E. 1980. Inductively coupled argon plasma as an ion source for mass spectrometric determination of trace elements. Analyt. Chem., 52, 2283-2289.

Hulmston, P. 1983. A pneumatic recirculating nebulizer system for small sample volumes. Analyst, Lond., 108, 166-170.

Hulmston, P. \& McKillop, S. 1985. Nebulization characteristics of a microprocessor-controlled recirculating nebulizer for inductively coupled plasma atomic-emission spectrometric analysis of small sample volumes. Analyst, Lond., 110, 559-562.

Kinniburgh, D.G. \& Miles, D.L. 1983. Extraction and chemical analysis of interstitial water from soils and rocks. Environ. Sci. Technol., 17, 362-368.

Kniseley, R.N., Amenson, H., Butler, C.C. \& Fassel, V.A. 1974. An improved pneumatic nebulizer for use at low nebulizing gas flows. Appl. Spectrosc., 28, 285-286.

Long, S.E. \& Snook, R.D. 1983. Electrochemical preconcentration technique for use with inductively coupled plasma atomic-emission spectrometry. Analyst, Lond., 108, 1331-1338.

McLaren, J.W., Mykytiuk, A.P. \& Berman, S.S. 1985. Applications of inductively coupled plasma mass spectrometry in marine analytical chemistry. Colloq. Spectrosc. int., 24th, 1985, 395-396.

Michaud, E. \& Mermet, J.M. 1982. Iron spectrum in the 200-300 nm range emitted by an inductively coupled argon plasma. Spectrochim. Acta, 37B, 145-164.

Miles, D.L. \& Cook, J.M. 1982. The determination of sulphate in natural waters by inductively-coupled plasma emission spectrometry. Analytica chim. Acta, 141, 207-212. 
Ng, R.C.L. \& Horlick, G. 1985a. A real-time correlationbased data processing system for interferometric signals. Appl. Spectrosc., 39, 841-847.

Ng, R.C.L. \& Horlick, G. 1985b. Correlation-based data processing for an inductively coupled plasma/Fourier transform spectrometer system. Appl. Spectrosc., 39, 834-840.

Olivares, J.A. \& Houk, R.S. 1985 . Ion sampling for inductively coupled plasma mass spectrometry. Analyt. Chem., 57, 2674-2697.

Parsons, M.L., Forster, A. \& Anderson, D. 1980. An atlas of spectral interferences in ICP spectroscopy. New York: Plenum.

Reed, T.B. 1961. Induction-coupled plasma torch. J. appl. Phys., 32, 821-824.

Stubley, E.A. \& Horlick, G. 1985a. Measurement of inductively coupled plasma emission spectra using a Fourier transform spectrometer. Appl. Spectrosc., 39, 805-810.

Stubley, E.A. \& Horlick, G. 1985b. A windowed slewscanning Fourier transform spectrometer for inductively coupled plasma emission spectrometry. Appl. Spectrosc., 39, 811-817.

Sturgeon, R.E., Berman, S.S., Desaulniers, A. \& Russell, D.S. 1980. Pre-concentration of trace metals from sea-water for determination by graphite-furnace atomic-absorption spectrometry. Talanta, 27, 85-94.

Sturgeon, R.E., Berman, S.S. \& Willie, S.N. 1982. Concentration of trace metals from sea-water by complexation with 8-hydroxy-quinoline and adsorption on $\mathrm{C}_{18}$ - bonded silica gel. Talanta, 29, 167-171.

Taylor, C.E. \& Floyd, T.L. 1981. Inductively coupled plasma-atomic emission spectrometric analysis of environmental samples using ultrasonic nebulization. Appl. Spectrosc., 35, 408-413.

Thompson, M. \& Pahlavanpour, B. 1979. Reduction of tin and germanium to hydrides for determination by inductively-coupled plasma atomic emission spectrometry. Analytica chim. Acta, 109, 251-258.

Thompson, M., Pahlavanpour, B., Walton, S.J. \& Kirkbright, G.F. 1978a. Simultaneous determination of trace concentrations of arsenic, antimony, bismuth, selenium and tellurium in aqueous solution by introduction of the gaseous hydrides into an inductively coupled plasma source for emission spectrometry. Part I. Preliminary studies. Analyst, Lond., 103, 568-579.

Thompson, M., Pahlavanpour, B., Walton, S.J. \& Kirkbright, G.F. 1978b. Simultaneous determination of trace concentrations of arsenic, antimony, bismuth, selenium and tellurium in aqueous solution by introduction of the gaseous hydrides into an inductively coupled plasma source for emission spectrometry. Part II. Interference studies. Analyst, Lond., 103, 705-713.

Thompson, M., Pahlavanpour, B. \& Thorne, L.T. 1981. The simultaneous determination of arsenic, antimony, bismuth, selenium and tellurium in waters by an inductively coupled plasma/volatile hydride method. Wat. Res., 15, 407-411.

Thompson, M., Ramsey, M.H. \& Pahlavanpour, B. 1982. Water analysis by inductively coupled plasma atomic emission spectrometry after a rapid preconcentration. Analyst, Lond., 107, 1330-1334.

Trafford, J.M. 1987. Investigation of spectral interferences in the determination of trace elements in water by ICP-OES. In: Chemical analysis in environmental research, edited by A.P. Rowland, 56-58. (ITE symposium no. 18.) Abbots Ripton: Institute of Terrestrial Ecology.

Uehiro, T., Morita, M. \& Fuwa, K. 1984. Vacuum ultraviolet emission line for determination of aluminium by inductively coupled plasma atomic emission spectrometry. Analyt. Chem., 56, 2020-2024.

Vos, G., van Dordrecht, P. \& ten Bras, P.W. 1984. Preconcentration of trace metals for their determination with ICP-AES. Fortschr. atomspektrom. Spurenanal., 1, 491-499.

Wendt, R.A. \& Fassel, V.A. 1965. Induction coupled plasma spectrometric excitation source. Analyt. Chem., 37, 920-922.

Winge, R.K., Fassel, V.A., Peterson, V.J. \& Floyd, M.A. 1985. Inductively coupled plasma-atomic emission spectroscopy. An atlas of spectral information. (Physical sciences data, vol. 20.) Amsterdam: Elsevier.

Wohlers, C.C. 1985 . Experimentally obtained wavelength tables for the ICP. ICP Inf. Newsl.; 10, 593-688. 


\title{
Trace element measurements of environmental water samples using inductively coupled plasma optical emission spectrometry
}

\author{
J M COOK \\ British Geological Survey, Hydrogeology Research Group, Wallingford
}

\section{Introduction}

One of the advantages of inductively coupled plasma optical emission spectrometry (ICP-OES) as an analytical technique is that major, minor and trace element determinations can be performed simultaneously, thus minimizing sample handling and reducing sample contamination. However, for dilute waters, detection limits obtained by ICPOES are not always sufficiently sensitive to allow the direct determination of some important trace elements. Sample pre-concentration is often required and any procedure which is used must therefore be applicable to a wide range of elements, in order to utilize the multi-element capability of the ICP. Thus, a simple method of evaporation under ultra-clean conditions was developed at BGS Wallingford, initially for the purpose of determining trace element concentrations in groundwaters, where many determinands were found to be present in unpolluted sources at very low levels.

Subsequently, the procedure has proved to be very robust when applied to rain and surface waters in studies of acidic deposition.

Underlying the methodology described here is the broader philosophy of trace element measurement. This paper reviews some of the precautions which need to be taken at each stage, from sample collection to data interpretation, and discusses them in relation to the determination of trace elements in natural waters by ICP-OES.

\section{Sample handling strategy}

To obtain reliable environmental data it is important to make a critical assessment of the procedures adopted at each of the 4 interdependent stages of sample collection, sample storage, laboratory analysis and data interpretation. Each stage will influence the accuracy and precision of the final result. Miles and Cook (1981) have outlined the problems of collecting data on the inorganic chemical composition of groundwaters.

At all stages of handling the samples, the overall objective should be to minimize:

i. contamination of the sample,

ii. loss of analyte by adsorption on to surfaces, and

iii. modification of the chemical form of the analyte.
For example, during sample collection and storage, attention should be focused on the materials used in the construction of the collection apparatus and the sample containers themselves. Pre-treatment of apparatus and containers is often necessary, particularly to reduce contamination.

The overall aims of a project may well dictate whether filtered or unfiltered samples are collected. A common practice is to use a filter with a nominal pore size of $0.45 \mu \mathrm{m}$ as an arbitrary division between 'dissolved' and 'particulate' material. This distinction may be inadequate, especially for samples containing colloidal material (Danielsson 1982). A study of the particle size distribution of iron and manganese species in fresh waters by Laxen and Chandler (1983) showed that it was essential to filter on-site, as changes in the size distribution occurred within several hours. Filtration introduces the possibility of contamination from the apparatus and loss of analyte by adsorption (Gardner \& Hunt 1981).

Consideration should be given to the stability of the analyte during storage. Sorption losses on to container surfaces have been demonstrated by Massee et al. (1981) for a number of trace elements, and Batley and Gardner (1977) have reviewed published data on storage experiments for various analytes.

Altogether there is a wealth of literature which addresses the problems associated with the sampling and storage of natural waters. In the end, whatever the procedure adopted, the essential prerequisite is that it be thoroughly evaluated, prior to its application to a particular project.

Once a sample reaches the laboratory, anything that comes in contact with it is a potential source of contamination. A direct consequence of this is a requirement for (i) a very clean working environment, and (ii) a source of high-purity water.

At BGS Wallingford this requirement is achieved in the following manner.

i. Air is filtered before it enters the trace element laboratory, and a positive pressure is maintained in the room, relative to the external atmosphere. Laminar flow hoods are used to 
provide an extra clean working area within the laboratory. The effectiveness of these measures can be judged from Figure 1, which compares the levels of iron, lead and zinc in the ambient air outside with those of the filtered air inside the laboratory and that produced by the laminar flow hoods. Even coarse filtration reduces the levels significantly, and the metal concentrations in the air in the laminar flow hoods are a fraction of those of the ambient air.

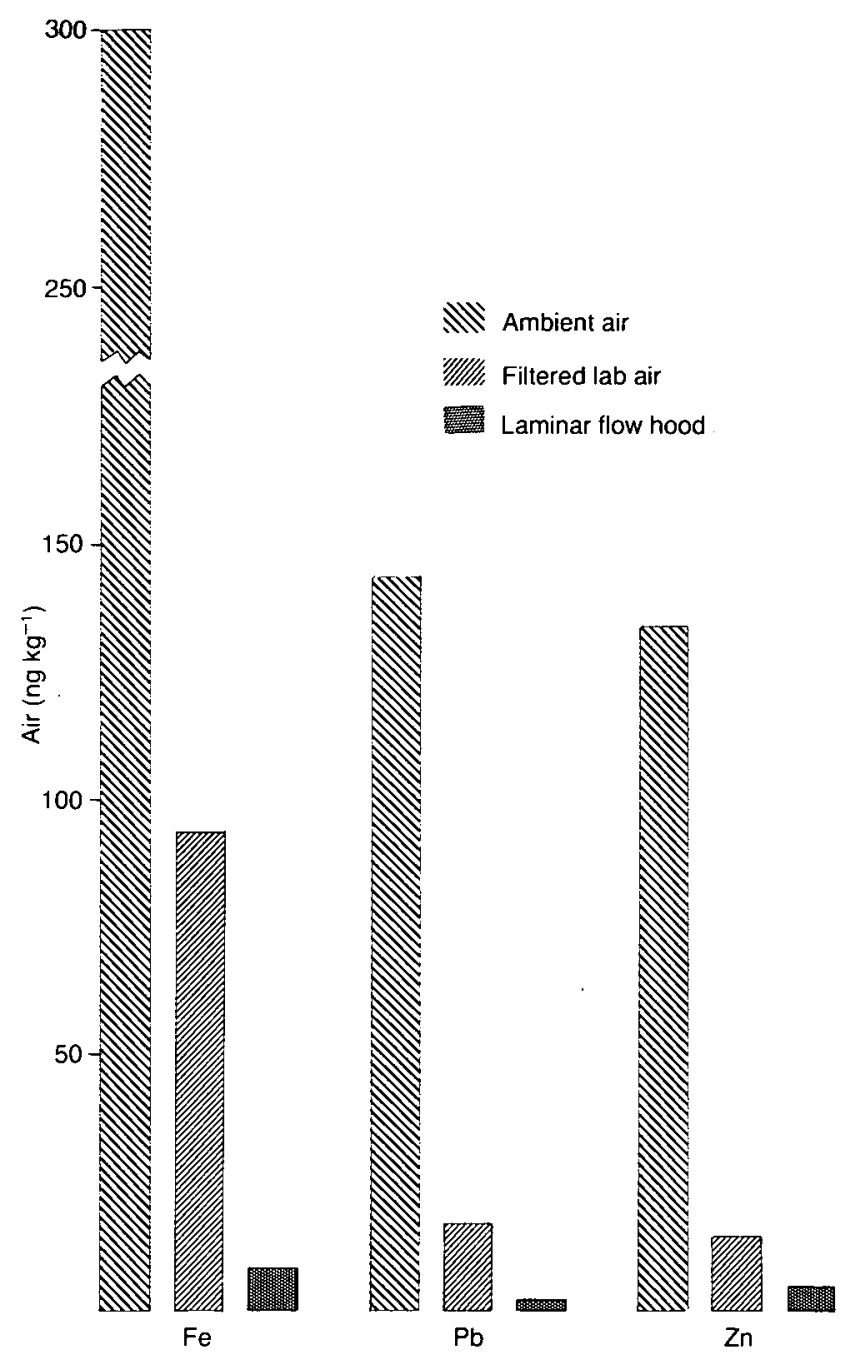

Figure 1. Concentrations of particulate iron, lead and zinc in the filtered laboratory air and laminar flow hoods, compared with those of the unfiltered atmosphere

ii. Water from a reverse osmosis plant is supplied to a Millipore system containing a pre-filter, 2 mixed-bed ion exchange columns, one column of activated carbon and a final filter of pore size $0.22 \mu \mathrm{m}$. The final water produced has a

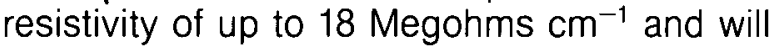
be referred to as MilliQ water in this paper.

3 Collection and storage of trace element samples

One litre polyethylene bottles were soaked in $50 \% \mathrm{v} / \mathrm{v}$ Analar $\mathrm{HCl}$ for 24 hours, rinsed with high-purity water (MilliQ), soaked in $10 \% \mathrm{v} / \mathrm{v}$ high-purity Aristar $\mathrm{HCl}$ for another 24 hours, and copiously rinsed and stored full of MilliQ water. Just before transport to the field, the bottles were rinsed a further 3 times in MilliQ water and packed into plastic bags.

All plastic tubing and filtration equipment with which the water comes in contact was also acidwashed, rinsed with MilliQ water and rinsed thoroughly with the sample before its final collection.

High-purity Aristar $\mathrm{HCl}$ was added to the samples to give a final concentration of $1 \% \mathrm{v} / \mathrm{v}$, lowering the $\mathrm{pH}$ to approximately $\mathrm{pH} 1-2$ to stabilize the trace elements in solution and discourage adsorption on to the container walls. A blank of MilliQ water was also acidified in an identical manner in the field, to check on contamination from the bottles and the acid. Samples were stored at $4^{\circ} \mathrm{C}$ in the dark until required.

\section{Pre-concentration by evaporation}

PTFE beakers, of $500 \mathrm{ml}$ capacity, were thoroughly soaked in $50 \% \mathrm{v} / \mathrm{v}$ Aristar $\mathrm{HCl}$ overnight and copiously rinsed with MilliQ water. Four hundred millilitres of sample were poured into each beaker and placed under an infra-red lamp in a laminar flow hood. After 6-7 hours, the approximately $5 \mathrm{ml}$ of solution that remained was decanted into an acid-washed $20 \mathrm{ml}$ volumetric flask. The PTFE beaker was rinsed with $0.2 \mathrm{ml}$ Aristar $\mathrm{HCl}$ and several aliquots of MilliQ water, and all the washings were decanted into the flask and made up to volume; this procedure resulted in a 20 -fold concentration of the sample.

Blanks of $1 \% \mathrm{v} / \mathrm{v}$ Aristar $\mathrm{HCl}$ in MilliQ water were also carried through the whole analytical procedure with each set of evaporations to monitor contamination levels.

\section{Analysis by ICP-OES}

All measurements were carried out using an Applied Research Laboratories (ARL) 34000C inductively coupled plasma optical emission spectrometer, with a 44-channel vacuum polychromator, operated under the compromise conditions given in Trafford (1987). A typical analytical programme determines 28 elements simultaneously, using conventional pneumatic nebulization, with an uptake rate of just over $2 \mathrm{ml}$ $\min ^{-1}$.

The ARL $34000 \mathrm{C}$ is fitted with a scanning accessory for multi-element analysis (SAMI), which is linked to the primary slit of the polychromator. Under computer control, the SAMI displaces the primary slit in precise increments, causing the spectrum to move across the secondary slits. In this way, detailed information 
on the spectral structure in the region of each analyte wavelength can be obtained.

In trace element analysis, particular care has to be taken in the interpretation of small signals, and scans obtained with the SAMI are an invaluable aid in this process. The power of the scanning facility is demonstrated for an evaporated acidic surface water which has been scanned around the $\mathrm{Be} 313.04 \mathrm{~nm}$ line (Figures $2 \mathrm{a} \& 2 \mathrm{~b}$ ). At this wavelength, the background has some structure (Figure 2a) and it is not easy to quantify the amount of $\mathrm{Be}$ in the sample. However, if the computer is used to subtract the background signal from the sample signal, the difference scan in Figure $2 \mathrm{~b}$ is produced, showing a clean beryllium peak of about $2 \mu \mathrm{g} \mathrm{I}^{-1}$, which represents a concentration of $0.1 \mu \mathrm{gl}^{-1}$ in the original sample.
Scans in the neighbourhood of analyte lines are also useful when investigating possible spectral interferences (Miles 1987). Stray light from a strong emitter such as calcium can cause a shift in the background signal, as shown in the scan around the yttrium $371.03 \mathrm{~nm}$ line in Figure 3 . The sample is a shallow groundwater which contained about $20 \mathrm{mg} \mathrm{I}^{-1}$ calcium before pre-concentration. The evaporated sample does contain a measurable amount of yttrium, but about one third of the total signal is due to the background shift produced by the $400 \mathrm{mg} \mathrm{I}^{-1}$ calcium present in solution after pre-concentration. The background can be subtracted manually or by computer, leaving a signal of $8 \mu \mathrm{g} \mathrm{I}^{-1}$ yttrium, which represents a concentration of $0.4 \mu \mathrm{g} \mathrm{I}^{-1}$ yttrium in the original solution.

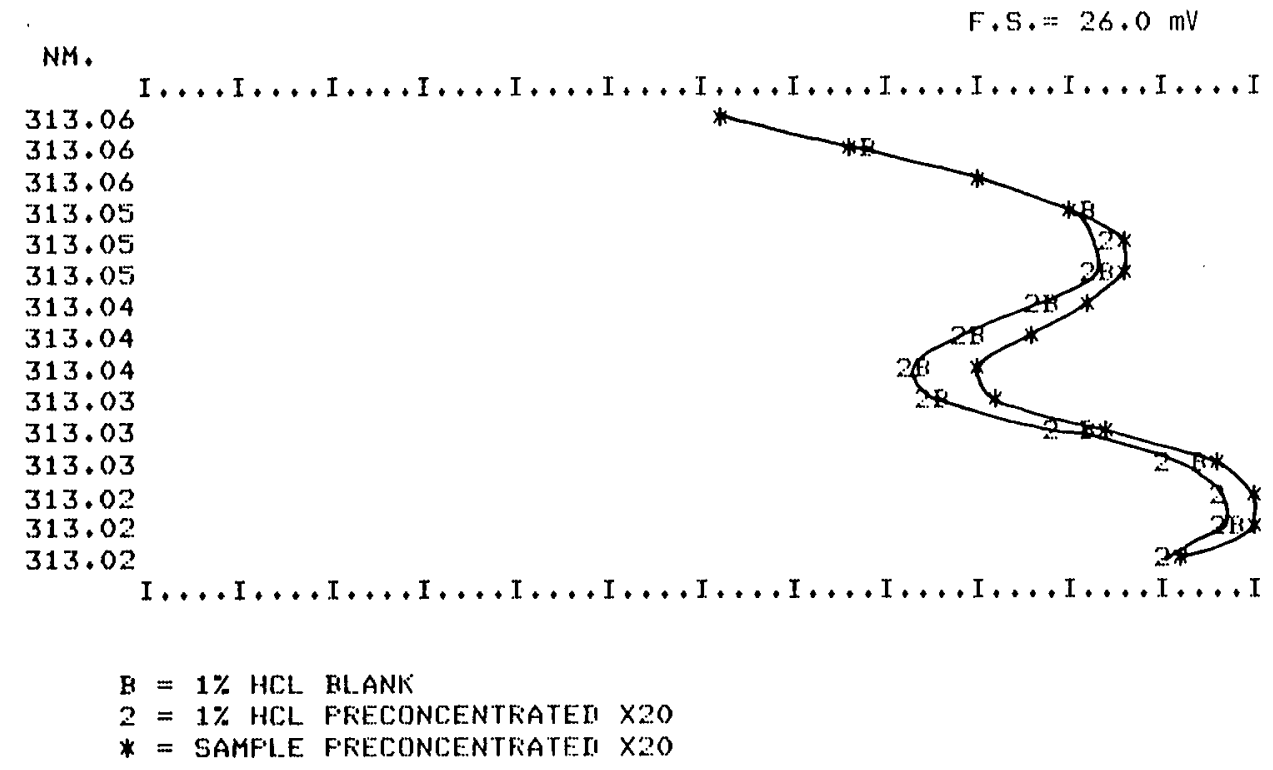

Figure 2a. Scans around the $313.04 \mathrm{~nm}$ beryllium line obtained while aspirating a pre-concentrated acidic surface water and blanks, indicating a small quantity of beryllium present in the pre-concentrated sample

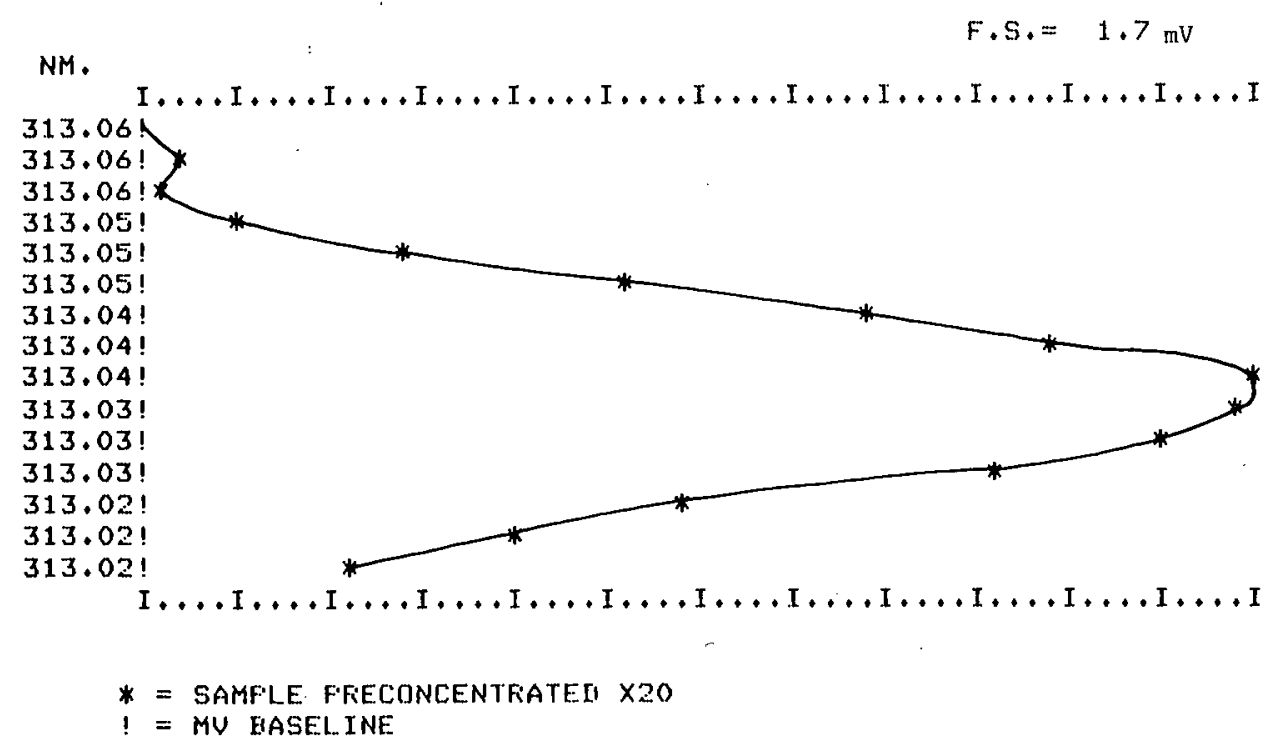

Figure $2 b$. Scan data in Figure $2 a$ displayed in an alternative format by subtracting the blank from the pre-concentrated sample signal to reveal a sharp beryllium peak of about $2 \mu \mathrm{g}^{-1}$ 


\section{Data evaluation}

The blanks which are carried through the preconcentration step are normally low and reproducible but, in spite of all the precautions taken, they always contain small amounts of boron, barium, iron and zinc. A typical iron blank is about $30 \mu \mathrm{g} \mathrm{I}^{-1} \mathrm{Fe}$ and is significant when compared with the iron signal from the preconcentrated sample of rainwater (Figure 4). Such a blank will degrade the ultimate detection limit obtainable, but in practice this is very seldom a limiting factor for most of the waters under investigation.

To assess the recovery of the pre-concentration procedure, a standard solution was analysed before and after pre-concentration. Table 1 shows that the recovery is better than $95 \%$ for a wide range of elements. Typical recoveries are also illustrated by results from surface waters from Loch Fleet, which is situated in a granitic upland catchment in SW Scotland, and is the subject of a multidisciplinary project on acidic deposition and the effect of liming a catchment. Data from this project are shown in Table 2 for elements sensitive enough to be detected both before and after evaporation. The agreement is good and, after pre-concentration, extra confidence can be placed in the second significant figure.

For those elements which cannot be determined directly by ICP-OES, pre-concentration by a factor of 20 permits measurements of several elements well below $1 \mu \mathrm{g} \mathrm{I}^{-1}$ (Table 3). The figures for lead

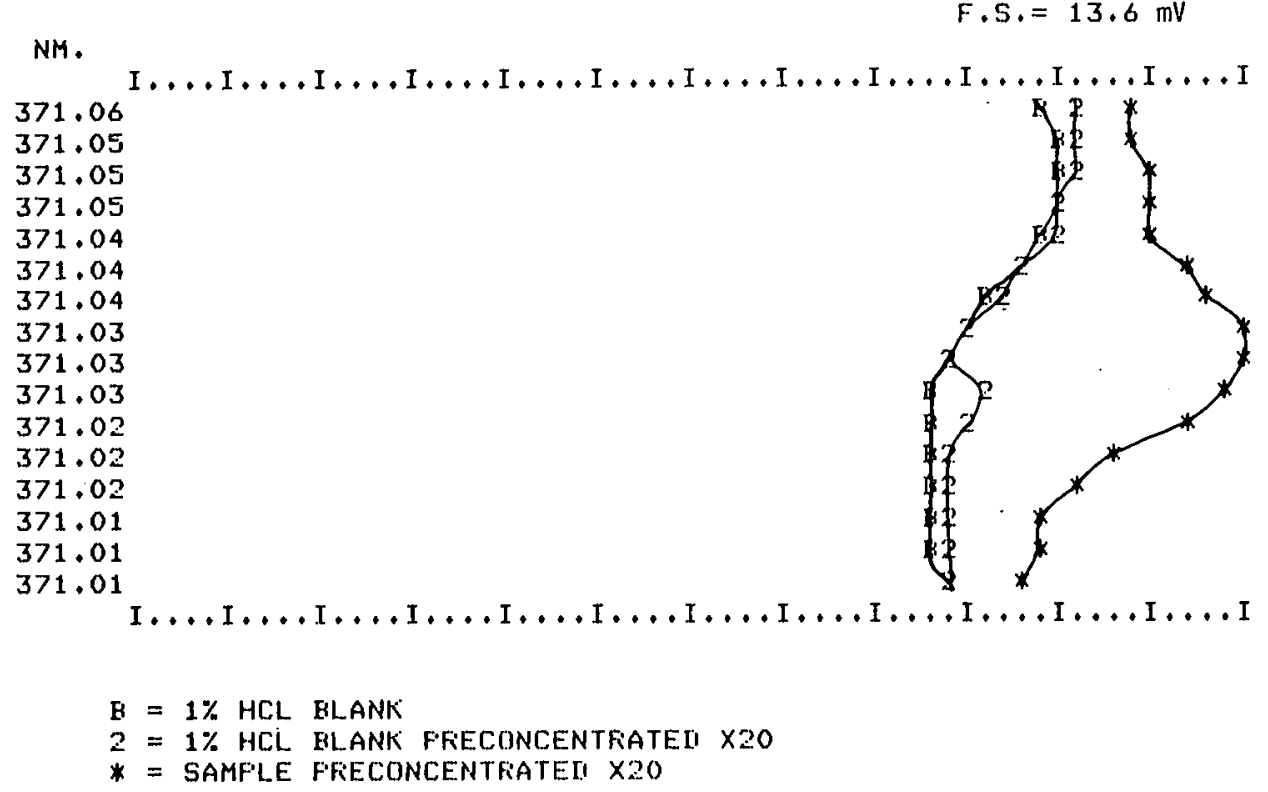

Figure 3. Scan around the $371.03 \mathrm{~nm}$ yttrium line obtained by aspirating a pre-concentrated shallow groundwater, showing the background shift caused by $400 \mathrm{mg} \mathrm{I}^{-1} \mathrm{Ca}$ present in the pre-concentrated sample

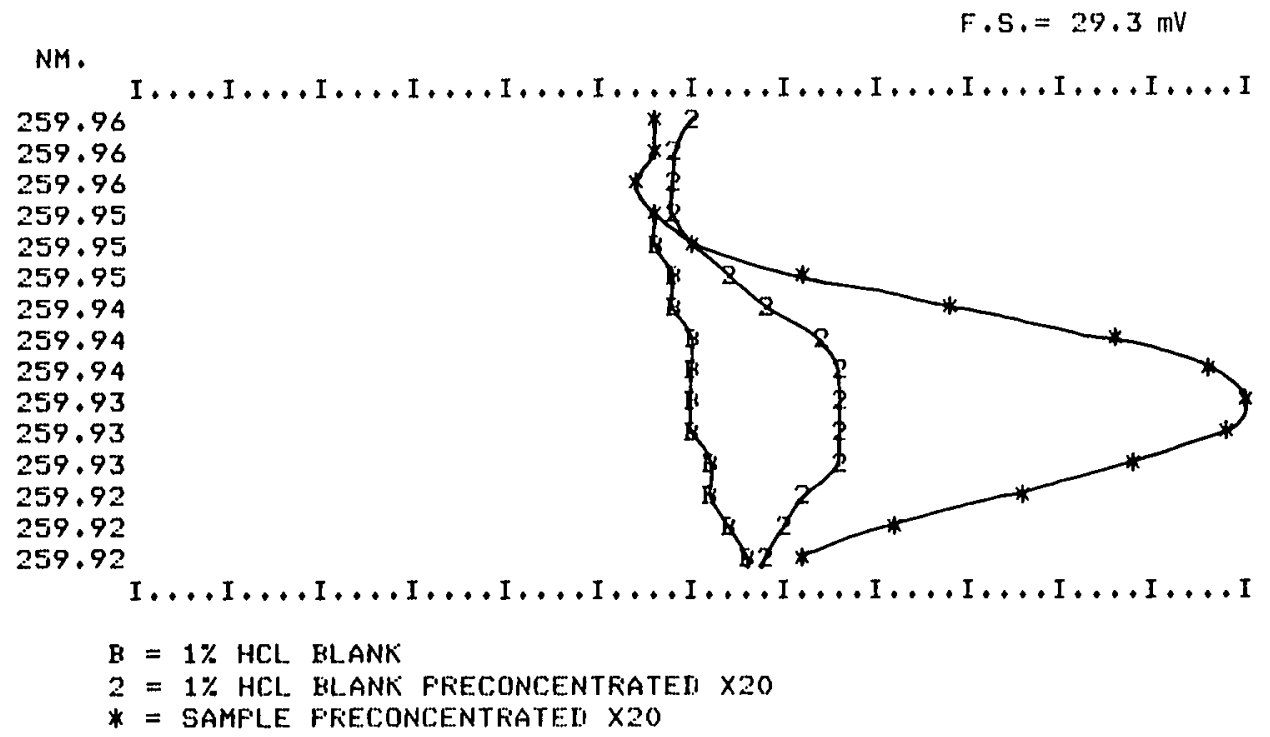

Figure 4. Scan around $259.94 \mathrm{~nm}$ iron line illustrating that a typical pre-concentrated iron blank contains a significant amount of iron compared with a pre-concentrated sample of rainwater 
indicate that the improvement in detection limit is greater than a factor of 20; this is a result of the extra work involved in interpreting the small signals above background, using the scans, which would not be done normally in routine analysis.

Table 1. Recoveries obtained by evaporation of a

\begin{tabular}{lccc}
\multicolumn{3}{c}{ standard solution. Concentrations in $\mu \mathrm{g} \mathrm{I}^{-1}$} \\
\hline Element & $\begin{array}{c}\text { Before } \\
\text { evaporation }\end{array}$ & $\begin{array}{c}\text { After } \\
\text { evaporation } \times 20\end{array}$ & $\begin{array}{c}\% \\
\text { recovery }\end{array}$ \\
\hline $\mathrm{Y}$ & 44 & 846 & 98 \\
$\mathrm{Ba}$ & 48 & 942 & 98 \\
$\mathrm{Mn}$ & 44 & 863 & 98 \\
$\mathrm{Cu}$ & 46 & 873 & 94 \\
$\mathrm{Fe}$ & 44 & 896 & 100 \\
$\mathrm{~V}$ & 47 & 900 & 96 \\
$\mathrm{Cd}$ & 20 & 397 & 99 \\
$\mathrm{Co}$ & 40 & 811 & 101 \\
$\mathrm{Zn}$ & 38 & 765 & 99 \\
$\mathrm{Ni}$ & 154 & 3060 & 99 \\
$\mathrm{Mo}$ & 154 & 3010 & 97 \\
$\mathrm{Al}$ & 178 & 3380 & 93 \\
$\mathrm{~Pb}$ & 163 & 3330 & 102 \\
\hline
\end{tabular}

*All recoveries calculated after blank correction

Table 2. Comparison of major and minor element determinations on samples from Loch Fleet outflow (30.8.85) before and after preconcentration

\begin{tabular}{lcl}
\hline Element & $\begin{array}{c}\text { Original measurement } \\
\left(\mathrm{mg} \mathrm{l}^{-1}\right)\end{array}$ & $\begin{array}{c}\text { After pre-concentration } \\
\left(\mathrm{mg} \mathrm{l}^{-1}\right)\end{array}$ \\
\hline $\mathrm{Na}$ & 4.0 & 4.0 \\
$\mathrm{~K}$ & $<0.5$ & 0.22 \\
$\mathrm{Ca}$ & 0.82 & 0.86 \\
$\mathrm{Mg}$ & 0.52 & 0.56 \\
$\mathrm{SO}_{4}$ & 4.4 & 4.5 \\
$\mathrm{Sr}$ & 0.005 & 0.0052 \\
$\mathrm{Ba}$ & 0.039 & 0.042 \\
$\mathrm{Mn}$ & 0.17 & 0.17 \\
$\mathrm{Fe}$ & 0.13 & 0.13 \\
$\mathrm{Zn}$ & 0.032 & 0.035 \\
$\mathrm{Al}$ & 0.18 & 0.18 \\
\hline
\end{tabular}

Table 3. Comparison of trace element determinations on samples from Loch Fleet outflow (30.8.85) before and after pre-concentration

\begin{tabular}{lcc} 
Element & $\begin{array}{c}\text { Original measurement } \\
\left(\mu \mathrm{g} \mathrm{I}^{-1}\right)\end{array}$ & $\begin{array}{c}\text { After pre-concentration } \\
\left(\mu \mathrm{g} \mathrm{I}^{-1}\right)\end{array}$ \\
\hline $\mathrm{B}$ & $<35$ & 12 \\
$\mathrm{Li}$ & $<10$ & 0.9 \\
$\mathrm{Be}$ & $<1$ & 0.10 \\
$\mathrm{Y}$ & $<2$ & 0.08 \\
$\mathrm{~V}$ & $<20$ & 0.3 \\
$\mathrm{Cu}$ & $<10$ & 1.6 \\
$\mathrm{Ni}$ & $<100$ & 4 \\
$\mathrm{~Pb}$ & $<200$ & 13 \\
\hline
\end{tabular}

Table 4. Chemical data for Loch Fleet inflow and outflow (30.8.85) compared with bulked rain for August 1985

\begin{tabular}{lccc}
\hline Element & $\begin{array}{c}\text { August } \\
\text { rain }\end{array}$ & Inflow & Outflow \\
\hline & \multicolumn{4}{c}{$\mathrm{mg} \mathrm{I}^{-1}$} \\
$\mathrm{Na}$ & 1.3 & 2.5 & 4.0 \\
$\mathrm{Mg}$ & 0.13 & 0.32 & 0.56 \\
$\mathrm{SO}_{4}$ & 1.4 & 2.6 & 4.5 \\
& & $\left.\mu\right|^{-1}$ & \\
$\mathrm{Al}$ & $<5$ & 300 & 180 \\
$\mathrm{Fe}$ & 2.6 & 120 & 130 \\
$\mathrm{Mn}$ & 1.3 & 23 & 170 \\
$\mathrm{Sr}$ & 1.6 & 3.2 & 5.2 \\
$\mathrm{Cu}$ & 1.5 & 1.2 & 1.6 \\
$\mathrm{Y}$ & $<0.05$ & 0.21 & 0.08 \\
$\mathrm{Be}$ & $<0.05$ & 0.06 & 0.10 \\
$\mathrm{Ni}$ & $<1$ & $<1$ & 4 \\
\hline
\end{tabular}

\section{Results}

Representative trace element data obtained using the technique of pre-concentration by evaporation and measurement by ICP-OES from the Loch Fleet catchment are shown in Table 4, as an example of the precision and sensitivity of the method. A selection of the data for the outflow and major inflow to Loch Fleet are compared with those for the bulked rainfall for the same month. Some of the main features of the data generally are the following.

i. Sodium, magnesium and sulphate show a similar proportional increase in concentration between the rain, the major inflow and the outflow.

ii. The aluminium data represent the total fraction less than $0.45 \mu \mathrm{m}$. From several months' data it has been observed that these values for the inflow are variable and usually greater than the concentration in the outflow, whereas the aluminium level in the outflow is normally between 0.18 and $0.19 \mathrm{mg} \mathrm{|}^{-1}$.

iii. For iron, the inflow and outflow concentrations are about the same and there is no apparent trend. In contrast, manganese displays an order of magnitude increase in the outflow over the inflow.

iv. Reliable low level data for strontium have been obtained which show that strontium behaves in a similar manner to many of the major elements.

v. There are similar levels of copper in the rain, inflow and outflow waters indicating that rain is probably the major source of copper in the catchment. 
vi. Traces of yttrium and beryllium are detected, which are probably derived from the granite; there is constantly more yttrium in the inflow than the outflow.

vii. Nickel is always detected in the outflow.

\section{Conclusions}

To obtain reliable trace element data, it is necessary to appreciate the problems which may arise and the precautions which need to be taken all the way through sample collection, sample storage, laboratory analysis and data interpretation. A method of pre-concentrating water samples by simple evaporation prior to analysis by ICP-OES was originally developed for trace element analysis of groundwaters and has been successfully applied to rain- and surface waters.

\section{Summary}

Sample collection, sample storage, laboratory analysis and data interpretation are 4 interdependent stages in the measurement of any environmental sample. Each stage will influence the accuracy and precision of the final result, and this is particularly true when handling natural waters where the elements of interest may be present at well below $1 \mathrm{mg} \mathrm{I}^{-1}$. The problems which arise and the precautions which need to be taken are discussed.

Detection limits obtained by ICP-OES are not sufficiently sensitive to determine some important trace elements directly, and pre-concentration of the sample may be necessary. However, any preconcentration technique used must be applicable to many elements, in order to utilize the multielement capability of the ICP. A method of preconcentrating water samples by simple evaporation under ultra-clean conditions is discussed.

Primary spectroscopic data from a sophisticated computer-controlled instrument such as an ICP require careful interpretation, especially when deciphering small signals close to the detection limit. Typical data on trace element levels in groundwaters and dilute surface waters subject to acidic deposition are presented.

\section{References}

Batley, G.E. \& Gardner, D. 1977. Sampling and storage of natural waters for trace metal analysis. Wat. Res., 11, 745-756.

Danielsson, L.G. 1982. On the use of filters for distinguishing between dissolved and particulate fractions in natural waters. Wat. Res., 16, 179-182.

Gardner, M.J. \& Hunt, D.T.E. 1981. Adsorption of trace metals during filtration of potable water samples with particular reference to the determination of filterable lead concentration. Analyst, Lond., 106, 471-474.

Laxen, D.P.H. \& Chandler, I.M. 1983. Size distribution of iron and manganese species in freshwaters. Geochim. Cosmochim. Acta, 47, 731-741.

Massee, R., Maessen, F.J.M.J. \& De Goeij, J.J.M. 1981. Losses of silver, arsenic, cadmium, selenium and zinc traces from distilled water and artificial sea-water by sorption on various container surfaces. Analytica chim. Acta, 127, 181-193.

Miles, D.L. 1987. The application of inductively coupled plasmas to the analysis of natural waters and acidic deposition. In: Chemical analysis in environmental research, edited by A.P. Rowland, 40-49. (ITE symposium no. 18.) Abbots Ripton: Institute of Terrestrial Ecology.

Miles, D.L. \& Cook, J.M. 1981. Chemical aspects of the collection and evaluation of data on the quality of groundwater. In: Quality of groundwater, edited by W. Van Duijvenbooden, P. Glasbergen \& H. van Lelyveld, 725-731. (Studies in environmental science no. 17.) Amsterdam: Elsevier.

Trafford, J.M. 1987. Investigation of spectral interferences in the determination of trace elements in water by ICP-OES. In: Chemical analysis in environmental research, edited by A.P. Rowland, 56-58. (ITE symposium no. 18.) Abbots Ripton: Institute of Terrestrial Ecology. 


\title{
Investigation of spectral interferences in the determination of trace elements in water by ICP-OES
}

\author{
J M TRAFFORD \\ British Geological Survey, Hydrogeology Research Group, Wallingford
}

\section{Introduction}

Inductively coupled plasma optical emission spectrometry (ICP-OES) is an established technique for the inorganic analysis of waters for major, minor and trace elements. At the British Geological. Survey's (BGS) laboratories at Wallingford, an Applied Research Laboratories $34000 \mathrm{C}$ ICP is at present calibrated for the simultaneous determination of 28 elements in groundwaters; it operates under compromise conditions given in Table 1.

Table 1. Compromise ICP operating parameters for the ARL $34000 \mathrm{C}$

\begin{tabular}{|c|c|}
\hline Spectrometer & $\begin{array}{l}\text { ARL } 34000 C \text { Quantovac; } 1-\mathrm{m} \\
\text { Paschen-Runge mounting; } \\
\text { grating ruled } 1080 \text { lines } \mathrm{mm}^{-1} \\
\text { Primary slit width } 20 \mu \mathrm{m} \\
\text { Secondary slit width range } \\
37.5-75 \mu \mathrm{m}\end{array}$ \\
\hline Frequency & $27.12 \mathrm{MHz}$ \\
\hline Forward power & $1080 \mathrm{~W}$ \\
\hline Reflected power & $0-5 W$ \\
\hline Observation height & $17 \mathrm{~mm}$ above load coil \\
\hline Argon flow rates & $\begin{array}{l}\text { Coolant } 11 \mid \min ^{-1} \text {, plasma } 1.2 । \\
\min ^{-1}, \text { carrier } 1 \mid \min ^{-1}\end{array}$ \\
\hline Sample uptake rate & $2.5 \mathrm{ml} \mathrm{min}^{-1}$ \\
\hline Sample acidity & $1 \% \mathrm{v} / \mathrm{vHCl}$ \\
\hline Nebulizer & $\begin{array}{l}\text { Concentric glass, J E Meinhard } \\
\text { model TR-30-A3 }\end{array}$ \\
\hline Read-out & $\begin{array}{l}\text { Digital read-out of mean signal } \\
\text { from } 310 \text {-second integrations }\end{array}$ \\
\hline
\end{tabular}

The Hydrogeochemistry Section of BGS Wallingford has a particular interest in the occurrence and behaviour of trace elements in groundwaters and surface waters vulnerable to acidic deposition, funded by a major commissioned research contract from the Department of the Environment (DoE) and various science budget projects. Because the natural levels of many elements in these waters are extremely low, a pre-concentration procedure, based on evaporation under infra-red lamps in ultra-clean conditions, has been developed. However, this method of pre-concentration is non-selective and the resulting high concentrations of alkaline-earth elements give rise to spectral interferences. These have been thoroughly investigated and appropriate interelement corrections entered into the instrument's data processing software to minimize their effect.
Normally, the levels of iron in natural waters are low and do not cause any problems. Recently, some iron-rich groundwaters were collected and pre-concentrated. The enhanced iron concentration in this particular set of samples, combined with the fact that iron has a very linerich emission spectrum, made it necessary to investigate its potential spectral interference in the determination of other trace elements.

2 Investigations into spectral interferences caused by high concentrations of iron

Iron solutions of $200 \mathrm{mg} \mathrm{I}^{-1}$ Fe were prepared by dilution from 2 different stock solutions:

\section{i. $1000 \mathrm{mg} \mathrm{l}^{-1} \mathrm{Fe}$ AAS standard (Spectrosol, BDH Chemicals)}

ii. $1000 \mathrm{mg} \mathrm{I}^{-1} \mathrm{Fe}$, prepared by dissolution of $\mathrm{Fe}$ powder (Specpure, Johnson Matthey Chemicals) in Aristar grade $\mathrm{HCl}$.

Scans over small wavelength regions around the spectral lines of interest were obtained by displacing the primary slit in precise increments under computer control.

Wavelength scans of the 2 different Fe solutions were obtained for each of the trace element wavelengths listed in Table 2, and plotted against an appropriate blank. With the BDH solution, peaks were observed at the $\mathrm{Sr}, \mathrm{Cr}$ and $\mathrm{Co}$ lines, whereas the corresponding scans of the Specpure solution were indistinguishable from those of the blank. Figure 1 illustrates the response obtained at the $407.77 \mathrm{~nm} \mathrm{Sr}$ line for both $\mathrm{Fe}$ solutions and shows that significant amounts of $\mathrm{Sr}$ are present as impurities in the $\mathrm{BDH}$ AAS Fe solution. Similar results were

Table 2. Trace elements routinely determined by ICPOES at Wallingford

Element Wavelength $(\mathrm{nm})$ Element Wavelength $(\mathrm{nm})$

\begin{tabular}{llcl}
\hline $\mathrm{Sc}$ & 361.38 & $\mathrm{Cr}$ & 267.72 \\
$\mathrm{Sr}$ & 407.77 & $\mathrm{Ni}$ & 231.60 \\
$\mathrm{Y}$ & 371.03 & $\mathrm{Mo}$ & 202.03 \\
$\mathrm{Ba}$ & 455.40 & $\mathrm{Al}$ & 308.21 \\
$\mathrm{Mn}$ & 257.61 & $\mathrm{~Pb}$ & 220.35 \\
$\mathrm{Be}$ & 313.04 & $\mathrm{Co}$ & 228.62 \\
$\mathrm{Cu}$ & 324.75 & $\mathrm{Zn}$ & 202.55 \\
$\mathrm{~V}$ & 311.07 & $\mathrm{Ce}$ & 380.15 \\
$\mathrm{Cd}$ & 226.50 & $\mathrm{La}$ & 398.85 \\
$\mathrm{Zr}$ & 343.82 & $\mathrm{~B}$ & 249.68 \\
& & $\mathrm{Li}$ & 670.78 \\
\hline
\end{tabular}


obtained for $\mathrm{Co}$ and $\mathrm{Cr}$.

However, for both Fe solutions, peaks of similar intensity were observed near the $\mathrm{Zn}, \mathrm{Zr}, \mathrm{V}$ and $\mathrm{Cd}$ wavelengths, as illustrated by a comparison of the 2 scans at the $266.50 \mathrm{~nm}$ Cd line in Figure 2. A search of various line tables (Brenner \& Eldad 1984; Parsons et al. 1980; Michaud \& Mermet 1982) revealed $\mathrm{Fe}$ lines close to, or coincident with, the $\mathrm{Zn}, \mathrm{Zr}, \mathrm{V}$ and $\mathrm{Cd}$ lines, as shown in Table 3.

Once the existence of spectral interferences from weak $\mathrm{Fe}$ lines at these analyte wavelengths had been established, it was relatively straightforward to calculate apparent concentrations for $\mathrm{Zn}, \mathrm{Zr}, \mathrm{V}$ and $\mathrm{Cd}$ caused by the iron present in the samples (Table 4) and to use these to automatically correct any trace element signals recorded.

Table 3. Wavelengths of interfering Fe lines listed in spectral line atlases

Element Wavelength $(\mathrm{nm})$ Fe line $(\mathrm{nm})$ Reference

\begin{tabular}{llll}
\hline $\mathrm{Zr}$ & 343.82 & 343.83 & 1,2 \\
$\mathrm{Cd}$ & 226.50 & 226.50 & 1 \\
$\mathrm{~V}$ & 311.07 & 311.07 & 1 \\
$\mathrm{Zn}$ & 202.55 & 202.55 & 3 \\
\hline
\end{tabular}

1 Brenner \& Eldad (1984)

2 Parsons et al. (1980)

3 Michaud \& Mermet (1982)

SCAN OF SFECTROSOL FEFRIC NITFATE STANLAREL AFOUND SK $407.77 \mathrm{~nm}$

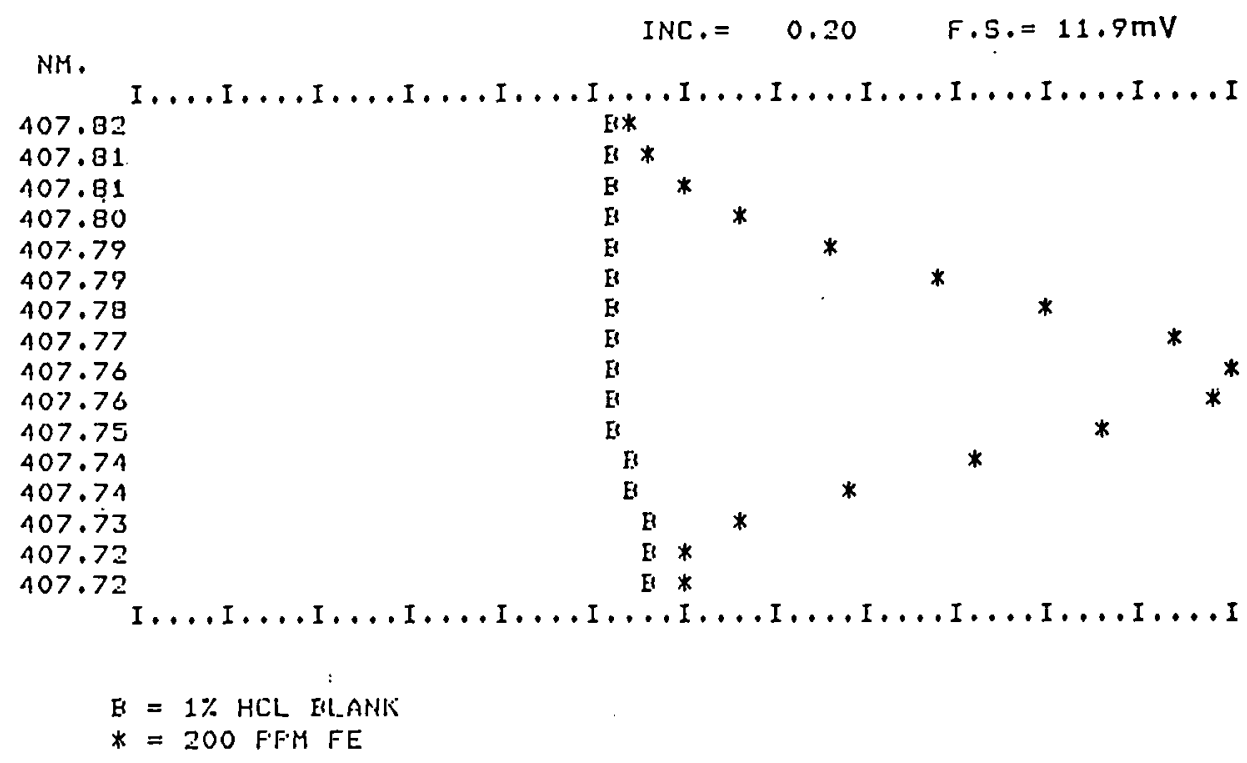

SCAN OF STANIAREI FFEFAFEEI FFOM SFECFURE IFION FOWDER ARIOUND SF: $407.77 \mathrm{~nm}$

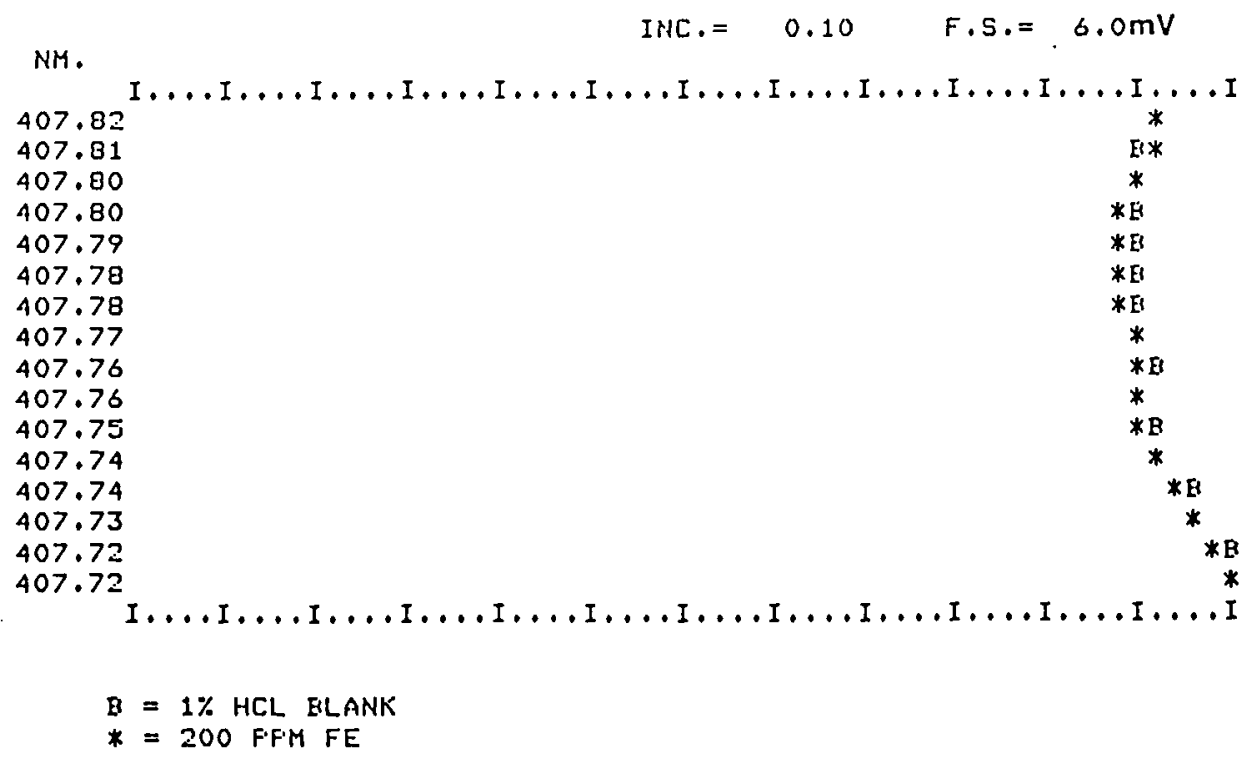

Figure 1. Scans around the $407.77 \mathrm{~nm} \mathrm{Sr}$ line of a $\mathrm{BDH}$ iron solution and a standard prepared from Specpure iron powder reveal that there is a significant strontium impurity in the BDH solution 
Table 4. Apparent analyte concentration caused by the presence of $200 \mathrm{mg} \mathrm{I}^{-1} \mathrm{Fe}$

\begin{tabular}{lc}
\hline Element & Apparent concentration $\mathrm{mg} \mathrm{I}^{-1}$ \\
\hline $\mathrm{Zr}$ & 0.025 \\
$\mathrm{Cd}$ & 0.054 \\
$\mathrm{~V}$ & 0.023 \\
$\mathrm{Zn}$ & 0.023 \\
\hline
\end{tabular}

3 Conclusions

3.1 Comparison of 2 iron standards showed the need for careful selection of contaminationfree stock solutions in multi-element analysis.

3.2 Good line atlases are invaluable as an aid to identifying interfering lines when augmented by spectral scans.

3.3 The effect of sample pre-treatment must be taken into account. Spectral interferences not normally encountered in water analysis by ICP-OES become significant following sample concentration by evaporation.

\section{References}

Brenner, I.B. \& Eldad, H. 1984. A spectral line atlas for multitrace and minor element analysis of geological and ore mineral samples by ICP-AES. ICP Int. NewsI., $10,451-508$

Michaud, E. \& Mermet, J.M. 1982. Iron spectrum in the 200-300 $\mathrm{nm}$ range emitted by an inductively coupled argon plasma. Spectrochim. Acta, 37B, 145-164.

Parsons, M.L., Forster, A. \& Anderson, D. 1980. An atlas of spectral interferences in ICP spectroscopy. New York: Plenum.
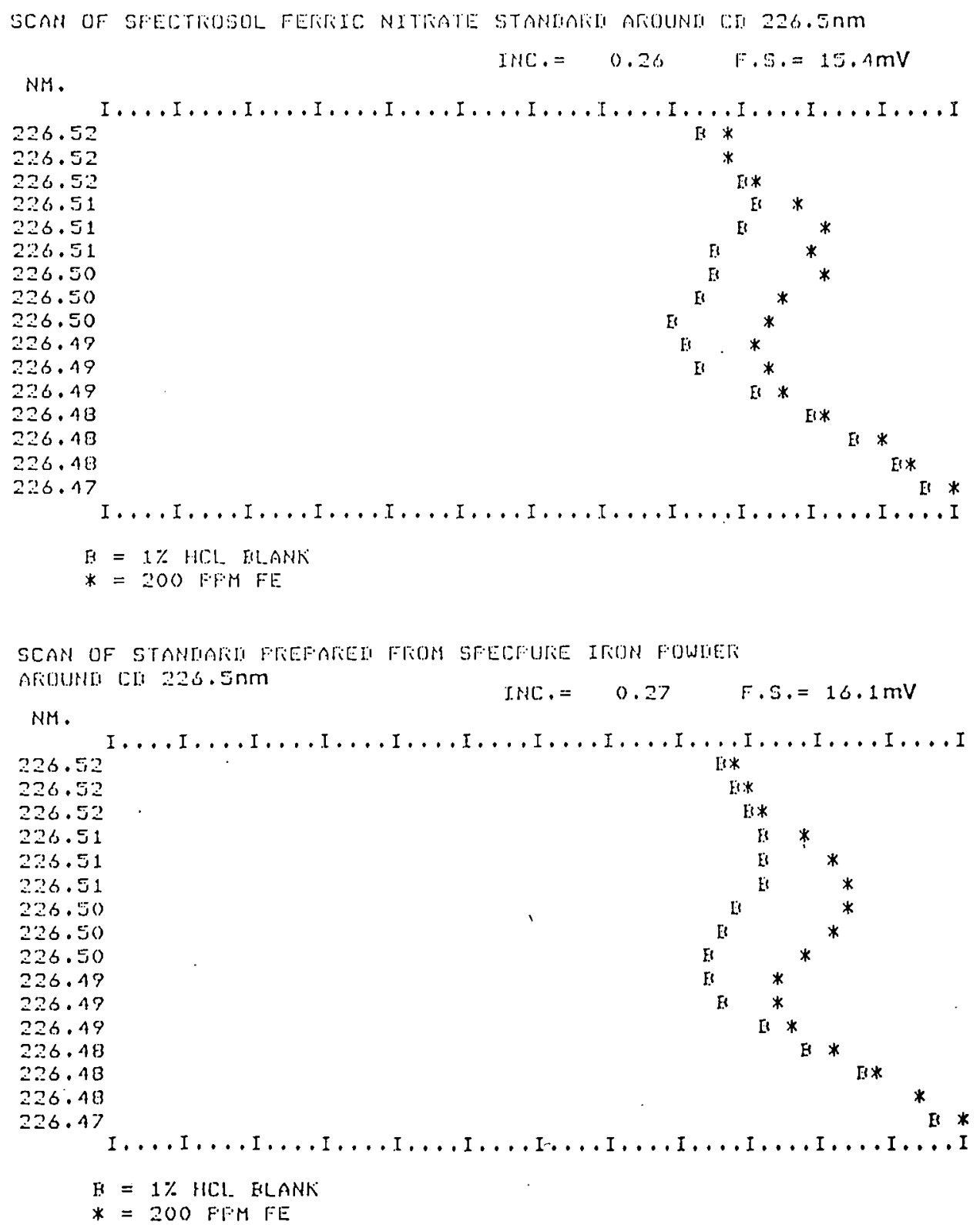

Figure 2. Scans around the $226.50 \mathrm{~nm} \mathrm{Cd}$ line of a $\mathrm{BDH}$ iron solution and a standard prepared from Specpure iron powder give very similar responses. This is due to the presence of a weak iron.line also at $226.50 \mathrm{~nm}$ 


\title{
Chemical sensors for environmental research
}

\author{
TE EDMONDS \\ Department of Chemistry, Loughborough University of Technology, Loughborough
}

\section{Introduction}

Analytical chemistry is an essential part of environmental research. Chemical systems are of great significance in the lithosphere, hydrosphere, biosphere and atmosphere: qualitative and quantitative estimation of these systems is a primary requisite to the understanding of the ecology of each of these areas. Hitherto, the analytical chemistry has been laboratory-based, samples being brought from the field for analysis. Although this arrangement has served the needs of environmentalists adequately for many years, portable analytical techniques that can be taken out to the sample will open up new areas for probing and understanding the environment.

A general class of devices that could provide such a service are the chemical sensors. The term 'chemical sensor' is rather diffuse; just what constitutes a chemical sensor is rather difficult to define. At the very least, it should encompass devices that can carry out an analytical procedure with the minimum of intervention from an operator. In addition, it should be portable and capable of operating in situ. A chemical sensor may be the size of a pinhead or may weigh several kilograms. Its manufacture may be so simple that an ordinary laboratory could produce them (piezoelectric crystal gas monitors are good examples of this type); alternatively, complex manufacturing facilities may be required such as those needed for the production of ion-sensitive FETS. Finally, a chemical sensor may be located anywhere within the environment, from the human blood stream to the bottom of the North Sea.

In spite of the diversity of chemical sensors discussed in the previous paragraph, all chemical sensors have a number of similar characteristics. Somewhere in the sensor is a transducer, that transforms a chemical property of the analyte (usually concentration) into an electrical signal. Some transducers are inherently selective; for example, the LEDs that are used in nondispersive IR gas sensors emit the wavelengths at which the target gas molecules absorb. Other transducers are not selective, and selectivity must be provided by incorporating a piece of selective chemistry into their structure. Often the simplest way to do this is by coating the transducer with a membrane of some form in which the specific chemistry is immobilized. ISEs are an example of this sort of approach. Similarly, all sensors should be rugged devices that respond sensitively and rapidly to the target analyte. A few selected examples of chemical sensors are presented in this paper to give an idea of the range and current status of chemical sensing.

\section{Gas sensing with piezoelectric crystal monitors}

Not only must a chemical sensor respond to a particular molecular species, or group of related compounds, but it must also discriminate between the target analyte and the full range of other chemical species in the immediate environment. In the case of gas or vapour sensors based on piezoelectric crystals, chemical coatings are applied to the crystal in an attempt to introduce some degree of selectivity. Water vapour, which is at a relatively high concentration in the atmosphere, tends to interact in a nonspecific way with these coatings. The aim of this work was to build a system that could be operated at 'realistic' temperatures and humidities, ie a sensor that could be operated in the environment, without the need for thermostatting, removal of water vapour, or frequent calibration. This paper discusses a method of doing this, in which archival data are collected, and used interactively with real-time data, to produce a corrected response to the target analyte (ammonia in this case).

\subsection{Apparatus}

The use of piezoelectric transducers as gas monitors has been described elsewhere (Edmonds \& West 1982) and a review of the field has recently appeared (Alder \& McCallum 1983). Details of the crystals, oscillating circuitry and cell design are presented by Edmonds and West (1982). The cells used in this study were made of stainless steel; a small temperature sensor was located in the base of one of the cells. A 2-stage gas dilution system was used to provide a continuous stream of clean, dry laboratory air which could be suitably loaded with water vapour from a humidifying line, and ammonia from a certified air/ammonia mixture supplied in a pressurized cylinder by Rank Hilger. The humidifier and the detector cells were located in a thermostat water bath. The entire gas rig, the detector cells, humidifier, water bath and Shaw 'Bradford' Yellow Spot humidity probe were enclosed in a constant temperature box. The temperature in this box could be maintained at a constant value with a tolerance of $\pm 0.5^{\circ} \mathrm{C}$. The signal from each of the 2 sensors used in this study was read by a frequency meter (AMF Venner 7737), and was subsequently passed to a 
microcomputer system based on an Intel 80/10B.

\subsection{Results and discussion}

Two sensor crystals were used, one coated with polyvinyl pyrollidone (PVP), and the other with silver chloride. PVP-coated crystals responded rapidly and sensitively to ammonia and water vapour in the gas stream: silver chloride-coated crystals responded to water vapour only. Extensive studies of these 2 sensors were carried out, with a view to using them in tandem for the determination of atmospheric ammonia concentrations. In this work a number of variables were identified that determined the response of the PVP-coated crystals to ammonia. These variables are summarized in Table 1.

Table 1. Variables affecting the response of the PVPcoated crystal to ammonia

Variable Comments

Coating mass The amount of ammonia is a positive of PVP function of the mass of PVP on the crystal. This variable must be accounted for in a real system.

Temperature Both the sorption of water and ammonia were strongly influenced by temperature. An optimum was noted in each case, and no simple relationship was observed. This variable must be accounted for in a real system.

Humidity Not only did the PVP sorb water, but also the amount of ammonia sorbed was decreased for a given gas stream concentration, indicating some competition for sites between the 2 species. This variable must be accounted for in a real system.

Flow rate

The response to ammonia was a complex function of the flow rate of the carrier gas through the detector cells. In a portable system this variable could be held at a constant value.

Clearly, to build a sensor system that could be operated in the real world, the response from the PVP-coated crystal needed to be corrected for the variables shown in Table 1. Such a system could only be constructed around the processing power of a microcomputer, in which real-time data from various sensors could be used with archival data generated at an earlier stage, to produce a corrected response from the PVP-coated crystal. This, indeed, was our approach. In some instances, we were able to write a simple algorithm that related to the response of the crystal to a variable, eg coating mass. In other cases, the relationship between the variable and the response was far from clear. Under these circumstances, look-up tables were constructed in the microcomputer's firmware. These tables contained, for example, the response versus concentration profile for ammonia at various temperatures at a PVP-coated crystal. The data used for these algorithms and look-up tables were generated over a period of time and for a range of conditions. Wherever possible, the individual data points represented the mean of many readings, the intention being to generate a true archival data set. Once this data set had been generated, it could be used with real-time data from the other sensors in the system (temperature probe readout, and response from the silver chloride-coated crystal), and the coating mass of the PVP crystal to generate from the response of the PVP-coated crystal a value for the concentration of ammonia.

There are several stages involved in calculating the ammonia concentration from the response of the PVP-coated crystal. First, the response is corrected for the additive effect of water vapour. Real-time data from the silver chloride-coated crystal and the temperature probe are used here, in conjunction with archival data relating the response of the 2 different piezoelectric sensors to water vapour. This procedure also generates data that can be used to assess how much water has been sorbed by the PVP coating, and hence to calculate a correction factor for the diminished sorption of ammonia that occurs in the presence of water sorption. The coating mass is then used to correct for the variation in response that arises for different coating masses. Finally, the temperature is used again, along with the water vapour and mass-corrected response from the PVP-coated crystal, to select an appropriate value for the ammonia concentration from the look-up table. Results from such a set of calculations are shown in Table 2.

Table 2. Results for the determination of ammonia at a PVP-coated crystal

\begin{tabular}{lcc}
\hline $\begin{array}{l}\text { Sample } \\
\text { concentration ppb }\end{array}$ & $\begin{array}{c}\text { Analysed } \\
\text { concentration ppb }\end{array}$ & $\begin{array}{c}\% \\
\text { difference }\end{array}$ \\
\hline 100 & 100 & 0 \\
480 & 286 & 41 \\
4000 & 4400 & 10 \\
4000 & 3625 & 9.5 \\
400 & 370 & 8.3 \\
1000 & 800 & 20 \\
9 & 10 & 10 \\
1000 & 598 & 40 \\
--- & --- \\
4320 & 6 & - \\
300 & 6 & - \\
100 & 6 & - \\
480 & 6 & - \\
\hline
\end{tabular}

\subsection{Conclusions}

The results in the first part of the Table are acceptable: a wide range of ammonia 
concentrations are adequately assessed at various humidities and several temperatures. In the second part of the Table, one of the results was obtained for a freshly prepared crystal, the other for a crystal at the end of its working life (approximately one month for a PVP-coated crystal and 3 months for a silver, silver chloridecoated crystal). A variable that has not been accounted for in this system is ageing of the coating. This is a complex phenomenon, that alters the PVP-crystal's response to both ammonia and water vapour. All the archival data were obtained for crystals in between the 2 age extremes, as were the results in the first part of the Table. The final 2 results in the Table are not explicable.

There is a need to improve and refine the methods that have been used. The effect of coating ageing should be included, as well as applying a coating mass and temperature correction to the response of the silver chloride crystal before using it for water vapour correction. Not only should a wider range of data be used for this work, but more sophisticated methods of processing the data should be tried.

$3 \mathrm{pH}$ measurement with low-cost fibre optic chemical sensors

Fibre optic probes are chemical sensors, but, compared to, say, piezoelectric crystals or ionsensitive electrodes, the overall chemical transducer is rather complicated. The fibre optic probe is a complex transducer consisting of 2 optical/electronic arrangements associated with the light source and the signal detector. However, a workable fibre optic probe can be constructed using much simpler light source and detector systems than have been employed hitherto.

\subsection{Apparatus}

In keeping with the objective of simplicity and low cost, step-index polymer cable consisting of a polymethyl methacrylate core with fluorinated polymer cladding was selected. The core/ cladding diameter $(1.00 \mathrm{~mm})$, numerical aperture (0.47) and attenuation (150 dB kM at $600 \mathrm{~mm}$ ) render this cable unsuitable for transmission of data over long distances (on account of both the attenuation and the modal dispersion), but for short lengths of cable (in this case less than 50 $\mathrm{cm}$ ) the cable is adequate. An obvious source to use was a light-emitting diode (LED). LEDs exhibit a virtually linear relationship between radiated power and forward current, and this, coupled with their rapid rise time (typically 100 ns), simplifies the design of the power supply (an appropriate voltage source and limiting resistor is adequate) and obviates the need for mechanically chopping the light, should a pulsed system be desirable. In this work, a Honeywell 'Sweetspot' diode was used with a peak emission wavelength of $665 \mathrm{~nm}$ and a bandwidth of $22 \mathrm{~nm}$. The LED was run at a continuous forward current of $50 \mathrm{~mA}$. The bandwidth is typical of surface-emitting LEDs; edge-emitting devices may have a narrower band pass. The 'Sweetspot' range of optoelectric devices is designed to couple with fibre optic system via 'DNP' connectors. The relatively narrow bandwidth and ease of coupling to fibre optic cables are 2 further advantages of LEDs. On the debit side, the emitted power of an LED is subject to variation due to both ageing effects and temperature, and the restricted range of wavelengths available is a severe limitation too. The detector was a 'Sweetspot' PIN photodiode. In common with most devices of this type, the diode is sensitive to light throughout the visible region and the near infra-red, but is relatively more sensitive at longer wavelengths. When the diode is reverse-biased, it-acts as a high impedence variable current source, the current being a linear function of the intensity of light incident on its active surface. The circuitry for amplifying this signal is straightforward, consisting of a JFET operational amplifier configured as a current to voltage converter with a gain of $10^{6}$.

\subsection{Probe design}

All the probes that were used consisted of independent source and detector optical fibres, brought into close physical contact at the sensor end. The sensor consisted of an immobilized zone of coloured indicator. Two methods were used for immobilization: sorption of the indicator on to XAD-2 beads (cross-linked styrene divinyl benzene copolymer) (Kirkbright et al. 1984a, b); and incorporation of the indicator into a porous membrane such as 'collodion' (cellulose nitrate), usually with $5 \mu \mathrm{m}$ beads of XAD-2 to improve the
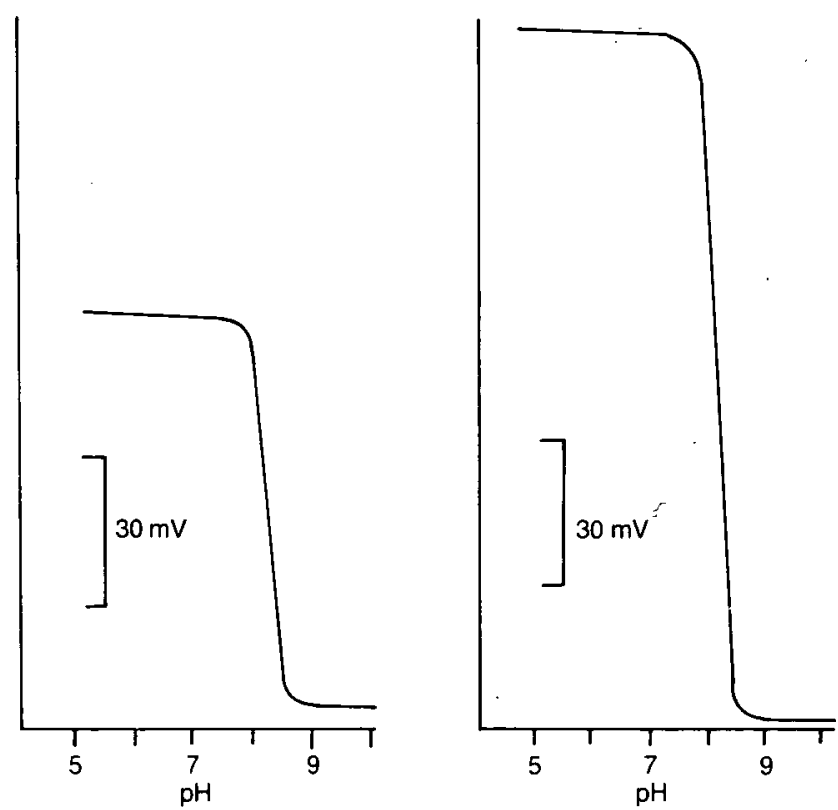

Figure 1. $\mathrm{pH}$ response of collodion membrane probes 
light scattering in the membrane. The target in this work was fabrication of a device that would respond to $\mathrm{pH}$ in the 'environmental' range of 4.0-8.0. Bromothymol blue was chosen as the indicator, having a $\lambda \max$ at $620 \mathrm{~nm}$ and $\mathrm{pH}$ transition interval from 6.0 to 7.6. Typical responses to $\mathrm{pH}$ for collodion membrane sensors are shown in Figure 1. Two facts are immediately obvious from these curves. First, the $\mathrm{pH}$ transition range is not in the 6.0-7.5 region, but takes place some $1.5 \mathrm{pH}$ units later. This is not unexpected; a shift in the value of $\mathrm{pH}$ transition region, and/or a shift in the absorption spectrum, due to absorption of indicator on to colloids, is well known (Klotz 1947), and has been deliberately used to improve spectrophotometric methods (Dagnall et al. 1967). The variation in response for the 2 probes also comes as no surprise. Conservative calculations indicate that less than $0.5 \%$ of the incident light is reflected back along the detector fibre, and this inefficiency, coupled with the rather rudimentary probe design, is bound to lead to poor probe-to-probe irreproducibility. The time taken to reach an equilibrium response is a function of membrane thickness (see Table 3).

One of the probes was tested for reproducibility by taking readings in buffers of $\mathrm{pH} 4.0,7.0$ and 10.0 respectively. The results are shown in Table 4.

We have investigated the effect of immobilization on $\lambda$ max and the $\mathrm{pK}_{\text {ind }}$ of a range of $\mathrm{pH}$ indicators. The results are summarized in Table 5 .

\subsection{Conclusions}

The simple low-cost system described here has demonstrated that low-cost fibre optic chemical sensors may be constructed. Clearly, a number of features need to be improved, not least being the probe design, both from the point of view of efficiency and reproducibility. The source and detector electronics should be pulsed and tuned respectively to enable the discrimination of the chemical signal from the ambient light. (All the work reported here was carried out with the sensor in a light-tight box.) Reproducibility and drift in the system should be investigated more rigorously, but a reference channel (ie a green LED) should improve the system performance here. Perhaps the most interesting

Table 3. Response time of fibre optic pH probe for different membrane thicknesses

\begin{tabular}{lc}
\hline $\begin{array}{l}\text { Membrane } \\
\text { thickness } \\
(\mathrm{mm})\end{array}$ & $\begin{array}{c}\text { Response } \\
\text { time } \\
(\mathrm{min})\end{array}$ \\
\hline 3 & 30 \\
2 & 15 \\
1 & 7.5 \\
\hline
\end{tabular}

Table 4. Reproducibility of fibre optic $\mathrm{pH}$ probe

\begin{tabular}{lrrrr}
\hline Buffer & \multicolumn{4}{c}{ Response to $\mathrm{pH}(\mathrm{mV})$} \\
solution $\mathrm{pH}$ & 1 & \multicolumn{1}{c}{ M } & \multicolumn{1}{c}{3} & \multicolumn{1}{c}{ Mean } \\
\hline 4.0 & 138.0 & 140.0 & 139.0 & $139.8 \pm 1.2$ \\
7.0 & 137.8 & 137.7 & 137.5 & $137.7 \pm 0.2$ \\
10.0 & 66.0 & 67.6 & 67.8 & $67.1 \pm 1.1$ \\
\hline
\end{tabular}

Table 5. Effects of immobilizing $\mathrm{pH}$-sensitive indicators

\begin{tabular}{|c|c|c|c|c|c|c|}
\hline Indicator & Form & $\begin{array}{l}\text { Colour change } \\
\text { (increasing } \mathrm{pH} \text { ) }\end{array}$ & $\begin{array}{l}\lambda \max \\
(\mathrm{nm})\end{array}$ & $\begin{array}{l}\triangle \lambda \max \\
(\mathrm{nm})\end{array}$ & $\mathrm{pK}_{\text {ind }}$ & $\Delta \mathrm{pK}_{\text {ind }}$ \\
\hline Methyl red & $\begin{array}{l}\text { Aqueous/methanolic } \\
\text { immobilized }\end{array}$ & $\begin{array}{l}\text { Red-yellow } \\
\text { Red-yellow }\end{array}$ & $\begin{array}{l}525 \\
540\end{array}$ & +15 & $\begin{array}{l}5.1 \\
8.7\end{array}$ & +3.6 \\
\hline Bromothymol blue & $\begin{array}{l}\text { Aqueous/methanolic } \\
\text { immobilized }\end{array}$ & $\begin{array}{l}\text { Yellow-blue } \\
\text { Yellow-blue }\end{array}$ & $\begin{array}{l}616 \\
620\end{array}$ & +4 & $\begin{array}{l}7.2 \\
10.9\end{array}$ & +3.7 \\
\hline Bromocresol green & $\begin{array}{l}\text { Aqueous/methanolic } \\
\text { immobilized }\end{array}$ & $\begin{array}{l}\text { Yellow-blue } \\
\text { Yellow-blue }\end{array}$ & $\begin{array}{l}616 \\
615\end{array}$ & +1 & $\begin{array}{l}4.6 \\
4.6\end{array}$ & 0 \\
\hline Bromophenol blue & $\begin{array}{l}\text { Aqueous/methanolic } \\
\text { immobilized }\end{array}$ & $\begin{array}{l}\text { Yellow-purple } \\
\text { Yellow-royal blue }\end{array}$ & $\begin{array}{l}590 \\
600\end{array}$ & +10 & $\begin{array}{l}4.0 \\
4.6\end{array}$ & +0.6 \\
\hline Phenol red & $\begin{array}{l}\text { Aqueous/methanolic } \\
\text { immobilized }\end{array}$ & $\begin{array}{l}\text { Yellow-red } \\
\text { Yellow-red }\end{array}$ & $\begin{array}{l}560 \\
580\end{array}$ & +20 & $\begin{array}{l}7.7 \\
9.0\end{array}$ & +1.2 \\
\hline Cresol red (1) & $\begin{array}{l}\text { Aqueous/methanolic } \\
\text { immobilized }\end{array}$ & $\begin{array}{l}\text { Pink-yellow } \\
\text { Pink-yellow }\end{array}$ & $\begin{array}{l}520 \\
540\end{array}$ & +20 & $\begin{array}{l}1.0 \\
4.3\end{array}$ & +3.3 \\
\hline Cresol red (2) & $\begin{array}{l}\text { Aqueous/methanolic } \\
\text { immobilized }\end{array}$ & $\begin{array}{l}\text { Yellow-red } \\
\text { Yellow-red }\end{array}$ & $\begin{array}{l}570 \\
590\end{array}$ & +20 & $\begin{array}{l}8.1 \\
9.1\end{array}$ & +1.0 \\
\hline
\end{tabular}


conclusion from this work is that there is every possibility of modifying the chemistry of the sensor to suit the rather restricted wavelength range available from commercial LEDs. Thus; acid-base indicators whose $\mathrm{pH}$ transition seemed too low for the production of an 'environmental' $\mathrm{pH}$ probe may yet be of use, because of the shift of $\mathrm{pK}_{\text {ind }}$ arising from immobilization in a membrane. A concomitant shift in the $\lambda$ max also makes the choice more appropriate. We noted a more extended $\mathrm{pH}$ response when the indicator was incorporated in a membrane in which amine groups were known to be present in significant numbers. Our interpretation of this finding is that some form of buffering occurs within the membrane. If this is so, then other exciting possibilities are opened up for tuning the chemistry of the system.

\section{4 lon sensing with coated wire electrodes}

Ion-sensitive electrodes represent a relatively mature sensor technology, and their applications in soil, plant and food analysis are legion. In spite of their frequency of use, these devices (ISES) suffer from some serious problems, not least being their lack of selectivity. Other problems include drift and deterioration of electrode performance with time, both these effects leading to the frequent need to recalibrate the electrode. A related type of sensor exhibits similar disadvantages, but has the singular merits of being small and disposable. Consequent upon this, the whole design philosophy of chemical monitoring is altered. Instead of frequent and often labour-intensive recalibrations, the monitoring system can switch from one sensor to another, as the end of the reliable calibration lifespan of the sensor is approached. An alternative strategy concerns the use of the sensor as a oneshot disposable probe for situations where sample integrity must be maintained and/or cross-contamination avoided.

The device concerned is the coated wire electrode (CWE). Essentially, it could be viewed as a simplified ISE in which the internal reference electrode and filling solution have been eliminated. CWEs may be fabricated by simply coating a metal conducting wire with an appropriate membrane-forming material (such as PVC) in which a suitable receptor system is located. Typical receptor systems include: valinomycin for potassium ions (Cattrall et al. 1974); sodium, ammonium or potassium salts of tetraphenylborate for ammonium ions (Hopirtean \& Stefaniga 1976); Aliquat 336S (suitably prepared as the salt of the target anionic species) for detergent and simple anionic species such as nitrate (Fujinaga et al. 1974; Kneebone \& Freiser 1973). More recently, the PVC membrane has been omitted, and sensor species such as antigens or antibodies, or polymer films, have been coated directly on to the wire (Solsky 1982; Heineman et al. 1980). A review of CWEs has recently appeared in Cattrall and Hamilton (1984).

CWEs suffer from 2 distinct problems, not shared by their more conventional counterparts. There is an absence of a formal thermodynamically describable internal reference system. In conventional ISEs, the potential that develops across the sensing membrane is sensed by, and measured with respect to, 2 reference electrodes, one internal and one external to the electrode. The measured potential for the entire system can then be thought of as containing 2 components. An analyte-activity-insensitive potential, which is assumed constant for all measurements, arises from the potentials of the reference systems and other sources. The analytically significant signal arises from the boundary potentials at the 2 membranes solution interfaces, and any diffusion potential caused by variation of the counter ion concentration through the membrane. In the CWE, the former potential is determined by the well-defined potential of the external reference electrode, and by a rather loosely defined system that arises at the internal metal/membrane interface. This is of less consequence when compared to the second problem associated with CWEs: their response is sensitive to the mole fraction of receptor species in the membrane. To a first approximation, this is not so for ISEs, and has the implications that the response of a CWE will drift as reagent is leached from the membrane. This response will be accentuated for some electrodes at low concentrations of the primary analyte ion. In addition, the response of a CWE will be a function of the degree of water absorption from the analyte solution.

\subsection{Apparatus}

The coated wire electrodes were prepared by an adaptation of a method proposed by Freiser (1980). A piece of copper wire approximately $6 \mathrm{~cm}$ long was cut, and one end was 'sanded' smooth with fine-grade emery paper. The wire was then washed with laboratory detergent and water, thoroughly washed with distilled water, and dried with acetone. It was then rinsed with chloroform and allowed to dry.

The wire was hung in a vertical position; the smooth end of the wire was dipped rapidly in the coating solution several times, and the film of the coating solution left on the wire was allowed to dry in air for about 30 seconds. This dipping and drying procedure was repeated until a plastic bead approximately $2 \mathrm{~mm}$ in diameter was obtained. This bead was allowed to dry in air for about 30 minutes; the exposed part of the wire was wrapped in 'Vitafilm' (Goodyear) and the sensor bead was placed to soak overnight in a $10^{-1} \mathrm{M}$ solution of a nitrate salt (usually sodium). 
After soaking, the electrode tip was washed with distilled water, dabbed dry with a tissue,. and was then ready for use.

Electrodes incorporating 3 basic types of electroactive material were tested:

i. quaternary ammonium salts based on large organic groups

ii. transition metal-organic ligand complexes

iii. nitron-nitrate precipitate.

i. Two different commercially available quaternary ammonium salts were used:

Tetradodecyl ammonium bromide (Fluka) Aliquat $336 \mathrm{~S}$ (Tricaprylmethyl ammonium
chloride) (Aldrich)

ii. The transition metal-ligand complexes tris (1,10-phenanthroline), iron (II) nitrate (Cattrall et al. 1974), bis (neocupreine) copper (I) nitrate (Hopirtean \& Stefaniga 1976), Nickel (II) biquinolyl nitrate (Fujinaga et al. 1974) and tris (2,2-Bipyridyl) nickel (II) nitrate were prepared from the appropriate metal salts and chelating agents, as described in the literature. These complexes were characterized, where possible, by their UV-visible absorption spectra.

iii. The precipitate of nitron-nitrate was prepared from commercially available nitron (1,4diphenyl-4,5-dihydro-3,5-phenylimino-1,2,4triazole hydroxide, inner salt) (BDH chemicals) and a solution of a nitrate salt as described in the literature (Cope \& Barab 1917; Collins 1907).

The electrode coating solutions were prepared by dissolving the electroactive material in tetrahydrofuran (or cyclohexanone) along with polyvinyl chloride powder (ICl) and a suitable plasticizer (a dialkyl phthalate) if required.

All potential measurements were made on a Radiometer PHM 64 digital pH meter against an EIL saturated calomel reference electrode. The measurements were made in unstirred standard solution at ambient temperature (which was recorded).

Nitrate standards were prepared by the serial dilution of a $10^{-1} \mathrm{M}$ stock solution made up with analytical reagent grade sodium nitrate in distilled water. All nitrate standards were made up in $10^{-1} \mathrm{M}$ potassium dihydrogen orthophosphate solution, which has the effect of keeping the ionic strength of the standard solutions constant, and thus allows the calibration of the electrode directly in concentration units.
4.2 Results and discussion

4.2.1 Calibration

The responses of the electrodes constructed were measured in standard solutions containing $10^{-1} \mathrm{M}$ nitrate. As the phosphate ions present in the standards do not contribute to the potential produced by the electrode, the response of the electrodes in the standard nitrate solutions can be described by a form of the Nernst equation, ie

$E=E^{*}-2.303 \frac{R T}{F} \log \left(\mathrm{NO}_{3}^{-}\right)$

where $E^{*}$ is a constant which depends on the type of external reference electrode chosen, internal metallic conductor and electroactive material used. $\mathrm{R}, \mathrm{T}$ and $\mathrm{F}$ all have their usual meaning.

Calibration curves were thus obtained by plotting the potential $E$ (millivolts) against the negative logarithm of the nitrate ion concentration ( $p$ $\mathrm{NO}_{3}{ }^{-}$). The best response characteristics were shown by electrodes incorporating the 2 quaternary ammonium salts as ion exchangers.

Thus, tetradodecyl ammonium bromide (TDDAB)based electrodes having the membrane composition: 4\% TDDAB, 29\% PVC powder and $67 \%$ di-n-butyl phthalate platicizer in tetrahydrofuran, showed a linear range of $10^{-1} \mathrm{M}$ to $10^{-5} \mathrm{M}$ nitrate, with an electrode slope (found by the least squares method) of between $90 \%$ and $95 \%$ of the theoretical response (see Figure 2).

\subsubsection{Selectivity}

The effect of the following anions, $\mathrm{Cl}^{-}, \mathrm{Br}^{-}, \mathrm{I}^{-}$, $\mathrm{SO}_{4}{ }^{2-}$ and $\mathrm{NO}_{2}^{-}$, was investigated using the mixed solution method (Method III of Srinivason \& Rechnitz 1969). The effects were measured at $10^{-1} \mathrm{M}$ and $10^{-3} \mathrm{M}$ levels of $\mathrm{NO}_{3}^{-}$and $10^{-1} \mathrm{M}$ levels of interferent. The results are shown in Table 6 . The selectivity coefficients compare well with those obtained for commercial electrodes.

Table 6. TDDAB-based electrode: selectivity coefficients

\begin{tabular}{|c|c|c|c|}
\hline Interferent, X & 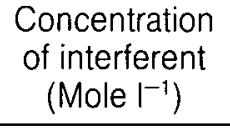 & $\begin{array}{l}\text { Concentration } \\
\text { of nitrate } \\
\left(\text { Mole }\left.\right|^{-1} \text { ) }\right.\end{array}$ & $\mathrm{K}_{\mathrm{NO}_{3},} \mathrm{X}$ \\
\hline $\mathrm{Cl}^{-1}$ & $10^{-1}$ & $10^{-1}$ & $3.96 \times 10^{-3}$ \\
\hline $\mathrm{Cl}^{-1}$ & $10^{-3}$ & $10^{-3}$ & $3.39 \times 10^{-3}$ \\
\hline $\mathrm{NO}_{2}^{-}$ & $10^{-1}$ & $10^{-1}$ & $6.10 \times 10^{-2}$ \\
\hline $\mathrm{NO}_{2}^{-}$ & $10^{-1}$ & $10^{-3}$ & $6.14 \times 10^{-2}$ \\
\hline $\mathrm{NO}_{2}^{-}$ & $10^{-3}$ & $10^{-3}$ & $6.10 \times 10^{-2}$ \\
\hline $\mathrm{SO}_{4}^{2-}$ & $10^{-1}$ & $10^{-3}$ & $1.39 \times 10^{-3}$ \\
\hline $\mathrm{Br}^{-4}$ & $10^{-1}$ & $10^{-1}$ & 0.218 \\
\hline $\mathrm{Br}^{-}$ & $10^{-1}$ & $10^{-3}$ & 0.225 \\
\hline $\mathrm{Br}^{-}$ & $10^{-3}$ & $10^{-3}$ & 0.213 \\
\hline $1^{-}$ & $10^{-1}$ & $10^{-1}$ & 10.3 \\
\hline $1^{-}$ & $10^{-1}$ & $10^{-3}$ & 10.6 \\
\hline j & $10^{-3}$ & $10^{-1}$ & 9.94 \\
\hline $1^{-}$ & $10^{-3}$ & $10^{-3}$ & 10.2 \\
\hline
\end{tabular}


4.2.3 Long-term stability and time-dependent response

The TDDAB electrodes were immersed in a $10^{-2} \mathrm{M}$ nitrate solution, and the $\mathrm{mV}$ response measured over a period of 6 days. After an initial rapid drop of around $10 \mathrm{mV}$ in the first 30 hours, the electrode response stabilized, and showed a $-1 \mathrm{mV}$ change in the next 5 days. Electrodes that were made and then stored in a dry condition for 3 months were reactivated by soaking in $10^{-1} \mathrm{M}$ nitrate solution for $30 \mathrm{~min}$. The performance of these electrodes was similar to those that were freshly made.

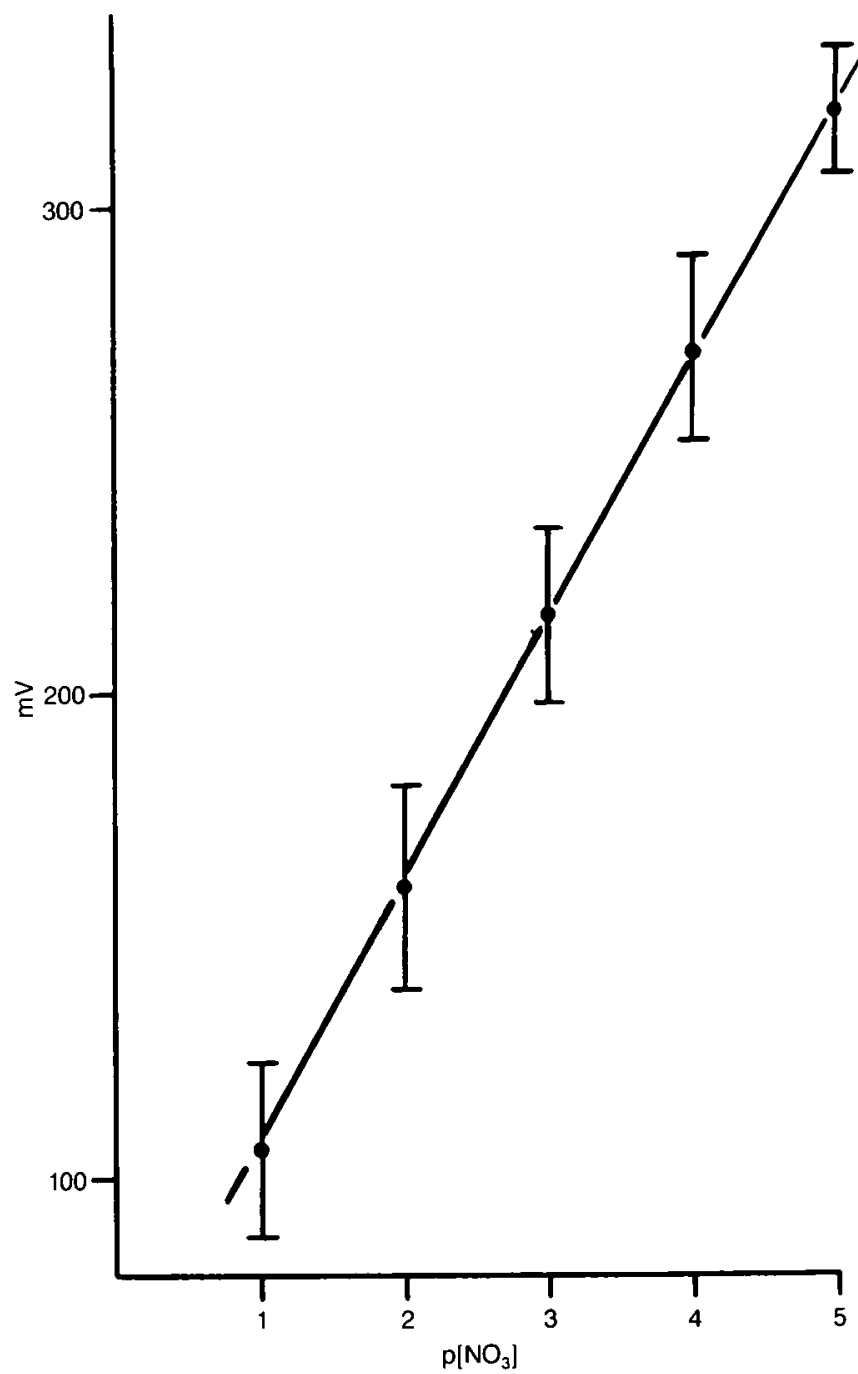

Figure 2. Response of 13 coated wire electrodes to $\mathrm{NO}_{3}^{-}$. Solid line represents the average response, the error bars are \pm one standard deviation. Individual slopes ranged from 53.4 to $55.6 \mathrm{mV}$ per decade, and correlation coefficients from 0.9998 to 1.000

\subsection{Conclusions}

Certainly within the limits of the very simple experiments that have been carried out, CWEs look like promising devices. The results of Figure 2 are temperature-corrected, but otherwise undoctored for 13 different electrodes that were made on 3 different dates. No attempt has been made to provide internal reference system for these electrodes. (A range of these are suggested, including coating a silver wire with a bead of $\mathrm{AgBr}$ followed by an epoxy/bromide mixture. The PVC coating is cast on top of this pseudo-reference electrode.) This lack of internal reference element may help to explain the shift in response to $10^{-2} \mathrm{M}$ nitrate that was observed over a period of time.

\section{Current problems in chemical sensing in the environment}

The brief and rather selective compilation on sensors presented above made no mention of many other chemical sensor technologies. ChemFETs (Janata \& Huber 1980) are devices based on chemically modified field effect transistors (FETs). They can be fabricated using the manufacturing techniques of the electronic industry, and several different sensors may be integrated on a single chip. These and other sensors will, perhaps, occupy significant niches in the array of sensors available to the environmental analyst. A vast catalogue of sensor types is more likely to be confusing than helpful, when considering the current state of chemical sensing. In many respects, the piezoelectric crystal monitor is a model sensor, in that the sensing and transduction functions are so clearly identifiable. It is also a model sensor in that, although there are many laboratory applications for the piezoelectric detector, there are very few real applications. Even well-tried sensors such as ISEs must be judged as successful laboratory devices, but real sensing applications are few and far between.

Undoubtedly, the reasons for the poor showing of chemical sensors in situations other than laboratory applications arise from 3 distinct failures.

i. Most chemical sensors are insufficiently selective.

ii. Most chemical sensors are not stable.

iii. Most chemical sensors have limited working lives.

The essence of chemical sensing in the environment is that the probe can be located in the desired spot, and then ignored. Constant recalibration, maintenance, or replacement impose as significant a burden on manpower as does sampling. In a recent report on sensors in agriculture (ARC Working Party 1982), the following point was made: 'What is required, ideally in every case, is a small robust transducer (sensor) that can be coupled to a modern solidstate data logger so as to facilitate repeated/ multiple measurements'. Few devices have reached the stage of development where they could be left connected to a data logger for 
anything other than a fairly restricted period.

\section{Conclusions}

Chemical sensing has developed in a rather piecemeal fashion, and throughout this development there has been an over-emphasis on the transducers. The heart of chemical sensing is the quantitative recognition of molecular and ionic species. Thus, the real need is to investigate and develop selective, sensitive, stable and robust chemical systems. Typical candidates might be immunoassays, immobilized enzymes, bi-lipid layer membranes, conducting polymers, polymer-bound sensor systems, host-guest systems and activated metal surfaces. Some chemistries, such as those concerned with modified electrodes, would have to be developed in conjunction with a particular transducer, but for many the question of probing the chemistry with a suitable transducer could assume a secondary significance. To a certain extent, this process is already taking place: immunoassay systems have been probed by both potentiometric and spectroscopic transducers; there is a growing interest in the chemistry of modified electrodes (Murray 1984).

A secondary approach to chemical sensing is to consider the response of a series of different nonspecific, or partially selective, sensors to various chemical species. The output of such a system could then be examined by a range of powerful data processing techniques that are collectively referred to as chemometrics. Chemometrics may be defined (Kowalski 1977) as 'the development and application of mathematical and statistical methods to extract useful chemical information from chemical measurements'. Such an approach has been applied with some success to simple binary and ternary systems of sensors.

Finally, one should not lose sight of the fact that for many sensors the actual information required may be a simple 'yes' or 'no' answer to the question 'Is the analyte present at a particular concentration?' Alternatively, the sensor may be required to monitor a trend rather than make a 95\% certain discrimination between 50.00 and $50.01 \mathrm{ppm}$ of the analyte. These considerations, at least, bring the future of reliable chemical sensing in the environment a little closer.

\section{Summary}

Three types of chemical sensor are described in this paper: piezoelectric crystal gas monitors; fibre optic probes; coated wire electrodes. In each case, the sensor consists of a non-specific transducer on which a chemically sensitive membrane or surface is formed. The principles of the transducers are discussed, along with chemical and other methods of improving their performance. The limitations of current sensors are reviewed, and suggestions made for future work.

\section{Acknowledgements}

The results presented in this paper represent the efforts of many individuals. I am most grateful to them all, especially Prof T S West, Dr S M Fraser, Mr I D Ross, Mr I G Sinclair and Mr K A Ellis.

\section{References}

Agricultural Research Council. 1982. Sensors in agriculture. (Report.) ARC Working Party on Transducers.

Alder, J.F. \& McCallum, J.J. 1983. Piezoelectric crystals for mass and chemical measurements. A review. Analyst, Lond., 108, 1169-1189.

Cattrall, R.W. \& Hamilton, I.C. 1984. Coated-wire ionselective electrodes. Ion-sel. Electrode Rev., 6, $125-172$

Cattrall, R.W., Tribuzio, S., Freiser, H. 1974. Potassium ion responsive coated wire electrode based on valinomycin. Analyt. Chem., 46, 2223-2224.

Collins, S.W. 1907. The "Nitron" method for the estimation of nitric acid. Analyst, Lond., 32, 349-357.

Cope, W.C. \& Barab, J. 1917. "Nitron" as a gravimetric agent for the analysis of substances used in explosives. J. Am. Chem. Soc., 39, 504-514.

Dagnall, R.M., West, T.S. \& Young, G. 1967. The Catechol Violet colour reaction for Tin (IV) sensitised by Cetyltrimethyl ammonium bromide. Analyst, Lond., 92, 27-30.

Edmonds, T.E. \& West, T.S. 1982. A quartz crystal piezoelectric device for monitoring organic gaseous pollutants. Analyt. chim. Acta, 117, 147-157.

Freiser, H. 1980. Coated wire ion-selective electrodes. In: Ion-selective electrodes in analytical chemistry, edited by H. Freiser, vol. 2, 89-105. London: Plenum.

Fujinaga, T., Okazi, S. \& Freiser, H. 1974. Ion selective electrodes responsive to anionic detergents. Analyt. Chem., 46, 1842-1844.

Heineman, W.R., Wieck, H.J. \& Yacynyck, A.M. 1980. Polymer film chemically modified electrode as a potentiometric sensor. Analyt. Chem., 52, 345-346.

Hopirtean, E. \& Stefaniga, E. 1976. Membrane electrodes of the metallic-wire plastic type. II. Membrane electrodes for organic cations. Revue roum. Chim., 21, 305-312.

Janata, J. \& Huber, R.J. 1980. Chemically sensitive field effect transistors. In: Ion-selective electrodes in analytical chemistry, edited by $H$. Freiser, vol. 2, 107-174. London: Plenum.

Kirkbright, G.F., Narayanaswamy, R. \& Welti, N.A. 1984a. Fibre-optic pH probe base on the use of an immobilised colorimetric indicator. Analyst, Lond., 109, 1025-1028. 
Kirkbright, G.F., Narayanaswamy, R. \& Welti, N.A. 1984b. Studies with immobilised chemical reagents using a flow-cell for the development of chemically sensitive fibre-optic devices. Analyst, Lond., 109, 15-18.

Klotz, I.M. 1947. Effects of salts and proteins on the spectra of some dyes and indicators. Chem. Rev., 41, 373-399.

Kneebone, B.M. \& Freiser, H. 1973. Determination of nitrogen oxides in ambient air using a coated-wire nitrate ion selective electrode. Analyt. Chem., 45, 449-451.

Kowalski, B.R., ed. 1977. Chemometrics: theory and application. (ACS symposium series 52.) Washington DC: American Chemical Society.

Murray, R.W. 1984. Chemically modified electrodes. In: Electroanalytical chemistry: a series of advances, edited by A.J. Bard, vol. 13. 191-368. New York: Marcel Dekker.

Solksy, R.L. 1982. Ion-selective electrodes in biomedical analysis. CRC Crit. Rev. anal. Chem. (Chem. Rubb. Co.), 14, 1-52.

Srinivason, K. \& Rechnitz, G.A. 1969. Selectivity studies on liquid membrane, ion selective electrodes. Analyt. Chem., 41, 1203-1208. 


\title{
Measurement of microbial biomass in soil
}

\author{
E D VANCE and P C BROOKES \\ Soils and Plant Nutrition Department, Rothamsted Experimental Station, Harpenden
}

\section{Introduction}

The soil microbial biomass (ie the sum total of fungi, bacteria, protozoa, algae and other microorganisms in soil) has been estimated to be many times the living weight of all other animals (vertebrate and invertebrate) in grassland ecosystems (Clark 1970). The biomass is also highly labile compared with other soil components, and thus plays a key role in the cycling of plant nutrients, especially $\mathrm{N}, \mathrm{P}$ and $\mathrm{S}$. For example, Brookes et al. (1984) calculated that the annual flux of $P$ through the biomass in grassland soils averaged $23 \mathrm{~kg} \mathrm{Pha}^{-1} \mathrm{yr}^{-1}$, equal to the annual $P$ uptake in the herbage.

The study of microbial biomass has been aided by recent developments of methods which allow the soil microbial biomass to be studied in situ. Many of these new techniques will be reviewed here, and particular attention given to the advantages and disadvantages of the main approaches used.

\section{Methods for measuring the soil biomass \\ 2.1 Direct microscopy}

Microscopic counting and sizing of microorganisms in soil preparations remains the standard technique for quantifying microbial biomass. Although time-consuming and prone to several sources of error, agreement between measurements by direct microscopic observation and indirect methods confirms that the latter measure biomass, and not some other soil constituent. In this section, we will briefly discuss some of the major considerations for direct microscopic measurements of microbial biomass. More detailed and technical aspects are reviewed elsewhere (Jenkinson \& Ladd 1981; Schmidt \& Paul 1982).

A microscopic technique for directly counting micro-organisms in a soil suspension was introduced by Conn (1918). The major problem was the varied thickness of the suspension, which prevented a truly representative count. The problem can be overcome, however, by using a plastic adhesive material with a hole of known diameter on the slide (Schmidt \& Paul 1982), to ensure an even thickness throughout the smear.

Another more widely used slide preparation method is the agar film technique (Jones \& Mollison 1948), which involves the suspension of soil in dilute agar. A small volume of suspension is pipetted on to a hemocytometer slide, covered with a cover slip, and allowed to solidify. The agar film of known thickness is then stained with phenolic analine blue before microscopic examination.

More recently, a membrane filter technique (Hanssen et al. 1974) has been introduced. Micro-organisms from a soil suspension are trapped on a membrane filter of small pore size and then observed directly on the filter. This method is more rapid than the agar film technique and can be more easily adapted to fluorescent staining.

These direct microscopic methods have 3 major problems: the method used to disperse the soil organisms, the type of stain used, and the factors used to convert microscopic counts to biomass carbon.

The 3 most commonly used procedures for preparing soil suspensions (water, detergent, and/or agar) are: shaking (with or without previous soil grinding), blender mixing (Babiuk \& Paul 1970), or ultrasonifying with stirring (Jenkinson et al. 1976). All three methods were compared by Jenkinson et al. (1976). They found that, although the methods were ranked in the order: blending $>$ ultrasonics $>$ shaking and grinding, for total numbers of organisms extracted, the ultrasonic dispersion method gave the highest biovolumes because of the greater dispersion efficiency of hyphal and large spherical organisms. The advantage of the ultrasonic method may be less for coarser-textured soils, and ultrasonifying for too long may cause injury to organisms (Ramsey 1984).

Various staining procedures have been used. Phenolic analine blue (PAB) has the advantage of staining both bacteria and fungi and is considered to stain only live organisms, ie those filled with protoplasm (Jones \& Mollison 1948). Frankland (1974, 1975) concluded that the fungal hyphae stained with PAB under bright field was an underestimate of total hyphae present, because not all hyphae stained, although PAB over-estimated live hyphae because some dead hyphae stained. She consequently developed a method for measuring live fungal biomass by determining the proportion of hyphae with cell contents under phase contrast without staining (Frankland 1975). One disadvantage of phase contrast, however, is that it is not suitable for counting bacteria in the presence of inorganic soil particles (Jenkinson \& Ladd 1981).

Acridine orange $(A O)$ is a commonly used. 
the extra $\mathrm{CO}_{2}$ evolved from a previously chloroform-fumigated soil, following fumigant removal and aerobic incubation, compared to that evolved from a similarly incubated but nonfumigated soil, results from the decomposition of microbial cells killed by the fumigant (Figure 2). The method involves fumigation of soil samples with alcohol-free chloroform for 24 hours under vacuum, fumigant removal, and aerobic incubation of fumigated and unfumigated samples for 10 days at $25^{\circ} \mathrm{C}$. Biomass carbon is calculated from $F_{c} / k_{c}$, where $F_{c}=\left[\left(\mathrm{CO}_{2}-\mathrm{C}\right.\right.$ evolved from the fumigated soil) minus $\left(\mathrm{CO}_{2}-\mathrm{C}\right.$ evolved from the unfumigated soil)]. The constant, $k_{c}$, is taken to be 0.45 at $25^{\circ} \mathrm{C}$, on the basis that $45 \%$ of the carbon in micro-organisms added to fumigated soils is evolved as $\mathrm{CO}_{2}-\mathrm{C}$ during 10 days of aerobic incubation (Jenkinson \& Ladd 1981). A similar value for $k_{c}\left(0.41\right.$ at $\left.22^{\circ} \mathrm{C}\right)$ was found by Anderson $\&$ Domsch (1978a) by measuring decomposition rates of 15 species of ${ }^{14} \mathrm{C}$-labelled fungi and 12 species of ${ }^{14} \mathrm{C}$-labelled bacteria and calculating a weighted average decomposition rate, assuming a $3: 1$ fungal/bacterial ratio in soil.

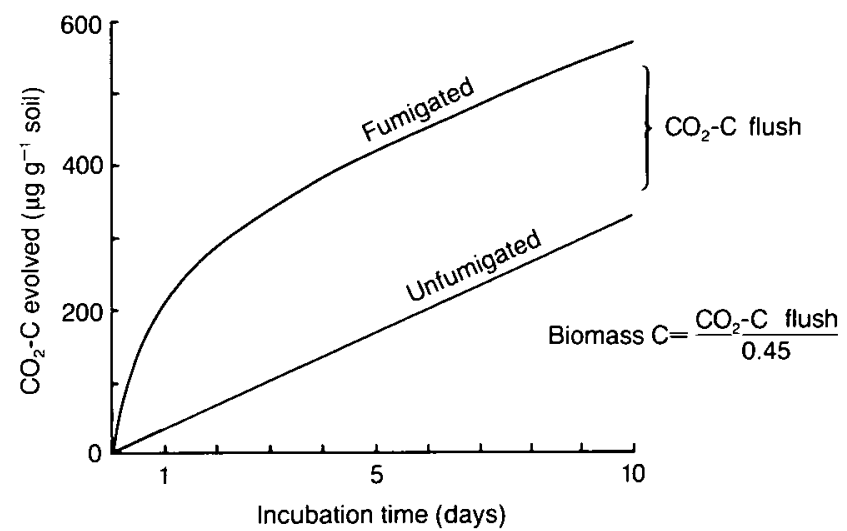

Figure 2. Respiration curves $\left(\mathrm{CO}_{2}-\mathrm{C}\right.$ evolution) for $\mathrm{CHCl}_{3}$-fumigated and unfumigated forest soil samples $(p H 7.2)$

One of the basic assumptions of the fumigation method is that chloroform does not alter the decomposability of non-biomass soil organic matter. Enhanced decomposability of nonbiomass organic matter could contribute to the 'flush' of respiration observed in fumigated samples. The validity of this assumption is supported by the observation that different biocidal treatments: $\mathrm{CHCl}_{3}$, methyl bromide, and gamma irradiation (Powlson \& Jenkinson 1976), and carbon disulphide (Kudeyarov \& Jenkinson 1976), produce flushes of similar size. Other supportive evidence comes from experiments on soil that had been non-uniformly labelled with ${ }^{14} \mathrm{C}$ (by incubation with ${ }^{14} \mathrm{C}$-labelled ryegrass for one year): similar amounts of $\mathrm{CO}_{2}-\mathrm{C}$ with similar specific activities were evolved, whether the soil was irradiated or fumigated with $\mathrm{CHCl}_{3}$ (Jenkinson 1966, 1976). This result implies that both agents are acting on the same soil fraction. This fraction is probably the soil microbial biomass because treatments as different as irradiation and $\mathrm{CHCl}_{3}$ fumigation are unlikely to render the same non-biomass fraction decomposable to about the same extent. Estimates of microbial biomass measured by the fumigation method were found to be very similar to the amounts measured by direct microscopy (Jenkinson et al. 1979; Oades \& Jenkinson 1979) for a wide range of soil types (Figures 3a \& 3b).

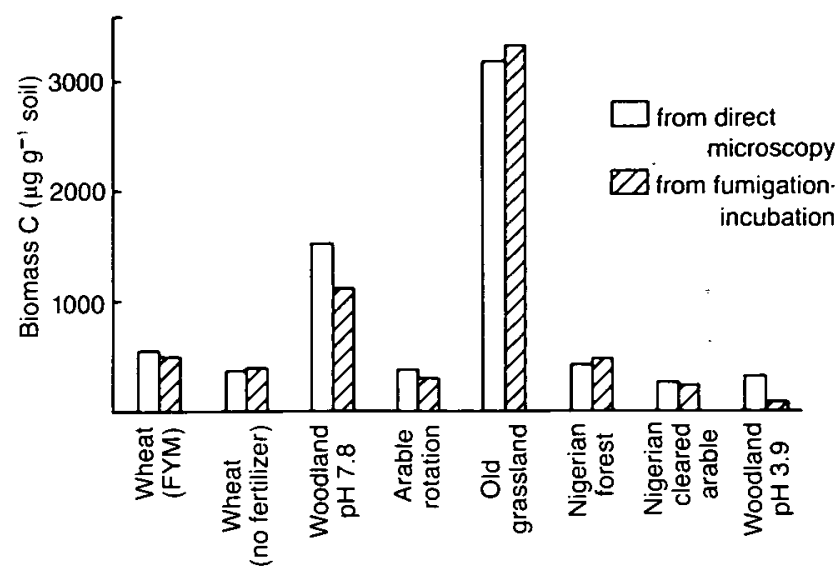

Figure 3a. The relationship between biomass $C$ measured by direct microscopy and by $\mathrm{CHCl}_{3}$ fumigation-incubation (from Jenkinson et al. 1976)

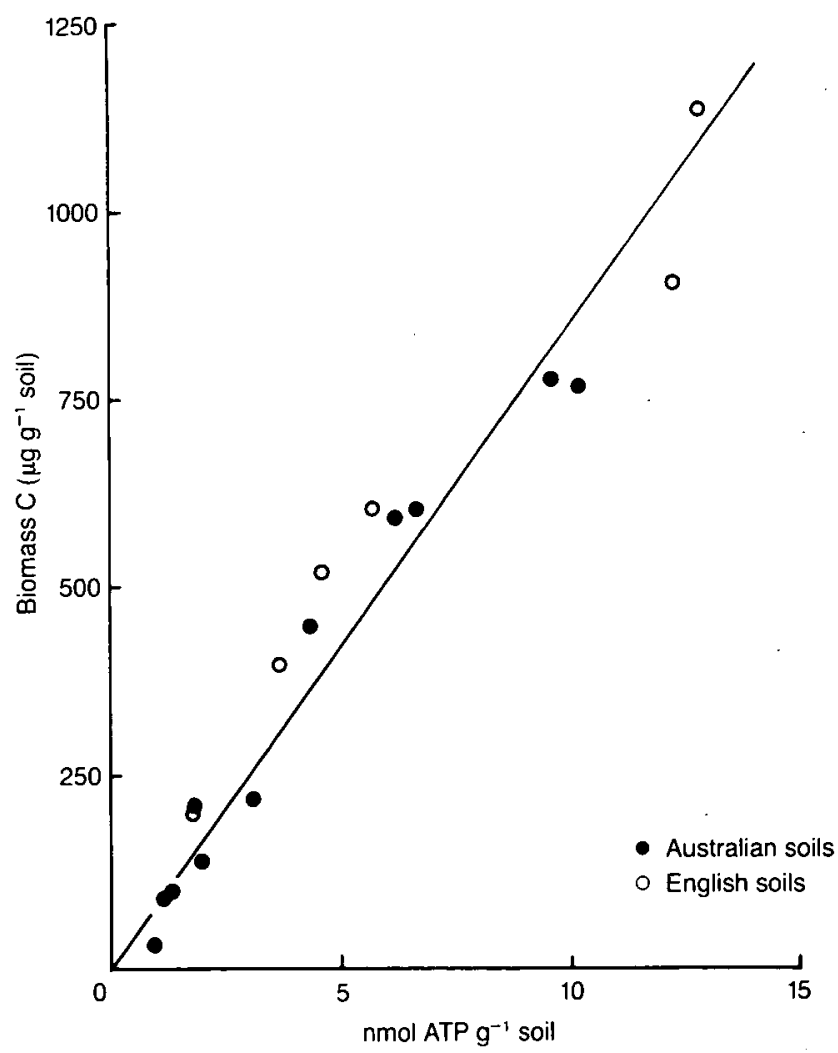

Figure $3 b$. The relationship between biomass $C$ measured by $\mathrm{CHCl}_{3}$ fumigation-incubation and soil ATP concentration for 11 Australian and 6 English soils (from Jenkinson et al. 1979; Tate \& Jenkinson 1983) 
Another assumption in the fumigation method is that the small microbial population which recolonizes the fumigated soil (about 10\% of the original population) has the same ability to decompose non-biomass soil organic matter during the 10-day aerobic incubation period as the native soil population. This is implied in the calculation of biomass, in which the $\mathrm{CO}_{2}-\mathrm{C}$ evolved from the unfumigated soil is subtracted from $\mathrm{CO}_{2}-\mathrm{C}$ evolved from the fumigated soil. This assumption has been criticized (Voroney \& Paul 1984) because the recolonizing population in fumigated soils is known to be smaller in amount (Jenkinson \& Powlson 1976a), diversity, and metabolic capability (Voroney 1983). Because of this, Voroney and Paul (1984) proposed that biomass carbon be calculated from the $\mathrm{CO}_{2}-\mathrm{C}$ evolved from the fumigated soil alone, assuming that there is negligible attack on non-biomass soil organic carbon by the recolonizing population in fumigated soil over the 10-day incubation period. The major argument against this theory is that fumigated soils, despite their reduced microbial population, respire at similar rates to unfumigated soils once the flush is over (Jenkinson \& Powlson 1976a). Furthermore, Voroney (1983), using a soil in which the biomass was much more heavily labelled with ${ }^{14} \mathrm{C}$ than the soil organic matter as a whole, found that the specific activity of the $\mathrm{CO}_{2}$ evolved by the fumigated soil fell after only a few days' incubation to a value very similar to that of the unfumigated control soil. This result again suggests that non-biomass $\mathrm{CO}_{2}-\mathrm{C}$ was being evolved from both fumigated and non-fumigated soils.

Another variation of the fumigation method involves the use of mathematical models to predict the size of the mineralizable biomass $\mathrm{C}$ and its mineralization rate (Chaussod \& Nicolardot 1982). They also proposed a modification to the original fumigation method, with the flush taken as the difference in $\mathrm{CO}_{2}-\mathrm{C}$ evolved between the 0-7 day and 7-14 day incubation periods of the fumigated samples only.

There are some limitations to the use of the fumigation method. As with most soil biological assays, soils must not be air dried because this process solubilizes native organic matter, rendering it decomposable, and kills a portion of the biomass (Powlson \& Jenkinson 1976). In addition, the fumigation method may not give valid measurements of biomass immediately after the addition of fresh substrates (Jenkinson \& Powlson 1976b).

Using ${ }^{14} \mathrm{C}$-labelled substrate additions, Martens (1985) found that the rates of decomposition of added substrates (eg glucose and wheat roots) differed in fumigated and unfumigated soil. Biomass calculations in the amended soils were only valid after substantial degradation of the substrates had occurred, 3 days for glucose, 14 days for cellulose, and 28 days for wheat roots.

There may also be interference from abiotic $\mathrm{CO}_{2}$ production when the fumigation method is used on calcareous soils (Jenkinson \& Powlson 1976b). This effect can be largely overcome by pre-incubation of the moist soil $(40 \% \mathrm{WHC})$ in the presence of soda lime for 10 days before fumigation (Jenkinson \& Powlson 1976b). The biomass thus measured is that in the soil at the end of the pre-incubation period, and may well be a little less than that present at the beginning.

The present fumigation method has not been applicable to strongly acid soils like those commonly found under forests and other natural vegetation. The problem was first detected by Jenkinson et al. (1976), who found that biomass measured by fumigation was only about a seventh of that measured by direct microscopy in a strongly acid ( $\mathrm{pH} 3.9$ ) woodland soil, although there was relatively good agreement between the 2 methods for 7 soils of higher $\mathrm{pH}$. In the same soil, a similar discrepancy between biomass measured by fumigation and from soil ATP concentration was found subsequently (Jenkinson et al. 1979). Low biomass estimates using the fumigation method have been found in other strongly acid soils (Adams \& Laughlin 1981; Adams \& Adams 1983) and acid organic soils (Williams \& Sparling 1984).

There are 2 components to the $\mathrm{CO}_{2}-\mathrm{C}$ evolution from a fumigated soil during fumigationincubation, viz $\mathrm{CO}_{2}-\mathrm{C}$ evolved due to decomposition of biomass killed by the fumigant and $\mathrm{CO}_{2}-\mathrm{C}$ evolved due to basal respiration of non-biomass soil organic matter. In the case of a neutral soil, it is assumed that the microbial recolonizing population mineralizes both the killed biomass (assumption 1), and also nonbiomass soil organic matter (assumption 2) to the same extent as that by the native microbial population in non-fumigated soil. Some of the evidence for both assumptions has already been reviewed in this paper. There is evidence to suggest that assumption 1 is also correct in acid soils. Added yeast cytoplasm extracts decomposed to only a slightly lower extent in a fumigated, strongly acid ( $\mathrm{pH} 3.9$ ), soil than in a fumigated neutral soil (Powlson \& Jenkinson 1976). Assuming that killed soil biomass decomposes in a similar way to yeast extract, it follows that $k_{c}$ values for acid soils are only slightly lower than those for neutral soils.

However, the shape of the respiration curve in a fumigated acid soil is usually very different to that of a neutral soil. Such curves for a typical neutral and an acid forest soil respectively are shown in 
Figures 2 and 4 . In the neutral soil, once the flush is over (ie about day 4), rates of $\mathrm{CO}_{2}-\mathrm{C}$ evolution in both the fumigated and non-fumigated soil are very similar, ie assumption 2 is again satisfied. However, the shape of the respiration curve of the acid soil (Figure 4) suggests strongly that assumption 2 is not satisfied in this case, ie there is reduced mineralization of non-biomass soil organic carbon in the fumigated soil compared to the non-fumigated soil. Thus, after an initial lag phase, there is a rapid rise in $\mathrm{CO}_{2}-\mathrm{C}$ evolution, similar to that in a neutral fumigated soil, and attributable to the mineralization of the biomass killed by the fumigant. However, after this flush is over (ie about day 5), the rates of $\mathrm{CO}_{2}-\mathrm{C}$ evolution in the control and fumigated soil continue to diverge, rather than become similar. The reason for the divergence is that respiration in the nonfumigated soil continues at a steady rate, but respiration in the fumigated soil is negligible, even up to 15 days after the initial flush is over. We suggest that this is because the microbial recolonizers in an acid fumigated soil are capable of decomposing the biomass killed by the fumigant, but are incapable of much mineralization of non-biomass soil organic matter, even 15-20 days after fumigation.

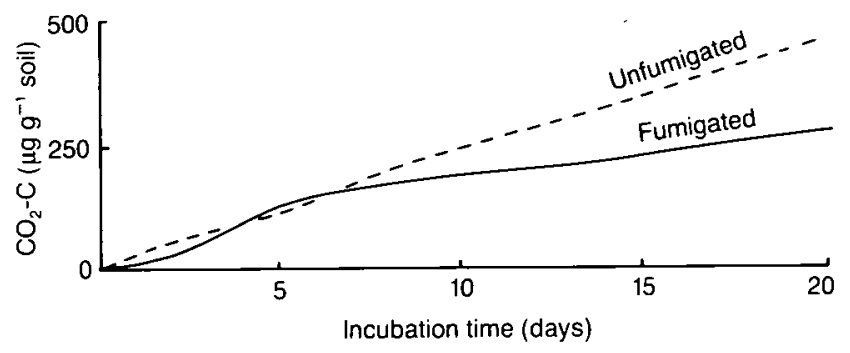

Figure 4. Respiration curves for $\mathrm{CHCl}_{3}$ fumigated and unfumigated samples of a strongly acid soil ( $p H$ 4.2)

We are testing this hypothesis at Rothamsted by measuring decomposition of micro-organisms grown in vitro and by comparing biomass measurements by direct microscopy, ATP, and fumigation in a range of forest soils varying from $\mathrm{pH} 3.2$ to 7.2. Some preliminary results, presented in Figure 5, show the relationship between biomass measured by direct microscopy and by a modified version of the fumigation method. Soils are treated as follows: when soil pH is below 4.2, $\mathrm{CO}_{2}$ evolved from unfumigated soils is not subtracted from that evolved from fumigated soils. Above this $\mathrm{pH}, \mathrm{CO}_{2}$ production from the unfumigated sample is subtracted from fumigated soil $\mathrm{CO}_{2}$ production in the usual way. The relationship between biomass measured by the 2 methods remained fairly constant, with an average ratio close to $1: 1$ over a wide range of both $\mathrm{pH}$ and biomass content.
An equally good relationship was found between biomass calculated from soil ATP concentrations and by the modified fumigation method. The concentration of ATP in the biomass averaged 9.1 $\times 10^{-6} \mathrm{M} \mathrm{ATP}^{-1}$ biomass $\mathrm{C}$, very similar to that previously measured in a range of neutral and near-neutral soils (Jenkinson et al. 1979; Oades \& Jenkinson 1979). These results also strongly indicate that biomass ATP concentrations are similar in neutral and acid soil, so that ATP can serve as a reliable measure of soil biomass content in acid soils.

Our present results suggest that the fumigation method, as originally proposed, breaks down at a critical $\mathrm{pH}$ of about 4.2 , because at or below this $\mathrm{pH}$ the recolonizers cannot mineralize nonbiomass soil organic matter even 15-20 days after fumigation. The simple modification to the method that we propose needs to be tested on other acid soils before its general applicability can be confirmed.

\subsection{The physiological method}

The physiological method for measuring microbial biomass, introduced by Anderson and Domsch (1978b), uses the initial respiratory response of the soil microbial population to glucose additions as a measure of the amount of biomass present. After the concentration of glucose needed to give maximum response is determined, the respiration rate of the glucose-amended soil is measured over a period (usually one hour) too short to allow microbial proliferation. The rate of evolution of $\mathrm{CO}_{2}$ was significantly correlated $(\mathrm{r}=0.96)$ with biomass measured by the fumigation method for 50 different soils. One advantage of the physiological method is that it can be used with selective inhibitors of bacterial or fungal activity, allowing the biomass to be separated into the 2 components (Anderson \& Domsch 1978b). This

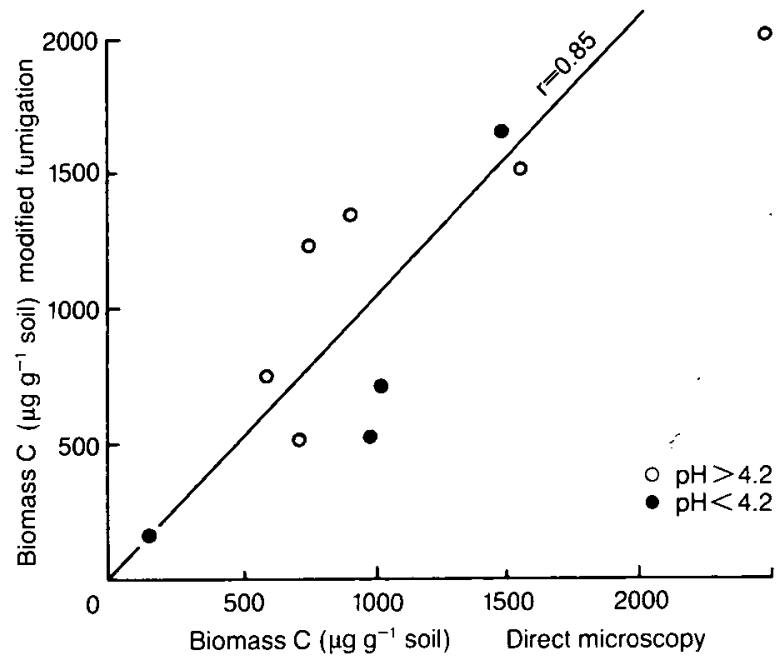

Figure 5. The relationship between biomass measured by modified fumigation-incubation and by direct microscopy for acid and neutral forest soils 
approach, however, has been challenged (Ross et al. 1981). Biomass measured by the physiological method has been found to correlate well with other measures of biomass and activity (eg Domsch et al. 1979).

The physiological method is based on the assumption that the various components of the microbial population, which may respond differently to the glucose addition, are present in the same proportions in different soils (Jenkinson \& Ladd 1981). Because the method is calibrated against the fumigation-incubation method, results from the physiological method must be interpreted with caution when applied to soils where the fumigation method breaks down (eg strongly acid soils or soils with fresh substrate additions). Williams and Sparling (1984) found that biomass calculated using the physiological method did not agree well with results from the fumigation method in acid organic soils.

\subsection{Measurement of nutrients immobilized in the soil microbial biomass}

Quantities of nutrients contained in the soil biomass have traditionally been estimated by measuring microbial biomass carbon and calculating other nutrient concentrations from values determined from laboratory-grown microorganisms (Ausmus et al. 1975; Baath \& Söderström 1979; Anderson \& Domsch 1980). The use of the chloroform fumigation technique to measure biomass carbon has led to other, related, procedures for measuring nutrients in the biomass, notably $\mathrm{N}, \mathrm{P}$ and $\mathrm{S}$. Fumigation has been known for a long time to release inorganic $\mathrm{N}$ from organic forms in soil, both directly, and during subsequent aerobic incubation (Russell \& Hutchinson 1909; Waksman \& Starkey 1923). The idea that the inorganic $N$ and $C$ thus released by fumigation came from the biomass led to the development of methods for measuring carbon and other nutrients in microbial biomass. The term 'stress labile N', used to denote nitrogen released in a fumigated soil during 10-day aerobic incubation, was introduced by Ayanaba et al. (1976). This term was used as an indication of the 'quality' of organic $\mathrm{N}$ and was found to be related to cropping history. A close linear relationship was shown between 'stress labile $N$ ' and biomass $C$ for 20 Nigerian soils studied. Ross et al. (1980) found that ratios of biomass $\mathrm{C}$ to mineral $\mathrm{N}$ flush varied from 8 to 23 in 9 New Zealand soils under grassland, however, and questioned the use of the $\mathrm{N}$ flush to calculate microbial biomass.

The estimation of biomass $\mathrm{N}$ by the fumigationincubation procedure has proved to be more uncertain than biomass $\mathrm{C}$, first, because the $\mathrm{N}$ content of microbial cells is much more variable than the $\mathrm{C}$ content, and, second, because some of the $\mathrm{N}$ mineralized during the incubation of fumigated soil is reimmobilized (Jenkinson 1976; Marumoto et al. 1982). These 2 factors are probably related.

Paul and Juma (1981) measured nitrogen mineralized in fumigated soil and assumed a $k_{N}$ value of 0.25 to calculate microbial biomass $\mathrm{N}$ and the flux of $\mathrm{N}$ through the biomass in soils receiving labelled substrates. Two approaches have recently been introduced to overcome the problem of $\mathrm{N}$ immobilization in the fumigationincubation procedure. Voroney and Paul (1984) labelled the microbial biomass in situ by adding ${ }^{14} \mathrm{C}$-glucose and ${ }^{15} \mathrm{~N}-\mathrm{KNO}_{3}$ to soil, incubating and measuring $\mathrm{C}$ and $\mathrm{N}$ mineralization following fumigation. From these studies, they proposed a variable $k_{N}$, using an adjustment factor calculated from the ratio of $\mathrm{CO}_{2}-\mathrm{C}$ evolved to $\mathrm{N}$ mineralized during incubation to correct for $\mathrm{N}$ immobilization.

A second approach to overcoming the problem of $\mathrm{N}$ immobilization during biomass $\mathrm{N}$ determinations was introduced by Shen et al. (1984), who assumed that a constant fraction of the $\mathrm{N}$ released from the killed population was reimmobilized. Making this assumption, $k_{N}$ was calculated to be 0.68 from the ratio of $\mathrm{C}$ flush to $\mathrm{N}$ flush, taking the average $\mathrm{C} / \mathrm{N}$ ratio of microorganisms to be 6.7 and a $k_{c}$ value of 0.45 .

A new method for measuring biomass $N$ has been developed, based on the extra $\mathrm{N}$ (organic + inorganic) extracted by $0.5 \mathrm{M} \mathrm{K}_{2} \mathrm{SO}_{4}$ from a fumigated soil compared to an unfumigated control (Brookes et al. 1985a, b). Total N rendered extractable by fumigation was strongly correlated with $F_{N}$ determined by the fumigation-incubation method in 37 soils. Because this new method does not require an aerobic incubation, it overcomes the problem of $\mathrm{N}$ immobilization and can be done in one day instead of 10 . However, the problem remains of establishing an agreed factor to convert $\mathrm{N}$ rendered extractable by fumigation to biomass $\mathrm{N}$.

2.6 Measurement of phosphorus and sulphur in the biomass

Direct extraction methods have also been developed for measuring biomass phosphorus (Brookes et al. 1982; Hedley \& Stewart 1982) and sulphur (Saggar et al. 1981). For biomass $\mathrm{P}$, soil is either fumigated with $\mathrm{CHCl}_{3}$ vapour (Brookes et al. 1982) or liquid $\mathrm{CHCl}_{3}$ (Hedley \& Stewart 1982) to lyse microbial cells, followed by extraction with $0.5 \mathrm{M} \mathrm{NaHCO}_{3}$. The 2 methods differ further in that Brookes et al. (1982) used a known addition of $\mathrm{KH}_{2} \mathrm{PO}_{4}$ during extraction to correct for adsorption of inorganic $P$ released by fumigation. Hedley and Stewart (1982) found that removal of inorganic $P$ from the soil, using exchange resins prior to extraction, increased the accuracy of the method. However, both groups obtained values for $k_{p}$ of about 0.4 . 
Brookes et al. (1982) showed that about $90 \%$ of the total $P\left(P_{i}\right)$ released by $\mathrm{CHCl}_{3}$ after a $24 \mathrm{~h}$ fumigation was inorganic $\left(P_{i}\right)$, presumably because of enzymic hydrolysis of organic $P$ in the lysed cells. On the basis of this finding, it was suggested that $\mathrm{NaHCO}_{3}$-extractable $\mathrm{P}_{\mathrm{i}}$ alone might be used for measuring biomass $P$. However, recent work using forest soils suggests that in acid soils $P_{i}$ makes up a much lower percentage of $P_{t}$ (Table 1). The extractable organic $P$ released by $\mathrm{CHCl}_{3}$ in acid soils must be investigated further to determine whether it is actually derived from the biomass, or from nonbiomass soil organic matter. There is evidence that $\mathrm{CHCl}_{3}$ may extract $\mathrm{P}$ from fresh plant material added to soil (McLaughlin \& Alston 1985; Sparling et al. 1985).

Table 1. Ratios of inorganic $P\left(P_{i}\right)$ to total $P\left(P_{i}\right)$ released by $\mathrm{CHCl}_{3}$ and extracted by $0.5 \mathrm{M}$ $\mathrm{NaHCO}_{3}$, for 10 forest soils

\begin{tabular}{ccc}
\hline Soil number & $\mathrm{pH}$ & $\mathrm{CHCl}_{3}$-released $\mathrm{P}_{\mathrm{i}}$ as $\%$ of $\mathrm{P}_{\mathrm{t}}$ \\
\hline 1 & 7.2 & 99 \\
2 & 6.1 & 70 \\
3 & 5.2 & 78 \\
4 & 5.2 & 85 \\
5 & 5.1 & 71 \\
6 & 4.2 & 76 \\
7 & 4.1 & 45 \\
8 & 3.8 & 26 \\
9 & 3.5 & 42 \\
10 & 3.4 & 33 \\
\hline
\end{tabular}

The original method for estimating biomass sulphur in soil (Saggar et al. 1981) used liquid $\mathrm{CHCl}_{3}$ as a lysing agent, followed by measurement of total $\mathrm{S}$ extracted by $\mathrm{CaCl}_{2}$ or $\mathrm{NaHCO}_{3}$. Strick and Nakas (1984) obtained more reproducible results for biomass $S$ contents of forest soils with high uptake adsorption capacity by (i) using $\mathrm{NaH}_{2} \mathrm{PO}_{4}$ as the extractant, (ii) using $\mathrm{CHCl}_{3}$ vapour instead of liquid $\mathrm{CHCl}_{3}$, (iii) using moist soil that had not been air dried and rewetted, and (iv) pre-leaching soil to remove non-biomass soil $S$. They obtained $k_{s}$ values of 0.37 and 0.25 for 0 horizons under coniferous and hardwood forests, respectively.

\section{Summary}

The soil microbial biomass is the agent of breakdown of organic material in soils, mineralizing organically bound nutrients into inorganic forms which can be used by plants. The biomass thus provides a labile sink for N, P and S, and plays a key role in the cycling of these plant nutrients.

Methods have been developed to measure microbial biomass in soil and the nutrients held in the biomass. Direct microscopic counting is the standard method and allows some separation of the microbial population into live, dead, active, and inactive fractions based on selective staining. A more rapid method is the measurement of soil ATP which only occurs in living cells. Extractants for ATP should be acidic, or contain other agents capable of inactivating ATPases, which would otherwise hydrolyse ATP during extraction, and hence give apparently low soil ATP concentrations.

The fumigation-incubation method is widely used. $\mathrm{CO}_{2}$ evolved during decomposition of microorganisms killed by chloroform fumigation is related to the amount of soil biomass originally present. Special modifications are needed, however, to apply the method to strongly acid (ie $<\mathrm{pH} 5)$ soils. Biomass measured by fumigation correlates well with that measured by direct microscopy and with soil ATP concentration.

The respiratory response of the soil biomass to glucose amendment (the physiological method) is closely related to the amount of microbial biomass measured by fumigation-incubation. The physiological method has been used with selective inhibitors to separate the microbial biomass into fungal and bacterial components.

Modifications of the fumigation-incubation procedure permit the measurement of nutrients $(N, P, S)$ contained in the biomass. For example, biomass $N$ can be estimated from the flush of mineral $\mathrm{N}$ following soil fumigation and aerobic incubation. Under some conditions, $\mathrm{N}$ can be immobilized or denitrified, but this can be overcome using a recently developed procedure, which involves determination of the organic + inorganic soil- $\mathrm{N}$ released by fumigation and extracted by $\mathrm{K}_{2} \mathrm{SO}_{4}$, without aerobic incubation. Similar extraction methods have also been developed to measure biomass $S$ and $P$ in soil. These direct extraction methods have the advantage that soils do not need pre-incubation before analysis. This step is required in the fumigation-incubation and ATP methods to allow microbial activity to stabilize following disturbance due to sampling.

\section{Acknowledgements}

The authors appreciate the help of $\operatorname{Dr} D S$ Jenkinson and $\operatorname{Mr} A E$ Johnston for review and criticism of the manuscript. E D Vance would like to thank the United States-United Kingdom Educational Commission for a Fulbright Scholarship.

\section{References}

Adams, T.McM. \& Adams, S.N. 1983. The effects of liming and soil $\mathrm{pH}$ on carbon and nitrogen contained in the soil biomass. J. agric. Sci., Camb., 101, 553-558. 
Adams, T.McM. \& Laughlin, R.J. 1981. The effects of agronomy on carbon and nitrogen contained in the soil biomass. J. agric. Sci., Camb., 97, 319-327.

Ahmed, M., Oades, J.M. \& Ladd, J.N. 1982. Determination of ATP in soils: effect of soil treatments. Soil Biol. Biochem., 14, 273-279.

Anderson, J.P.E. \& Domsch, K.H. 1978a. Mineralization of bacteria and fungi in chloroformfumigated soils. Soil Biol. Biochem., 10, 207-213.

Anderson, J.P.E. \& Domsch, K.H. 1978b. A physiological method for the quantitative measurement of microbial biomass in soils. Soil Biol. Biochem., 10, 215-221.

Anderson, J.P.E. \& Domsch, K.H. 1980. Quantities of nutrients in the microbial biomass of selected soils. Soil Sci., 130, 211-216.

Ausmus, B.S. 1973. The use of the ATP assay in terrestrial decomposition studies. In: Modern methods in the study of microbial ecology, edited by $\mathrm{T}$. Rosswall, 223-234. (Ecological bulletin no. 17.) Stockholm: Swedish Natural Science Research Council.

Ausmus, B.S., Edwards, N.T. \& Witkamp, M. 1975. Microbial immobilization of carbon, nitrogen, phosphorus and potassium: implications for forest ecosystem processes. In: The role of terrestrial and aquatic organisms in decomposition processes, edited by J.M. Anderson \& A. Macfadyen, 397-416: (Symposium of the British Ecological Society, 17th, 1518 April.) Oxford: Blackwell Scientific.

Ayanaba, A., Tuckwell, S.B. \& Jenkinson, D.S. 1976. The effects of clearing and cropping on the organic reserves and biomass of tropical forest soils. Soil Biol. Biochem., 8, 519-525.

Baath, E. \& Söderström, B. 1979. Fungal biomass and fungal immobilization of plant nutrients in Swedish coniferous forest soils. Rev. Ecol. Biol. Sol., 16, 477-489.

Babiuk, L:A. \& Paul, E.A. 1970. The use of fluorescein isothiocyanate in the determination of the bacterial biomass of grassland soil. Can. J. Microbiol., 16, $57-62$.

Bakken, L.R. \& Olsen, R.A. 1983. Buoyant densities and dry matter contents of micro-organisms: conversion of a measured biovolume into biomass. Appl. environ. Microbiol., 45, 1188-1195.

Bratbak, G. \& Dundas, I. 1984. Bacterial dry matter content and biomass estimations. Appl. environ. Microbiol., 48, 755-757.

Brookes, P.C., Kragt, J.F., Powlson, D.S. \& Jenkinson, D.S. 1985a. Chloroform fumigation and the release of soil nitrogen: the effects of fumigation time and temperature. Soil Biol. Biochem., 17, 831-836.

Brookes, P.C., Landman, A., Pruden, G. \& Jenkinson, D.S. 1985b. Chloroform fumigation and the release of soil nitrogen: a rapid direct extraction method for measuring microbial biomass nitrogen in soil. Soil Biol. Biochem., 17, 837-842.

Brookes, P.C., Powlson, D.S. \& Jenkinson, D.S. 1982. Measurement of microbial biomass phosphorus in soil. Soil Biol. Biochem., 14, 319-329.

Brookes, P.C., Powlson, D.S. \& Jenkinson, D.S. 1984. Phosphorus in the soil microbial biomass. Soil Biol. Biochem., 16, 169-175.

Brookes, P.C., Tate, K.R. \& Jenkinson, D.S. 1983. The adenylate energy charge of the soil microbial biomass. Soil Biol. Biochem., 15, 9-16.

Casida, L.E. 1971. Micro-organisms in unamended soil as observed by various forms of microscopy and staining. Appl. Microbiol., 21, 1040-1045.

Chaussod, R. \& Nicolardot, B. 1982 Mesure de la biomasse microbienne dans les sols cultivés. I. Approche cinétique et estimation simplifiée du carbone facilement minéralisable. Rev. Ecol. Biol. Sol., 19, $501-512$.

Chuang, T.Y. \& Ko, W.H. 1981. Propagule size: its relation to population density of micro-organisms in soil. Soil Biol. Biochem., 13, 185-190.

Clark, F.E. 1970. The microbial component of the ecosystem. (Technical report no. 52.) Grasslands Biome. U.S. International Biological Program.

Conn, H.J. 1918. The microscopic study of bacteria and fungi in soil. Tech. Bull. N.Y. St. agric. Exp. Stn, no. 64.

Domsch, K.H., Beck, Th., Anderson, J.P.E., Söderström, B., Parkinson, D. \& Trolldenier, G. 1979. A comparison of methods for soil microbial population and biomass studies. Z. Pfl.-Ernähr. Bodenk., 142, $520-533$.

Eiland, F. 1979. An improved method for determination of adenosine triphosphate (ATP) in soil. Soil Biol. Biochem., 11, 31-35.

Eiland, F. 1983. A simple method for quantitative determination of ATP in soil. Soil Biol. Biochem., 15, $665-670$.

Elliot, E.T., Cole, C.V., Fairbanks, B.C., Woods, L.E., Bryant, R.J. \& Coleman, D.C. 1983. Short-term bacterial growth, nutrient uptake, and ATP turnover in sterilized, innoculated and C-amended soil: the influence of $\mathrm{N}$ availability. Soil Biol. Biochem., 15, 85-91.

Fairbanks, B.C., Woods, L.E., Bryant, R.J., Elliot, E.T., Cole, C.V. \& Coleman, D.C. 1984. Limitations of ATP estimates of microbial biomass. Soil Biol. Biochem., 16, 549-558.

Frankland, J.C. 1974. Importance of phase-contrast microscopy for estimation of total fungal biomass by the agar film technique. Soil Biol. Biochem., 6, 409-410. 
Frankland, J.C. 1975. Estimation of live fungal biomass. Soil Biol. Biochem., 7, 339-340.

Hanssen, J.F., Thingstad, T.F. \& Goksoyr, J. 1974. Evaluation of hyphal lengths and fungal biomass in soil by a membrane filter technique. Oikos, 25, 102-107.

Hedley, M.J. \& Stewart, J.W.B. 1982. Method to measure microbial biomass phosphorus in soils. Soil Biol. Biochem., 14, 377-385.

Jenkinson, D.S. 1966. Studies on the decomposition of plant material in soil. II. Partial sterilization of soil and the soil biomass. J. Soil Sci., 17, 280-302.

Jenkinson, D.S. 1976. The effects of biocidal treatments on metabolism in soil. IV. The decomposition of fumigated organisms in soil. Soil Biol. Biochem., 8, 203-208.

Jenkinson, D.S. \& Ladd, J.N. 1981. Microbial biomass in soil: measurement and turnover. In: Soil Biochemistry, edited by E.A. Paul \& J.N. Ladd, vol. 5 , 415-471. New York: Dekker.

Jenkinson, D.S. \& Oades, J.M. 1979. A method for measuring adenosine triphosphate in soil. Soil Biol. Biochem., 11, 193-199.

Jenkinson, D.S. \& Powlson, D.S. 1976a. The effects of biocidal treatments on metabolism in soil. I. Fumigation with chloroform. Soil Biol. Biochem., 8, 167-177.

Jenkinson, D.S. \& Powison, D.S. 1976b. The effects of biocidal treatments on metabolism in soil. V. A method for measuring soil biomass. Soil Biol. Biochem., 8, 209-213.

Jenkinson, D.S., Davidson, S.A. \& Powlson, D.S. 1979. Adenosine triphosphate and microbial biomass in soil. Soil Biol. Biochem., 11, 521-527.

Jenkinson, D.S., Powlson, D.S. \& Wedderburn, R.W.M. 1976. The effects of biocidal treatments on metabolism in soil. III. The relationship between soil biovolume, measured by optical microscopy and the flush of decomposition caused by fumigation. Soil Biol. Biochem., 8, 189-202.

Jones, P.C.T. \& Mollison, J.E. 1948. A technique for the quantitative estimation of soil micro-organisms. J. gen. Microbiol., 2, 54-69.

Kudeyarov, V.N. \& Jenkinson, D.S. 1976. The effects of biocidal treatments on metabolism in soil. VI. Fumigation with carbon disulphide. Soil Biol. Biochem., 8, 375-378.

Lee, C.C., Harris, R.F., Williams, J.D.H., Armstrong, D.E. \& Syers, J.K. 1971. Adenosine triphosphate in lake sediments: I. Determination. Proc. Soil Sci. Soc. $A m$. 35, 82-86.

Lundgren, B. 1981. Fluorescein diacetate as a stain of metabolically active bacteria in soil. Oikos, 36, 17-32.

Lundgren, B. 1984. Size classification of soil bacteria: effects on microscopically-estimated biovolumes. Soil
Biol. Biochem., 16, 283-284.

Luria, S.E. 1960. The bacterial protoplasm: composition and organization. In: The bacteria, edited by I.C. Gunsalus \& R.Y. Stanier, vol. 1, 1-34. New York: Academic Press.

Martens, R. 1985. Limitations in the application of the fumigation technique for biomass estimations in amended soils. Soil Biol. Biochem., 17, 57-63.

Marumoto, T., Anderson, J.P.E. \& Domsch, K.H. 1982. Decomposition of ${ }^{14} \mathrm{C}$ - and ${ }^{15} \mathrm{~N}$-labelled microbial cells in soil. Soil Biol. Biochem., 14, 461-467.

McLaughlin, M.J. \& Alston, A.M. 1985. Measurement of phosphorus in the soil microbial biomass: influence of plant material. Soil Biol. Biochem., 17, 271-274.

Nannipieri, P., Johnson, R.L. \& Paul, E.A. 1978. Criteria for measurement of microbial growth and activity in soil. Soil Biol. Biochem., 10, 223-229.

Oades, J.M. \& Jenkinson, D.S. 1979. Adenosine triphosphate content of the soil microbial biomass. Soil Biol. Biochem., 11, 201-204.

Paul, E.A. \& Johnson, R.L. 1977. Microscopic counting and adenosine 5-triphosphate measurement in determining microbial growth in soils. Appl. environ. Microbiol., 34, 263-269

Paul, E.A. \& Juma, N.G. 1981. Mineralization and immobilization of soil nitrogen by microorganisms. In: Terrestrial nitrogen cycles, edited by F.E. Clark \& T. Rosswall, 179-195. (Ecological bulletin no. 33.) Stockholm: Swedish Natural Science Research Council.

Powlson, D.S. \& Jenkinson, D.S. 1976. The effects of biocidal treatments on metabolism in soil. II. Gamma irradiation, autoclaving, air-drying and fumigation. Soil Biol. Biochem., 8, 179-188.

Ramsey, A.J. 1984. Extraction of bacteria from soil: efficiency of shaking or ultrasonification as indicated by direct counts and autoradiography. Soil Biol. Biochem., 16, 475-481.

Ross, D.J., Tate, K.R., Cairns, A. \& Meyrick, K.F. 1981. Fluctuations in microbial biomass indices at different sampling times in soils from tussock grasslands. Soil Biol. Biochem., 13, 109-114.

Ross, D.J., Tate, K.R., Cairns, A. \& Pansier, E.A. 1980. Microbial biomass estimations in soils from tussock grasslands by three biochemical procedures. Soil Biol. Biochem., 12, 375-383.

Russell, E.J. \& Hutchinson, H.B. 1909. The effect of partial sterilization of soil on the production of plant food. J. agric. Sci., Camb., 111, 111-144.

Saggar, S., Bettany, J.R. \& Stewart, J.W.B. 1981 Measurement of microbial sulfur in soil. Soil Biol. Biochem., 13, 493-498.

Schmidt, E.L. \& Paul, E.A. 1982. Microscopic methods 
for soil micro-organisms. In: Methods of soil analysis, edited by A.L. Page, R.H. Miller \& D.R. Keeney, part 2, 803-820, 2nd ed. (American Society of Agronomy series no. 9.) Madison: American Society of Agronomy.

Schnurer, J., Clarholm, M. \& Rosswall, T. 1985. Microbial biomass and activity in an agricultural soil with different organic matter contents. Soil Biol. Biochem., 17, 611-618.

Shen, S.M., Pruden, G. \& Jenkinson, D.S. 1984. Mineralization and immobilization of nitrogen in fumigated soil and the measurement of microbial biomass nitrogen. Soil Biol. Biochem., 16, 437-444.

Söderström, B.E. 1977. Vital staining of fungi in pure culture and in soil with fluorescein diacetate. Soil Biol. Biochem., 9, 59-63.

Söderström, B.E. 1979a. Some problems in assessing the fluorescein diacetate-active fungal biomass in the soil. Soil Biol. Biochem., 11, 147-148.

Söderström, B.E. 1979b. Seasonal fluctuations of active fungal biomass in horizons of a podzolized pineforest soil in central Sweden. Soil Biol. Biochem., 11, $149-154$.

Sparling, G.P., Ord, B.G. \& Vaughan, D. 1981. Microbial biomass and activity in soils amended with glucose. Soil Biol. Biochem., 13, 99-104.

Sparling, G.P., West, A.W. \& Whale, K.N. 1985. Interference from plant roots in the estimation of soil microbial ATP, C, N and P. Soil Biol. Biochem., 17, $275-278$.

Strick, J.E. \& Nakas, J.P. 1984. Calibration of a microbial sulfur technique for use in forest soils. Soil Biol. Biochem., 16, 289-291.

Tate, K.R. \& Jenkinson, D.S. 1982a. Adenosine triphosphate measurement in soil: an improved method. Soil Biol. Biochem., 14, 331-335.

Tate, K.R. \& Jenkinson, D.S. 1982b. Adenosinetriphosphate (ATP) and microbial biomass in soil: effects of storage at different temperatures and at different moisture levels. Commun. Soil Sci. Plant Anal., 13, 899-908.

Van Veen, J.A. \& Paul, E.A. 1979. Conversion of biovolume measurements of soil organisms, grown under various moisture tensions, to biomass and their nutrient contents. Appl. environ. Microbiol., 37, $686-692$

Verstraete, W., Van de Werf, H., Kucnerowicz, F., Ilaiwi, M., Verstraeten, L.M.J. \& Vlassak, K. 1983. Specific measurement of soil microbial ATP. Soil Biol. Biochem., 15, 391-396.

Voroney, R.P. 1983. Decomposition of crop residues. Ph.D. thesis, University of Saskatchewan, Saskatoon.

Voroney, R.P. \& Paul, E.A. 1984. Determination of $k_{c}$ and $k_{N}$ in situ for calibration of the chloroform fumigation-incubation method. Soil Biol. Biochem., 16, 9-14.

Waksman, S.A. \& Starkey, R.L. 1923. Partial sterilization of soil, microbiological activities and soil fertility. I. Soil Sci., 16, 137-157.

Webster, J.J., Hampton, G.J. \& Leach, F.R. 1984. ATP. in soil: a new extractant and extraction procedure. Soil Biol. Biochem., 16, 335-342.

Williams, B.L. \& Sparling, G.P. 1984. Extractable N and $P$ in relation to microbial biomass in U.K. acid organic soils. Pl. Soil., 76, 139-148.

Wynn-Williams, D.D. 1985. Photofading retardant for epifluorescence microscopy in soil micro-ecological studies. Soil Biol. Biochem., 17, 739-746. 


\title{
Assessment of stress to microbial biomass
}

\author{
K KILLHAM \\ Department of Soil Science, University of Aberdeen, Aberdeen
}

\section{Introduction}

The fundamental role of the microbial biomass in the cycling of organic matter and in controlling active nutrient pools strongly suggests that the effect of any environmental stress on the microbial biomass will be intimately related to stress effects on crops, on natural vegetation, and on ecosystem productivity.

To date, most assessments of the effects of an environmental stress on the microbial biomass have been based on assay of respiration or enzyme activity. Recent studies of effects of acid rain on biomass have used respiration with or without substrate amendment (eg Bryant et al. 1979; Hovland et al. 1980; Strayer \& Alexander 1981) or activity of dehydrogenase and other soil enzymes (Francis et al. 1980), as likely indicators of possible effects. Recent work by myself and others suggests, however, that these parameters are not the best ones to determine the true impact of environmental stress on the functioning of the microbial biomass. Physiological studies of water stress, for example, have shown that soil microorganisms divert an increasing proportion of energy from growth into maintenance of cell integrity as stress increases (Killham \& Firestone 1984). In this case, the energy diversion is needed for solute transport to counteract osmotic stress. This diversion of carbon from biosynthesis to maintenance energy requirements will occur for all environmental stresses which are adverse to the microbial cell. It might well be expected, therefore, that an increasing proportion of carbon uptake will be respired with increasing stress. Indeed, in marine micro-organisms, increasing $C$ diversion into respiration has been shown to be a function of increasing stress (Griffiths et al. 1984). It is suggested, therefore, that $\mathrm{CO}_{2}$ evolution alone cannot be used as a suitable indicator of environmental stress to microbial biomass.

A factor which incorporates partitioning of assimilated carbon into biomass growth as well as respiration is clearly necessary. This paper reports, by means of experiments using labelled C substrates and different microbial populations, a comparison between the ratio of respired $\mathrm{C}$ / biomass-incorporated $\mathrm{C}$ with respired $\mathrm{C}$ and dehydrogenase activity as indicators of environmental stress to microbial biomass in a range of habitats.

\section{Materials and methods}

2.1 Soil and leaf litter samples

2.1.1 Soil

A sandy loam (Tarves series) under arable cultivation was sampled from Turriff, 20 miles north of Aberdeen, Scotland (National Grid reference NJ734506). The soil was sieved $(<2$ $\mathrm{mm}$ ), packed into $15 \mathrm{~cm}$ diameter pots, and then the pots were sprayed twice-weekly with a range of treatment solutions. Three control pots received distilled water, 3 received $0.15 \mathrm{M} \mathrm{NaCl}$, and 3 received $0.3 \mathrm{M} \mathrm{NaCl}$. The treatments were designed to represent irrigation water of varying salinity. Treatment period was 20 weeks and the treatments were equivalent to $35 \mathrm{~cm}$ of rainfall. After 20 weeks, the surface soil $(0-2 \mathrm{~cm}$ depth) of each pot was removed and mixed thoroughly in plastic bags.

\subsubsection{Leaf litter}

Needles of Ponderosa pine (Pinus ponderosa) were collected by litter trap over a 24 -h period from a site in the western Sierra Nevada, northern California, USA. The needles were cut into approximately $2 \mathrm{~cm}$ lengths, and $10 \mathrm{~g}$ portions of litter were put into $2 \mathrm{~mm}$ mesh litter bags which were then placed just below the surface of the litter layer of intact forest floor profiles. Plastic cylinders $(15 \mathrm{~cm}$ diameter, $40 \mathrm{~cm}$ length) were used to contain the profiles. Profiles were sprayed

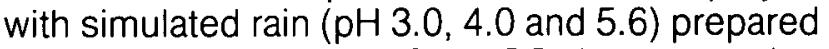
using an acid mix of $\mathrm{HNO}_{3} / \mathrm{H}_{2} \mathrm{SO}_{4}$ in a proportion of $3: 2$ and with base ions to simulate northern Californian precipitation (McColl 1981).

Table 1. Quantities of heavy metals added to simulated rain $\left(\mu \mathrm{g} \mathrm{ml}^{-1}\right)$

\begin{tabular}{lcccccc}
\hline Heavy metal load & $\mathrm{Cu}$ & $\mathrm{Ni}$ & $\mathrm{Pb}$ & $\mathrm{Zn}$ & $\mathrm{Fe}$ & $\mathrm{Co}$ \\
\hline None & - & - & - & - & - & - \\
Low & 0.3 & 0.2 & 0.1 & 0.1 & 1.0 & - \\
High & 4.2 & 6.0 & 0.2 & 0.1 & 1.1 & 0.1 \\
\hline
\end{tabular}

All rain treatments had the following initial ionic composition $\left(10^{-3} \mathrm{M}\right): \mathrm{Mg}^{2+}, 3 ; \mathrm{Ca}^{2+}, 3.5 ; \mathrm{NH}_{4}^{+}$, $14 ; \mathrm{Na}^{+}, 15 ; \mathrm{K}^{+}, 1.5$ (plus the required concentration of the $3: 2$ acid mix to produce the desired $\mathrm{pH}$ ). For each rain acidity, 3 heavy metal loads ('none', 'low', and 'high') were added, making 9 rain treatments in all (Table 1). The compositions of the 'high' and 'low' heavy metal loads were designed to approximate depositions observed downwind of the Coniston $\mathrm{Ni} / \mathrm{Cu}$ smelter, Sudbury, Ontario, at about 1.6 and $16 \mathrm{~km}$, respectively (Hutchinson \& Whitby 1976). Treatments were applied twice-weekly to 3 replicate profiles over a 22-month period; treatments totalled $150 \mathrm{~cm}$ of rainfall. 


\subsection{Incubation of samples with ${ }^{14} \mathrm{C}$ glucose}

Triplicate samples of soil $(25 \mathrm{~g})$ and of leaf litter (5 g) were placed in $500 \mathrm{ml}$ sealed Erlenmeyer flasks with an oxifluor $\mathrm{CO}_{2}$ trap and the samples amended with ${ }^{14} \mathrm{C}$ glucose $\left(1: 11 \mathrm{mCi} \mathrm{mg}^{-1}\right)$. Glucose $\left(1000 \mu \mathrm{g} \mathrm{g}^{-1}\right)$ was added as an aqueous solution, evenly pipetted over the surface of the samples, to achieve a sample moisture content of $30 \% \mathrm{w} / \mathrm{w}$ : the glucose concentration used was found to give maximum $\mathrm{C}$ uptake during incubation. After $3 \mathrm{~h}$ incubation at $25^{\circ} \mathrm{C}$, the oxifluor $\mathrm{CO}_{2}$ trap was removed and concentration of $\mathrm{CO}_{2}$ determined. The samples were then placed on a membrane $(0.45 \mu \mathrm{m})$, washed (quarter strength Ringers solution used to prevent osmotic stress to microbial cells) to remove residual glucose not taken up by the microbial populations, and the concentration of ${ }^{14} \mathrm{C}$ glucose in the washings determined. Radioactive carbon was quantified by liquid scintillation counting using a Beckman LS-100C. Subtraction of ${ }^{14} \mathrm{C}$ glucose not taken up by the microbial biomass and remaining in the soil from initial substrate concentration enabled calculation of ${ }^{14} \mathrm{C}$ glucose uptake (equation 1). Then, by subtracting respired ${ }^{14} \mathrm{C}$ from ${ }^{14} \mathrm{C}$ uptake, biomass-incorporated ${ }^{14} \mathrm{C}$ was calculated (equation 2).

${ }^{14} \mathrm{C}$ uptake $=$ initial ${ }^{14} \mathrm{C}$ substrate concentration residual ${ }^{14} \mathrm{C}$ in soil

${ }^{14} \mathrm{C}$ uptake - respired ${ }^{14} \mathrm{C}=$ biomass ${ }^{14} \mathrm{C}$

These calculations are based on the assumption that washing is effective in removing all residual glucose from the samples (see below) and that, in the short period, there was not significant efflux of ${ }^{14} \mathrm{C}$-labelled metabolites (other than $\mathrm{CO}_{2}$ ) from the microbial cells.

\subsection{Effectiveness of extraction of glucose}

To test the efficiency of quarter strength Ringers solution in removing all residual glucose not taken up by the microbial community, several soil and leaf litter samples were sterilized (autoclaved for 1 $h$ on 3 successive occasions) and then amended with $1000 \mathrm{ppm}{ }^{14} \mathrm{C}$ glucose. Samples were washed, as previously described, and the extract used for determination of ${ }^{14} \mathrm{C}$ activity. In addition, the samples were then extracted with $0.2 \mathrm{M} \mathrm{HCl}$ (shaken for $30 \mathrm{~min}$, then filtered) and the acid extracts also tested for ${ }^{14} \mathrm{C}$ activity. This procedure was carried out for 6 soils of varying $\mathrm{pH}$, clay and organic matter content to determine the suitability of water extraction of glucose for a wide range of soils. The saline-sodic soil (no. 5) was also amended with sodium borate (50 ppm B) and sodium molybdate (50 ppm Mo) prior to glucose amendment to investigate whether these salts, sometimes occurring in sodic soils, complex added glucose.
2.4 Determination of soil dehydrogenase activity

Soil dehydrogenase activity was determined by supplying 2,3,5-triphenyltetrazolium chloride (TC) as an artificial terminal $\mathrm{H}^{+}$-acceptor, and measuring reduction of the dye (Casida et al. 1964).

\subsection{Sample storage}

Soil samples and contents of litter bags were stored in polythene bags at $4^{\circ} \mathrm{C}$ prior to incubation with ${ }^{14} \mathrm{C}$ glucose or determination of dehydrogenase activity.

\subsection{Statistical analysis}

An SNK multiple range test was used for statistical analysis of the data (Zar 1974).

\section{Results and discussion}

There are 2 main conclusions concerning assessment of the effect of environmental stress on the microbial biomass of soil and leaf litter which can be drawn from the data shown in Figures 1-4.

i. Increasing environmental stress generally caused a reduction in soil and leaf litter respiration, a reduction in soil dehydrogenase activity, and an increase in the ratio of respired $\mathrm{C} /$ biomass-incorporated $\mathrm{C}$ for both soil and leaf litter.

ii. The most sensitive indicator of environmental stress was the ratio of respired $\mathrm{C} /$ biomassincorporated C. For a given increase in stress, the increase in the above ratio was, on average, twice as great as the magnitude of the concomitant reduction in either respiration or dehydrogenase activity.

It would appear, therefore, that the effect of environmental stress on microbial populations can be much better assessed by determining the allocation of $\mathrm{C}$ uptake into both biomass and respiration, rather than by the widely used methods of determining either rates of respiration or dehydrogenase activity. To partition assimilated $C$ in the above manner, samples of soil and leaf litter, which had previously been subjected to various environmental stresses, were incubated with ${ }^{14} \mathrm{C}$ glucose as substrate for their microbial populations. ${ }^{14} \mathrm{C}$ activities in respired and biomass-incorporated fractions were then determined. A substrate concentration of 1000 ppm $\mathrm{C}$ was identified as producing maximum reaction velocity $\left(\mathrm{CO}_{2}\right.$ evolution), and an incubation period of $3 \mathrm{~h}$ was selected to preclude the possibility of significant quantities of ${ }^{14} \mathrm{C}$ labelled metabolic products (amino-acids, organic acids, enzymes, etc) other than $\mathrm{CO}_{2}$ effluxing from microbial cells. Possible strategies of longerterm stress responses of microbial communities, involving leakage of metabolites as well as non- 


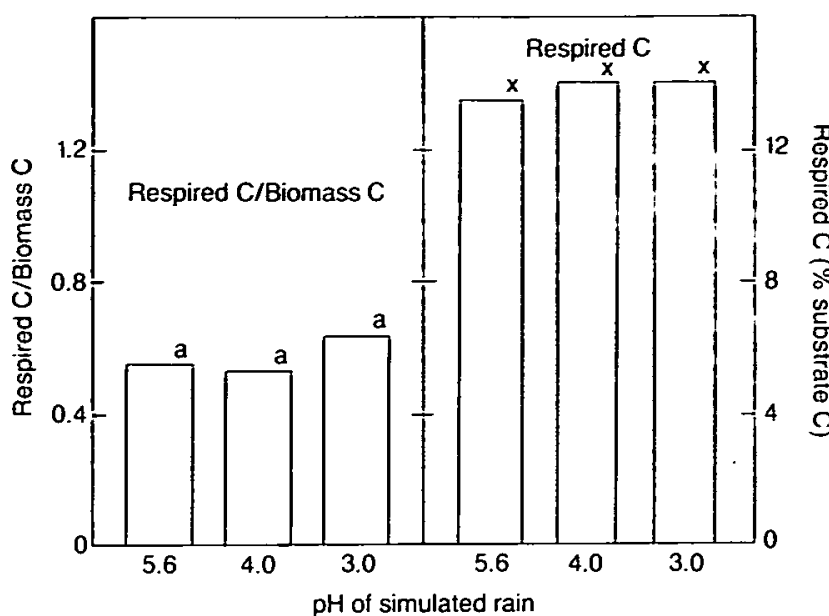

Figure 1. Effect of $\mathrm{pH}$ of simulated rain on partitioning of assimilated substrate $C$ by the microbial biomass of Ponderosa pine needle litter. Letters indicate significant $(P<0.05)$ differences between means

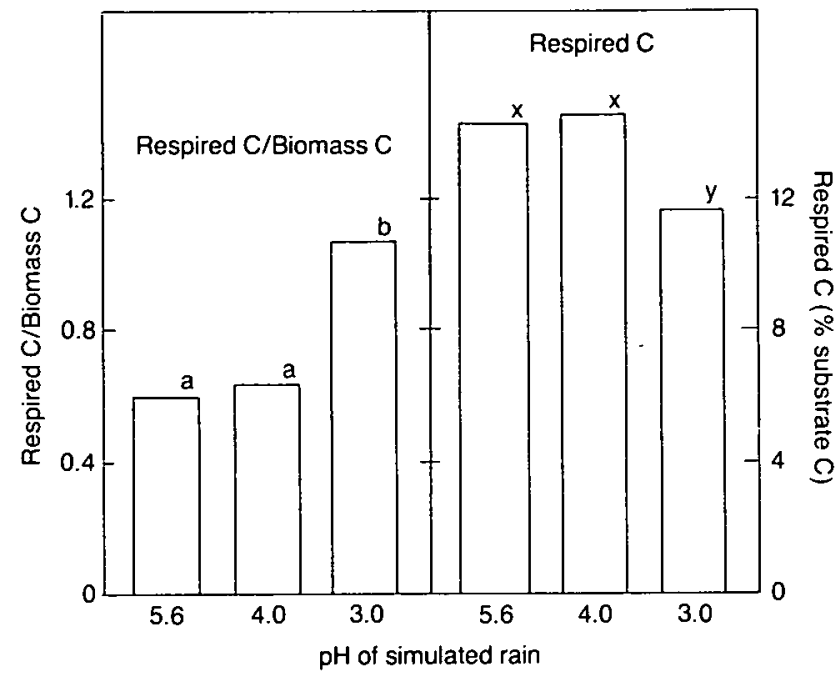

Figure 2. Effect of $\mathrm{pH}$ of simulated rain, containing the 'high' heavy metal load, on partitioning of assimilated substrate $C$ by the microbial biomass of Ponderosa pine needle litter. Letters indicate significant $(P<0.05)$ differences between means

physiological mechanisms of response, have been reviewed (Daigger \& Grady 1982).

In the case of the pine litter samples exposed to treatments designed to simulate possible pollution loads downwind of a metal smelter, neither acidity nor heavy metal load (in isolation) of the treatments caused significant $(P<0.05)$ stress (as determined by changes in respiration or in respired $\mathrm{C} /$ biomass-incorporated $\mathrm{C}$ ) to the microbial biomass (Figures 1, 2 \& 3). Even the extreme pH 3.0 treatment, when applied without an additional heavy metal load, had no significant effect. It was only when heavy metal loads were applied in the most acid ( $\mathrm{pH} 3.0)$ simulated rain that significant stress was detected. When the 'high' heavy metal load was applied in the pH 3.0

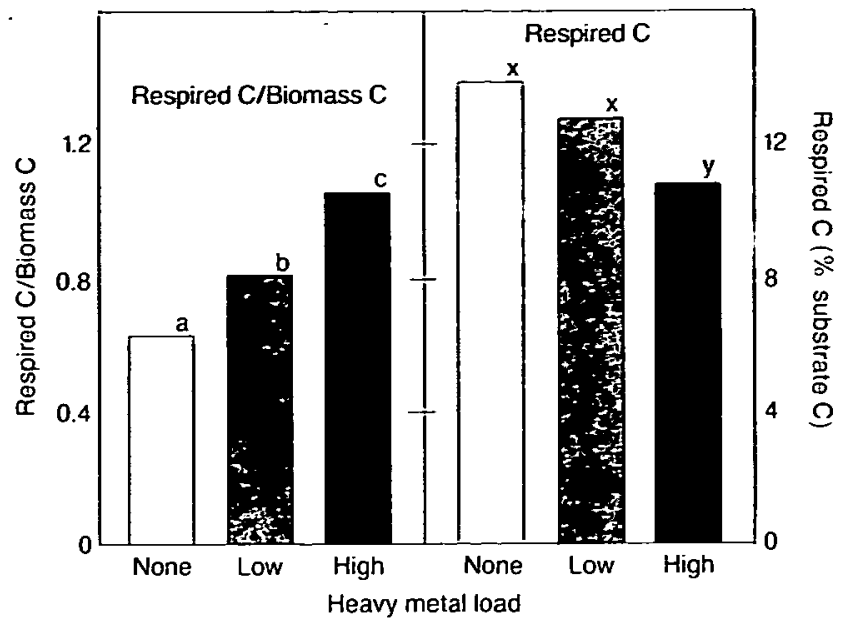

Figure 3. Effect of heavy metal load, applied in simulated rain $(\mathrm{pH} 3.0)$ on partitioning of assimilated substrate $C$ by the microbial biomass of Ponderosa pine needle litter. Letters indicate significant $(P<0.05)$ differences between means

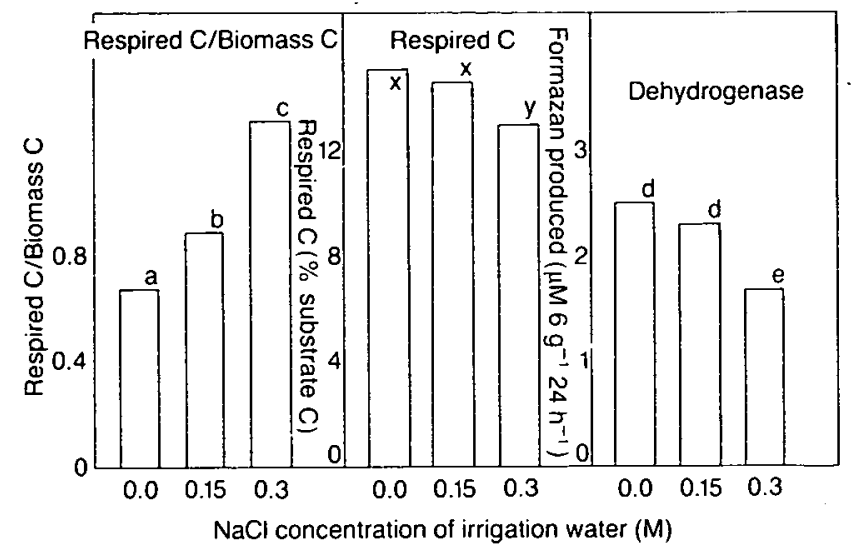

Figure 4. Effect of $\mathrm{NaCl}$ concentration of irrigation water on partitioning of assimilated substrate $C$ and on dehydrogenase activity of soil microbial biomass. Letters indicate significant $(P<0.05)$ differences between means

treatment, the ratio of respired $\mathrm{C} / \mathrm{biomass}$ incorporated $\mathrm{C}$ increased by $75 \%$, while respired $\mathrm{C}$ alone decreased by only $28 \%$, compared to controls ( $\mathrm{pH}$ 5.6, no metals). This greater sensitivity of the ratio of respired C/biomassincorporated $\mathrm{C}$ as a stress indicator was also evident for soils exposed to the $\mathrm{pH} 3.0$, 'low' metals treatment, where the ratio increased by $30 \%$ despite respiration not being significantly changed (Figure 2). There was no glucose uptake in sterile, control soil samples under any of the treatments used. In the case of the soil samples irrigated under regimes of varying salinity, stress to the microbial biomass was detected even when the least saline of the saline treatments $(0.15 \mathrm{M}$ $\mathrm{NaCl}$ ) was used (Figure 4). Again, however, stress-induced changes in the ratio of respired $\mathrm{C} /$ biomass-incorporated $\mathrm{C}$ were considerably greater than corresponding changes in either respiration or dehydrogenase activity. In fact, 
when soils were irrigated with $0.15 \mathrm{M} \mathrm{NaCl}$, stress to the microbial biomass could only be detected by determination of respired C/biomassincorporated $\mathrm{C}$, there being no significant change in respiration or dehydrogenase compared to control soils receiving distilled water.

A marked discrepancy between the effects of environmental stress on the ratio of respired $\mathrm{C} /$ biomass-incorporated $\mathrm{C}$ and on respiration or dehydrogenase activity raises fundamental questions concerning our future approach to assessing the impact of environmental stresses, and concerning interpretation of previous studies which relied solely on respiration or dehydrogenase as the determinants of stressinduced changes in microbial activity. One can easily hypothesize a situation where the respiration rate of a microbial community is effectively unchanged by some environmental stress, despite the fact that both $C$ uptake and $C$ flow into growth of biomass have been drastically reduced. In the context of the findings of this study, such a situation is far from inconceivable. Growth of the microbial biomass could even be stopped entirely, despite the fact that respiration data alone would suggest no adverse impact of the environmental stress. Such a situation is represented by Figure 5 which shows a hypothetical response of the energy budget of microbial biomass to an increasing environmental stress. Growth of the biomass ceases when the entire energy budget is used for maintenance requirements. At higher stresses, cell damage/ death will result because more energy is required for maintenance than may be available.

The validity of the technique reported here is based on the assumption that a simple quarter strength Ringers solution is effective in removing all residual glucose, not taken up by the microbial population, from the soil and leaf litter samples. This assumption was tested by glucose amendment of sterile samples and, after the normal washing procedure, extracting with $0.2 \mathrm{M}$ $\mathrm{HCl}$ and assaying the acid extracts for ${ }^{14} \mathrm{C}$ activity. Washing was highly effective in removing residual glucose, not only from the soil and leaf litter samples used in this study, but also from several other soils of varying $\mathrm{pH}$, clay and organic matter content (Table 2). With the exception of the high organic matter peat soil (no. 4), at least $95 \%$ of the glucose added to the sterilized soils was recovered. Also, when borate or molybdate was added to the saline-sodic soil of high pH 9 (no. 5), complexing of glucose occurred and recoveries were substantially reduced. That borates and molybdates can complex glucose is well established (Foster \& Stacey 1953; Murayama 1977; Cheshire et al. 1979). It is proposed, therefore, that this new technique for determining stress to the microbial biomass will be suitable for most soil types, as well as leaf litter samples. Soils of exceptionally high organic matter content as well as saline or saline-sodic soils containing borates or molybdates will be less suited, without modification of the method.

The technique used in this study offers a rapid, simple, and much more sensitive alternative to assaying respiration or dehydrogenase activity as an indicator of physiological stress to microbial biomass. Greatly increased sensitivity in identification and determination of stress suggests that extrapolations of respiration or dehydrogenase data alone to the ecological ramifications of environmental disturbances should be treated with great caution.

\section{Summary}

By supplying ${ }^{14} \mathrm{C}$-labelled glucose as substrate, the ratio of respired $\mathrm{C} /$ biomass-incorporated $\mathrm{C}$ was determined for the microbial biomass of samples of soil and leaf litter after their exposure to a range of environmental stresses. The ratio of respired $\mathrm{C} /$ biomass-incorporated $\mathrm{C}$ was found to be a much more sensitive indicator of the impact of stress than either respiration or dehydrogenase

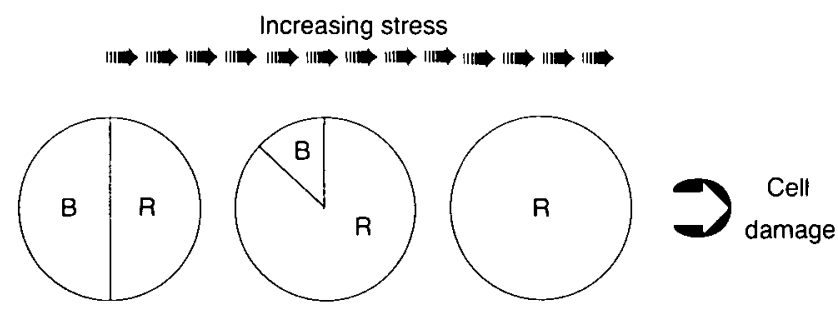

Figure 5. Possible response pattern in terms of carbon-allocation strategy, of the microbial biomass to increasing environmental stress

Table 2. Efficiency of extraction of glucose

\begin{tabular}{lcccc}
\hline Soil & $\mathrm{pH}$ & \% organic C & \% clay & \% glucose recovered \\
\hline 1. Turriff & 4.4 & 3.3 & 8.4 & 98 \\
2. Tillycorthie & 5.8 & 22.9 & 10.1 & 97 \\
3. Cruden bay clay & 5.1 & 3.1 & 17.7 & 96 \\
4. Red moss peat & 3.4 & 46.4 & 0.0 & 88 \\
5. Ethiopian saline soil & 8.0 & 2.3 & 10.3 & 95 \\
6. Soil 5 $+50 \mu \mathrm{g} \mathrm{B}\left(\mathrm{g}^{-1}\right.$ soil) & 8.0 & 2.3 & 10.3 & 79 \\
7. Soil 5 $+50 \mu \mathrm{g} \mathrm{Mo}\left(\mathrm{g}^{-1}\right.$ soil) & 8.0 & 2.3 & 10.3 & 86 \\
\hline
\end{tabular}


activity, which are currently most widely used as stress indicators for microbial biomass. The ratio decreased as the magnitude of environmental stress increased, suggesting that there is an increasing diversion of carbon in the biomass from biosynthesis to maintenance energy requirements. Patterns of response of the microbial biomass to environmental stress are discussed in relation to carbon allocation by the biomass, and to biomass growth.

\section{References}

Bryant, R.D., Gordy, E.A. \& Laishley, E.J. 1979. Effect of soil acidification on the soil microflora. Water Air \& Soil Pollut., 11, 437-445.

Casida, L.E., Klein, D.A. \& Santoro, T. 1964. Soil dehydrogenase activity. Soil Sci., 98, 371-376.

Cheshire, M.V., Mundie, C.M. \& Shepherd, H. 1979. Transformation of carbohydrate constituents of grass during decomposition in soil. J. Sci. Fd Agric., 30, 330.

Daigger, G.T. \& Grady, C.P.L. 1982. The dynamics of microbial growth on soluble substrates - a unifying theory. Wat. Res., 16, 365-382.

Foster, A.B. \& Stacey, M. 1953. Chromatography of some carbohydrate derivatives. J. appl. Chem., Lond., 3, 19.

Francis, A.J., Olson, D. \& Bernatsky, R. 1980. Effect of acidity on microbial processes in a forest soil. In: Ecological impacts of acid precipitation, edited by $\mathrm{D}$. Drablos \& A. Tollans, 166-167. (Proc. int. Conf., Norway, 1980.) Oslo-As: SNSF.

Griffiths, R.P., Caldwell, B.A. \& Morita, R.Y. 1984.
Observations on microbial per cent respiration values in arctic and subarctic marine waters and sediments. Microb. Ecol., 10, 151-164.

Hovland, J., Abrahamsen, G. \& Ogner, C. 1980. Effects of artificial acid rain on decomposition of spruce needles and on mobilization and leaching of elements. PI. Soil, 56, 365-378.

Hutchinson, T.C. \& Whitby, L.M. 1976. The effects of acid rainfall and heavy metal particulates on a boreal forest ecosystem near the Sudbury smelting region of Canada. In: Proc. int. Symp. Acid Precipitation and the Forest Ecosystem, 1st, 1976, edited by L.S. Dochinger \& T.A. Seliga, 745-765. (General technical report NE23.) USDA Forest Service.

Killham, K. \& Firestone, M.K. 1984. Salt stress control of intracellular solutes in streptomycetes indigenous to saline soils. Appl. environ. Microbiol., 47, 301-306.

McColl, J.G. 1981. Effects of acid rain on plants and soils in California. (Final report no. PB82-122-110, Contract A8-136-31.) Springfield: NTIS.

Murayama, S. 1977. An automated anion-exchange chromatographic procedure for the estimation of saccharides in acid hydrolysates of soil. Soil Sci. Plant Nutr. Jap., 23, 247-252.

Strayer, R.F. \& Alexander, M. 1981. Effects of simulated acid rain on glucose mineralization and some physicochemical properties of forest soils. J. environ. Qual., 10, 460-465.

Zar, J.H. 1974. Biostatistical analysis. New Jersey: Prentice-Hall. 


\section{Mineralization of organic phosphorus in relation to soil factors, determined using isotopic ${ }^{32} \mathrm{P}$ labelling}

A F HARRISON

ITE, Merlewood Research Station, Grange-over-Sands

\section{Introduction}

The mineralization of organically bound phosphorus, which forms a major fraction of the soil $P$ capital (Harrison 1979), is essential to the maintenance of the phosphorus cycle and the replenishment of the available $P$ in the soil in forest ecosystems (Harrison 1985). The trees and ground flora, in a local phosphorus-deficient deciduous woodland - Meathop Wood - take up about $11.4 \mathrm{~kg} \mathrm{P} \mathrm{ha}^{-1} \mathrm{yr}^{-1}$ from the soil, and this amount is about the average annual uptake for temperate woodlands and forests. If it is assumed that all the $P$ taken up by the vegetation is derived from mineralization of organic phosphorus in the top $5 \mathrm{~cm}$ of the soil profile, then the average rate of mineralization required through the year is only about $95 \mathrm{mg} \mathrm{P} \mathrm{m}^{-2}$ month $^{-1}$ or $4 \mu \mathrm{g} \mathrm{P} \mathrm{g}{ }^{-1}$ soil month $^{-1}$. This amounts to about $0.2 \%$ to $1 \%$ of the organic phosphorus pool in Lake District woodland soils each month. Furthermore, small differences in mineralization rates at the level of $<5 \mu \mathrm{g} \mathrm{P} \mathrm{g}{ }^{-1}$ soil month ${ }^{-1}$, caused by variation in soil conditions or site management factors, could be quite important in influencing the productivity of both the local woodlands and other UK forest plantations, as they are frequently P-deficient. These rates of mineralization are extremely low.

These conclusions are probably relevant to most ecosystems, for only a small proportion of the soil organic phosphorus needs to be mineralized to provide significant quantities of inorganic phosphorus to plants (Greb \& Olsen 1967). With such low rates of mineralization being potentially important, how do we attempt to determine the factors, such as soil and environmental conditions and site management, which have a controlling influence on the rate of soil organic phosphorus mineralization?

At ITE's Merlewood Research Station, we have tried to determine organic $P$ mineralization rates using the conventional incubation methods, but the results from such techniques are far from satisfactory for local woodland soils. Often reductions in the labile organic phosphorus, that extractable in Olsen's bicarbonate (Bowman \& Cole 1978a), during incubation are not paralleled by an apparent and equivalent increase in inorganic phosphorus, so we cannot be confident that mineralization is actually taking place. Only the net changes in the labile organic and inorganic phosphorus are being measured by these techniques, and both may change in their extractability during incubation. Also, error terms on the measurements are large, particularly in relation to the low rates of the mineralization required in the ecosystem (see Halstead et al. 1963), so that few statistically significant changes in organic or inorganic phosphorus contents of soils are detected on incubation, even after incubation for a period of 6 months (Harrison 1982a). The conventional techniques of incubation appear to be too insensitive and imprecise to answer the problem of how soil and environmental conditions and site management factors influence organic phosphorus mineralization rates in woodland and forest soils.

Consequently, there is a need for another approach to the assay of comparative rates of organic phosphorus mineralization in these woodland soils. I have developed a method in which ${ }^{32} \mathrm{P}$-labelled ribose-nucleic acid (RNA is a component of the labile fraction of soil organic phosphorus - Bowman \& Cole 1978b) was added to soils, which were subsequently incubated. The amount of mineralization was determined following the recovery of the ${ }^{32} \mathrm{P}$ from soils and its partitioning into organic and inorganic forms. The main attribute of the method is the considerably improved sensitivity due to the use of ${ }^{32} \mathrm{P}$ as a tracer and its capacity to provide gross, rather than net, conversion rates. It was sensitive enough to detect highly significant differences in rates of mineralization in the woodland soils, after only $24 \mathrm{~h}$ incubation at $13^{\circ} \mathrm{C}$, the period being shorter and the temperature being lower than in commonly used incubation methods.

\section{Soils and methods}

Soil samples were collected from the $0-5 \mathrm{~cm}$ depth (after the removal of the litter layer) from brown earth, brown podzolic and rendzina profiles from 13 different Lake District woodlands. Twentyfive samples (1-3 per woodland) were collected in October 1973, and a similar set was obtained the following May. Soils were sieved $(2 \mathrm{~mm})$ to remove stones and root material, but were otherwise used in a fresh condition. They varied considerably in their physical and chemical properties (Harrison 1982b).

Subsamples of each fresh soil were compacted into polystyrene 'sterilin' tubes, so that each tube contained $10 \mathrm{~cm}^{3}$ soil at its natural bulk density. After equilibrating the soils at $13^{\circ} \mathrm{C}$ (the average soil temperature at the times of the year sampled) 
for one day, $1 \mathrm{ml}$ of ${ }^{32} \mathrm{P}$-RNA (containing $97 \mu \mathrm{g}$ $\mathrm{RNA} \equiv 7.8 \mu \mathrm{g} P$, with average molecular weight 30000 and a specific activity of $c 130 \mathrm{GBq}$ per $10^{-3} \mathrm{M}$ ) was distributed in the soil of each tube; using a hypodermic syringe. The ${ }^{32}$ P-RNA was added in an amount less than generally found to be present in soils. The tubes were incubated for $24 \mathrm{~h}$ at $13^{\circ} \mathrm{C}$, after which the soil in each tube was mixed and divided into 4 equal weighed subsamples, each of which was added to $100 \mathrm{ml}$ of an extractant solution in a polypropylene bottle. The suspension was then subjected to ultrasonic vibration ( $50 \mathrm{~W}, 20 \mathrm{kHz}$ at $6-8 \mu$ amplitude) for 5 min. Bottles were shaken subsequently overnight on a reciprocal shaker in a waterbath at $18^{\circ} \mathrm{C}$. Subsamples of the suspension were centrifuged and the ${ }^{32} \mathrm{P}$-labelled phosphorus in the supernatant partitioned into inorganic and organic forms, using a method similar to that of Martin and Doty (1949); inorganic ${ }^{32} \mathrm{P}$ transferred into the isobutanol-benzene layer with an efficiency of $>99.5 \%$. Total ${ }^{32} \mathrm{P}$ recovered in the original supernatant and inorganic ${ }^{32} \mathrm{P}$ recovered in the organic layer were determined, after addition to fluor, by liquid scintillation spectrometry. To determine the degree of ${ }^{32} \mathrm{P}-\mathrm{RNA}$ hydrolysis caused by the extraction and separation procedures, control samples were also prepared for all soils; ${ }^{32}$ P-RNA was added to soil, immediately extracted, and partitioned into organic and inorganic forms. Recoveries of ${ }^{32} \mathrm{P}$ from the 50 soils ranged from $56 \pm 2$ to $104 \pm 6 \%$, with only 10 soils having recoveries of $<80 \%$; recovery was negatively related to the amounts of extractable calcium $\left(r^{2}=0.71^{* *}\right)$ and clay $\left(r^{2}=0.42^{* *}\right)$ in the soils. In the calculations of the mineralization rate, it has been assumed that ${ }^{32} \mathrm{P}$ not recovered from the soil was apportioned between organic and inorganic forms in the same ratio as that extracted. Further details of the methodology are presented in Harrison (1982a).

\section{Results}

The rates of net mineralization of the ${ }^{32} \mathrm{P}-\mathrm{RNA}$ in the 50 soils ranged from -29 to $190 \mathrm{ng} \mathrm{P} \mathrm{cm}^{-3}$ soil day $^{-1}$, with a least significant difference of about $10 \mathrm{ng}$. These rates of mineralization are equivalent to 0.75 to $5.7 \mu \mathrm{g} \mathrm{P} \mathrm{cm} \mathrm{cm}^{-3}$ soil month ${ }^{-1}$. The negative values are attributable to net immobilization of the small amount of inorganic ${ }^{32} \mathrm{P}$ present in the ${ }^{32} \mathrm{P}-\mathrm{RNA}$ preparation. Net immobilization of inorganic $P$ occurred in 12 of the October samples, with no May samples having negative mineralization rates. Partially as a result, soils collected in October had lower rates of mineralization $\left(9.2 \pm 7.8 \mathrm{ng} \mathrm{P} \mathrm{cm}^{-3}\right.$ soil day $\left.{ }^{-1}\right)$ than those collected in May $\left(45.9 \pm 9.8 \mathrm{ng} \mathrm{P} \mathrm{cm}^{-3}\right.$ soil day $\left.^{-1}\right)$. Soils over limestone, irrespective of the time of the year collected, had higher rates of mineralization ( $56 \pm 14.2 \mathrm{ng} P \mathrm{~cm}^{-3}$ soil day ${ }^{-1}$ ) than those soils over slates, shales and andesite- tuff rocks $\left(10 \pm 4.2 \mathrm{ng} \mathrm{P} \mathrm{cm}^{-3}\right.$ soil day $\left.{ }^{-1}\right)$. There were also strong interactive effects of the time of year and the underlying geology, as shown by covariance analysis, on the relationships between mineralization rate and soil chemical and physical properties (Table 1). In general, however, strong and significant positive relationships were found with soil $\mathrm{pH}$ and extractable calcium contents, and available phosphorus contents (expressed as a combined function of water-soluble, isotopically exchangeable and Olsen's bicarbonate extractable inorganic phosphorus) across all soils (Table 2). Fifty per cent of the variation in ${ }^{32} \mathrm{P}-\mathrm{RNA}$ mineralization rate was accounted for by the 3 'available' $P$ variables, sometimes more when the soils were partitioned according to the geology and time factors. A significant negative relationship was also found between mineralization rate and the Olsen's bicarbonate extractable organic phosphorus content (particularly when expressed as a percentage of the total organic phosphorus) of soils; the latter is considered to be the labile fraction of soil organic phosphorus (Bowman \& Cole 1978a). Relationships with phosphatase activity and respiration rate in the soils were found only for soils overlying slates, shales and andesite-tuff rocks. Around $90 \%$ of the variation in rates of mineralization in the soils was accounted for by significant soil properties (not all the measured soil properties are mentioned in this paper). Further details of the relationships between the rate of ${ }^{32} \mathrm{P}-\mathrm{RNA}$ mineralization and soil properties are presented in Harrison (1982b).

\section{Discussion}

The question of whether or not analytical procedures to be applied to soils are sensitive

Table 1. Effects ${ }^{1}$ of geology and time of sampling on relationships between ${ }^{32}$ P-RNA mineralization rate and properties in 50 soils

\begin{tabular}{|c|c|c|c|c|}
\hline Property & $\begin{array}{r}\mathrm{Ge} \\
\text { Slope }\end{array}$ & $\begin{array}{l}\text { ology } 2 \\
\text { Elevation }\end{array}$ & Slope & $\begin{array}{l}\text { Time }^{3} \\
\text { Elevation }\end{array}$ \\
\hline $\mathrm{pH}$ & NS & NS & $\star$ & 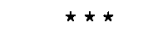 \\
\hline Extractable $\mathrm{Ca}$ & NS & NS & $\star \star$ & * \\
\hline${ }^{32} \mathrm{P}$-exchangeable $\mathrm{P}_{\mathrm{i}}$ & NS & NS & NS & NS \\
\hline Water-soluble $\mathrm{P}_{\mathrm{i}}$ & NS & *** & $\star \star \star$ & $\star \star \star$ \\
\hline Extractable $P_{i}$ & $\star$ & 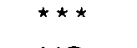 & NS & * \\
\hline Extractable $\mathrm{P}_{0}$ & * & NS & NS & * * \\
\hline Extractable $P_{0} \% P_{t}$ & NS & NS & $\star$ & * * \\
\hline Phosphatase activity & & $\star \star \star \star$ & NS & 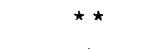 \\
\hline Soil respiration & NS & * * & NS & * \\
\hline
\end{tabular}

1 As shown by covariance analysis

${ }^{*},{ }^{*},{ }^{*}$ * Significant at $\mathrm{P}<0.05, \mathrm{P}<0.01$ and $P<0.001$ respectively

${ }^{2}$ Group 1 Soils on slates, shales and Andesite-tuffs Group 2 Soils on limestone

${ }^{3}$ Group 1 October sampling

Group 2 May sampling 
Table 2. Relationships between ${ }^{32} \mathrm{P}-\mathrm{RNA}$ mineralization rates and some soil properties ${ }^{1}$

\begin{tabular}{|c|c|c|c|c|c|c|c|c|c|c|}
\hline \multirow{3}{*}{ Property } & \multirow{2}{*}{\multicolumn{2}{|c|}{ All soils }} & \multicolumn{4}{|c|}{ Geology } & \multicolumn{4}{|c|}{ Time } \\
\hline & & & \multicolumn{2}{|c|}{$\begin{array}{c}\text { Slates \& } \\
\text { Andesites }\end{array}$} & \multicolumn{2}{|c|}{ Limestone } & \multicolumn{2}{|c|}{ October } & \multicolumn{2}{|c|}{ May } \\
\hline & \pm & $r^{2}$ & \pm & $r^{2}$ & \pm & $r^{2}$ & \pm & $r^{2}$ & \pm & $r^{2}$ \\
\hline $\begin{array}{l}\mathrm{pH} \\
\text { Extractable } \mathrm{Ca}\end{array}$ & $\begin{array}{c}+ \\
(+)\end{array}$ & $\begin{array}{l}0.42^{* *} \\
0.49^{* *}\end{array}$ & $\begin{array}{l}(+) \\
+\end{array}$ & $\begin{array}{l}0.48^{* \star} \\
0.62^{\star *}\end{array}$ & $\begin{array}{l}+ \\
+\end{array}$ & $\begin{array}{l}0.24^{\star} \\
0.27^{\star}\end{array}$ & $\begin{array}{c}+ \\
(+)\end{array}$ & $\begin{array}{l}0.30^{\star \star} \\
0.44^{\star \star}\end{array}$ & $\begin{array}{l}+ \\
+\end{array}$ & $\begin{array}{l}0.67^{\star} \\
0.73^{\star}\end{array}$ \\
\hline $\begin{array}{l}{ }^{32} \mathrm{P} \text {-exchangeable } \mathrm{P}_{\mathrm{i}} \\
\text { Water-soluble } \mathrm{P}_{\mathrm{i}} \\
\text { Extractable } \mathrm{P}_{\mathrm{i}} \\
\text { Extractable } \mathrm{P}_{\circ} \\
\text { Extractable } \mathrm{P}_{0}^{\circ} \% \mathrm{P}_{\mathrm{i}}\end{array}$ & $\begin{array}{l}+ \\
+ \\
+ \\
(-) \\
(-)\end{array}$ & $\begin{array}{l}0.42^{\star \star} \\
0.14^{\star \star} \\
0.27^{\star \star} \\
0.24^{\star \star} \\
0.43^{\star \star}\end{array}$ & $\begin{array}{l}+ \\
+ \\
+ \\
(-)\end{array}$ & $\begin{array}{l}0.35^{\star *} \\
0.24^{\star *} \\
0.24^{* *} \\
0.32^{\star \star}\end{array}$ & $\begin{array}{l}+ \\
(+) \\
+ \\
-\end{array}$ & $\begin{array}{l}0.27^{*} \\
0.36^{*} \\
0.28^{*} \\
0.24^{*}\end{array}$ & $\begin{array}{l}(+) \\
+ \\
+ \\
-\end{array}$ & $\begin{array}{l}0.56^{\star \star} \\
0.77^{\star} \\
0.79^{\star \star} \\
0.27^{\star \star}\end{array}$ & $\begin{array}{l}+ \\
(-) \\
(-)\end{array}$ & $\begin{array}{l}0.47^{*} \\
0.42^{*} \\
0.52^{*}\end{array}$ \\
\hline $\begin{array}{l}\text { Phosphatase activity } \\
\text { Soil respiration }\end{array}$ & + & $0.10^{\star}$ & $\begin{array}{l}(+) \\
(+)\end{array}$ & $\begin{array}{l}0.60^{\star *} \\
0.51^{\star \star}\end{array}$ & & & & & & \\
\hline
\end{tabular}

- Properties expressed $\mathrm{cm}^{-3}$; ( ) significant quadratic term

enough to measure the likely biologically significant differences in the parameters of particular interest in a study should always be asked, preferably before embarking on the study. In the case of the present method, the use of ${ }^{32} \mathrm{P}$ as a tracer has markedly increased the sensitivity obtainable and also made it possible to measure both mineralization and microbial immobilization processes at the same time. The mineralization rates measured, using this method, are of the same order as those likely to be significant in the replenishment of available phosphorus in the local woodland soils. The method also has the following advantages: (i) it generates reasonably precise estimates of mineralization in soils; (ii) the pattern of the relationships between mineralization rate and soil properties appears to be theoretically acceptable; and (iii) it is sensitive enough to be able to detect interactive effects of geology and season in those relationships as well. Moreover, a very high proportion of the variation in the ${ }^{32}$ P-RNA mineralization rates between soils could be accounted for by the measured soil properties.

As a consequence, it appears to be quite suitable for studies determining the various influences of soil conditions, crop type, environmental and land management factors on rates of organic phosphorus mineralization in soils. It could also provide answers to questions about the relative uptake by plants and micro-organisms of phosphorus from the labile organic phosphorus pool during the growing season (Tate 1984). Analysis of the effects of all these factors, through the development of predictive models, is important, as the mineralization of organic phosphorus is a key process in the phosphorus cycle of managed or 'natural' terrestrial ecosystems and the maintenance of soil fertility (Harrison 1985, 1987).

\section{Summary}

An isotopic method, to examine the mineralization of labile organic phosphorus in soils at the low rates likely to be significant in the nutrition of forest trees, is briefly outlined. The method uses ${ }^{32} \mathrm{P}$-labelled RNA, added at $780 \mathrm{ng} \mathrm{P} \mathrm{cm}^{-3}$, and allows adjustments to be made for its hydrolysis induced during the soil extraction and organicinorganic separation phases of the procedure. Rates of mineralization in 50 soils, with $\mathrm{pH}$ ranging from 3.1 to 7.5 , varied from -29 to $190 \mathrm{ng}$ $\mathrm{P} \mathrm{cm}{ }^{-3}$ when incubated for $24 \mathrm{~h}$ at $13^{\circ} \mathrm{C}$. The rates of mineralization were primarily related to soil $\mathrm{pH}$ and extractable calcium, and nearly $50 \%$ of their variation was related to the availability of $P$ in the soils. Using covariance analysis, interactions of site geology and time of the year were found in the relationships between mineralization rate and a range of soil properties. Over $90 \%$ of the total variation in rates of mineralization could be accounted for by soil chemical, physical and biological properties. The method is considered to be useful in understanding the influences of soil conditions and environmental factors on the rate of organic phosphorus mineralization in soils.

\section{References}

Bowman, R.A. \& Cole, C.V. 1978a. Transformations of organic phosphorus substrates in soils as evaluated by $\mathrm{NaHCO}_{3}$ extraction. Soil Sci., 125, 49-54.

Bowman, R.A. \& Cole, C.V. 1978b. An exploratory method for fractionation of organic phosphorus from grassland soils. Soil Sci., 125, 95-101.

Greb, B.W. \& Olsen, S.R. 1967. Organic phosphorus in calcareous Colorado soils. Proc. Soil Sci. Soc. Am., 31, 85-89.

Halstead, R.L., Lapensee, J.M. \& Ivarson, K.C. 1963. Mineralization of soil organic phosphorus with particular reference to the effect of lime. Can. J. Soil Sci., 43, 97-106. 
Harrison, A.F. 1979. Variation in four phosphorus properties in woodland soils. Soil Biol. Biochem., 11, 393-403.

Harrison, A.F. 1982a. ${ }^{32} \mathrm{P}$-method to compare rates of mineralization of labile organic phosphorus in woodland soils. Soil Biol. Biochem., 14, 337-341.

Harrison, A.F. 1982b. Labile organic phosphorus mineralization in relationship to soil properties. Soil Biol. Biochem., 14, 343-351.

Harrison, A.F. 1985. Effects of environment and management on phosphorus cycling in terrestrial ecosystems. J. environ. Manage., 20, 163-179.

Harrison, A.F. 1987. Soil organic phosphorus: a world literature review. Slough: Commonwealth Agricultural Bureaux. In press.

Martin, J.B. \& Doty, D.M. 1949. Determination of inorganic phosphate. Modification of the isobutyl alcohol procedure. Analyt. Chem., 21, 965-967.

Take, K.R. 1984. The biological transformation of $P$ in soil. PI. Soil, 76, 245-256. 


\title{
Reference materials for ecological analysis
}

\author{
A P ROWLAND
}

ITE, Merlewood Research Station, Grange-over-Sands

\section{Introduction}

Quality control is an essential feature of analytical procedures, but in the chemical analysis of ecological samples it is difficult to select ideal control materials when there are a large number of determinands. Certified vegetation reference materials are available to check at intervals the accuracy of methods which will initially have been verified by comparison with existing procedures or by standard addition tests. In routine use, reagent blanks will also need to be included to assess the bias from background levels or contamination. Replicate analyses will indicate the elemental precision.

The use of certified vegetation materials as routine control samples can raise problems. Only a few have been made available in the USA and Europe, and large quantities are expensive or even unobtainable. The levels of some nutrients may be far from ideal for the work of a particular laboratory, and some elements of interest may not be certified even provisionally. Under these circumstances, there is a case for a laboratory to prepare its own reference material where repeated analyses will in time become the equivalent of certification. Only a small amount of an existing certified material need then be purchased for an occasional check.

In the laboratories at ITE's Merlewood Research Station an internal control sample of heather (Calluna vulgaris) has been in use for many years. This paper reviews the factors involved in its selection and analysis, and the suitability of alternative vegetation species. For soil analysis, long-term data have been accumulated from a local drift soil, and these data have proved useful when developing new methods. Natural waters and leachates are inherently unstable and, as such, are unsuitable for control samples, so a synthetic control sample has to be prepared. Development of ion chromatography methodology was aided considerably by the use of a synthetic reference solution, and some of the development work will be discussed briefly.

\section{Materials and methods}

\subsection{Vegetation}

2.1. Samples were dried at $40^{\circ} \mathrm{C}$ for 24 hours and ground to $<0.7 \mathrm{~mm}$. All results were expressed on a dry weight basis.

2.1.2 Sample solutions were prepared for total nutrient analysis using a modified Kjeldahl digestion (Parkinson \& Allen 1975).
2.1.3 $\mathrm{N}$ in solution was estimated using an indophenol blue AutoAnalyzer colorimetric method (Rowland 1983).

2.1.4 Other nutrients were determined as in Allen et al. (1974), and are as follows:

$\mathrm{Na}, \mathrm{K}$ - flame photometry

$\mathrm{Ca}, \mathrm{Mg}$ - atomic absorption including lanthanum addition

$\mathrm{Mn}, \mathrm{Cu}, \mathrm{Zn}-$ atomic absorption

$\mathrm{P}, \mathrm{Fe}-$ automated colorimetry using AutoAnalyzer methods.

All standard solutions were compensated by the addition of digested reagent blank.

2.2 Soil

2.2.1 Soil samples were dried at $40^{\circ} \mathrm{C}$, screened through a $2 \mathrm{~mm}$ sieve and then ball-milled to $<0.15 \mathrm{~mm}$.

2.2.2 Samples were digested and analysed for $N$ and $P$ by adapting the procedures previously outlined (Rowland \& Grimshaw 1985).

2.3 Natural waters

2.3.1 Sample solutions were filtered $(<0.45 \mu \mathrm{m})$, stored at $4^{\circ} \mathrm{C}$, and analysed as soon as possible.

2.3.2 $\mathrm{NO}_{3}^{-}, \mathrm{Cl}^{-}$and $\mathrm{SO}_{4}{ }^{2-}$ were estimated using ion chromatography (Dionex 2010i) under standard conditions (Rowland 1986).

2.3.3 Instructions for preparing the synthetic control sample are as follows. Dissolve separately $0.571 \mathrm{~g} \mathrm{NH}_{4} \mathrm{NO}_{3}, 0.955 \mathrm{~g} \mathrm{KCl}$ $2.027 \mathrm{~g} \mathrm{MgSO}_{4} .7 \mathrm{H}_{2} \mathrm{O}, 0.8266 \mathrm{~g} \mathrm{NaCl}, 0.755$ g NaH $\mathrm{PO}_{4} .2 \mathrm{H}_{2} \mathrm{O}, 0.6714 \mathrm{~g} \mathrm{Na}_{2} \mathrm{SiF}_{6}$ and $2.1980 \mathrm{~g} \mathrm{CaCl}_{2} \cdot 6 \mathrm{H}_{2} \mathrm{O}$. Mix together all solutions except $\mathrm{CaCl}_{2} \cdot 6 \mathrm{H}_{2} \mathrm{O}$, then add this drop-wise with stirring and finally dilute to 1 litre and store at $1-4^{\circ} \mathrm{C}$. Prepare a fresh working control sample weekly by diluting the stock 100 -fold. This prescription yields elemental concentrations ( $\mathrm{mg} \mathrm{I}^{-1}$ ) of 1.0 $\mathrm{NH}_{4}-\mathrm{N}, 1.0 \mathrm{NO}_{3}-\mathrm{N}, 5.0 \mathrm{~K}, 2.0 \mathrm{Mg}, 5.0 \mathrm{Na}$, $0.15 \mathrm{PO}_{4}-\mathrm{P}, 16.9 \mathrm{Cl}, 2.64 \mathrm{SO}_{4}-\mathrm{S}, 1.0 \mathrm{Si}$ and $4.0 \mathrm{Ca}$.

\section{Results and discussion}

3.1 Vegetation

In ecological research, the macronutrients are of most interest $(\mathrm{N}, \mathrm{P}, \mathrm{K}, \mathrm{Ca}, \mathrm{Mg})$, with certain micronutrients (ie $\mathrm{Mn} \mathrm{Cr}, \mathrm{Zn}$ ) and other elements (Na) quantified occasionally. Heather was chosen as a control sample because, at the time (early 
1970s), many studies included this species and others of similar composition. However, it has become apparent that the digestion conditions for this particular material are more critical than those for most other plant materials, and in some cases the precision has been unsatisfactory. Procedures for preparing and analysing plant material were therefore re-examined to highlight potentially critical stages and sources of error relevant to the use of this control sample.

Precision tests to assess random error had been used to determine warning and action limits for use on control charts (Shewhart). For most species and elements, the coefficient of variation (CV) was better than $2 \%$, but for heather 4 elements ( $\mathrm{Na}, \mathrm{Fe}, \mathrm{Cu} \& \mathrm{Zn}$ ) recorded a $\mathrm{CV}$ worse than $5 \%$, and up to $30 \%$ for $\mathrm{Cu}$. It is difficult to isolate individual components of random error, but the main operations were assessed in an attempt to isolate the likely causes. Subsampling of plant material can be a significant source of random error if the sample is non-homogeneous, but, as most of the elemental analysis showed acceptable precision on the sample solutions, this did not appear to be a significant problem. Dissolution of the vegetation using acid digestion is performed under carefully controlled conditions, and the heather control sample appears more resistant to oxidation than other material. However, variation in nutrient values obtained appears small even under extreme conditions (Table 1), indicating that large random errors are unlikely to occur from the normal temperature variations during oxidation. Precision levels are relatively much larger when the nutrient sample contents are low and close to the detection limit. It is, therefore, these factors which account primarily for the wider precision limits due to random error.

Table 1. 'Recovery' of macronutrients from heather using different digestion treatments

\begin{tabular}{lrrrr}
\hline & \% recovery (compared to mean) \\
\hline Low temperature & 96 & 104 & 93 & 98 \\
Routine method & 100 & 106 & 95 & 100 \\
Excess heat & 99 & 106 & 95 & 100 \\
\hline
\end{tabular}

Several of the sources contributing to random error can also lead to systematic error or bias. Over the years, the main sources of bias have been eliminated through improved laboratory practices and routine servicing/checking of the vital equipment. The quality control sample is included to determine when bias has occurred in a batch, although, if this control is subject to a gross random error not affecting the samples, it can provide false information. Bias arising from, say, faulty calibration or from correction for reagent blank contamination can be greater when solution concentrations are close to the detection limit or at the lower end of the analytical range. In the light of our conclusions, the use of other natural species as control samples was investigated in order to work at nutrient levels more optimal for the equipment used and for the range of materials now analysed.

Nutrient data from leaves, current year's growth or aerial tissue of 172 species from the UK sample in surveys from late July to early August over several years (H M Grimshaw \& S E Allen, pers. comm.) are summarized (Figures 1, $2 \& 3$ ). For $\mathrm{Ca} 16$ species and for $\mathrm{Na} 23$ species have been excluded because levels were extreme. Leaves of 3 species: alder (Alnus glutinosa), hazel (Corylus avellana) and meadowsweet (Filipendula ulmaria), and leaflets of rosebay willow-herb (Chamaenerion angustifolium) appear to be optimal for nearly all the 10 elements, because the nutrient value of the species fell within $25-85 \%$ of the analytical range selected for the equipment. These plants are widespread in Europe and therefore potentially suitable as European reference materials. In addition, leaves of holly (llex aquifolium) and hawthorn (Crataegus spp.)
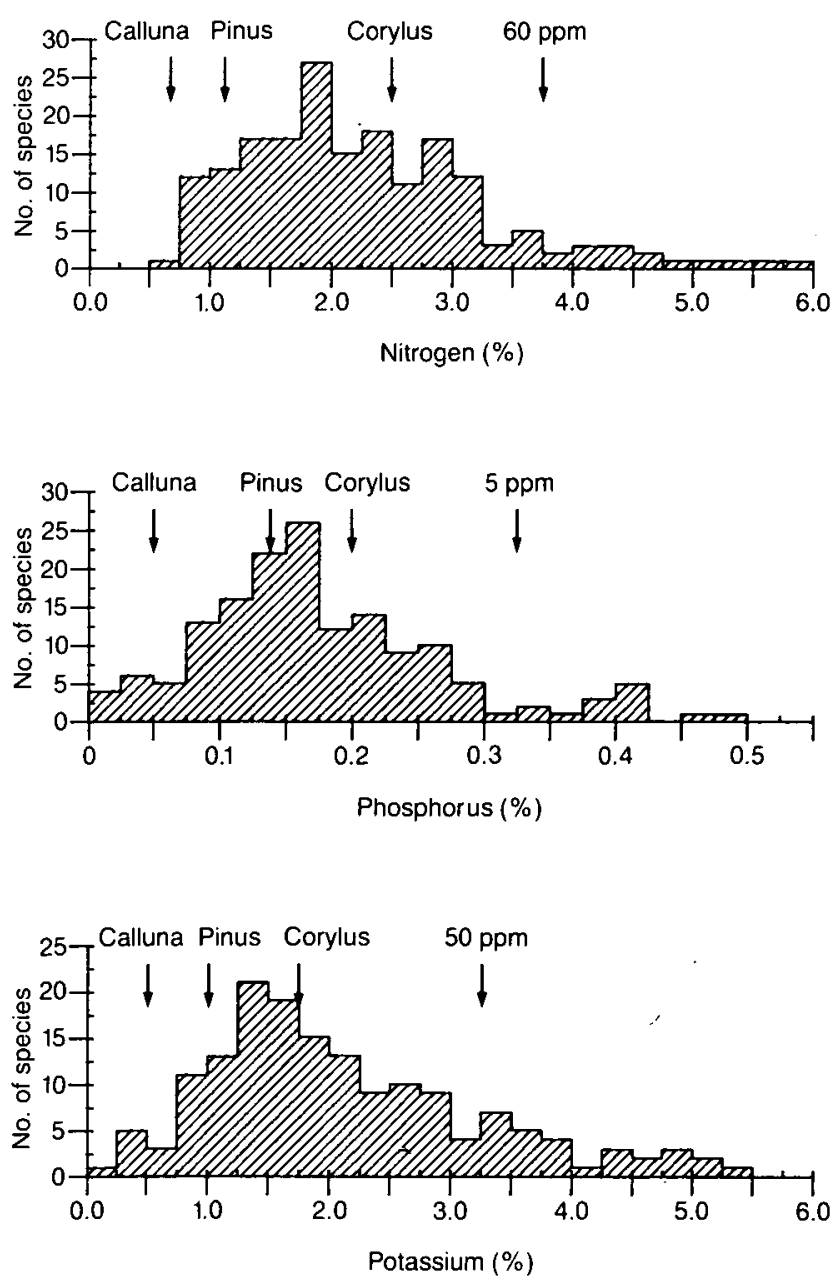

Figure 1. Frequency distributions for $N, P$ and $K$ in vegetation (the $p p m$ value is the concentration in solution after dilution for analysis) 

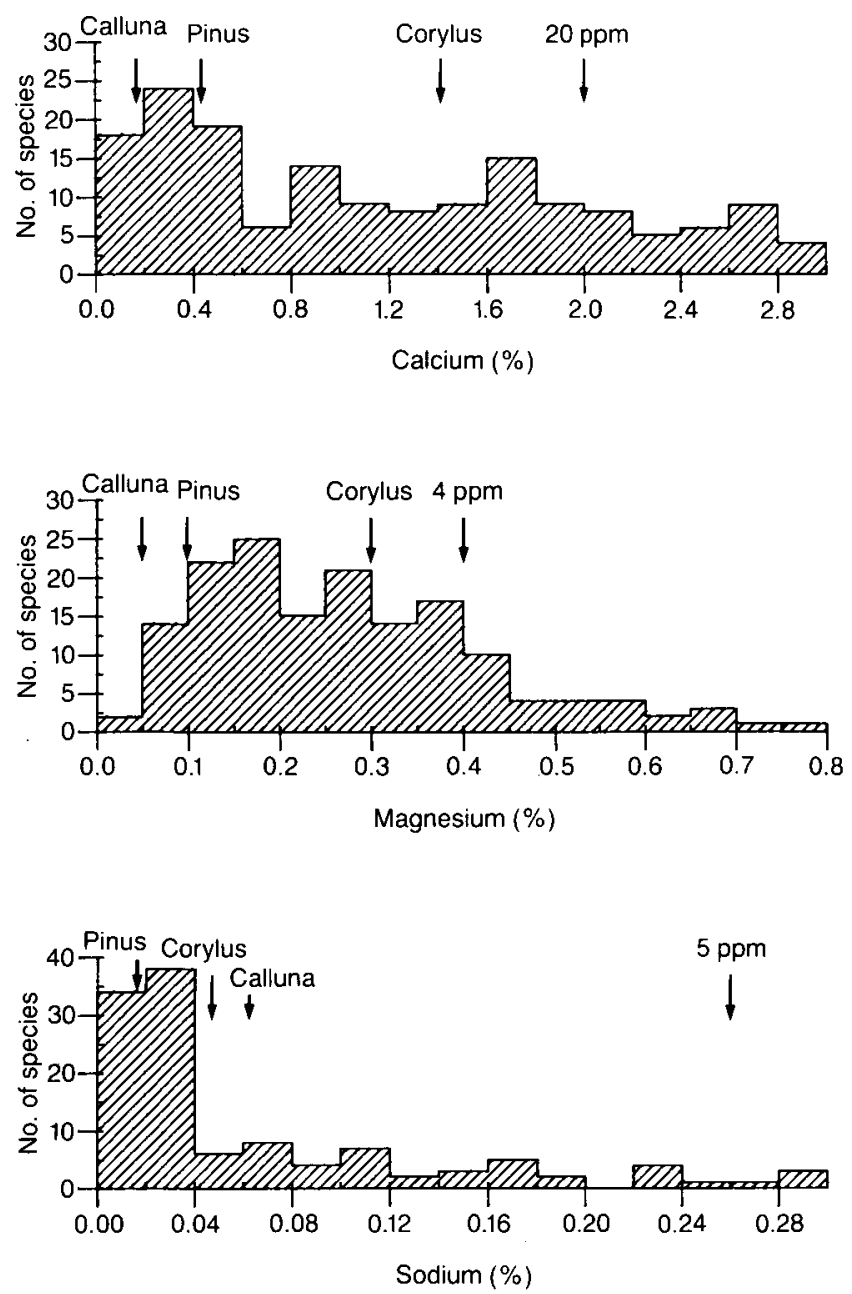

Figure 2. Frequency distributions for $\mathrm{Ca}, \mathrm{Mg}$ and $\mathrm{Na}$ in vegetation (see Figure 1)

are suitable for $\mathrm{N}, \mathrm{P}, \mathrm{K}$ in particular, as their values for these 3 elements coincide with the modes of distribution. In practice, hazel was selected as a reference material to supplement the heather, along with pine (Pinus sylvestris), which is a species commonly encountered in many studies. The relative positions of heather, hazel and pine are given on the distribution diagrams (Figures 1, 2 \& 3). To obtain a better indicator of analytical bias, one or both of these control samples are included with each analytical batch.

As suggested earlier, the certified plant materials currently available do not meet all the requirements of ecological work, although they are of value for specific tests. The National Bureau of Standards pine needles or citrus leaves, or the Commision of European Communities olive leaves would be the most suitable, but are low in potassium. Bowen's kale and the CEC aquatic plant are much higher in nitrogen and phosphorus than in natural vegetation in the UK, and the NBS tomato leaves are much higher in nitrogen and potassium.

\subsection{Soil}

The natural variation of soil nutrient data is much
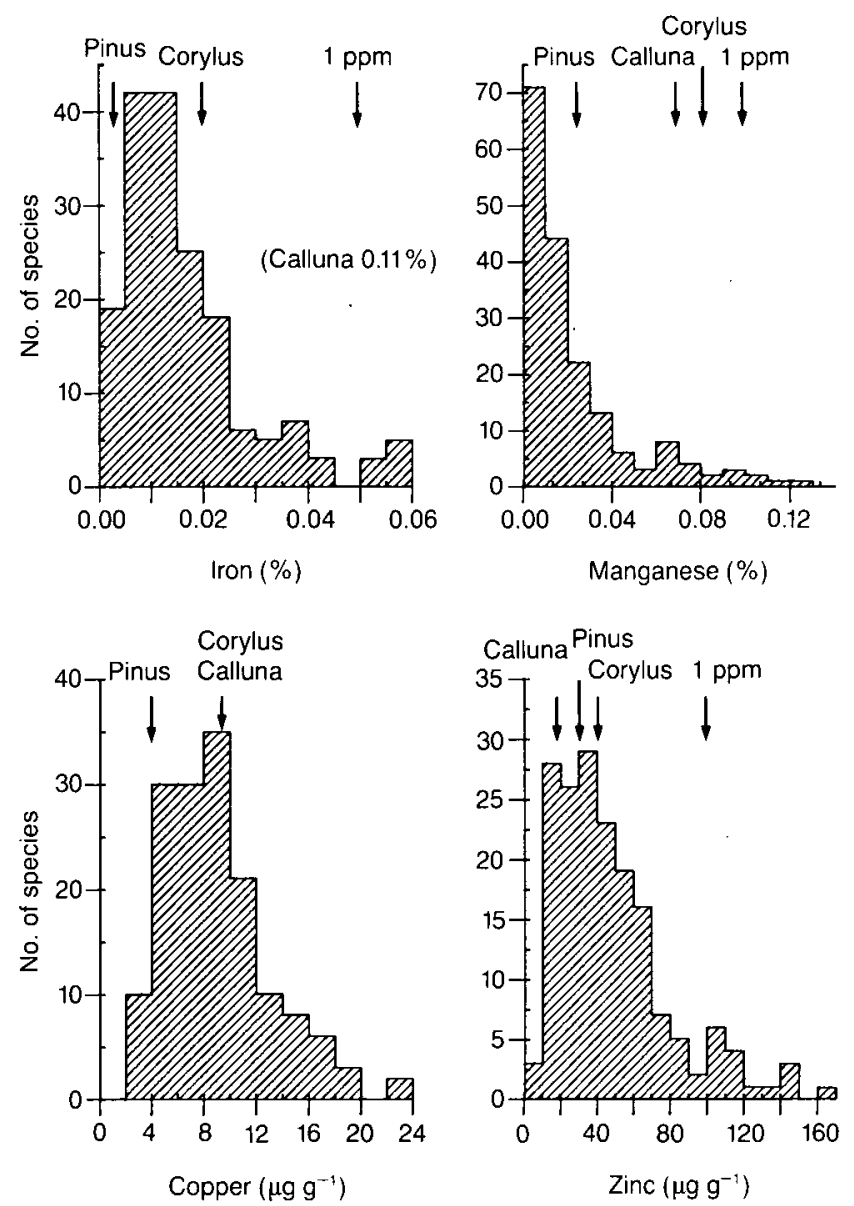

Figure 3. Frequency distributions for $\mathrm{Fe}, \mathrm{Mn}, \mathrm{Cu}$ and $Z n$ in vegetation (see Figure 1)

greater than for plant material. Because extraction values are required for most soil nutrients and totals only for $\mathrm{N}$ and $\mathrm{P}$, and because the material is more heterogeneous, the tests are less easy to reproduce. Accuracy checks have to be through recovery and comparison tests, as there are no reference materials with certified 'available' nutrient values. The range of nutrient values in soil is so variable that it is impossible to select one ideal quality control sample to cover a wide range of soil types. At Merlewood, a local glacial drift control soil sample has been used for some years. It has a low nutrient status, eg $0.3 \% \mathrm{~N}$, and therefore the precision for this element is poorer than for most British soils. The working control limits for operation are around $\pm 10 \%$ for extractable nutrients and $\pm 5 \%$ for totals.

Control data over a long time period supplement development work, and may be used to illustrate changes in accuracy and precision. The introduction of a modified soil digestion procedure (Rowland \& Grimshaw 1985; Grimshaw 1987), together with improved sample handling techniques, have reduced the working limits from $\pm 12 \%$ to $\pm 5 \%$.

\subsection{Waters}

A wide variety of natural waters generated by research on acid rain, geochemical and nutrient 
cycling, and clear-felling of forests has to be analysed chemically in the author's laboratory. Previous attempts to use control samples with natural waters were over-shadowed by storage deterioration.

Least changes occurred in samples which were filtered $(<0.45 \mu \mathrm{m})$, stored at $1-4^{\circ} \mathrm{C}$ rather than frozen, and analysed without delay. However, a synthetic sample prepared from laboratory reagents (Section 2.3), and stored in concentrated form, was found to be stable if stored at $1-4^{\circ} \mathrm{C}$. This control sample provides a check on bias because (unlike heather) its exact composition is known. The composition of the synthetic control solution can be adjusted to match the sample composition so that it is subject to the same systematic errors.

The synthetic control sample has been crucial in the development of ion chromatography methods. This non-specific technique has been automated to determine $\mathrm{Cl}^{-}, \mathrm{NO}_{3}{ }^{-}$, and $\mathrm{SO}_{4}{ }^{2-}$ in approximately 8000 samples $\mathrm{yr}^{-1}$. The margin for error in a multi-ion technique is much smaller than that in single-ion analysis because each ion provides an independent check.

As the control sample has proven theoretical values, development problems such as verification of non-linear calibration, instrumental drift and sample carry-over are minimized. The overall error over a one-month period for each element was found to be about $1 \% \mathrm{CV}$.

\section{Conclusion}

Inter-laboratory studies sometimes produce disturbing results (Sherlock et al. 1985), and these authors point out that inaccurate and unreliable data rarely meet the customers' needs. Once a reliable method has been selected and tested, quality control procedures using selected materials, replication and blank determination should become accepted practice. Careful selection of the control sample and the continuity of long-term routine analysis are important to assess laboratory bias, and the data may be useful to assess method development.

\section{Summary}

Ecological research often involves the chemical analysis of samples over long time periods, when analytical techniques may improve or even be superseded. Therefore, it is of the utmost importance to maintain stocks of internal control materials to monitor such changes. For historical reasons, a heather (Calluna vulgaris) vegetation reference has been used for 20 years and, in comparison with other vegetation samples, it has proved difficult to handle. Data are presented to demonstrate the suitability of this and alternative materials for use as vegetation control samples. The importance of soil and synthetic water references are also illustrated by examples from recent nutrient and pollution studies.

\section{References}

Allen, S.E., Grimshaw, H.M., Parkinson, J.A. \& Quarmby, C. 1974. Chemical analysis of ecological materials. Oxford: Blackwell Scientific.

Grimshaw, H.M. 1987. Total phosphorus estimation in soils. In: Chemical analysis in environmental research edited by A.P. Rowland, 92-95. (ITE symposium no. 18.) Abbots Ripton: Institute of Terrestrial Ecology.

Parkinson, J.A. \& Allen, S.E. 1975. A wet oxidation procedure suitable for the determination of nitrogen and mineral nutrients in biological material. Commun. Soil Sci. Plant Anal., 6, 1-11.

Rowland, A.P. 1983. An automated method for the determination of ammonium- $\mathrm{N}$ in ecological materials. Commun. Soil Sci. Plant Anal., 14, 49-63.

Rowland, A.P. 1986. Automated suppressed ion chromatography as applied to acid rain research. Analyt. Proc., 23, 308-309.

Rowland, A.P. \& Grimshaw, H.M. 1985. A wet oxidation procedure suitable for total nitrogen and phosphorus in soil. Commun. Soil Sci. Plant Anal., 16, $551-560$.

Sherlock, J.C., Evans, W.H., Hislop, J., Kay, J.J., Law, R., McWeeney, D.J., Smart, G.A., Topping, G. \& Wood, R. 1985. Analysis - accuracy and precision. Chem. Br., 11, 1019-1021. 


\title{
The determination of total phosphorus in soils by acid digestion
}

\author{
H M GRIMSHAW \\ ITE, Merlewood Research Station, Grange-over-Sands
}

\section{Introduction}

Phosphorus is of major significance in plant nutrition and the various forms in soil have long been studied intensively. Such investigations often require knowledge of the total content in soil, particularly as primary mineral levels are often quite low for this element. Hence, it is important that reliable estimates of the total level can be made.

Absolute chemical methods for bringing minerals, particularly silicates, into solution have always depended on fusion or hydrofluoric acid procedures, although it is well known that the commonest variants $\left(\mathrm{Na}_{2} \mathrm{CO}_{3}\right.$ fusion and $\mathrm{HF}+$ $\mathrm{HClO}_{4}$ ) cannot bring all minerals into solution. Fortunately, the mineral phosphates are, as a group, relatively soluble in strong acids, and this property, coupled with a growing need for convenient procedures in soil analysis, led, many decades ago, to substitute methods being proposed for phosphorus. These methods were based on acid dissolution, and perchloric acid was a favourite because it is also a strong oxidizing agent for soil organic matter.

A common perchloric acid procedure involved digesting $2 \mathrm{~g}$ dried soil with $30 \mathrm{ml}$ acid, with the option of a nitric acid pre-treatment if the organic content was high (Jackson 1958). However, although this digestion has been widely used, some workers have suggested that the phosphorus recovery might sometimes be low (Muir 1952; Syers et al. 1968). Various mechanisms could, in theory, be responsible for this loss, but there is evidence to suggest that incomplete release from the sample is involved (Sommers \& Nelson 1972).

In addition to these problems, there appeared to be a safety risk in the large-scale use of neat perchloric acid, particularly if perchloric salts were allowed to accidently dry out. In more recent years, the need for adequate fume cupboard facilities when using this acid has also been stressed. The neat perchloric acid digestion was therefore not used on a routine basis at ITE's Merlewood Research Station. Instead, a nitricperchloric-sulphuric system was adopted for soil phosphorus and was taken from the procedure already in use in the laboratory for vegetation. This system followed the method of Piper (1950), but on a smaller scale. Although it was a strong oxidizing system, it was safer to use because the presence of sulphuric acid greatly reduced the risk of drying out.

However, some comparison with a hydrofluoric acid method was required for soils analysed at that time. These tests involved 24 chalk soil samples from 6 sites in southern England, whose mean percentage total phosphorus content (with standard error) was $0.094 \pm 0.005$, following a hydrofluoric-perchloric digestion of $0.1 \mathrm{~g}$ sample, and $0.096 \pm 0.004$ with a nitric-perchloricsulphuric digestion of $0.05 \mathrm{~g}$. These particular digestions both included $1 \mathrm{ml}$ sulphuric acid instead of $0.5 \mathrm{ml}$ and dilution to $100 \mathrm{ml}$ not $50 \mathrm{ml}$ (see below). It was concluded that the 2 systems were equally effective for these soils.

At a later stage, the nitric-perchloric-sulphuric procedure was replaced by a sulphuric-peroxide system for vegetation. Although this system had somewhat less oxidizing power and required a catalyst, it had the advantage of recovering nitrogen in the same digest as used for other elements (Allen et al. 1974; Parkinson \& Allen 1975). Recently this method has been adopted at Merlewood for estimating nitrogen and phosphorus in soils (Rowland \& Grimshaw 1985). This paper records comparisons between the 2 systems which were made for the recovery of total phosphorus from a range of soil types, and includes supplementary data obtained with a hydrofluoric-perchloric system. Factors relevant to the overall performance of the sulphuricperoxide method are also examined briefly.

\section{Materials and methods}

2.1 Soils and minerals

Samples (103) covering 8 soil types in the United Kingdom were originally taken as part of a soil fertility study led by $\operatorname{Dr}$ A F Harrison of Merlewood. The soil types were described pedologically by Dr M Hornung of ITE's Bangor Research Station. Samples were dried $\left(40^{\circ} \mathrm{C}\right)$, sieved $(<2 \mathrm{~mm})$ and a subsample ground $(<0.15$ $\mathrm{mm}$ ) prior to analysis. The approximate organic contents were estimated by loss-on-ignition at $550^{\circ} \mathrm{C}$ ( 2 hours). Mean values of the types ranged from $7 \%$ to $85 \%$ of the dry matter. Mineral samples of fluorapatite $\mathrm{Ca}_{5}\left(\mathrm{PO}_{4}\right)_{3} \mathrm{~F}$ (from Norway) and monazite (W Australia) were supplied by University College of North Wales (Bangor) and ground to a fine powder. 
2.2 Nitric-perchloric-sulphuric digestion

An air-dried ground sample $(0.05 \mathrm{~g})$ was weighed into a $50 \mathrm{ml}$ Kjeldahl flask and digested with $3 \mathrm{ml}$ $5+1$ nitric acid (SG 1.42) + perchloric acid (60\%) and $0.5 \mathrm{ml}$ sulphuric acid (SG 1.84). The digestion was controlled to avoid rapid loss of acid or excess heating. The flasks were gently boiled for about one hour with only a gradual loss of mainly nitric acid. As the white fume stage approached, heating was increased a little to remove white perchloric fumes and continued for about 15 minutes until mainly sulphuric acid remained. The digest was now more viscous but drying out was not permitted. When cool, the digests were diluted to $50 \mathrm{ml}$ (using a Zippette), mixed and the silica residue allowed to settle. Blank solutions (acids only) were also digested. The final solution was $1 \%$ acid $(\mathrm{v} / \mathrm{v})$ and used without further dilution to estimate phosphorus.

\subsection{Sulphuric-peroxide digestion}

The digestion mixture was prepared by mixing $350 \mathrm{ml}$ hydrogen peroxide (100 vol), $14 \mathrm{~g}$ lithium sulphate and $0.42 \mathrm{~g}$ selenium powder (catalyst), followed by the careful addition of $420 \mathrm{ml}$ sulphuric acid. The mixture was stored at $2^{\circ} \mathrm{C}$ and was stable for 3-4 weeks. For digestion, $0.2 \mathrm{~g}$ airdry ground samples were weighed into a $50 \mathrm{ml}$ Kjeldahl flask. The digestion mixture was added $(4.4 \mathrm{ml})$ and digested at low heat until the initial vigorous reaction subsided. Heat was then gradually increased and continued for 2 hours. When cool, the digest was diluted to $50 \mathrm{ml}$, mixed and the silica residue allowed to settle. Blank solutions (digestion mixture only) were also digested. The final solution was $5 \%$ acid ( $(v / v)$ and was further diluted 5 times before estimating phosphorus.

\subsection{Hydrofluoric-perchloric digestion}

An air-dried ground sample $(0.05 \mathrm{~g})$ was weighed into a platinum crucible and $7 \mathrm{ml}$ hydrofluoric acid $(40 \%)$ and $1 \mathrm{ml}$ perchloric $(60 \%)$ added in succession. Crucibles were heated gently at $200-220^{\circ} \mathrm{C}$ for 2 hours with the lid on, followed by evaporation to white fumes. When cool, $3 \mathrm{ml}$ nitric acid and $0.5 \mathrm{ml}$ sulphuric acid were added and digested until white fumes reappeared and continued for about 15 minutes. Digests were finally made up to $50 \mathrm{ml}$ in a volumetric flask.

\subsection{Estimation of phosphorus}

Phosphorus was determined using an automated molybdenum-blue colorimetric procedure with an AutoAnalyzer, as described by Allen et al. (1974). Standards were compensated with $1 \%$ sulphuric acid or digested sulphuric-peroxide reagents as appropriate.

\section{6}

Moisture contents were determined on separate subsamples of air-dry soil to correct analytical results to a dry $\left(105^{\circ} \mathrm{C}\right)$ basis.

\section{Results and discussion}

3.1 Comparison of digestion procedures

The data in Table 1 show the mean phosphorus contents of each soil type, as recorded by both digestion systems. Differences between the 2 systems were minor for all soil types and none significant at $P<0.05$. The standard errors were also very similar for a given soil type. The digestions appeared to be equally effective, regardless of the organic content of the soil types. Further examination showed that the phosphorus levels themselves were not significantly correlated at $P<0.05$ with the organic contents over 103 soil samples $(r=-0.029)$. This result, in turn, may reflect the fact that, on average, only $65 \%$ of the total phosphorus was organically bound as shown by data not presented here. It was concluded that the 2 digestion systems recovered comparable amounts of phosphorus from the soils tested. Further evidence was required to show if this was a full recovery.

\subsection{Precision}

Table 1 includes standard errors which represent the overall variations between 13 soil samples for

Table 1. Comparison of digestion procedures for 8 soil types showing mean percentage total phosphorus with standard errors (dry matter basis)

\begin{tabular}{|c|c|c|c|c|}
\hline \multirow[b]{2}{*}{ Soil type } & \multirow[b]{2}{*}{ Sites } & \multirow{2}{*}{$\begin{array}{l}\mathrm{LOI} \\
(\%)\end{array}$} & \multicolumn{2}{|c|}{$\%$ phosphorus } \\
\hline & & & 'Peroxide'1 & 'Perchloric'2 \\
\hline Pleaty gley & 13 & 35 & $0.073 \pm 0.009$ & $0.069 \pm 0.009$ \\
\hline Gley & 13 & 10 & $0.105 \pm 0.015$ & $0.100 \pm 0.015$ \\
\hline Acidic brown earth & 13 & 15 & $0.074 \pm 0.008$ & $0.074 \pm 0.008$ \\
\hline Basic brown earth & 13 & 7 & $0.085 \pm 0.014$ & $0.080 \pm 0.012$ \\
\hline Podzol & 13 & 9 & $0.018 \pm 0.004$ & $0.019 \pm 0.004$ \\
\hline Peaty podzol & 13 & 50 & $0.064+0.006$ & $0.060+0.006$ \\
\hline Brown podzol & 13 & 13 & $0.058 \pm 0.007$ & $0.063 \pm 0.008$ \\
\hline Peat & 12 & 85 & $0.069 \pm 0.008$ & $0.062 \pm 0.008$ \\
\hline Overall mean $(\overline{\mathbf{x}})$ & 103 & & $0.068 \pm 0.004$ & $0.066 \pm 0.004$ \\
\hline
\end{tabular}

1 'Peroxide' = sulphuric-peroxide digestion

2 'Perchloric' $=$ nitric-perchloric-sulphuric digestion 
each soil type. These errors include both site and sampling variations, as well as the analytical component. A measure of the latter which will include both digestion and colorimetric variation can be obtained by digesting replicates of one sample. Four samples were selected as being representative of 4 soil types and 10 replicates from each sample were digested by the sulphuricperoxide system and analysed as before. The mean values of the 10 replicates and their standard errors are given in Table 2. Although these errors inevitably include variation within a sample, Table 2 still indicates a very satisfactory level of precision for this digestion method.

\subsection{Sample preparation}

It is a general recommendation in the texts that only finely ground samples should be handled at the weights required for these types of digestion. The greater homogeneity of the ground sample allows a weight of $0.2 \mathrm{~g}$ to be reasonably representative of the sample, as shown by the narrow standard error limits in Table 2. Comparable data were obtained for seived but unground material which are not presented here, but they confirm that the precision is less satisfactory. These data also suggest that a slightly higher $(6-9 \%)$ recovery of phosphorus was obtained from the ground samples of the soil types (peat and peaty gley). This was considered to be due to an increase in surface area presented to the sulphuric-peroxide mixture.

\subsection{Digestive conditions}

Digestion of $0.1 \mathrm{~g}$ and $0.2 \mathrm{~g}$ portions of soil showed that comparable recoveries were obtained. However, weights in excess of $0.2 \mathrm{~g}$ are not recommended for soil because excess mineral matter is undesirable for smooth control

Table 2. Precision of the sulphuric-peroxide digestion. Mean percentage phosphorus and standard errors for 10 replicates of one sample of a soil type (dry matter basis)

\begin{tabular}{lc}
\hline Soil type & $\%$ phosphorus \\
\hline Pleaty gley & $0.063 \pm 0.000$ \\
Gley & $0.044 \pm 0.001$ \\
Podzol & $0.0096 \pm 0.0005$ \\
Peat & $0.046 \pm 0.000$ \\
\hline
\end{tabular}

of the sulphur-peroxide system, although up to $0.4 \mathrm{~g}$ is acceptable for vegetation (Parkinson \& Allen 1975). Although temperature control is not critical, only minimal heating should be used during the initial vigorous reactions and increased gradually after this stage, but avoiding excessive loss of sulphuric acid fumes.

The time required for the digestion of soil was also examined for periods up to 4 hours. Four soil types were selected and the data are presented in Table 3. The results suggested that the digestion is complete after 2 hours. This period was adopted in digesting the 103 soil samples, and only 2 digests had a yellowish tint at the conclusion. In these 2 cases, the colour was considered to be mineral rather than organic in origin.

\subsection{Mineral phosphate}

Data for mineral phosphate are presented in Table 4. They show that the sulphuric-peroxide digestion gave a phosphorus recovery of $103 \%$ from a fluorapatite sample of known composition, whilst hydrofluoric-perchloric and nitricperchloric-sulphuric systems recovered approximately $95 \%$. Recovery from the monoazite sample was more variable, and no theoretical phosphorus content was available because unknown amounts of the rare earth elements cerium, lanthanum and neodynium were present in this particular material. It left a white precipitate following the sulphuric-peroxide digestion which may have been a peroxide of one or more of the rare earth elements.

The results were satisfactory regarding fluorapatite because of the recovery and because the apatite group (including the chlor- and

Table 4. Recovery of phosphorus from replicates of a single fluorapatite mineral sample by various methods

\begin{tabular}{lc}
\hline Method & \% phosphorus \\
\hline Theoretical $^{\prime}$ & 18.4 \\
Peroxide $^{1}$ & 18.9 \\
Perchloric $^{2}$ & 17.6 \\
$\mathrm{HF}^{-} \mathrm{HClO}_{4}$ & 17.5 \\
\hline
\end{tabular}

1,2 see Table 1

Table 3. Recovery of total phosphorus from soil by the sulphuric-peroxide digestion over various time intervals. Mean percentage phosphorus for 3 replicates of one sample of each soil type

\begin{tabular}{lcccccc}
\hline Soil type & \multicolumn{7}{c}{ Time (hours) } \\
\hline Gley & 1.0 & 1.5 & 2.0 & 2.5 & 3.0 & 4.0 \\
Acid brown earth & 0.045 & 0.044 & 0.046 & 0.045 & 0.046 & 0.047 \\
Podzol & 0.037 & 0.037 & 0.035 & 0.034 & 0.033 & 0.035 \\
Peat & 0.012 & 0.012 & 0.012 & 0.012 & 0.012 & 0.012 \\
\hline
\end{tabular}


hydroxy-forms) is the commonest source of primary mineral phosphorus in nature (Mason \& Berry 1968). However, problems encountered in digesting monazite suggested that rarer forms of mineral phosphorus might not be fully recovered by these digestion procedures.

\section{Conclusions}

It was concluded that both digestion systems could recover total phosphorus satisfactorily from the 8 types tested. This would be a full recovery if apatite was the dominant form of primary mineral phosphorus in these soils, although direct evidence for this latter assumption was not available at the time. Forms of phosphorus which appear to be difficult to digest may be sufficiently scarce to suggest that they will rarely lead to a significantly low recovery. However, further work is required on soils containing non-apatite phosphate minerals to evaluate this point.

The paper ends with a caution. It was noted earlier that the sulphuric-peroxide digestion was adopted for vegetation because nitrogen can be determined in the same digest as is used for several other elements. This statement is valid for soil only as regards the estimation of nitrogen and phosphorus. Other mineral elements are not recovered from soil by wet digestion methods, unless hydrofluoric is present, because they are often bound up in silicates or other resistant minerals which, unlike phosphates, are largely insoluble in acids.

\section{Summary}

Two wet oxidation procedures are compared with regard to their effectiveness in the estimation of total phosphorus in soils. One method is a conventional procedure based on nitric, perchloric and sulphuric acids. The second is based on sulphuric acid and hydrogen peroxide, and has been widely used for plant materials but so far little used for soils. Eight soil types plus 2 mineral phosphate samples are examined and sample preparation is taken into account. Reference is made to a classical hydrofluoric plus perchloric acid procedure. The data suggest that a sulphuric-peroxide system is effective in assessing total phosphorus in soils.

\section{References}

Allen, S.E., Grimshaw, H.M., Parkinson, J.A. \& Quarmby, C. 1974. Chemical analysis of ecological materials. Oxford: Blackwell Scientific.

Jackson, M.L. 1958. Soil chemical analysis. Englewood Cliffs, NJ: Prentice-Hall.

Mason, B. \& Berry, L.G. 1968. Elements of mineralogy. London: Freeman.

Muir, J.W. 1952. Determination of total phosphorus in soil. Analyst, Lond., 77, 313-317.

Parkinson, J.A. \& Allen, S.E. 1975. A wet oxidation procedure suitable for the determination of nitrogen and mineral nutrients in biological materials. Commun. Soil Sci. Plant Anal., 6, 1-11.

Piper, C.S. 1950. Soil and plant analysis. University of Adelaide.

Rowland, A.P. \& Grimshaw, H.M. 1985. A wet oxidation procedure suitable for total nitrogen and phosphorus in soil. Commun. Soil Sci. Plant Anal., 16, $551-560$.

Sommers, L.E. \& Nelson, D.W. 1972 . Determination of total phosphorus in soils: a rapid perchloric acid digestion procedure. Proc. Soil Sci. Soc. Am., 36, 902-904.

Syers, J.K., Williams, J.D.H. \& Walker, T.W. 1968. Determination of total phosphorus in soils and parent materials. N.Z. J. agric. Res., 11, 757-762. 


\section{A comparative study of ashing procedures for the analysis of $N, P$ and $K$ in small amounts of plant materials}

P L GUPTA

Unit of Comparative Plant Ecology, Department of Botany, University of Sheffield, Sheffield

\section{Introduction}

Many growth studies require chemical analysis of plants for N, P and K. Ashing of plant samples is required to remove organic matter and the 2 methods most commonly used involve dry and wet digestion. Either of these 2 methods can cause problems during the subsequent analysis (Gorsuch 1970; Parkinson \& Allen 1975; Watling \& Wardale 1979). Dry ashing is relatively simple but $N$ is lost completely, whilst ashing samples above $500^{\circ} \mathrm{C}$ can result in losses of $\mathrm{P}$. In contrast, wet ashing involves the use of various concentrated acids and catalytic agents. This method may be tedious and can result in matrix interference and contamination. The limited amounts of plant sample produced in many growth studies are an added complication. It was, therefore, essential to compare various ashing procedures for the analysis of all the 3 elements in small amounts of plant materials. As a further check, the recoveries of added $\mathrm{N}, \mathrm{P}$ and $\mathrm{K}$ in a plant sample were determined by both manual and auto-analytical methods. Also, because of its involvement in wet ashing, the effects of $\mathrm{Cu}$ on standard solutions of $\mathrm{N}$ and $\mathrm{P}$ were investigated.

\section{Materials and methods}

Shoot material of annual meadow-grass (Poa annua) was chosen from one of our growth experiments carried out in solution culture. It contained relatively higher concentrations of nutrients than most field-grown plants. Therefore, most of the elements were at a high enough concentration to be detected in small amounts of ashed samples.

\subsection{Comparison of ashing procedures}

\subsubsection{Dry ashing}

A $100 \mathrm{mg}$ plant sample was weighed into a porcelain crucible $(36 \mathrm{~mm}$ diameter) and then placed in a muffle furnace at room temperature. The sample was ashed at $490^{\circ} \mathrm{C}$ for 17 hours or overnight. The ash was dissolved in $4 \% \mathrm{v} / \mathrm{v}$ $\mathrm{H}_{2} \mathrm{SO}_{4}$.

\subsubsection{Wet ashing}

i. Kjeldahl digestion

Plant samples of $100 \mathrm{mg}$ were weighed into $150 \mathrm{~mm}$ long $\times 15 \mathrm{~mm}$ diameter pyrex glass tubes. To each tube was added $1 \mathrm{ml} \mathrm{H}_{2} \mathrm{SO}_{4}$ and one of the following digestion mixtures:

a. $100 \mathrm{mg}$ mixture of $\mathrm{K}_{2} \mathrm{SO}_{4}+\mathrm{CuSO}_{4}+\mathrm{Se}$ powder (100:10:1) b. $100 \mathrm{mg}$ mixture of $\mathrm{Na}_{2} \mathrm{SO}_{4}+\mathrm{Se}$ powder $(100: 1)$

c. $100 \mathrm{mg}$ mixture of $\mathrm{Na}_{2} \mathrm{SO}_{4}+\mathrm{CuSO}_{4}+\mathrm{Se}$ powder (100:10:1)

d. $250 \mathrm{mg}$ mixture of $\mathrm{Na}_{2} \mathrm{SO}_{4}+\mathrm{Se}$ powder $(100: 1)$

They were then digested on an aluminium Thermal Block at $315^{\circ} \mathrm{C}$ for $4-5 \mathrm{~h}$. The digest was diluted with distilled water to $4 \% \mathrm{v} / \mathrm{v}$ acid.

ii. Acid oxidation

A $100 \mathrm{mg}$ plant sample was weighed into a glass tube as described in 2.1.2 (i). It was then digested with $0.5 \mathrm{ml} 60 \%$ perchloric acid and $0.5 \mathrm{ml} \mathrm{H}_{2} \mathrm{SO}_{4}$ at $260^{\circ} \mathrm{C}$ for $2-3 \mathrm{~h}$.

\subsection{Recovery of added N, $P$ and $K$}

A solution of $0.5 \mathrm{mg} \mathrm{N}$ as $\left(\mathrm{NH}_{4}\right)_{2} \mathrm{SO}_{4}, 0.08 \mathrm{mg} \mathrm{P}$ as $\mathrm{NaH}_{2} \mathrm{PO}_{4} \cdot 2 \mathrm{H}_{2} \mathrm{O}$ and $0.2 \mathrm{mg} \mathrm{K}$ as $\mathrm{K}_{2} \mathrm{SO}_{4}$ was added to tubes containing $0 \mathrm{mg}$ and $20 \mathrm{mg}$ plant samples. These and another set of tubes containing only $20 \mathrm{mg}$ plant samples were also ashed by the method described in 2.1.2 (i) (c).

\subsection{Effect of copper on $\mathrm{N}$ and $\mathrm{P}$}

A range of $\mathrm{Cu}$ concentrations, ie $0-100 \mathrm{mg} \mathrm{l}^{-1}$, added to $5 \mathrm{mg} \mathrm{I}^{-1} \mathrm{P}$ and $10 \mathrm{mg} \mathrm{l}^{-1} \mathrm{~N}$ standard solutions respectively.

\subsection{Comparison of different sample sizes}

A range of 5-100 $\mathrm{mg}$ samples was ashed by the micro-Kjeldahl digestion procedure as described in 2.1 .2 (i), using $100 \mathrm{mg}$ mixture of $\mathrm{Na}_{2} \mathrm{SO}_{4}+$ $\mathrm{CuSO}_{4}+$ Se powder (100:10:1). The ashed solutions were analysed for $\mathrm{N}$ by the indophenol blue method, and for $\mathrm{P}$ by the modified method of sulphomolybdic acid and $\mathrm{SnCl}_{2}$ on $\mathrm{AC1}$ (Pye Unicam, Automatic Chemistry Unit). N was also determined by the manual Kjeldahl distillation procedure and $P$ by the sulphomolybdic acid method (Allen et al. 1974). K was determined by flame photometry. All standards were made with the addition of respective digestion mixtures of acids and salts.

\section{Results and discussion}

3.1 Effect of ashing procedures

The contents of N,P and $\mathrm{K}$ analysed in plant digests (Table 1) showed that in samples ashed dry $\mathrm{N}$ was completely lost and the $\mathrm{K}$ levels were lower than in wet digests. In contrast, the results for $\mathrm{N}, \mathrm{P}$ and $\mathrm{K}$ in samples ashed wet, either by the 
Table 1. Concentrations of N, P and K in $100 \mathrm{mg}$ plant samples ashed by various methods. Mean of 5 replicates as $\mathrm{mg} \mathrm{g}^{-1}( \pm \mathrm{SD})$

\begin{tabular}{lccc}
\hline Ashing method & $\mathrm{N}$ & $\mathrm{P}$ & $\mathrm{K}$ \\
\hline 1. Dry & $\mathrm{ND}$ & 6.00 & 49.9 \\
2. Wet & & & \\
i. Micro-Kjeldahl & & & \\
a. & 42.4 & 5.47 & $\mathrm{C}$ \\
b. & $(1.4)$ & $(0.13)$ & \\
& 42.4 & 6.23 & 55.0 \\
c. & $(3.5)$ & $(0.28)$ & $(0.3)$ \\
& 43.5 & 6.15 & 60.7 \\
d. & $(2.3)$ & $(0.52)$ & $(0.9)$ \\
& 40.5 & 5.31 & 62.4 \\
ii. Acid oxidation & $(1.6)$ & $(0.08)$ & $(0.9)$ \\
& 42.5 & 6.16 & 55.0 \\
Merlewood & $(2.2)$ & $(0.16)$ & $(1.0)$ \\
& 43.5 & 6.05 & 58.0 \\
& $(0.8)$ & $(0.10)$ & $(0.0)$ \\
\hline
\end{tabular}

$\mathrm{ND}=$ not detectable

$\mathrm{C}=$ contamination from digestion mixture

micro-Kjeldahl digestion procedure using $1 \mathrm{ml}$ $\mathrm{H}_{2} \mathrm{SO}_{4}$ and $100 \mathrm{mg}$ of $\mathrm{Na}_{2} \mathrm{SO}_{4}+\mathrm{CuSO}_{4}+\mathrm{Se}$ powder $(100: 10: 1)$, or by the acid oxidation procedure, were similar to the values independently obtained by ITE's Merlewood laboratory. The results of other wet digests showed that $\mathrm{K}_{2} \mathrm{SO}_{4}$ caused contamination of $\mathrm{K}$ but was otherwise acceptable. When $\mathrm{Cu}$ was absent from the digestion mixture, amber-coloured solutions were produced. A larger weight of digestion mixture containing $\mathrm{CuSO}_{4}$ reduced $\mathrm{P}$ content (see Section 3.3). This result indicates that, though ashing of plants by wet acid oxidation is generally adequate, the micro-Kjeldahl procedure is most suitable. The use of perchloric acid is not advised because it can cause explosions.

\subsection{Recovery of N, P and K}

The results in Table 2 show that $93-101 \%$ recovery of all the added elements was achieved

Table 2. Percentage recovery of added N, P and K into $20 \mathrm{mg}$ plant samples wet digested and analysed by manual and automatic methods. Means of 3 replicates $( \pm S D$ )

\begin{tabular}{lccccc} 
& \multicolumn{4}{c}{ Manual } & \multicolumn{4}{c}{ Automatic } \\
& N & photometer \\
Sample & P & N & P & K \\
\hline Plant + NPK & 101 & 93 & 101 & 101 & 98 \\
NPK & $(2)$ & $(2)$ & $(1)$ & $(2)$ & $(0)$ \\
& 99 & 100 & 95 & 95 & 100 \\
& $(2)$ & $(1)$ & $(2)$ & $(2)$ & $(0)$ \\
\hline
\end{tabular}

in the presence and absence of plant samples. There was little or no difference in the results of $\mathrm{N}$ and $P$ analysed by manual or auto-analytical methods, indicating that there is no matrix interference from the digestion mixture on the chemistry of $N$ and $P$.

\subsection{Effect of Cu interference}

The results in Table 3 show that $\mathrm{Cu}$ did not interfere with the determination of $N$, whereas $P$ was depressed in the presence of $\mathrm{Cu}$. The depression increased with increasing levels of $\mathrm{Cu}$ to a maximum of $c 10-15 \%$. However, although the amount of $\mathrm{Cu}$ added in the $100 \mathrm{mg}$ digestion mixture was more than $100 \mathrm{mg} \mathrm{I}^{-1} \mathrm{Cu}$, it had no deleterious effect on the estimation of $P$ (see Tables $1 \& 2$ ). In contrast, the addition of larger weights of digestion mixture containing $\mathrm{CuSO}_{4}$ again caused low recovery in the $P$ estimation. This suggests that the amount of $\mathrm{Cu}$ added in the digestion mixture should be reduced to the minimum level required to produce an adequate end-point.

Table 3. Effect of copper on the $\mathrm{N}$ and $\mathrm{P}$ standard solutions

\begin{tabular}{crc}
$\begin{array}{l}\text { Level of Cu added } \\
\left(\mathrm{mg} \mathrm{I}^{-1}\right)\end{array}$ & $\mathrm{N}$ & $\mathrm{P}$ \\
\hline 0 & 10.0 & 5.0 \\
10 & 10.0 & 4.65 \\
20 & 10.0 & 4.50 \\
30 & 10.0 & 4.45 \\
45 & 9.9 & 4.35 \\
50 & 9.9 & 4.35 \\
100 & 10.0 & 4.35 \\
\hline
\end{tabular}

Table 4. Concentrations of $\mathrm{N}, \mathrm{P}$ and $\mathrm{K}$ in different plant weights ashed by wet Kjeldahl digestion method. Mean of 5 replicates as $\mathrm{mg} \mathrm{g}^{-1}$ $( \pm \mathrm{SD})$

Digestion mixture

Sample $1 \mathrm{ml} \mathrm{H}_{2} \mathrm{SO}_{4}+100 \mathrm{mg}\left(\mathrm{NA}_{2} \mathrm{SO}_{4}+\mathrm{CuSO}_{4}+\mathrm{Se}\right)$ weight

\begin{tabular}{cccc} 
(mg) & $\mathrm{N}$ & $\mathrm{P}$ & $\mathrm{K}$ \\
\hline 5 & 52.4 & 6.49 & 58.5 \\
& $(3.6)$ & $(0.30)$ & $(3.8)$ \\
10 & 49.2 & 6.42 & 57.5 \\
& $(2.0)$ & $(0.42)$ & $(1.8)$ \\
20 & 48.0 & 6.03 & 57.4 \\
& $(0.9)$ & $(0.05)$ & $(1.8)$ \\
50 & 44.3 & 5.92 & 55.0 \\
& $(0.6)$ & $(0.04)$ & $(0.0)$ \\
100 & 43.5 & 6.15 & 60.7 \\
& $(2.3)$ & $(0.52)$ & $(0.9)$ \\
\hline
\end{tabular}


3.4 Effect of different sample sizes

The results in Table 4 show that the $\mathrm{N}$ content increased with decreased sample weights, ie $\mathrm{N}$ was c $20 \%$ higher in $5 \mathrm{mg}$ and $8-10 \%$ higher in $20 \mathrm{mg}$, than in $50 \mathrm{mg}$ samples. This increase occurred because the error of estimation was exaggerated by increased sample dilution. The differences in the levels of $\mathrm{P}$ and $\mathrm{K}$ found were small and showed no consistent trends due to sample weight, suggesting that a sample weight of as little as $5 \mathrm{mg}$ can be digested adequately and analysed, providing that small samples are diluted to the minimum volume required for analysis.

\section{Conclusion}

The destruction of organic matter in plants is not a problem - the important consideration is whether the ashing procedure chosen produces accurate and reproducible results. Second, the ashing procedure has to be safe and without contamination on the subsequent analysis of N,P and $\mathrm{K}$. Analytical discrepancies can arise in the chemical analysis of small amounts of plant material because of a variety of processing and instrumental errors. The most important, in this instance, is the effect of large dilutions on smallsize samples, which affects $N$ results more than the other elements. It is clear from the results that the plant material ashed by the micro-Kjeldahl digestion procedure using $1 \mathrm{ml} \mathrm{H}_{2} \mathrm{SO}_{4}$ and 100 mg digestion mixture of $\mathrm{Na}_{2} \mathrm{SO}_{4}+\mathrm{CuSO}_{4}+\mathrm{Se}$ powder (100:10:1) is most suitable. This procedure gave c 93-101\% recoveries of added $\mathrm{N}, \mathrm{P}$ and $\mathrm{K}$ in plant samples by both manual and auto-analytical methods. Also, both the small- and large-size samples were analysed with reasonable accuracy. It appears that low results may occur if samples are digested with diges tion mixture containing large' amounts of 'Cu salts. It is, therefore, advisable to reduce to a minimum the use of $\mathrm{Cu}$ in the digestion mixture.

It is suggested that the digestion of plants in pyrex tubes on the thermal block increases turnover, and that the subsequent analysis of $\mathrm{N}$ and $\mathrm{P}$ on the AutoAnalyzer reduces the cost.

\section{Summary}

A comparative study of various dry and wet ashing procedures using $100 \mathrm{mg}$ plant samples was made on the nutrient levels of $N, P$ and $K$. Samples digested with $1 \mathrm{ml} \mathrm{H}_{2} \mathrm{SO}_{4}$ and $100 \mathrm{mg}$ Kjeldahl digestion mixture of $\mathrm{Na}_{2} \mathrm{SO}_{4}+\mathrm{CuSO}_{4}+$ Se powder (100:10:1) gave similar levels of N, $P$ and $K$ to those obtained by ITE's Merlewood laboratory. When less than $50 \mathrm{mg}$ plant weight was digested, results for $\mathrm{N}$ increased by $5-10 \%$, whereas there was no such effect on $P$ and $K$ levels. Recoveries of added $\mathrm{N}, \mathrm{P}$ and $\mathrm{K}$ in wet digested plant samples gave $93-100 \%$ recovery of all the elements, suggesting that the wet microKjeldahl digestion method is suitable for the analysis of N, P and $\mathrm{K}$ in very small amounts of plant samples.

Large numbers of samples can be digested in pyrex tubes by the micro-Kjeldahl digestion procedure on thermal blocks. Analysis of $\mathrm{N}$ and $\mathrm{P}$ on semi-automatic or AutoAnalyzer systems also increases turnover, which is an important consideration under present economic conditions.

\section{Acknowledgements}

I would like to thank Prof I $H$ Rorison for his help in the preparation of this paper and Mr A P Rowland, ITE Merlewood, for arranging the test sample analysis.

\section{References}

Allen, S.E., Grimshaw, H.M., Parkinson, J.A. \& Quarmby, C. 1974. Chemical analysis of ecological materials. Oxford: Blackwell Scientific.

Gorsuch, T.T. 1970 . The destruction of organic matter. Oxford: Pergamon.

Parkinson, J.A. \& Allen, S.E. 1975. A wet oxidation procedure suitable for the determination of nitrogen and mineral nutrients in biological materials. Commun. Soil Sci. Plant Anal., 6, 1-11.

Watling, H.R. \& Wardale, I.M. 1979. For the analysis of biological materials by atomic absorption spectroscopy. In: The analysis of biological materials, edited by L.R.P. Butler, 69-80. Oxford: Pergamon. 


\title{
A controlled flow rate leaching method for the determination of exchangeable acidity and aluminium in soils
}

\author{
K A B LOGAN and A D IRONSIDE \\ Hill Farming Research Organisation, Bush Estate, Penicuik
}

\section{Introduction}

A $1 \mathrm{M} \mathrm{KCl}$ solution is considered suitable for displacing exchangeable acidity and aluminium from acid soils (McLean 1965; Pratt \& Bair 1961; Sivasubramaniam \& Talibudeen 1972), but several methods (see references) including leaching and/or extraction have been used. The methods vary in soil to solution ratio from 1:10 to $1: 500$, in length of contact time of soil with solution from 1 $\min$ to $24 \mathrm{~h}$, and in whether the soil and solution are shaken or allowed to stand. While some studies comparing leaching with extraction methods show little difference (Dewan \& Rich 1970 ), others show that there is more variation in extraction than leaching and that, for some soils, leaching removes more Al (Bache \& Sharp 1976a; Lee et al. 1985). The longer the leaching period, the more $A l$ is released in total (Bhumbla \& McLean 1965), but with progressive leaching there is a gradual decrease in the release of $\mathrm{Al}$ (Bache \& Sharp 1976a). Pratt and Bair (1961) suggest that soils should be filtered immediately to prevent including non-exchangeable $\mathrm{Al}$ in the measurement, while Lin and Coleman (1960) and Sivasubramaniam and Talibudeen (1972) prefer slow leaching. The amount of $\mathrm{Al}$ released depends on the flow rate of the extracting solution through the soil and, if the flow rate is not controlled, it will vary with soil type, and spurious results will be obtained.

A leaching method with a controlled flow rate is described which is more efficient and reliable than a manual method previously used at the Hill Farming Research Organisation.

\section{Experimental method}

Eleven soils were leached in duplicate by a manual method and a controlled flow rate method. Exchangeable acidity was measured by titration against $0.02 \mathrm{M} \mathrm{NaOH}$ (Logan et al. 1985a) and exchangeable $\mathrm{Al}$ by coloration with Alizarin red (Logan et al. 1985b).

\subsection{Manual leaching}

A $10 \mathrm{~g}$ sample of air-dry soil $(<2 \mathrm{~mm})$ was weighed into a $100 \mathrm{ml}$ beaker, mixed with $50 \mathrm{ml} 1$ $\mathrm{M} \mathrm{KCl}$ solution and left to stand overnight. After filtering through a Whatman no. 1 filter, the soil was washed with small portions of $1 \mathrm{M} \mathrm{KCl}$ until $100 \mathrm{ml}$ leachate was collected. Filtering should take at least $2 \mathrm{~h}$ (McLean 1965). The washing was continued until a further $2 \times 100 \mathrm{ml}$ leachates were collected. Each $100 \mathrm{ml}$ leachate was analysed separately and summed to give total soil exchangeable acidity and $\mathrm{Al}$.

\subsection{Controlled flow rate leaching}

A $2.5 \mathrm{~g}$ sample of air-dry soil $(<2 \mathrm{~mm})$ was weighed into a Whatman filter thimble $(27 \times 80$ $\mathrm{mm}$ external), then placed inside a plastic syringe barrel (B-D Plastipak $50 \mathrm{ml}$ ) with a small bore tube leading from the base into a $250 \mathrm{ml}$ volumetric flask. The soil was wetted with a little $1 \mathrm{M} \mathrm{KCl}$ solution, and the tube sealed with a bung through which $1 \mathrm{M} \mathrm{KCl}$ was continuously pumped at $0.6 \mathrm{ml}$ $\mathrm{min}^{-1}$ until $250 \mathrm{ml}$ leachate was collected.

\section{Results and discussion}

Both exchangeable acidity and exchangeable $\mathrm{Al}$ were significantly greater $(P<0.001)$ when soil was leached by the controlled flow rate method (Table 1). This result can be explained by the greater soil/solution ratio of 1:100 compared with $1: 30$ for the manual method. Analysis of the third $100 \mathrm{ml}$ manual leachates (Table 2) showed that they contained between $10 \%$ and $20 \%$ of the total manual exchangeable acidity and Al, suggesting that exchange was incomplete. This suggestion is supported by Bache and Sharp (1976a), where leaching was complete at a soil/solution ratio of about 1:100.

The standard errors of the 2 methods were the same, but the coefficient of variation was less for the controlled flow rate method.

\section{Conclusions}

With manual methods, leaching conditions differ with soil type; extractant flows quickly through a sandy soil (often less than 2 h), but very slowly through peat. The controlled flow rate method leaches soils for the same time period and soil/ solution ratio, allowing better comparisons to be made of exchangeable acidity and $\mathrm{Al}$ in different soil types.

Exchangeable acidity analysis must be carried out as soon as possible (Bache \& Sharp 1976b), so that there is a limit to the number of samples which can be analysed in a day. As the manual method requires $3 \times 100 \mathrm{ml}$ leachates, and hence 3 analyses for each sample, far fewer determinations can be made, compared with the controlled flow rate method.

The main advantages of the controlled flow rate 
Table 1. Exchangeable acidity and exchangeable aluminium for 11 soils leached by the controlled flow rate and manual methods

\begin{tabular}{|c|c|c|c|c|}
\hline \multirow{2}{*}{$\begin{array}{l}\text { Soil } \\
\text { no. }\end{array}$} & \multicolumn{2}{|c|}{ Exchangeable acidity (meq $100 \mathrm{~g}^{-1}$ ) } & \multicolumn{2}{|c|}{ Exchangeable $\mathrm{Al}$ (meq $100 \mathrm{~g}^{-1}$ ) } \\
\hline & Manual $^{1}$ & Controlled flow ${ }^{1}$ & Manual $^{\top}$ & Controlled flow \\
\hline 1 & 5.35 & 6.60 & 4.87 & 6.45 \\
\hline 2 & 4.97 & 6.13 & 4.44 & 5.15 \\
\hline 3 & 1.26 & 2.00 & 0.94 & 1.89 \\
\hline 4 & 5.19 & 6.43 & 4.77 & 6.39 \\
\hline 5 & 5.21 & 6.64 & 4.62 & 6.31 \\
\hline 6 & 2.30 & 3.28 & 1.75 & 1.60 \\
\hline 7 & 3.03 & 4.19 & 2.49 & 3.86 \\
\hline 8 & 4.84 & 6.25 & 4.17 & 6.69 \\
\hline 9 & 1.23 & 1.79 & 0.76 & 1.32 \\
\hline 10 & 5.23 & 6.66 & 4.34 & 6.69 \\
\hline 11 & 5.15 & 6.68 & 4.26 & 6.13 \\
\hline$\overline{\mathbf{x}}$ & 3.97 & 5.15 & 3.40 & 4.77 \\
\hline $\mathrm{SE}^{2}$ & 0.13 & 0.13 & 0.12 & - \\
\hline CV\% & 3.22 & 2.49 & 3.38 & - \\
\hline
\end{tabular}

1 Values are means of duplicate leachates

2 Pooled standard error of 11 pairs of duplicates

Table 2. Exchangeable acidity and exchangeable Al in first, second and third manual leachates for 11 soils (means of duplicate leaching)

\begin{tabular}{|c|c|c|c|c|c|c|}
\hline \multirow{2}{*}{$\begin{array}{l}\text { Soil } \\
\text { no. }\end{array}$} & \multicolumn{3}{|c|}{ Exchangeable acidity (meq $100 \mathrm{~g}^{-1}$ ) } & \multicolumn{3}{|c|}{ Exchangeable Al (meq $100 \mathrm{~g}^{-1}$ ) } \\
\hline & 1 & II & III' & 1 & II & III \\
\hline 1 & 3.98 & 0.83 & 0.55 & 3.63 & 0.79 & 0.46 \\
\hline 2 & 3.60 & 0.84 & 0.53 & 3.24 & 0.77 & 0.43 \\
\hline 3 & 0.70 & 0.31 & 0.25 & 0.43 & 0.32 & 0.20 \\
\hline 4 & 3.79 & 0.88 & 0.52 & 3.60 & 0.76 & 0.42 \\
\hline 5 & 3.50 & 1.10 & 0.61 & 3.18 & 0.95 & 0.49 \\
\hline 6 & 1.35 & 0.54 & 0.40 & 0.97 & 0.47 & 0.32 \\
\hline 7 & 1.82 & 0.75 & 0.46 & 1.49 & 0.68 & 0.33 \\
\hline 8 & 3.58 & 0.79 & 0.48 & 3.12 & 0.66 & 0.39 \\
\hline 9 & 0.72 & 0.29 & 0.22 & 0.34 & 0.27 & 0.15 \\
\hline 10 & 3.67 & 0.93 & 0.64 & 3.12 & 0.80 & 0.42 \\
\hline 11 & 3.62 & 0.97 & 0.56 & 3.01 & 0.81 & 0.45 \\
\hline
\end{tabular}

method are that exchange is more complete, flow rate is independent of soil type, and most of the leaching occurs overnight so that it is time-saving.

\section{References}

Bache, B.W. \& Sharp, G.S. 1976a. Characterisation of mobile aluminium in acid soils. Geoderma, 15, 91-101.

Bache, B.W. \& Sharp, G.S. 1976b. Soluble polymeric hydroxy-aluminium ions in acid soils. J. Soil Sci., 27, 167-174.

Bhumbla, D.R. \& McLean, E.O. 1965. Aluminium in soils. VI. Changes in $\mathrm{pH}$-dependent acidity, cationexchange capacity, and extractable aluminium with additions of lime to acid surface soils. Proc. Soil Sci. Soc. Am., 29, 370-374.

Dewan, H.C. \& Rich, C.I. 1970. Titration of acid soils. Proc. Soil Sci. Soc. Am., 34, 38-44.

Hoyt, P.B. 1977. Effects of organic matter content on exchangeable $\mathrm{Al}$ and $\mathrm{pH}$-dependent acidity of very acid soils. Can. J. Soil Sci., 57, 221-222.

Khalid, R.A. \& Silva, J.A. 1979. A study of soil aluminium extraction methods in relation to plant aluminium and yield in tropical soils. Trop. Agric., Trin., $56,53-63$.

Lee, R. \& Sharp, G.S. 1985. Extraction of 'available' aluminium from podzolized New Zealand soils of high aluminium status. Commun. Soil Sci. Plant Anal., 16, 261-274.

Lee, R., Bache, B.W., Wilson, M.J. \& Sharp, G.S. 1985. Aluminium release in relation to the determination of cation exchange capacity of some podzolized New Zealand soils. J. Soil Sci., 36, 239-253.

Lin, C. \& Coleman, N.T. 1960. The measurement of exchangeable aluminium in soils and clays. Proc. Soil Sci. Soc. Am., 24, 444-446.

Logan, K.A.B., Floate, M.J.S. \& Ironside, A.D. 1985a. 
The determination of exchangeable acidity and exchangeable aluminium in hill soils. Part 1. Exchangeable acidity. Commun. Soil Sci. Plant Anal., 16, $301-308$.

Logan, K.A.B., Floate, M.J.S. \& Ironside, A.D. 1985b. The determination of exchangeable acidity and exchangeable aluminium in hill soils. Part 2. Exchangeable aluminium. Commun. Soil Sci. Plant Anal., 16, 309-314.

Lopez-Hernandez, D. \& Burnham, C.P. 1973. Extraction methods for aluminium and iron in relation to phosphate adsorption. Commun. Soil Sci. Plant Anal., 4, 9-16.

MacLeod, L.B. \& Jackson, L.P. 1967. Water-soluble and exchangeable aluminium in acid soils as affected by liming and fertilization. Can. J. Soil Sci., 47, 203-210.

McLean, E.O. 1965. Aluminium. In: Methods of soil analysis, Part 2, edited by C.A. Black, D.D. Evans, J.L. White, L.E. Ensminger \& F.E. Clark, 978-998. (Agronomy monograph 9.) Wisconsin: American Society of Agronomy.

McLean, E.O., Heddleson, M.R. \& Post, G.J. 1959. Aluminium in soils: III. A comparison of extraction methods in soils and clays. Proc. Soil Sci. Soc. Am., 23, 289-293.

Pratt, P.F. \& Bair, F.L. 1961. A comparison of three reagents for the extraction of aluminium from soils. Soil Sci., 91, 357-359.

Rich, C.I. 1970. Conductometric and potentiometric titration of exchangeable aluminium. Proc. Soil Sci. Soc. Am., 34, 31-38.

Sivasubramaniam, S. \& Talibudeen, O. 1972. Potassium-aluminium exchange in acid soils. I. Kinetics. J. Soil Sci., 23, 163-176.

Stuanes, A.O., Ogner, G. \& Opem, M. 1984. Ammonium nitrate as extractant for soil exchangeable cations, exchangeable acidity and aluminium. Commun. Soil Sci. Plant Anal., 15, 773-778.

U.S. Department of Agriculture, Soil Conservation Service. 1972. Soil Survey laboratory methods and procedures for collecting soil samples. (Soil Survey investigation report no. 1.) USDA.

Yuan, T.L. 1959. Determination of exchangeable hydrogen in soils by a titration method. Soil Sci., $\mathbf{8 8}$, 164-167. 


\section{Appendix I: List of participants}

Mr J K Adamson, Institute of Terrestrial Ecology, Merlewood Research Station, Grange-over-Sands, Cumbria, LA11 6JU

$\mathrm{Mr} S \mathrm{E}$ Allen, Institute of Terrestrial Ecology, Merlewood Research Station, Grange-over-Sands, Cumbria, LA11 6JU

Ms $J$ Armstrong, Dept of Forestry, Universicy of Aberdeenshire, St Machar Drive, Aberdeen, Aberdeenshire, AB9 $2 \mathrm{UU}$

Miss T Balasuriya, Institute of Terrestrial Ecology, Merlewood Research Station, Grange-over-Sands, Cumbria, LA11 6JU

Mr P Belton, Dionex (UK) Ltd, Techno House, Low Lane, Horsforth, Leeds, West Yorkshire, LS18 4SS

Mr C A Backes, Freshwater Biological Association, The Ferry House, Far Sawrey, Ambleside, Cumbria, LA22 OLP

Mr I L Blackwood, School of Environmental Sciences, University of East Anglia, Norwich, Norfolk, NR4 7TJ

Mr N Breward, British Geological Survey, c/o Geochemical Division, 64-78 Grays Inn Road, London, WC1X 8NG

Mr A H F Brown, Institute of Terrestrial Ecology, Merlewood Research Station, Grange-over-Sands, Cumbria, LA11 6JU

Dr K A Brown, CEGB, Central Electricity Research Laboratories, Kelvin Avenue, Leatherhead, Surrey, KT22 7SE

Dr K R Bull, Institute of Terrestrial Ecology, Monks Wood Experimental Station, Abbots Ripton, Huntington, Huntingdonshire, PE17 2LS

Dr M A S Burton, Kings College, Fulham Road, London SW10 0QX

Dr J N Cape, Institute of Terrestrial Ecology, Bush Estate, Penicuik, Midlothian, EH26 OQB

Mr $\mathrm{H}$ Casey, Freshwater Biological Association, River Laboratory, East Stoke, Wareham, Dorset, BH20 6BB

Miss J M Cook, British Geological Survey, Maclean Building, Crowmarsh Gifford, Wallingford, Oxfordshire, OX10 8BB

Mrs G Coutts, The Macaulay Institute for Soil Research, Craigiebuckler, Aberdeen, Aberdeenshire, AB2 9SB

Dr M Cresser, Dept of Soil Science, University of Aberdeen, Meston Walk, Aberdeen, Aberdeenshire, AB9 2UE

Dr S P Cuttle, Welsh Plant Breeding Station, Plas Gogerddan, Aberystwyth, Dyfed, SY23 3EB
Dr W Davison, Freshwater Biological Association, The Ferry House, Far Sawrey, Ambleside, Cumbria, LA22 OLP

Mr I Derrick, Laboratory Manager, Rivers Division, North West Water Authority, New Town House Buttermarket Street, PO Box 12, Warrington, Cheshire, WA1 2QG

Dr A Edmonds, Dept of Chemistry, Loughborough University of Technology, Loughborough, Leicestershire, LE11 3TU

Dr A Edwards, Dept of Soil Science, University of Aberdeen, Meston Walk, Aberdeen, Aberdeenshire, AB9 2UE

Mr J R Ferrier, The Macaulay Institute for Soil Research, Craigiebuckler, Aberdeen, Aberdeenshire, AB2 9SB

Miss C Flower, The Macaulay Institute for Soil Research, Craigiebuckler, Aberdeen, Aberdeenshire, AB2 9SB

Mr M Gardner, Water Research Centre, PO Box 16 , Henley Road, Medmenham, Harlow, Buckinghamshire, SL7 $2 \mathrm{HD}$

Miss A Goldsmith, Dept of Trade and Industry, Warren Spring Laboratory, Gunnels Wood Road, Stevenage, Hertfordshire, SG1 2BX

Miss R Goodwin, Institute of Terrestrial Ecology, Merlewood Research Station, Grange-over-Sands, Cumbria, LA11 6JU

Miss S J Grayston, Dept of Microbiology, University of Sheffield, Sheffield, South Yorkshire, S10 2TN

Mr H M Grimshaw, Institute of Terrestrial Ecology, Merlewood Research Station, Grange-over-Sands, Cumbria, LA11 6JU

Dr P L Gupta, Unit of Comparative Plant Ecology, Dept of Botany, Sheffield University, Sheffield, South Yorkshire S10 2TN

Miss J R Hall, Institute of Terrestrial Ecology, Monks Wood Experimental Station, Abbots Ripton, Huntingdon, Huntingdonshire, PE17 2LS

Mr R Harriman, Freshwater Fisheries Laboratory, Pitlochry, Perthshire, PH16 5LB

Mr J A Harris, Dept of Biology, North East London Polytechnic, West Ham Precinct, Romford Road, Stratford, London, E15 4LZ

Dr A F Harrison, Institute of Terrestrial Ecology, Merlewood Research Station, Grange-over-Sands, Cumbria, LA11 6JU

Dr I Hawes, British Antarctic Survey, Madingley Road, Cambridge, Cambridgeshire, CB3 OET 
Dr J Hilton, Freshwater Biological Association, The Ferry House, Far Sawrey, Ambleside, Cumbria, LA22 OLP

Miss A L Hodgson, Institute of Terrestrial Ecology, Merlewood Research Station, Grange-over-Sands, Cumbria, LA11 6JU

Mr D W Hopkins, 20 Eskdale Terrace, Jesmond, Newcastle-upon-Tyne, Tyne and Wear, NE2 4DN

Mrs $G$ Howson, Institute of Terrestrial Ecology, Merlewood Research Station, Grange-over-Sands, Cumbria, LA11 6JU

Ms M lles, Dept of Forestry, University of Aberdeen, St Machar Drive, Aberdeen, Aberdeenshire, AB9 2UU

Dr P Ineson, Institute of Terrestrial Ecology, Merlewood Research Station, Grange-over-Sands, Cumbria, LA11. 6JU

Mr I Jane, MAFF, ADAS, Government Buildings, Kenton Bar, Newcastle-upon-Tyne, Tyne and Wear, NE1 2YA

Prof J N R Jeffers, Director, Institute of Terrestrial Ecology, Merlewood Research Station, Grange-overSands, Cumbria, LA11 6JU

Miss $S E$ Jewell, Institute of Terrestrial Ecology, Merlewood Research Station, Grange-over-Sands, Cumbria, LA11 6JU

Dr K C Jones, Dept of Biological Sciences, University of Lancaster, Lancaster, Lancashire, LA1 4XY

Mrs V H Kennedy, Institute of Terrestrial Ecology, Merlewood Research Station, Grange-over-Sands, Cumbria, LA11 6JU

Dr K Killham, Dept of Soil Science, University of Aberdeen, Meston Walk, Aberdeen, Aberdeenshire, AB9 2UE

Mr A Kindness, Dept of Soil Science, University of Aberdeen, Meston Walk, Aberdeen, Aberdeenshire, AB9 2UE

Mr J Lee, Dept of Human Sciences, University of Loughborough, Loughborough, Leicestershire, LE11 3TU

Mr P Leech, Institute of Terrestrial Ecology, Merlewood Research Station, Grange-over-Sands, Cumbria, LA11 6JU

Dr E C G Lemon, British Antarctic Survey, Madingley Road, Cambridge, Cambridgeshire, CB3 OET

Dr F R Livens, Institute of Terrestrial Ecology, Merlewood Research Station, Grange-over-Sands, Cumbria, LA11 6JU

Miss K A B Logan, Hill Farming Research Organisation, Bush Estate, Penicuik, Midlothian, EH26 OPY

Dr P Loveland, Soil Survey of England and Wales,
Rothamsted Experimental Station, Harpenden, Hertfordshire, AL5 2JQ

Dr L Lovegren, Dept of Inorganic Chemistry, University of Umea, S-901 87 Umea, Sweden

Dr G B Marshall, CEGB, Central Electricity Research Laboratories, Kelvin Avenue, Leatherhead, Surrey, KT22 7SE

Dr R B Marshall, The Animal and Grassland Research Institute, Hurley, Nr Maidenhead, Berkshire, SL6 5LR

Mr D L Miles, British Geological Survey, Maclean Building, Crowmarsh Gifford, Wallingford, Oxfordshire, OX10 8BB

Mrs C McClure, Institute of Terrestrial Ecology, Merlewood Research Station, Grange-over-Sands, Cumbria, LA11 6JU

Dr S P McGrath, Rothamsted Experimental 'Station, Harpenden, Hertfordshire, AL5 2JQ

Mr J C McKenzie, Hill Farming Research Organisation, Bush Estate, Penicuik, Midlothian, EH26 OPY

Miss W Nevell, Dept of Microbiology, University of Sheffield, Sheffield, South Yorkshire, S10 2TN

Dr P Newbould, Hill Farming Research Organisation, Bush Estate, Penicuik, Midlothian, EH26 OPY

Dr A G O'Donnell, Dept of Soil Science, University of Newcastle, Newcastle-upon-Tyne, Tyne and Wear, NE1 7RU

Mr J A Parkinson, Institute of Terrestrial Ecology, Merlewood Research Station, Grange-over-Sands, Cumbria, LA11 6JU

Mr T Peirson-Smith, Dept of Soil Science, University of Aberdeen, Meston Walk, Aberdeen, Aberdeenshire, AB9 2UE

Mr M F Proe, The Macaulay Institute for Soil Research, Craigiebuckler, Aberdeen, Aberdeenshire, AB2 9SB

Mr C Quarmby, Institute of Terrestrial Ecology, Merlewood Research Station, Grange-over-Sands, Cumbria, LA11 6JU

Dr B Reynolds, Institute of Terrestrial Ecology, Bangor Research Station, Penrhos Road, Bangor, Gwynedd, LL57 2LQ

Dr D Rimmer, Dept of Soil Science, University of Newcastle, Newcastle-upon-Tyne, Tyre and Wear, NE1 7RU

Mr J D Roberts, Institute of Terrestrial Ecology, Merlewood Research Station, Grange-over-Sands, Cumbria, LA11 6JU

Prof I Rorison, Unit of Comparative Plant Ecology, Dept of Botany, University of Sheffield, Sheffield, South Yorkshire, S10 27N 
Mr A P Rowland; Institute of Terrestrial Ecology, Merlewood Research Station, Grange-over-Sands, Cumbria, LA11 6JU

Dr U Skiba, Dept of Soil Science, University of Aberdeen, Meston Walk, Aberdeen, Aberdeenshire AB9 2UE

Mr B F L Smith, The Macaulay Institute for Soil Research, Craigiebuckler, Aberdeen, Aberdeenshire, AB2 9SB

Mr C J Smith, Institute of Hydrology, Maclean Building Crowmarsh Gifford, Wallingford, Oxfordshire, OX10 8BB

Mr B A R Tate, British Geological Survey, c/o Geochemical Division, 64-78 Grays Inn Road, London, WC1X 8NG

Miss E Taylor, DAFS, Freshwater Fisheries Laboratory, Pitlochry, Perthshire, PH16 5LB

Dr D J Tervet, Solway River Purification Board, Rivers House, Irongray Road, Dumfries, Dumfriesshire, DG2 OJE

Dr R J Thomas, Hill Farming Research Organisation, Bush Estate, Penicuik, Midlothian, EH26 OPY

Mr I P Thompson, School of Environmental Sciences, University of East Anglia, Norwich, Norfolk, NR4 7TJ

Dr E W Tipping, Freshwater Biological Association, The Ferry House, Far Sawrey, Ambleside, Cumbria, LA22 OLP
Miss J Trafford, British Geological Survey, Maclean Building, Crowmarsh Gifford, Wallingford, Oxfordshire, OX10 8BB

Mr E D Vance, Soils and Plant Nutrition Department, Rothamsted Experimental Station, Harpenden, Hertfordshire, AL5 2JQ

Dr M Wainwright, Dept of Microbiology, University of Sheffield, Sheffield, South Yorkshire, S10 2TN

Mr T A B Walker, The Macaulay Institute for Soil Research, Craigiebuckler, Aberdeen, Aberdeenshire, AB2 9SB

Mr J Walls, Institute of Hydrology, Maclean Building, Crowmarsh Gifford, Wallingford, Oxfordshire, OX10 8BB

Mr R S Warren, Dept of Biology, North East London Polytechnic, West Ham Precinct, Romford Road, Stratford, London, E15 4LZ

Ms M Whittaker, Institute of Terrestrial Ecology, Merlewood Research Station, Grange-over-Sands, Cumbria, LA11 6JU

Ms J Wolfenden, Dept of Biological Sciences, University of Lancaster, Lancaster, Lancashire, LA1 $4 X Y$

Mr P Wookey, institute of Terrestrial Ecology, Merlewood Research Station, Grange-over-Sands, Cumbria, LA11 6JU 

ISBN 0904282988

ISSN 0263-86I4 